ARTHUR UNGARETTI JUNIOR

\title{
Dor pélvica crônica de origem incerta: caracterização clínico demográfica de 81 doentes
}

Dissertação apresentada à Faculdade de Medicina da Universidade de São Paulo para obtenção do título de Mestre em Ciências

Área de concentração: Neurologia

Orientador: Dr. Manoel Jacobsen Teixeira

\section{SÃO PAULO}

2004 


\section{AGRADECIMENTOS}

- À minha esposa, minha cúmplice, pela sua paciência e compreensão até mesmo nos momentos mais difíceis que passamos paralelamente desde o início desta obra até a sua conclusão.

- Ao Prof. Dr. Manoel Jacobsen Teixeira, meu Mestre, meu Mentor, pela oportunidade inesquecível que me proporcionou.

- À Dra. Lin Tchia Yeng, pelas suas dicas, orientações e constantes mensagens de incentivo, que foram sem qualquer sombra de dúvida, inesquecíveis.

- À amiga Ana Maria de Souza, por sua paciência e colaboração no atendimento dos doentes durante meus períodos de ausência necessários para a confecção desta obra.

- Ao amigo Gildo Angelotti pelas dicas e pela amizade que nunca será esquecida.

- Ao novo amigo Dr. Mário E. Jimenez, pela sua excelência e capacidade na ajuda infindável para a elaboração desta obra.

- À minha querida falecida mãe, cuja inesquecível lembrança de amor proporcionou-me força para os piores momentos de cansaço físico e mental.

- À minha família, à qual dedico esta obra com amor e carinho.

- Aos doentes do Centro de Dor do Hospital das Clínicas da Faculdade de Medicina da Universidade de São Paulo que apesar do sofrimento têm a luminosidade e proteção Divina e estarão eternamente na minha lembrança, fazendo parte de minha restante existência.

- A todos os doentes que tive oportunidade de conhecer e que ainda não conheci, razão de minha existência profissional. 


\section{SUMÁRIO}

Lista de Abreviaturas

Lista de Figuras

Lista de Gráficos

Lista de Tabelas

Resumo

Summary

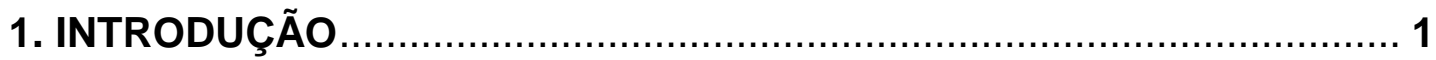

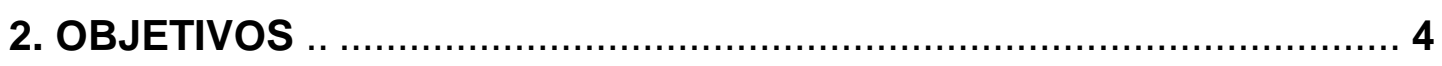

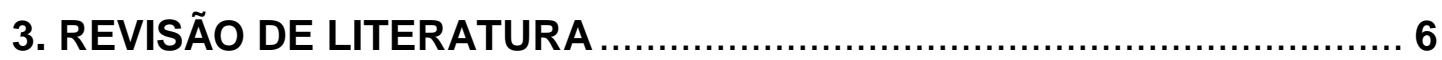

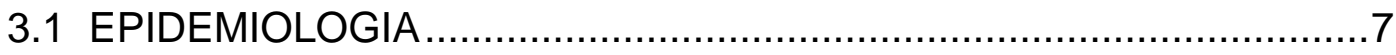

3.2 NOÇÕES BÁSICAS DA ANATOMIA E NEUROFISIOLOGIA DA DOR AGUDA E CRÔNICA ..............................................10

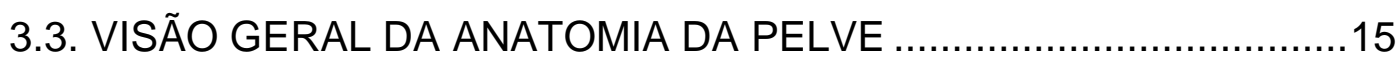

3.4. CAUSAS NÃO VISCERAIS DE DPC ...................................23

3.4.1. CAUSAS MUSCULOESQUELÉTICAS E MIOFASCIAIS ....... 23

3.4.2. CAUSAS NEUROPÁTICAS ...................................... 27

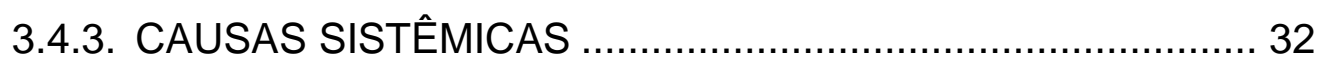

3.5. ASPECTOS PSICOSSOCIAIS ............................................. 33

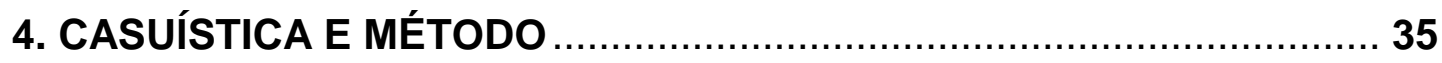

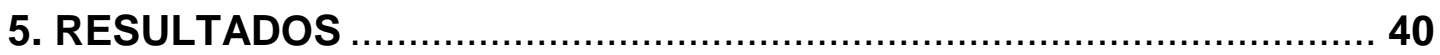

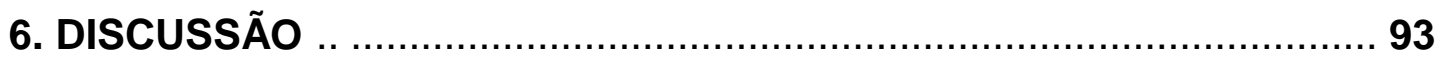

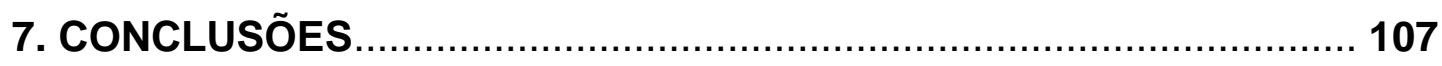

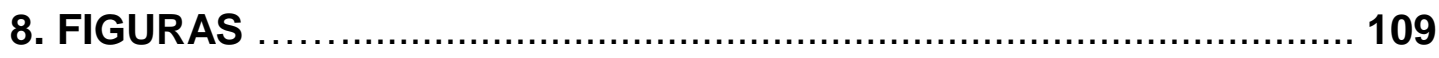

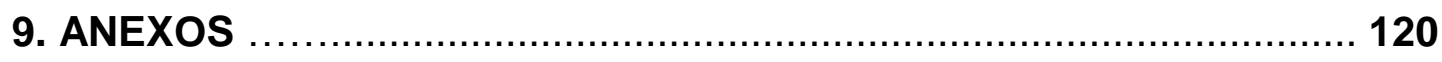

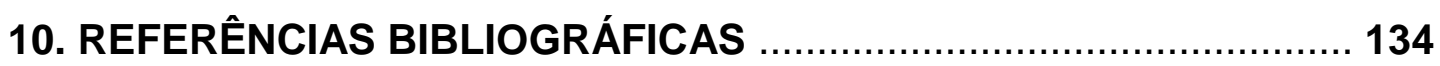




\section{LISTA DE ABREVIATURAS}
A.
Artéria

AA.

Artérias

DPCOI

Dor Pélvica Crônica de Origem Incerta

DPC

Dor Pélvica Crônica

HCFMUSP

Hospital das Clínicas da Faculdade de Medicina da Universidade de São Paulo

M.

Músculo

MM.

Músculos

N.

Nervo

NN.

Nervos

PGs

Pontos Gatilho

SDM

Síndrome Dolorosa Miofascial 


\section{LISTA DE FIGURAS}

FIGURA 1. Vias ascendentes da interpretação da dor...................... 110

FIGURA 2. Vias descendentes de controle da dor. ........................... 111

FIGURA 3. Sistema arterial de irrigação....................................... 112

FIGURA 4. Plexo sacral de nervos. ................................................ 113

FIGURA 5. Plexo lombar de nervos........................................... 114

FIGURA 6. PGs no m. obliquo externo........................................... 115

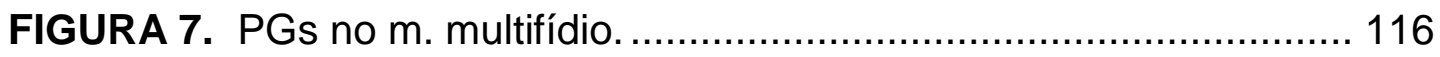

FIGURA 8. PGs no $m$. reto abdominal...................................... 117

FIGURA 9. Músculos na pelve feminina (visão inferior). ........................ 118

FIGURA 10. Alterações posturais da coluna vertebral. ........................ 119 


\section{LISTA DE GRÁFICOS}

GRÁFICO 1 - Distribuição dos pacientes quanto à atividade profissional..42

GRÁFICO 2 - Distribuição dos pacientes quanto ao sexo (\%)

GRÁFICO 3 - Distribuição dos resultados quanto ao sexo dos pacientes, a idade em faixas etárias e percentagem.

GRÁFICO 4 - Distribuição dos pacientes quanto à região afetada pela dor e o sexo em percentagem

GRÁFICO 5 - Distribuição dos pacientes quanto à característica da dor e sexo dos pacientes

GRÁFICO 6 - Distribuição dos pacientes quanto à expressão verbal da dor e sexo.

GRÁFICO 7 - Distribuição dos pacientes quanto aos Fatores Agravantes

/ Desencadeantes da dor e sexo dos pacientes

GRÁFICO 8 - Distribuição dos pacientes quanto aos Fatores de Melhora da dor e sexo dos pacientes

GRÁFICO 9 - Distribuição dos pacientes quanto aos Impactos da dor sobre as Atividades da Vida Diária (AVD) e o sexo dos pacientes

GRÁFICO 10 - Distribuição dos pacientes quanto aos Pontos Gatilho e o sexo dos pacientes

GRÁFICO 11 - Distribuição dos pacientes quanto ao diagnóstico principal e o sexo dos pacientes

GRÁFICO 12 - Distribuição dos pacientes quanto ao diagnóstico e o sexo dos pacientes

GRÁFICO 13A - Distribuição dos pacientes quanto à região de localização da dor, a faixa etária e o sexo dos pacientes (mulheres)

GRÁFICO 13 B- Distribuição dos pacientes quanto à região de localização da dor, a faixa etária e o sexo dos pacientes (homens) 
GRÁFICO 14A - Distribuição dos pacientes quanto à expressão verbal da dor, a faixa etária e o sexo dos pacientes - Mulheres

GRÁFICO 14B - Distribuição dos pacientes quanto à expressão verbal da dor, a faixa etária e o sexo dos pacientes - Homens

GRÁFICO 15 - Distribuição dos pacientes quanto ao diagnóstico e a região de localização da dor

GRÁFICO 16 - Distribuição dos pacientes quanto à Escala Visual Analógica (EVA) e o sexo dos pacientes

GRÁFICO 17 - Distribuição dos pacientes quanto à Escala Visual Analógica (EVA) e o diagnóstico

GRÁFICO 18 - Distribuição dos pacientes quanto à Escala Visual Analógica (EVA) e as faixas etárias dos pacientes

GRÁFICO 19 - Distribuição dos pacientes quanto à Escala Visual Analógica (EVA), as faixas etárias dos pacientes e o sexo.86

GRÁFICO 20 - Distribuição dos pacientes quanto ao tempo de dor e o sexo

GRÁFICO 21 - Distribuição dos pacientes quanto ao tempo de dor e o diagnóstico .88

GRÁFICO 22 - Distribuição dos pacientes quanto ao tempo de dor e as faixas etárias

GRÁFICO 23 - Distribuição dos pacientes quanto ao tempo de dor, as faixas etárias e o sexo 


\section{LISTA DE TABELAS}

TABELA 1 - Distribuição dos pacientes quanto à atividade profissional....41

TABELA 2 - Distribuição dos pacientes quanto ao sexo ( $\mathrm{Ne} \%$ )

TABELA 3 - Distribuição dos resultados quanto ao sexo dos pacientes, a idade em faixas etárias, $\mathrm{N}$ e percentagem

TABELA 4 - Distribuição dos pacientes quanto a região afetada pela dor e o sexo dos pacientes

TABELA 5 - Distribuição dos pacientes quanto à característica da dor e sexo dos pacientes

TABELA 6 - Distribuição dos pacientes quanto à expressão verbal da dor e sexo dos pacientes

TABELA 7 - Distribuição dos pacientes quanto aos Fatores Agravantes

/ Desencadeantes da dor e o sexo dos pacientes

TABELA 8 - Distribuição dos pacientes quanto aos Fatores de Melhora da dor e sexo dos pacientes

TABELA 9 - Distribuição dos pacientes quanto aos Impactos da dor sobre as Atividades da Vida Diária (AVD) e o sexo dos pacientes

TABELA 10 - Distribuição dos pacientes quanto aos Pontos Gatilho e 0 sexo dos pacientes

TABELA 11 - Distribuição dos pacientes quanto ao diagnóstico principal e o sexo dos pacientes

TABELA 12 - Distribuição dos pacientes quanto ao diagnóstico e o sexo dos pacientes.

TABELA 13 - Distribuição dos pacientes quanto à região de localização da dor, a faixa etária e o sexo dos pacientes

TABELA 14 - Distribuição dos pacientes quanto à expressão verbal da dor, a faixa etária e o sexo dos pacientes 
TABELA 15 - Distribuição dos pacientes quanto aos fatores agravantes e desencadeantes da dor, a faixa etária e o sexo dos pacientes

TABELA 16 - Distribuição dos pacientes quanto aos fatores de melhora da dor, a faixa etária e o sexo dos pacientes

TABELA 17 - Distribuição dos pacientes quanto aos impactos da dor sobre as Atividades da Vida Diária (AVD), a faixa etária e o sexo dos pacientes

TABELA 18 - Distribuição dos pacientes quanto aos pontos gatilho, a faixa etária e o sexo dos pacientes.

TABELA 19 - Distribuição dos pacientes quanto ao diagnóstico, a faixa etária e o sexo dos pacientes

TABELA 20 - Distribuição dos pacientes quanto ao diagnóstico e a região de localização da dor

TABELA 21 - Distribuição dos pacientes quanto à característica da dor e o diagnóstico.

TABELA 22 - Distribuição dos pacientes quanto à expressão verbal da dor e o diagnóstico

TABELA 23 - Distribuição dos pacientes quanto aos fatores agravantes e desencadeantes e o diagnóstico

TABELA 24 - Distribuição dos pacientes quanto aos fatores de melhora e o diagnóstico

TABELA 25 - Distribuição dos pacientes quanto ao Impacto sobre as Atividades da Vida Diária (AVD) e o diagnóstico

TABELA 26 - Distribuição dos pacientes quanto aos pontos gatilho e 0 diagnóstico

TABELA 27A - Distribuição dos pacientes quanto ao diagnóstico e a região de localização da dor

TABELA 27B - Distribuição dos pacientes quanto ao diagnóstico e a região de localização da dor (continução)

TABELA 28A - Distribuição dos pacientes quanto à região de localização da dor e os pontos gatilho. 
TABELA 28B - Distribuição dos pacientes quanto à região de localização da dor e os pontos gatilho (continuação) .............79

TABELA 28C - Distribuição dos pacientes quanto à região de localização da dor e os Pontos Gatilho (continuação) ............80

TABELA 29A - Distribuição dos pacientes homens, quanto ao diagnóstico, sexo e cirurgias a que foram submetidos (HOMENS)

TABELA 29B - Distribuição dos pacientes mulheres, quanto ao diagnóstico, sexo e cirurgias a que foram submetidos (MULHERES)

TABELA 30 - Distribuição dos pacientes quanto à Escala Visual Analógica (EVA) e o sexo dos pacientes

TABELA 31 - Distribuição dos pacientes quanto à Escala Visual Analógica (EVA) e o diagnóstico

TABELA 32 - Distribuição dos pacientes quanto à Escala Visual Analógica (EVA) e as faixas etárias dos pacientes.

TABELA 33 - Distribuição dos pacientes quanto à Escala Visual Analógica (EVA), as faixas etárias dos pacientes e o sexo ...86

TABELA 34 - Distribuição dos pacientes quanto ao tempo de dor e o sexo

TABELA 35 - Distribuição dos pacientes quanto ao tempo de dor e o diagnóstico

TABELA 36 - Distribuição dos pacientes quanto ao tempo de dor e as faixas etárias.

TABELA 37 - Distribuição dos pacientes quanto ao tempo de dor, as faixas etárias e o sexo

TABELA 38 - Distribuição dos pacientes quanto ao diagnóstico e nervos comprometidos 


\section{RESUMO}

UNGARETTI, A. JR. Dor pélvica crônica de origem incerta: caracterização clínico demográfica de 81 doentes. São Paulo, 2004. Dissertação (Mestrado) - Faculdade de Medicina da Universidade de São Paulo.

Foi caracterizada uma amostra de 81 doentes com dor relevante crônica pélvica de origem indefinida e na ausência de afecções viscerais, segundo a expressão sintomática, aspectos clínicos e síndromes álgicas. A média das idades foi de 48,6 anos. Foram identificadas anormalidades miofasciais pélvica em 55 doentes (67,9\%), neuropáticas em 10 (12,3\%) e miofasciais e neuropáticas em $16(19,8 \%)$. A descrição verbal da dor e as regiões acometidas pela dor, impactos funcionais, a evidenciação de pontos dolorosos e em gatilhos e os aspectos psicossociais dos doentes foram estabelecidos para melhorar a compreensão da condição clínica dos doentes. Traumatismos decorrentes de traumatismos cirúrgicos estavam relacionados à ocorrência da dor em $36(44,4 \%)$ doentes, sendo dor miofascial em 15 doentes (18,5\%), 6 (7,4\%) como neuropática e 15 (18,5\%) como dor miofascial e neuropática. 


\section{SUMMARY}

UNGARETTI, A. JR. Chronic pelvic pain of uncertain origin. Demographic characterization of a series of 81 patients. São Paulo, 2004. Dissertação (Mestrado) - Faculdade de Medicina da Universidade de São Paulo.

Eighty-one chronic pelvic pain patients (mean of ages 48.6 years old) without visceral abnormalities and uncertain etiology were characterized according to the symptomatic expression, clinical findings and pain syndromes. It was observed that in 55 patients there was pelvic miofascial pain (67.9\%), in 10 patients neuropathic (12.3\%) conditions and 16 (19.8\%) had miofascial and neuropathic abnormalities. The verbal description of pain, pain aspects as localization, aggravating and improvement factors, functional impact, the occurrence of trigger or tender points and the psychosocial aspects were determined to improve the comprehension of the clinical presentation of the patients. Surgical traumas were related to pain in $26(32.0 \%)$ patients, miofascial pain in $11(13.6 \%)$, neuropathic pain in $5(6.2 \%)$ and miofascial and neuropathic pain in 10 (12.3\%). 
1. INTRODUÇÃO 
De acordo com a Associação Internacional para estudos da dor (1986), dor é definida como uma "experiência sensorial e emocional desagradável, associada a lesão tecidual real ou potencial". A percepção e apreciação da dor e seu significado é um processo complexo que envolve aspectos sensitivos e culturais. Evoca respostas físicas e emocionais que podem se atenuadas, acentuadas ou perpetuadas pelas variáveis sócioculturais e psíquicas dos indivíduos e por condições ambientais. É uma experiência subjetiva e multidimensional. A intensidade da dor não é proporcional à extensão ou à natureza da lesão tecidual: depende da interação destes fatores múltiplos.

A dor pelviperineal é de extrema importância nas clínicas de ginecologia, proctologia, urologia e gastroenterologia. As etiologias e expressões dolorosas podem ser muito variadas, devido ao fato da dor poder ter origem tanto nas inúmeras vísceras presentes na pelve, no arcabouço músculo-esquelético da região pélvica e lombar, nas estruturas neurológicas, como também de origem psicossomática (TEIXEIRA et al, 2000). Pode ter uma localização extremamente variada, generalizada na região pélvica, referida na região anterior e posterior da coxa, região glútea, abdominal e lombar, superficial ou profunda, entre outras.

Apesar da dor pelviperineal crônica (DPC) ser bastante comum, a sua real incidência e prevalência ainda não foram muito bem estabelecidas. Em um estudo realizado nos Estados Unidos da América (EUA) em 1999, com mulheres com idade entre 18 e 50 anos, 14,7\% reportaram DPC. 45\% demonstraram improdutividade por esta condição clínica e 15\% disseram ter perdido algum tempo no trabalho pelo mesmo motivo. Calcula-se que $10 \%$ das consultas de ginecologia são por DPC (WESSELMAN, 1999). Em 30 a 
40\% dos casos, não se estabelece uma etiologia (DELLENBACH, 2001), apesar de toda uma condição técnica apurada existente para investigação.

As etiologias mais comuns da DPC de origem incerta (DPCOI) são as afecções musculo-esqueléticas e miofasciais. Dentre elas estão as modificações anatômicas das estruturas ósteoarticulares e musculares, decorrentes de diversos fatores como posturas viciosas, sobrecargas mecânicas, redução da potência funcional e da elasticidade tecidual, aumento do tônus muscular, múltiplos partos e seqüelas de fraturas (GAL et al., 1991). Dores decorrentes de neuropatias são causas consideradas por lesões do sistema nervoso periférico e do sistema nervoso central. Incluemse aqui as radiculopatias, lesões plexulares, tronculares, polineuropatias, dor do órgão amputado, mielopatias e encefalopatias (RAPKIN, 1990 e LIN, 1997). Doenças sistêmicas também podem ser causas de dor pelviperineal, como as discrasias sanguíneas, a anemia falciforme, as doenças do colágeno, o diabetes, as porfirias entre outras (HAMID, 1981). A natureza das anormalidades emocionais que se associam à dor pélvica não foi ainda totalmente esclarecida. São doentes mais ansiosas, deprimidas, introvertidas, apresentam traços neuróticos, histéricos e hipocondríacos, tendências suicidas, frigidez sexual, carência afetiva, dificuldade para relações sociais, desajustamentos conjugais e familiares, pertencem a famílias mais numerosas e têm maior freqüência de vários casamentos que a população geral (RASKIN, 1984).

Embora as causas de DPCOI sejam conhecidas e bem descritas, suas reais correlações clínicas no nosso meio ainda não estão bem estabelecidas. A escassez de dados nacionais justifica a necessidade de se determinar as características clínicas, sócio-demográficas e psicossociais destas afecções, possibilitando melhor planejamento das estratégias de tratamento e diminuindo o sofrimento e as incapacidades dos doentes. 
2. OBJETIVOS 
O comportamento da síndrome dolorosa crônica pelviperineal de causa não visceral é de difícil entendimento devido ao fato de vários fatores contribuírem para confundir o diagnóstico. Em uma amostra de doentes selecionados no ambulatório de Dor Crônica do HCFMUSP, estudou-se o comportamento desta síndrome dolorosa a fins de se obter uma melhor compreensão de suas características clínicas e subsídios para diagnóstico.

De uma maneira geral, este estudo implica em:

1. Caracterizar uma amostra do ponto de vista clínico-demográfico de doentes com DPCOI.

2. Demonstrar o comportamento clínico das DPCOI.

3. Definir as prováveis causas da DPCOI. 
3. REVISÃO DE LITERATURA 


\subsection{EPIDEMIOLOGIA}

De uma maneira geral uma mulher tem $5 \%$ de risco de ter uma DPC em toda a sua vida. Entretanto, pacientes com diagnóstico prévio de doença inflamatória pélvica tem quatro vezes mais risco de DPC (quase 20\%). É estimado que 30 a $50 \%$ de mais de 45 milhões de mulheres na gravidez nos Estados Unidos sofram de dismenorréia ou dor cíclica (TEIXEIRA et al, 2003).

$\mathrm{Na}$ Suécia, em um estudo realizado em mulheres com idade de dezenove anos, $70 \%$ das entrevistadas reportaram que já tinham tido dismenorréia onde mais de $50 \%$ disseram ter perdido tempo na escola ou no trabalho por esta condição. Em estudo mais recente nos Estados Unidos com 5263 mulheres com idade entre 18 e 50 anos, 14,7\% reportaram DPC. $15 \%$ deste montante disseram ter perdido tempo no trabalho por esta causa e $45 \%$ demonstraram improdutividade reduzida no trabalho. Estas estatísticas demonstram que a DPC exerce um fator de importância na carreira profissional e qualidade de vida das mulheres. Ainda nos Estados Unidos, $10 \%$ das consultas de pacientes em ambulatório de ginecologia são por DPC (WESSELMAN, 1999).

A DPC é um freqüente e difícil problema porque a despeito da qualidade e diversidade de procedimentos diagnósticos, nenhuma etiologia se acha em 30 a $40 \%$ de todos os casos. Aconselhamento psicológico ou psicoterapia são freqüentemente propostos e usualmente não aceitos (DELLENBACH, 2001).

Em um estudo realizado em mulheres que foram à procura de médicos de primeiros socorros nos EUA, 39,1\% reportaram dor (outras do que dismenorréia, dispareunia ou dores relacionadas ao intestino) ao menos 
uma vez e $11 \%$ tiveram dor por mais de cinco dias por mês ou ao menos um dia inteiro ou mais a casa mês. Em um estudo Gallup, aproximadamente 2 a $5 \%$ da população em idade reprodutiva reportaram significante impedimento de trabalho ou atividades do lar causado por DPC (STEEG, 1997). Em um outro estudo norte americano em uma universidade, também em consultórios de médicos de primeiro atendimento, $12 \%$ das mulheres reportaram DPC no momento e 33\% relataram história passada de DPC (HOWARD, 2000).

HOWARD em 1993 achou que 40\% das laparoscopias foram feitas para a DPC. 12 a 16\% das histerectomias são realizadas nos EUA por DPC, o que daria cerca de oitenta mil procedimentos por ano aproximadamente. $25 \%$ das mulheres em avaliação de DPC referiram ter sido submetida a uma histerectomia prévia sem uma resolução dos seus sintomas (MILBURN, 1993).

Embora pouco se saiba sobre a DPC, é um sério problema entre as mulheres e pouco se sabe sobre sua prevalência ou sobre seus efeitos nas vidas daqueles que a possuem. Um estudo feito nos EUA aponta que aproximadamente $20 \%$ das laparoscopias realizadas foram por DPC (REITER, 1991).

Poucos estudos têm examinado a associação entre DPC e qualidade de vida ou produtividade. Assim, pouco se sabe sobre os custos associados à DPC. Na Inglaterra, DAVIES et al (1992) estimaram os custos anuais das dores ginecológicas intratáveis em 158,4 milhões de libras para mulheres com diagnóstico de endometriose ou de doença sem diagnóstico reconhecido. Outras causas de DPC não foram consideradas neste estudo.

A DPC envolve múltiplos sintomas. Além disso, três diferentes definições tem sido utilizadas na literatura: duração (seis meses ou mais), anatomia e comportamento afetivo. Estudos clínicos correlacionados revelam que a DPC pode estar associada com uma série de condições anormais, ambas somáticas (como na endometriose) e não somáticas (funções gastrintestinais, psicológicas ou sem causa aparente). Dentre os fatores associados estão a perda de sono, depressão e disfunções entre as 
relações familiares e maritais. Mas mesmo assim, estes dados são pouco conhecidos. As suas relações com a qualidade de vida e prevalência são obscuras. Cerca de $56 \%$ das mulheres (773 casos) com DPC e com idade entre 18 e 50 anos entrevistadas em um estudo sobre as correlações clínicas, prevalência e qualidade de vida nos EUA em 1994 responderam que a condição dolorosa interferia no seu estado de motivação moderadamente, muito pouco ou extremamente. $82 \%$ responderam que tinham ainda energia para realizar as suas tarefas que tinham vontade por algumas vezes, um pouco ou nunca. $47 \%$ responderam que se sentiam "abatidas" por algumas vezes, por muitas vezes ou o tempo todo. Ainda $72 \%$ do montante entrevistado, $26 \%$ disseram que tiveram de ficar na cama por mais do que uma metade do dia ou um ou mais dias no último mês por causa da sua dor. 58\% revelaram redução de suas atividades diárias em um ou mais dias do último mês pelo mesmo motivo. $75 \%$ das mulheres não procuraram ajuda. $19 \%$ foram ao ginecologista. 10\% foram a médicos outros que não ginecologistas. $01 \%$ procuraram psiquiatras ou outros profissionais de saúde mental. 02\% foram submetidas a cirurgia enquanto 08\% realizaram outros procedimentos como ultrassom e 67\% usaram medicações de qualquer tipo, sendo que 56\% foram sem prescrição médica e $23 \%$ com prescrição médica (MATHIAS, 1996).

REITER e GAMBONE (1991) estudaram 122 mulheres com DPC após laparoscopia negativa e que completaram uma evolução médica e psicológica por um período de observação de no mínimo 06 meses. Patologia somática oculta foi encontrada em 47\% dos doentes incluindo 19 doentes com coexistente diagnóstico psicopatológico. Dor miofascial foi o mais comum diagnóstico somático. Nenhuma etiologia somática plausível fora diagnosticada nas 65 mulheres remanescentes (53\%) das 122 estudadas. 29\% não apontaram patologia somática não ginecológica, contra $19 \%$ de patologias ginecológicas e somente $6 \%$ já tinham sido submetidas a histerectomia prévia. As mulheres com diagnóstico de patologia somática apresentaram idade mais avançada do que o restante da população estudada. 


\subsection{NOÇÕES BÁSICAS DA ANATOMIA E NEUROFISIOLOGIA DA DOR AGUDA E CRÔNICA}

O conceito de dor para o comitê de taxonomia da Associação Internacional para o Estudo da Dor é que "dor é uma experiência sensorial desagradável, associada ou descrita em termos de lesões teciduais", é sempre subjetivo e cada indivíduo tem uma maneira pessoal para exprimi-la, de acordo com as suas experiências pessoais prévias (FIGUEIRÓ; TEIXEIRA, 2001).

As terminações nervosas livres são estruturas básicas de interpretação dos estímulos dolorosos existentes nos axônios dos neurônios aferentes primários, presentes nos tecidos de uma forma geral e são denominadas nociceptores. Uma vez estimuladas, estas estruturas conduzem o estímulo doloroso para o gânglio da raiz dorsal ao longo do axônio do neurônio aferente primário e caminham em direção ao corno posterior da medula espinhal, adentrando à medula espinhal (ANDRADE , 2001).

Os impulsos nociceptivos nos nervos periféricos do adulto são conduzidos por fibras não mielinizadas denominadas de fibras $C$ e ou por fibras mielinizadas finas denominadas fibras A-delta (TEIXEIRA e cols, 2003).

Os receptores nociceptivos são estimulados por substâncias químicas existentes no ambiente tecidual e desenvolvem potenciais de ação que servem para desencadear os estímulos nociceptivos da região em questão. Dentre elas destacam-se a bradicinina, serotonina, histamina, ácido aracdônico, acetilcolina, substância $\mathrm{P}$, leucotrienos, fator de ativação plaquetário, radicais ácidos, íons potássio, fator de necrose tumoral $\alpha$, AMPcíclico, prostaglandinas, interleucinas, dentre outros (WALL, MELZACK, 1994). Estas substâncias são liberadas no ambiente tecidual dos vasos sanguíneos, mastócitos e células traumatizadas e são responsáveis pela hiperalgesia observada em lesões traumáticas, inflamatórias e isquêmicas (CAMPBEL e cols, 1988, NENNESMO, 1986). 
Conforme SINDOU, 1972, no corno posterior da medula espinal, encontra-se a chamada zona de entrada das raízes posteriores. Um milímetro antes da penetração das radículas, a bainha de mielina produzida pela oligodendroglia se junta à bainha de mielina produzida pelas células de Schwann .

As fibras aferentes nociceptivas terminam predominantemente no corno dorsal da medula espinal que pode ser subdividido em seis camadas (lâminas) distintas de acordo com as características citológicas de seus neurônios. A lâmina I (camada superficial) recebe aferências diretas de fibras nociceptivas mielinizadas do tipo $A \bar{\delta}$ e indireta de fibras nociceptivas não-mielinizadas do tipo C através de interneurônios da lâmina II(substância gelatinosa). Os neurônios da lâmina $V$ (camada profunda) são predominantemente do tipo de amplo espectro dinâmico. Eles recebem aferências de baixo limiar de fibras mielinizadas de grande diâmetro $A \beta$ de mecanoreceptores, assim como aferências diretas e indiretas de fibras aferentes nociceptivas Aঠ e C. As células superficiais têm alto limiar, respondem somente a estímulos dolorosos de alta intensidade enquanto as profundas respondem tanto a estímulos dolorosos quanto tácteis (CORRÊA, 1997).

Segundo descreveu ANDRADE (2001), uma vez alcançado o corno posterior da medula espinal, os axônios das células dos receptores nociceptivos dos vários segmentos corporais agrupam-se para formarem os tratos ascendentes em direção ao sistema nervoso central mais especificamente o encéfalo. Distinguem-se tratos que cursam mais lateralmente ao tronco cerebral, filogeneticamente mais recentes e capazes de conduzir o estímulo mais rapidamente e tratos ascendentes mais mediais ao tronco cerebral, mais antigos e capazes de conduzirem os estímulos dolorosos mais lentamente. O trato neoespinotalâmico é o mais importante e é representado por axônios das células das lâminas I e V que na sua grande maioria cruzam para a porção anterior da medula espinal e alcançam a região antero-lateral para então se projetar em ascendência até os núcleos ventro-póstero-laterais e porções mais mediais do tálamo posterior. Outros tratos como o espinocervical e o trato dos núcleos da 
coluna dorsal também são tratos de condução rápida dos estímulos, porém são constituídos por feixes de axônios que transitam pela medula espinhal ipsilateral à entrada do neurônio aferente primário e somente cruzam o neuroeixo após sinapse no núcleo cervical lateral ou nos núcleos grácil (mediais) e cuneiforme (mais laterais), respectivamente e então se projetam para o tálamo. A partir daí, as terminações nervosas das vias de condução rápida da dor fazem sinapses com neurônios que se projetam para o córtex somatossensitivo. Os sistemas que conduzem os estímulos dolorosos de uma forma mais lenta são sistemas que se comunicam com outras estações intermediárias durante a sua ascendência rumo aos centros mais superiores. São ditos polissinápticos. São os tratos paleoespinotalâmico, espinomesencefálico, espinoreticular e proprioespinal que se comunicam com a formação reticular, (hipotálamo e sistema límbico) . A formação reticular relaciona-se a outra estrutura localizada no assoalho do quarto ventrículo, o lócus ceruleus, que parece estar relacionado diretamente às emoções de medo e ansiedade, estando também envolvido na modulação da dor (TEIXEIRA, 2001).

No segmento cefálico as aferências primárias levam o estímulo doloroso que caminha inicialmente pelo $\mathrm{V}$ par craniano principalmente $\mathrm{e}$ pelos VII, IX e X pares até os núcleos trigeminais encontrados no gânglio trigeminal e então se projetam ao tálamo, formação reticular e hipotálamo antes de alcançarem o córtex somatosensitivo. Cerca de 50\% das aferências primárias das raízes trigeminais são constituídas por fibras nervosas do tipo $\mathrm{C}$ e penetram no trato descendente trigeminal e alcançam a porção caudal do núcleo do trato espinal e do corno posterior da medula espinal cervical anterior (WALL, 1989 e ANDRADE, 2001).

A FIGURA 01 ilustra como os tratos ascendentes alcançam o córtex cerebral.

Das fibras nervosas presentes nos tratos espinotalâmico, espinoreticular, espinomesencefálico, espinocervical, pós-sináptico do funículo posterior e tratos intracornuais, $40 \%$ são de pequeno calibre (CORRÊA, 1997). Várias sensações são transmitidas pelos tratos 
espinotalâmicos, estimando-se que $54 \%$ delas são de dor e $46 \%$ de temperatura (TEIXEIRA, 2001).

No ser humano as fibras do trato espinotalâmico projetam-se nos núcleos do complexo ventrobasal, núcleo centrolateral e núcleos intralaminares do tálamo (BROWSHER, 1957). Há evidências de que colaterais do trato espinotalâmico projetam-se na formação reticular do bulbo, ponte e mesencéfalo, incluindo os núcleos gigantocelular, paragigantocelular e substância cinzenta periaquedutal no mesencéfalo (IGNELZI; ATIKINSON, 1980).

O componente discriminativo da dor somatotopicamente específico envolve os córtices somatosensoriais primário e secundário. As informações que provém ao córtex originam-se basicamente nos núcleos talâmicos ventrobasais que também são organizados somatotopicamente. O componente afetivo é integrado em diversas outras estruturas. Dos núcleos talâmicos parafasciculares partem feixes para o córtex cingulado, amígdala e outras estruturas límbicas. Além dos estímulos nociceptivos informarem sobre todos os componentes da dor, ativam também estruturas que modulam a passagem de estímulos que veiculam do neurônio primário para as células espinais. Prova disto é a substância cinzenta periaquedutal que demonstrou inibir os estímulos de dor quando estimulada eletricamente. Outras estruturas que demonstraram mesmo comportamento foram o córtex somatossensorial, o hipotálamo lateral, o núcleo pré tectal anterior, a área tegmentar lateral, o núcleo magno da rafe, o núcleo parabraquial, o locus ceruleus e os núcleos reticulares gigantocelular e paragigantocelular. A grande maioria destas estruturas envia comunicações (fazem sinapses) para os núcleos magnos da rafe e gigantocelular e paragigantocelular. Daí partem fibras nervosas que alcançam as lâminas I, II e V da medula espinal via funículo dorso-lateral. Via de regra, o aumento da atividade elétrica das celulas espinais em resposta a estímulos dolorosos periféricos é inibido quando se estimulam quaisquer daquelas estruturas. Assim o conjunto das estruturas nervosas nucleares descritas em soma com o funículo dorso-lateral forma o que se 
denomina sistema descendente de controle da dor, mecanismo central ou endógeno da modulação da dor (ANDRADE, 2001).

A FIGURA 02 ilustra as vias descendentes de controle da dor.

Nos terminais periféricos dos neurônios aferentes primários (nociceptores) existem receptores para bradicinina, prostaglandinas, opióides, histamina, serotonina, noradrenalina e acetilcolina, substâncias que são liberadas facilmente quando existe uma injúria tecidual. Isto promove uma cascata de eventos que são favorecidos pela cicloxigenase do tipo 2 (COX-2) que atua sobre o ácido aracdônico e facilita a produção de prostaglandinas, tromboxanes e leucotrienos, que atuam nos nociceptores e produzem AMP cíclico que então facilita a geração de estímulos (fenômeno de hiperalgesia periférica). A substância $P$ é liberada com este fenômeno e aumenta a estimulação dos próprios nociceptores atuando sobre os vasos sanguíneos rompidos pela lesão e atraindo macrógafos e mastócitos e plaquetas que promovem alterações da permeabilidade vascular local produzindo edema. Noradrenalina é liberada no local por diversos mecanismos, estimulada por exemplo pela ação da bradicinina e por estimulação de terminações nervosas simpáticas da região lesada. A acetilcolina estimula a produção de GMP cíclico que promove efeito oposto ao da hipersensibilização. Estes eventos também ocorrem no corno posterior da medula espinal e portanto facilitam a passagem dos estímulos nociceptivos. Fibras descendentes noradrenérgicas originárias do núcleo parabraquial, lócus ceruleus e núcleos reticulares gigantocelular e paragigantocelular e fibras serotoninérgicas originárias principalmente do núcleo magno da rafe controlam o sistema endógeno de controle da dor quando ativadas. As fibras serotoninérgicas ativam neurônios opióides intrínsecos da medula espinal produtores de encefalinas capazes de inibir a passagem do estímulo nocivo da aferência primária para a célula espinal na pré-sinapse (BONICA, 1990). 


\subsection{VISÃO GERAL DA ANATOMIA DA PELVE}

A pelve é a parte do tronco situada abaixo e posterior à parede do abdome. A estrutura esquelética da pelve consiste de um anel ósseo, ao qual se prendem os membros inferiores, estes amplamente cobertos, internos e externamente, por músculos $(\mathrm{mm}$.). Um espaço afunilado no interior da pelve é denominado cavidade pelvina. Existe duas paredes laterais, uma parede posterior e um assoalho. O esqueleto da pelve é formado pelos dois ossos dos quadris, anterior e lateralmente, e pelo sacro e cóccix posteriormente. Na mulher os ossos são mais finos e mais leves e a musculatura com freqüência não é tão proeminente. As juntas da pelve incluem as juntas lombossacral, sacrococcígea e sacrilíaca e a sínfise púbica. Os ligamentos sacrospinhais e sacrotuberais estão associados com as juntas da pelve, e o ligamento ileolombar forma uma importante conexão entre a coluna vertebral e a pelve. A parede da cavidade pelvina é subdividida em duas paredes laterais, uma parede posterior e um assoalho. O músculo (m.) obturatório interno, o nervo (n.) obturatório e os ramos dos vasos ilíacos internos, ureter, ligamento redondo na mulher e ducto deferente nos homens, o ovário, ligamentos sacrotuberal e sacroespinhais formam a parede lateral. Os ossos sacro e cóccix, o plexo lombossacro, o plexo venoso sacral, ramos dos vasos ilíacos internos, o $\mathrm{m}$. piriforme, a artéria (a.) sacral mediana e os troncos simpáticos formam a parede posterior. O assoalho pélvico é formado pelo peritôneo e pelos diafragmas pelvino e urogenital (GRAY, 1978).

A a. ilíaca interna ou hipogástrica fornece a maior parte da irrigação sanguínea da pelve. São seus ramos parietais a a. íleolombar, a sacral lateral, a obturatória, a glútea superior, a glútea inferior e a pudenda. Seus ramos viscerais são a a.umbilical, a a.vesical superior, a a.do ducto deferente, a a.vesical inferior, a a.uterina, a a.vaginal a por vezes a a.retal média. A veia (v.) ilíaca interna ou v. hipogástrica é um tronco curto que se une à v. ilíaca externa para formar a v. ilíaca comum. Na drenagem venosa 
incluem-se ainda as veias (vv.) glútea superior e inferior, v. pudenda interna, v. dorsal profunda do pênis ou clitóris, e os plexos venosos retal, vesical prostático, uterino, vaginal e sacral (GARDNER, 1978). A FIGURA 03 ilustra um aortograma normal lombar inferior em um homem.

A inervação da pelve é derivada, principalmente, de nervos (nn.) espinhais sacral e coccígeo e da parte pelvina do sistema nervoso autônomo. Cada um dos cinco nn. sacrais e o n. coccígeo se dividem em um ramo dorsal e um ventral no interior do canal sacral. Os ramos ventrais dos primeiros quatro $\mathrm{nn}$. sacrais emergem do canal sacral através dos forames sacrais. Os ramos ventrais e o quinto $n$. sacral entram na pelve entre o sacro e o cóccix. O ramo ventral do quarto n. sacral apresenta uma divisão superior e outra inferior; a divisão superior e os primeiros três ramos ventrais combinam-se no tronco lombossacro para formar o plexo sacral. Este apresenta doze ramos. Sete estão distribuídos pelas nádegas e pelo membro inferior enquanto os outros inervam estruturas pertencentes à pelve (GARDNER, 1978). Cada plexo sacral de nn. é uma substancial junção de vários nn. somáticos no topo de cada $\mathrm{m}$. piriforme na pelve. É formado pelo tronco lombossacro, por L4 e L5 do plexo lombar e o ramo anterior de S1 a S4, que entra na pelve através do forame sacral anterior. Lesões deste plexo de nn. podem causar severa e longa dor glútea ou de extremidade inferior ou perda de função. Este plexo inerva os mm. elevador do ânus, obturatório interno, coccígeo, piriforme, gêmeos e quadrado femural. Os ramos glúteos superior e inferior são ramos deste plexo e inervam os $\mathrm{mm}$. glúteos médio, mínimo, tensor da fascia lata e glúteo máximo respectivamente. Este plexo dá ainda os nn. pudendos, o cutâneo posterior femural e um outro ramo do quarto $n$. sacral que inerva o aspecto posterior do $\mathrm{m}$. esfíncter externo do ânus (ROGERS, 1998).

Ainda segundo ROGERS, 1998, o plexo sacral ainda é responsável pela origem do $n$. ciático, do ramo anterior de L4, L5, S1, S2 e S3, o maior $n$. do corpo humano. Outro grande nervo originário do plexo sacral é o $\mathrm{n}$. pudendo. Este penetra na região pélvica através do forame ciático menor. Contém eferentes simpáticos e parassimpáticos bem como aferentes 
viscerais. Contínuos estiramentos e compressão do n. pudendo raramente podem ser responsáveis por danos teciduais, edema ou escarificações no canal pudendo ou ao seu redor. Algumas lesões podem causar compressão deste n. e comprometer a sua função ou causar dores crônicas nesta área. São comuns em pessoas que trabalham sentadas por muito tempo ou em episiotomias profundas mediolaterais ( $\mathrm{nn}$. retais inferiores). $\mathrm{O} \mathrm{n}$. pudendo emite ainda um ramo para o lado inferior do m. elevador do ânus.

A FIGURA 04 ilustra o plexo sacral de nervos.

O plexo lombar de nn. consiste do ramo anterior de L1 a L4 e supre a inervação da parede abdominal baixa e coxas. É responsável pela inervação motora voluntária dos $\mathrm{mm}$. esqueléticos na pelve bem como eferentes simpáticos para a musculatura lisa das aa., arteríolas, vv. e vênulas nos $\mathrm{mm}$. e na pele. É composto pelos $\mathrm{nn}$. íliohipogástrico, ilioinguinal, fêmuro cutâneo lateral, genitofemural e obturador. Os dois primeiros são oriundos de $\mathrm{L} 1$, atravessam o $\mathrm{m}$. transverso abdominal em diferentes localizações e correm entre este $\mathrm{m}$. e o m. oblíquo interno ao nível da espinha ilíaca superior. O n. iliohipogástrico atravessa 0 m.oblíquo interno e caminha entre este e o m. oblíquo externo e vai inervar a pele da região púbica. $\mathrm{O}$. ílioinguinal caminha entre $0 \mathrm{~m}$. transverso abdominal e oblíquo interno para mais inferiormente penetrar no anel inguinal. Inerva o monte púbico e os grandes lábios bem como a região superior e medial da coxa. Incisões transversas ou excessiva tração durante procedimentos cirúrgicos ou suturas da fáscia podem resultar em lesões destes nervos. Em uretropexias vaginais estes nervos podem ficar presos e causar dores constantes na distribuição cutânea. São dores contínuas surdas ou em queimor irradiando para a região ilíaca medial para a região inguinal e genital (SMITH et al, 1984 e KOPPEL et al, 1984).

O n. genitofemural provém de L1 e L2 e é responsável pela inervação cutânea somente da região súpero anterior da coxa pelo seu ramo femural e do monte pubiano pelo seu ramo genital (que cursa pelo anel inguinal ). Em incisões ginecológicas transversas como a herniorrafia, a cesárea e apendicectomia e durante a retirada de linfonodos ilíacos podem ocorrer 
lesões neste nervo. Dor crônica, hiperalgesia e parestesias são comumente descritos nestes casos de lesão. Lesões do tipo encarceramento são também comuns (LYON, 1945 e HARMS et al, 1984).

O n. obturador é ramo de L2, L3 e L4. Corre pelo $\mathrm{m}$. psoas e aparece na pelve pelo forame obturado, junto com a artéria e v. obturada para inervar o $\mathrm{m}$. adutor e a área cutânea na coxa medial. Pode ser lesado durante dissecação ou cirurgias para retirada de linfonodos ou por afastadores ortostáticos de localizção profunda logo abaixo da linha arqueada do ílio, nas laparotomias. Lesão deste nervo ocasiona fraqueza do $\mathrm{m}$. adutor da coxa. O doente tem dificuldade em tracionar o membro inferior para medial e exibe uma marcha com os membros mais afastados. Deve ainda haver instabilidade dos joelhos e quadris. Se a lesão não for por rompimento, os danos podem ser auto limitados, mas felizmente são raros (ROGERS, 1998).

A FIGURA 05 ilustra o plexo lombar de nervos.

A parte simpática do sistema nervoso autônomo chega à pelve através de duas vias diferentes. Uma delas é a continuação do tronco simpático e a outra é a continuação do plexo aórtico. Anterior à quinta vértebra lombar fibras dos nervos esplâncnicos lombares formam o plexo hipogástrico superior. Na face anterior do osso sacro ao nível da parte inferior cada nervo hipogástrico se junta com os nervos esplâncnicos pélvicos do lado correspondente e formam os plexos hipogástricos inferiores direito e esquerdo. Daí mais inferiormente inervam o reto e a próstata, os nn. cavernosos do pênis e o plexo vesical que é responsável pela inervação da bexiga e parte do ureter, ducto deferente e vesícula seminal. O plexo útero vaginal inerva o útero, ovário, vagina, uretra e o tecido erétil do vestíbulo. O cólon e o sigmóide recebem fibras parassimpáticas préganglionares, componentes funcionais do plexo hipogástrico inferior (GARDNER, 1978). 


\section{Músculos paraespinhais superficiais}

Da metade do dorso para baixo dois grandes músculos existem e fazem parte da massa extensora da espinha. São eles o longuíssimo torácico e o íliocostal (torácico e lombar). Quando atuam unilateralmente produzem flexão lateral e rotação para o lado oposto. Atuando bilateralmente, estendem a coluna. Sua contribuição para a rotação parece ser menor. Comumente podemos achar PGs nestes grupos musculares e quando são encontrados no $\mathrm{m}$. iliocostal torácico, a dor se projeta mais para cima do dorso ao passo que quando são encontrados no $\mathrm{m}$. iliocostal lombar, a dor se projeta mais em direção caudal. Neste último, a dor se concentra no meio da região glútea. Estas dores são comumente conhecidas como "lumbago" (TRAVEL, 1992).

A FIGURA 06 ilustra os pontos gatilho no andar inferior do abdome relativos ao m. oblíquo externo.

\section{Músculos paraespinhais profundos}

São compostos pelos músculos semiespinhais e pelo $\mathrm{m}$. longuíssimo torácico e multifídios. Os mm. multifídios consistem de feixes curtos triangulares que se localizam profundamente ao semiespinhal. Atuando bilateralmente, o m. semiespinhal torácico, o multifídio torácico e lombar e rotadores estendem a coluna vertebral. Atuando unilateralmente rodam o ombro homolateral para frente. Referem dor primariamente à região ao redor do processo espinhoso da vértebra adjacente ao PG. Quando localizados de L1 a L5 podem referir dor anterior ao abdome. Quando localizados em S1 projetam dor para baixo em direção ao cóccix e conferem a este uma hipersensibilidade à pressão. A combinação é comumente conhecida como coccigodínea (TRAVEL, 1992).

A FIGURA 07 ilustra os PGs dos mm. multifídios. 


\section{Músculos abdominais}

A parede anterolateral do abdome é composta pelo $\mathrm{mm}$. oblíquo externo, oblíquo interno e transverso. Na parede anterior temos o m. reto do abdome e o piramidal. A contração dos $\mathrm{mm}$. oblíquos interno e externo, transverso e dos $\mathrm{mm}$. do diafragma da pelve determina uma parede abdominal e um assoalho pelvino tensos que resistem à pressão inferior do diafragma toracoabdominal durante esforços e tosse. São importantes na respiração, defecação, micção, no parto e no vômito. São importantes numa expiração forçada e limitam uma inspiração máxima, auxiliam os $\mathrm{mm}$. reto do abdome na flexão do tronco e na rotação do tronco quando funcionam em conjunto e determinam a inclinação do tronco em flexão lateral. Todos os mm. abdominais controlam a hiperextensão do tronco e auxiliam na fixação da caixa torácica óssea durante movimentos dos membros superiores (GARDNER, 1978). PGs ativos na parede anterolateral abdominal determinam dores referidas na virilha e testículo e em outras partes do abdome. PGs na borda superior do púbis e na metade lateral do ligamento inguinal podem estar relacionados ao $\mathrm{m}$. oblíquo externo e reto abdominal. Causam assim espasmo do $\mathrm{m}$. detrusor e dos $\mathrm{mm}$. esfíncter urinário produzindo micções freqüentes, retenção de urina e dor na virilha. Quando os PGs são ativos no $\mathrm{m}$. transverso abdominal, a dor referida aparece no abdome alto e em faixa. Quando presentes na porção inferior do reto abdominal, a dor se refere à região posterior lombar baixa e sacroilíaca. Quando presentes no ponto de McBurney simulam uma apendicite aguda. Ocorrem em doentes que se apresentam muito cansados, preocupados ou em período pré-menstrual (TRAVEL, 1992).

A FIGURA 08 ilustra os PGs na musculatura abdominal e a irradiação da dor. 


\section{Musculos da pelve}

O diafragma da pelve consiste dos $\mathrm{mm}$. elevadores do ânus $\mathrm{e}$ coccígeos, e das fáscias que cobrem as suas faces superior e inferior. Estas fáscias são parte das fáscia parietal da pelve e esta também inclui a fáscia que cobre as paredes laterais e posterior da pelve. A fáscia visceral está associada com os órgãos. Os mm. levantadores do ânus são os mais importantes do diafragma da pelve. Os coccígeos são relativamente sem importância. O elevador do ânus é variável em espessura e força, dispõe-se quase horizontalmente no assoalho da pelve. Divide-se em três partes: pubococcígea, puborretal e íliococcígea, designada de acordo com a sua direção e inserções de suas fibras. O m. pubococcígeo apresenta várias inserções. No homem algumas de suas fibras mais mediais se inserem na próstata (levantador da próstata). Na mulher algumas fibras mediais se inserem na uretra e vagina (pubovaginal) e outras envolvem a uretra e vagina (esfíncter da vagina). Dores na região do sacro, cóccix, reto, assoalho pélvico e área periretal, vagina e dorso baixo são comuns com 0 comprometimento desta musculatura e são as dores mais reconhecidamente referidas das dores da região perineal. $\mathrm{O} \mathrm{m}$. coccígeo localiza-se atrás do levantador do ânus. Este diafragma auxilia na sustentação das vísceras da pelve e resiste aos aumentos de pressão intra-abdominal. Junto com a musculatura abdominal anterior permite ao diafragma funcionar efetivamente em todas as atividades que necessitem de uma pressão aumentada. Aqui as dores são de projeção similar às do $\mathrm{m}$. elevador do ânus e referem-se ao quadril, dorso e cóccix, quando PGs ativos são encontrados. Estas dores limitam o ato de sentar. O m. levantador da próstata no homem e o $\mathrm{m}$. pubovaginal na mulher estão relacionados com a micção. O m. puborretal é responsável pela flexura na junção anorretal e ainda auxilia no parto (GARDNER, 1978).

Ainda na pelve encontramos os $\mathrm{mm}$. esfíncter externo e interno do ânus, o obturador interno, o bulboesponjoso, ísquiocavernoso e transverso do períneo. O anel mais interno do esfíncter do ânus tem inervação 
autonômica involuntária. O esfíncter externo é sob controle voluntário e mais elíptico na forma. Estão sob constante contração tônica que aumenta no esforço, fala, tosse, riso ou levantamento de peso. A contração se inibe durante o sono e a defecação. PGs nestes músculos ocasionam dores imprecisas na região anal e muitas dores na movimentação dos intestinos. O m. obturatório interno está envolvido por fáscias e está na parede lateral da pelve e cobre a maior parte do forame obturado. Não tem função motora na pelve. É um rotador lateral da coxa quando esta está estendida e funciona com outros rotadores laterais da coxa. PGs neste músculo causam dor e a sensação de que o reto está cheio com leve extensão da dor para posterior e inferior na coxa e podem ainda projetar dor para a vagina. $O$ bulboesponjoso no homem serve para esvaziar a uretra no final da micção e auxilia ainda na ereção. Na mulher fecha o orifício uretral na contração e auxilia na ereção do clitóris. Ainda na mulher, PGs nesta musculatura causa dispareunia, particularmente durante a entrada e dor contínua na região perineal. No homem causam dor na região retroescrotal, desconforto ao sentar ereto e por vezes certo grau de impotência. A contração do $\mathrm{m}$. ísquiocavernoso no homem serve para manter a ereção e na mulher age semelhantemente na manutenção da contração do clitóris. PGs nesta musculatura causam dor perineal mas causam pouca interferência nas relações sexuais. A contração do $\mathrm{m}$. transverso do períneo serve para fixar o corpo perineal na linha média e entre o ânus e a genitália e para suportar 0 assoalho pélvico (TRAVEL, 1992).

A FIGURA 09 ilustra o assoalho da pelve feminina com seus músculos em posição anatômica. 


\subsection{CAUSAS NÃO VISCERAIS DE DPC}

\subsubsection{CAUSAS MUSCULOESQUELÉTICAS E MIOFASCIAIS}

Os problemas musculoesqueléticos identificados como causa primária de DPC parecem ocorrer mais comumente em resposta a estresse repetitivo crônico e deslocamento associado à má postura, pobre condicionamento físico e mecânico corporal. $\mathrm{O}$ trauma direto das estruturas musculoesqueléticas é descrito com menor freqüência, mas é devido mais a acidentes, procedimentos cirúrgicos e traumas esperados que ocorrem durante a gravidez. Podem ser secundários na DPC como na hipertonia muscular que ocorre em indivíduos com disfunção urogenital, desuso póscirúrgico, complicações na cicatrização ou distúrbios psicogênicos. Estes problemas são caracterizados como disfunções ou como doenças. Disfunções quando existe alteração mecânica que se manifestam por um acréscimo ou decréscimo dos limites do movimento ou pela presença de uma aberração motora. Inclui os deslocamentos, as luxações, resistência e flexibilidade anormal e condições degenerativas. As doenças devem ser diagnosticadas e conduzidas por médicos ortopedistas ou outros preparados para tal (STEEGE, 1998).

As falhas de postura da coluna vertebral são causas muito comuns e expressam DPC. Consiste na cifose e lordose e escoliose acentuadas, combinadas ou não, que podem se iniciar na gravidez e se tornar uma disfunção após o parto. Uma escoliose funcional se desenvolve para compensar uma báscula de bacia que é causada por uma "perna curta", quando em ortostática, ou por uma pequena hemipelve quando sentado. Esta assimetria impõe um constante deslocamento muscular inadequado que perpetua PGs na musculatura paraespinhal adjacente, causando dor (TRAVEL, 1992).

A FIGURA 10 ilustra as alterações posturais da coluna vertebral com relação à normalidade. 
A síndrome toracolombar descrita por Paris em 1990 revela dor anterior e lateral ao abdome e quadril referida da região toracolombar em doentes que tiveram uma fusão de vértebras lombares baixas ou médias, configurando uma hipermobilidade da junção toracolombar. Os doentes adotam uma lordótica postura e freqüentemente aparece irritação do nervo fêmuro cutâneo lateral.

Alterações degenerativas do quadril ocorrem em indivíduos sedentários e acostumados a ficar muito tempo sentado ou mesmo na hipermobilidade que levam a uma destruição da cartilagem articular. Freqüentemente revelam dores na virilha e anteriores ao quadril e aparece mais nas mulheres (BAKER, 1998).

A diástase da sínfise púbica é outra causa descrita que pode ocorrer durante o trabalho e durante o parto e se não solucionada no pós-parto pode ocasionar dores crônicas na porção inferior do abdome e aumento de tensão muscular no assoalho pélvico e quadris. A palpação da diferença de altura entre os lados direito e esquerdo do púbis, associado com aumento de tensão e edema sugerem esta condição. Pode-se ter ainda luxações sacrococcígeas, rotação íliosacral e torções sacroilíacas como condições de DPC nas regiões sacroilíacas, assoalho pélvico e púbis (BAKER, 1998).

BOISSONNAULT (1988) relatou a separação do $\mathrm{m}$. reto abdominal como uma ocorrência durante o segundo e terceiro trimestre da gravidez bem como no período pós-parto e que pode contribuir para uma DPC. Ocorre por fraqueza da parede abdominal, diminuição do suporte visceral dado pelo assoalho pélvico que trabalha em conjunto com esta musculatura, favorecendo o aparecimento de PGs nesta região.

Uma queda ou outros traumas pode causar uma dor coccígea. Os deslocamentos do parto e as fraturas que podem ocorrer durante um parto forçado limitando a extensão sacrococcígea necessária para aumentar o diâmetro anteroposterior do canal do parto são condições de causa mais comuns, ocasionando dor no assoalho pélvico com aumento de tensão muscular. Em casos de fraturas ou luxações, o deslocamento do cóccix determina alterações do comprimento e tônus da musculatura do assoalho 
pélvico. Uma entidade clínica denominada coccigodínea é uma dor que se concentra no cóccix, freqüentemente irradiando para o reto, lateralmente à região glútea e ocasionalmente irradia para as coxas. É uma dor de característica severa, contínua, pulsátil, comumente em hábitos de prolongado assento. Traumas cirúrgicos ano retais são as causas mais comuns. Aparecem mais nas mulheres e estão relacionados com os traumas de modificação da postura do cóccix na gravidez e com os traumatismos pós-parto, bem como por espasmos da musculatura ao redor do cóccix e por inflamação da junta sacrococcígea (GRANET, 1946; SCHAPIRO, 1950; THIELE, 1937).

Freqüentemente a musculatura do assoalho pélvico torna-se hipotônica, hipertônica ou com diminuição de força. Quando está fraca e hipotônica leva ao relaxamento e pode causar DPC nas situações de trauma de parto ou em excesso de força no pós-parto. As pacientes referem uma sensação de "desabar" e em estágios mais avançados sofrem prolapso dos órgãos urogenitais e tornam-se incontinentes (BAKER, 1998).

TRAVEL e SIMONS (1992) relataram que os PGs na parede abdominal podem imitar desordens viscerais. Podem simular apendicites, doenças da bexiga, da vesícula biliar, hérnia diafragmática e úlcera péptica, carcinoma gástrico, colecistite crônica ou cólica biliar. Podem ocorrer por várias outras causas não viscerais como os danos iatrogênicos dos nervos periféricos após intervenções cirúrgicas e cicatrizes pós-cirúrgicas, por encarceramento dos nervos cutâneos abdominais (não necessariamente após intervenções cirúrgicas), por hérnias, síndromes miofasciais, síndrome da ponta das costelas $\left(8^{\mathrm{a}}, 9^{\mathrm{a}}\right.$ e $\left.10^{\mathrm{a}}\right)$ ), origem espinhal (quando as raízes dos nervos intercostais são irritadas na emergência da coluna, por fatores degenerativos dos ossos) ou ainda por hematoma espontâneo da bainha do m.reto (GALLEGOS, 1990). Quando um músculo é saudável e tem um bom fluxo sanguíneo, força e flexibilidade normais e não está submetido a microtraumas de repetição ou a um macrotrauma, não desenvolve PGs. PGs ocorrem em um músculo em resposta a um estresse agudo ou crônico, 
incluindo os microtraumas, desordens de sono e fadiga, macrotraumas e tensão e estresse psicossocial (COSTELLO, 1998).

As disfunções hipertônicas da musculatura abdominal e do assoalho pélvico podem ser causadas por vários fatores já mencionados acima. A hipertonia do m. elevador do ânus produz dor na região perivaginal, periretal, nos quadrantes abdominais inferiores, na região supra púbica, cóccix e coxa posterior. Nomes como proctalgia fugax, proctodínea, proctalgia e diafragma pélvico espástico são outras denominações para este fenômeno. Inflamação é considerada a causa mais freqüente desta condição. Trauma, como uma péssima postura no ato de se sentar e psiconeurose são outras causas que requerem consideração. Ocorreu em $80 \%$ de pacientes com idade entre 40 e 50 anos em um estudo. $25 \%$ apresentaram envolvimento do m. piriforme, é mais comum ser unilateral, mas pode ser bilateral. A dor é descrita como pulsátil e rítmica ou "pressão no reto" ou "dor dolorida" pelos doentes. O toque retal revela um grande aumento da tensão e espasmo na área de inserção dos mm. coccígeos e íliococcígeos e do ligamento sacroespinhal na espinha isquiática. O doente pode referir que não há relação da dor no cóccix na posição sentada. Quando ocorre durante o sono, habitualmente denomina-se proctalgia fugax (PARADIS, 1968; LILIUS, 1973; SOHN N. et al, 1982).

Diástase do músculo reto ou separação das bandas musculares na linha média causadas por obesidade ou gravidez pode causar dores suprapúbicas ou no abdome inferior em alguns casos (KOTARINOS, 1990).

A péssima mobilidade da cicatrização cirúrgica na parede abdominal ou no assoalho pélvico pode produzir DPC. A limitação da mobilidade em uma ou mais direções produz dor quando a direção desta limitação é estressada. É menos comum nas cirurgias de laparoscopia do que na laparotomia. Os encarceramentos dos nervos abdominais são freqüentes nestas condições (KESSLER, 1990).

Segundo LIN et al (2003), o diagnóstico da síndrome dolorosa miofascial depende exclusivamente da história e do exame físico. Suas características são de dor difusa em um músculo ou em grupos musculares. 
Geralmente são expressas em peso, queimor ou latejamento, surtos de dor e referência de dor à distância e às vezes com queixas de parestesias (sem padrão neuropático).

\subsubsection{CAUSAS NEUROPÁTICAS}

A dor neuropática é mediada por um distúrbio na sua condução. Não é uma simples sensação transmitida do sítio de lesão ao cérebro. A percepção da dor não é o mesmo que a transmissão de impulsos nervosos. O sinal enviado via nervos e neurotransmissores comunicam-se com os sinais do sistema límbico que contém toda uma experiência sensorial armazenada do indivíduo. Assim a dor (de uma forma geral) experimentada é afetada pelo que o indivíduo está pensando e sentindo naquele momento, de acordo com a sua personalidade e a presença de um diagnóstico, envolvendo suas circunstâncias de vida e ganho secundário. Portanto, dor não é objetiva, mas sim sempre subjetiva e é sempre um estado conceitual (BENSON, 1998).

Lesões intramedulares ou doenças do cone medular como tumores, esclerose múltipla, siringomielia, abscesso, trauma ou a combinações destes podem produzir dor na pelve ou no períneo. A dor é comumente espontânea, do tipo queimor, difusa e de difícil localização e freqüentemente associada com hiperalgesia, hiperpatia e parestesias. Lesões extramedulares intratecais como nos abscessos, neoplasias, metástases e hemorragias inicialmente produzem dores na região lombar e na pelve. Pode ser radicular quando é agravada pela tosse e distensão e estaria associado a um aumento de tensão paravertebral, parestesias, hipoestesias e perda de força e outros sinais envolvendo os segmentos da medula lombossacra onde a lesão está localizada. Compressões medulares causadas por tumores primários ou metastáticos, hemorragia ou abscessos que produzem pressão do cone medular invariavelmente produzem dores lombares e pélvica, mas envolvem também os membros inferiores. 
Aracnoidites são também causas de DPC, quando envolvem vários segmentos da cauda eqüina, mas ocasionalmente é limitada às raízes ou radículas dos nervos sacrais e coccígeos. Manifesta-se por dor, parestesias e déficits sensitivos e disfunção motora na "região da sela" e freqüentemente associado com disestesias (BONICA, 1990).

Lesões das raízes e radículas dos nervos espinhais do segmento lombossacro produzem uma radiculopatia e consequente radiculoalgia ou dor segmentar. São causadas por infecções por herpes zoster, infecções crônicas ou neuropatias metabólicas ou tóxicas ou por compressão das raízes nervosas, por nervos formados por tumores, protrusões discais, fratura de vértebras e osteofitos e artropatias (BONICA, 1990).

Lesões isoladas (mononeuropatias) ocorrem comumente na pelve. A mais comum é a lesão do tipo compressiva ou por estiramento do nervo pudendo, durante o trabalho e parto e fraturas da espinha isquiática. Traumas como os causados por injeções ou pelo assento de bicicletas, trauma do períneo ao andar a cavalo ou em queda com os membros inferiores em posição de abertura ou queda sobre objetos finos, são outras causas mais raras, mas de projeção bilateral. Caracteriza-se por dor de média a severa intensidade e de caráter em queimor com períodos de dor lancinante, hiperalgesia cutânea, hipalgesia, hipersensibilidade profunda, parestesia, formigamento e subjetiva paralisia. A hipersensibilidade cutânea pode ser tão severa que impede o indivíduo de sentar-se ou de ter relações sexuais. A parestesia pode fazer o doente coçar a região afetada o que resulta uma irritação na pele criando um círculo vicioso (BONICA, 1990).

As lesões do $\mathrm{n}$. ílioinguinal são mais comumente encontradas nos danos cirúrgicos, particulamente pela agulha na uretropexia (SHOOK, 1992). Um encarceramento do $\mathrm{n}$. ílioinguinal pode causar dor e dificuldades no diagnóstico. O ponto de encarceramento do nervo é medial à espinha anterosuperior. Após contornar as paredes internas do tronco e pelve, transpassa $0 \mathrm{~m}$. transverso abdominal e o m. oblíquo interno e cai sobre o funículo espermático sob o $\mathrm{m}$. oblíquo externo. Forma uma espécie de zigzag, daí o nervo é sujeito a irritação mecânica por cordões de fibras 
musculares sob certas condições de pressão, quando as margens dos degraus estão apertados contra o nervo. A dor é referida na região da virilha. Se a neuropatia é persistente, aparece fraqueza da porção inferior do abdome, região afetada com a formação de uma hérnia direta. $\mathrm{O}$ diagnóstico de uma neuropatia por encarceramento pode ser muito difícil de se diferenciar de condições como uma doença de quadril (lesões do tipo instabilidade), doença geniturinária, presença de uma hérnia e camptocormia (pessoas que tiveram dores lombares com irradiação para a virilha freqüentemente têm dor periférica, ou ao menos a síndrome toda classificada como psicogênica e chamada de camptocormia) (KOPELL et al, 1962).

Durante um estudo realizado por RANGER e MEHTA em 1971, onde 103 doentes foram tratados de dor abdominal persistente e sem causa intraabdominal determinada, 42 tinham sido submetidos à apendicectomia e 11 tinham problemas ginecológicos e ambos tinham diagnóstico de comprometimento do nervo íliohipogástrico, contra 10 doentes com dores na virilha e sem diagnóstico de hérnia inguinal, com clínica de comprometimento do nervo ílioinguinal.

A síndrome da neuralgia genitofemural foi primeiramente reportada por Magee em 1942 e mais tarde por Lyon em 1945. É sabido que adesões fibróticas encarceram ramos pequenos do nervo na região de uma cirurgia prévia ou de um trauma cego. Freqüentemente estes doentes são classificados como neuróticos ou falsos doentes. Este nervo nasce do primeiro e segundo plexo lombar vertebral e consiste principalmente de fibras sensitivas com um componente motor para o cremaster (reflexo cremasteriano). Cai na fáscia que reveste o abdome perfurando o $\mathrm{m}$. psoas e a fáscia próxima do psoas próxima à sua borda medial se opõe a terceira e quarta vértebra lombar. Desce abaixo do peritôneo na superfície do $\mathrm{m}$. grande psoas e cruza oblíquo atrás do ureter. Após o ligamento inguinal e sobre este, divide-se em ramo genital e femural. Grandes variações anatômicas que comunicam os ramos entre os nervos ilioinguinal, genitofemural e íliohipogástrico na região inguinal não são incomuns. Após 
o anel inguinal vai para o cremaster no homem e na mulher corre junto ao ligamento redondo do útero até terminar na pele do monte pubiano e grandes lábios. A dor é de expressão do tipo queimor e de caráter contínuo ou intermitente na região inguinal com irradiação para a pele da genitália e região súpero medial da coxa. Agrava-se pela marcha, inclinar-se para frente (curvar-se) ou por hiperextensão do quadril e melhora pela flexão da coxa quando deitado. Sensibilidade, ao longo do canal inguinal ou do anel inguinal pode ser detectada e hiperestesia na distribuição do nervo pode estar presente. Incisões como a Pfannenstiel ou o uso de retratores ortostáticos ou a formação de aderências pós-operatórias na região abdominal baixa e inguinal são bastante comuns. (BENSON, 1998 e STARLING et al, 1987).

HOWARD (2000) relatou que neuropatias compressivas do nervo obturatório são raras. Compressão pela cabeça fetal durante partos complicados ou pressão causadas por hérnias ou tumores intrapélvicos são os casos mais conhecidos. É comum nas cirurgias que envolvem o espaço de Retzius. Caracteriza-se por anormalidades sensoriais da face medial da coxa com denervação dos adutores, levando a uma fraqueza na adução da mesma (BENSON, 1998).

O encarceramento do $n$. fêmuro cutâneo lateral (meralgia parestésica) ocorre ao nível da espinha ilíaca superior produzindo mudanças sensoriais na lateral da coxa. A localização está naquele ponto onde existe a perfuração deste nervo na fáscia lata. Roth em 1895 foi o primeiro a descrever as neuropatias deste nervo e o primeiro a denominar o termo meralgia parestésica, juntamente com Bernhardt e Freud separadamente. Fatores agravantes icluem o uso prolongado de próteses ou espartilhos apertados que causam intermitente ou contínua pressão no nervo. É freqüente em obesos possivelmente pela tração do nervo exercida que o panículo adiposo pode exercer sobre o ligamento inguinal. Gravidez e outras causas que podem aumentar a pressão abdominal podem ser as causas. Recentemente os dados mostram de 01 a $02 \%$ de neuralgias por encarceramento após abertura e herniorrafia laparoscópica (HOWARD, 2000). 
As neuropatias do $\mathrm{n}$. femural são comumente resultado de traumas. Dentre as causa mais comuns estão os hematomas compressivos resultante de sangramentos em complicações cirúrgicas, como nas cistectomias via vaginal e histerectomias via vaginal de uma forma direta ou indireta nas compressões entre $0 \mathrm{~m}$. psoas e a parede lateral da pelve por afastadores retráteis. Estes comprometem ainda o suprimento sanguíneo do nervo causando a neuropatia. A síndrome do encarceramento do nervo femural no arco íliopectíneo, análogo ao túnel do carpo foi recentemente descrito. Produz fraqueza do quadríceps com subseqüente fraqueza na extensão do membro inferior bem como diminuição de sensibilidade sobre a região anterior e medial da coxa e da porção medial do membro inferior baixo. Quando existe fraqueza na flexão da coxa no quadril sugere comprometimento do $\mathrm{m}$. íliopsoas nos traumas de parto e durante o trabalho quando existe compressão das raízes lombares no momento em que estas entram no canal pélvico (HOWARD, 2000 e BENSON, 1998).

OKADA e TEIXEIRA (2003) denotaram a importância da expressão verbal na presença de uma dor neuropática. Não há uniformidade quanto à apresentação dos sintomas nos doentes que apresentam esta condição. Geralmente a dor é descrita como choques, tremor, pontadas e agulhadas. Pode ser paroxística, episódica ou contínua, referida ou irradiada em locais distantes e ser superficial ou profunda, ser acompanhada ou não de déficits sensitivos, alodínea, hiperpatia, hiperalgesia, disestesias e parestesias, espontânea ou evocada por estímulos físicos, químicos ou emocionais. Quando superficial, usualmente é descrita como queimor, agulhada e ardor e quando profunda, como doída, em pressão ou em aperto. Quando paroxística, tem caráter lancinante, em choque, pontada, agulhada ou facada, com duração de alguns segundos. Quando constante, é descrita como queimor, formigamento ou peso. 


\subsubsection{CAUSAS SISTÊMICAS}

Doentes com anormalidades da coagulação sanguínea como em hemofilias, hepatopatias ou uso de anticoagulantes podem apresentar sangramentos espontâneos após mínimos traumatismos. Quando o hematoma se infiltra nas estruturas nervosas ou somáticas podem gerar dor. Ocorre em hematomas retroperitoneais levando a impotência de músculos como o íliopsoas, mas quando muito volumosos podem comprometer o plexo lombossacro, o nervo ílioinguinal e gênito-femural, resultando em dor nos grandes lábios, região inguinal e face antero-medial da coxa. Exames como Tomografia computadorizada ou Ressonância magnética ou ultrassom podem elucidar o diagnóstico (HAMID, 1981).

Ainda segundo HAMID (1981), a anemia falciforme pode ser causa de dor aguda na pelve, por trombose e isquemia tecidual devido à falcização das hemácias no interior dos vasos sanguíneos.

$\mathrm{Na}$ artrite reumatóide e na periarterite nodosa a dor abdominal pode ocorrer, associadas ou não de peritonite. No diabetes, quando não controlada, dores abdominais não são incomuns e neuropatias autonômicas ocorrem em muitos casos. A porfiria aguda intermitente, porfiria variegata e corprofiria hereditária são heranças autossômicas dominantes e caracterizam-se por sintomas abdominais, neuropsiquiátricos e dermatológicos. As dores podem se manifestar na região abdominal e lombar irradiando para a região genital, associada a hipertonia da parede abdominal, vômitos e obstipação. Alguns quadros neuropáticos periféricos caracterizados por déficits sensitivos e motores estão geralmente associados (HAMID, 1981). 


\subsection{ASPECTOS PSICOSSOCIAIS}

Há uma série de evidências de que doentes com DPC apresentam alterações psicológicas mais evidentes que a população controle. A prevalência de mulheres com depressão em DPC é de aproximadamente $28 \%$ ao passo que quando comparado com mulheres portadoras de afecções ginecológicas em geral, passa a ser $3 \%$. Abuso sexual e físico em estudos norte americanos é controverso e varia de 20 a $80 \%$. A variação é grande devido aos critérios utilizados que são muito diferentes. Em outros estudos, a prevalência foi de $58 \%$ comparado com $30 \%$ do grupo controle que inclui doentes com afecções ginecológicas ou com dor, mas não de localização pélvica (BASU, 1981).

BENSON et al (1959) estudaram 35 mulheres com DPC funcional em uma clínica ginecológica, por métodos médico-psiquiátrico-psicológico por mais de três anos. Todos os doentes tiveram problemas psiquiátricos. Psiconeurose foi diagnosticado em 29 mulheres e psicose (esquizofrenia) em 6. Todas sempre resistiram invariavelmente à conclusão de que seus desconfortos ocorreram durante um psicofisiológico contexto (estresse de vida). Metade foram submetidas à psicoterapia e metade destas tiveram benefício com o tratamento.

RAPKIN et al (1984) acharam prevalência maior de abuso físico em população com dor crônica quando comparado com uma população com DPC. De 52 mulheres estudadas apenas 05 apresentavam enfermidades orgânicas que a justificassem e nas demais observaram um histórico de incesto, vários divórcios, ingestão de álcool e uso de drogas, caracterizando uma amostra com intensa desorganização social. 66\% tinham somatização e este índice se acresceu para $80 \%$ quando a história de dor era superior a 05 anos. As doentes eram deprimidas no geral e poliqueixosas. $O$ fato de termos anormalidades psicológicas ou psiquiátricas não indica que a dor seja imaginária. A associação de queixas de dor com transtornos emocionais não indica a ocorrência da dor em muitos casos. FIGUEIRÓ e 
TEIXEIRA (1995) não observaram mudanças ou diferenças no perfil comportamental em mulheres com dor pélvica com ou sem doença demonstrável. É bem possível que a ansiedade e a depressão, observadas em muitas dessas mulheres, sejam conseqüências e não a causa da dor pélvica. É provável que quando ocorrem anormalidades emocionais, os doentes direcionem a sede da dor para a pelve e não para outras regiões (RASKIN, 1984). 
O presente estudo baseia-se na observação de 81 doentes com DPCOI, atendidos no Ambulatório de Dor Crônica do Hospital das Clínicas da Faculdade de Medicina da Universidade de São Paulo, no período de janeiro de 2001 a fevereiro de 2004.

Todos os doentes foram examinados pelo autor, de acordo com protocolo desenhado para esta finalidade (anexo 1 e anexo 3 ).

Os critérios para a inclusão no estudo foram:

1. Ocorrência de dor crônica inquestionável obedecendo aos limites abaixo da linha imaginária que passa entre as cristas ilíaca, medial aos ligamentos inguinais dos dois lados, região glútea e de expressão interna na pelve como vaginal, anal ou perineal.

2. Dor crônica inquestionável dentro dos limites apresentados acima e que foram encaminhados por outras clínicas pertencentes ao HCFMUSP nas áreas de urologia, proctologia, ginecologia e gastroenterologia após terem sido devidamente avaliados nestas clínicas e não tiveram causa orgânica visceral definida para o diagnóstico da síndrome dolorosa.

3. Concordância com a participação no estudo.

4. Doentes portadores de DCPOI tratados cirurgicamente, porém sem causas evidentes de dor visceral de uma forma inquestionável.

Os critérios de exclusão foram:

1. Dor crônica definida como dor de origem comprovadamente visceral pelas outras clínicas pertencentes ao HCFMUSP como a urologia, proctologia, ginecologia e gastroenterologia.

2. Dor crônica definida como dor oncológica. 
3. Dor caracterizada inquestionavelmente como de origem central.

4. Dor caracterizada inquestionavelmente como de origem fibromiálgica.

5. Doentes que não tenham sido avaliados pelas clínicas de urologia, ginecologia, proctologia e gastroenterologia, conforme sua patologia ou suspeita diagnóstica.

6. Doentes que apresentam dores aparentemente miofasciais, mas que comprovadamente são reflexos víscero-somáticos.

Os seguintes aspectos da DPCOI foram avaliados:

1. Idade do doente

2. Sexo do doente

3. Localização regional da dor

4. Caráter da dor

5. Tempo do quadro doloroso

6. Tempo de aparecimento da dor após intervenção cirúrgica

7. Descritores espontâneos

8. Escala analógica visual (EVA) (anexo 2)

9. Agravantes e desencadeantes do fenômeno doloroso

10. Fatores de melhora

11. Impacto sobre atividades

12. Pontos Gatilho (PGs)

13. Tipo de cirurgia realizado

14. Nervos envolvidos no quadro doloroso

15. Causa da dor

A EVA auxiliou a quantificação de intensidade da dor. Foi solicitado ao doente para anotar um ponto que representou a intensidade da sua dor em uma linha numerada de zero a dez, onde temos nas extremidades "sem dor" e "pior dor" (JENSEN; KAROLY, 1992).

Todos os doentes foram submetidos a um exame geral, neurológico e fisiátrico completo onde os seguintes parâmetros foram de extrema ênfase: 
1. Estado geral dos doentes

2. Doenças presentes e associadas

3. Presença de hiperpatia

4. Presença de alodínea

5. Sensibilidade dolorosa

6. Presença de PGs

7. Determinação do acometimento neuropático periférico mais comum seja ele plexular, troncular, radicular ou segmentar envolvido com a presença da dor de caráter neuropático ou miofascial e neuropático.

Ao apresentarem dor de projeção intravaginal, perineal ou anal todos os doentes foram submetidos a toque retal e toque vaginal (anexo 3), onde se definiu por convenção, quando presentes, PGs classificados por horas como em um relógio.

A hiperpatia foi definida como reação álgica exacerbada após agulhamento repetido em um mesmo ponto da região examinada ou deflagração de dor intensa e desproporcional quando do agulhamento de áreas hiperálgicas. A alodínea foi definida quando houve uma reação dolorosa evocada ao se passar um tufo de algodão sobre a região examinada. A sensibilidade dolorosa foi avaliada com o uso de alfinetes sobre a região em exame.

A presença de PGs foi avaliada palpando-se as regiões referidas como hiperálgicas e observando-se a presença de "pontos nodulares" no tecido muscular abaixo do tegumento ou intravaginal ou intra-retal conforme a semiotécnica aplicada e quando intravaginal ou retal determinou-se a localização usando-se os números de um imaginário relógio.

Nas dores de caráter neuropático periférico, a determinação da projeção neuropática mais comum foi determinada pelo exame físico apropriado e foi definida como de projeção radicular, plexular, troncular ou segmentar. 
O exame clínico incluiu a avaliação do aparelho locomotor com ênfase para a ocorrência ou não de síndrome dolorosa miofascial (SDM) e de sua distribuição corporal.

De acordo com o inventário de auto-avaliação (anexo 1) o estado psicológico dos doentes foi classificado como: "normal, "depressivo" ou "ansioso".

Os casos foram estratificados em grupos, segundo a origem mais provável da dor, como:

1. Dores miofasciais (sem qualquer indício de fenômeno neuropático)

2. Dores neuropáticas (sem qualquer indício de fenômeno miofascial)

3. Dores miofasciais e neuropáticas (com fenômenos neuropáticos e miofasciais associados).

Conforme a intervenção cirúrgica realizada, estratificamos ainda os doentes em grupos como:

1. Dores miofasciais após trauma cirúrgico.

2. Dores neuropáticas após trauma cirúrgico.

3. Dores miofasciais e neuropáticas após trauma cirúrgico. 
5. RESULTADOS 
TABELA 1 - Distribuição dos pacientes quanto à atividade profissional

\begin{tabular}{lccllc}
\hline Profissão & N & $\%$ & Profissão & N & $\%$ \\
\hline DO LAR & 21 & 25,9 & PEDREIRO & 1 & 1,2 \\
AUXILIAR & 5 & 6,2 & PEDAGOGA & 1 & 1,2 \\
LAVRADOR & 3 & 3,7 & MECÂNICO & 1 & 1,2 \\
DOMESTICA & 3 & 3,7 & FUNILEIRO & 1 & 1,2 \\
VENDEDORA & 2 & 2,5 & FUNCIONARIA & 1 & 1,2 \\
SECRETARIA & 2 & 2,5 & FISIOTERAPEUTA & 1 & 1,2 \\
OPERADOR & 2 & 2,5 & ESTUDANTE & 1 & 1,2 \\
NÃO DECLARADO & 3 & 3,7 & ESCRITURARIA & 1 & 1,2 \\
MILITAR & 2 & 2,5 & ENGENHEIRO & 1 & 1,2 \\
MEDICO & 2 & 2,5 & ENFERMEIRA & 1 & 1,2 \\
FAXINEIRA & 2 & 2,5 & ENCARREGADA & 1 & 1,2 \\
COPEIRA & 2 & 2,5 & EEÇÃO & & 1,2 \\
BALCONISTA & 2 & 2,5 & COZINHEIRA & 1 & 1,2 \\
ADVOGADO & 2 & 2,5 & COSTUREIRA & 1 & 1,2 \\
TRADUTORA & 1 & 1,2 & COMERCIANTE & 1 & 1,2 \\
TEC PROCESS & 1 & 1,2 & BARBEIRO & 1 & 1,2 \\
DADOS & 1 & 1,2 & BANCÁRIO & 1 & 1,2 \\
SERV. PUBL. FED. & 1,2 & ARTESA & 1 & 1,2 \\
SEGURANÇA & 1 & 1,2 \\
REFORMADOR & 1 & 1,2 & ANALISTA & 1 & 1,2 \\
MOVEIS & 1 & 1,2 & AJUTEMAS & 1,2 \\
PSICÓLOGA & 1 & 1,2 & AGRICULTOR & 1 & 1,2 \\
PORTEIRO & & & & & \\
\hline
\end{tabular}

A Tabela 1 e Gráfico 1, demonstram que a prevalência da DPCOINV ocorreu mais sobre as profissões que exigem movimentação física no trabalho de forma intensa. 
GRÁFICO 1 - Distribuição dos pacientes quanto à atividade profissional

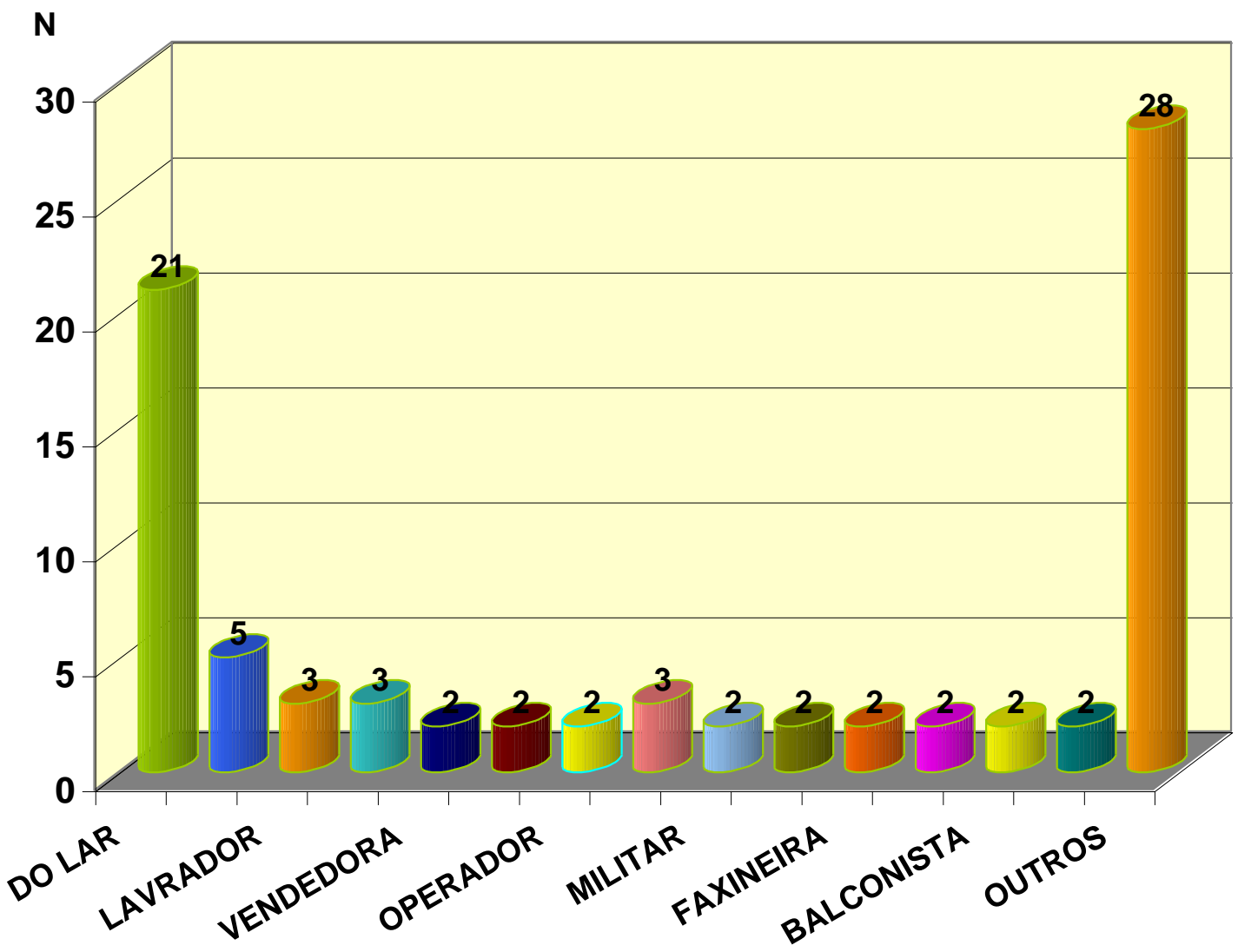


TABELA 2 - Distribuição dos pacientes quanto ao sexo ( $\mathrm{N}$ e \%)

\begin{tabular}{lc}
\hline Sexo & N (\%) \\
\hline Feminino & $57(70,4 \%)$ \\
Masculino & $24(29,6 \%)$ \\
TOTAL & $100(100,0 \%)$ \\
\hline
\end{tabular}

A DPCOINV incide mais sobre o sexo feminino do que no masculino (Tabela 2 e Gráfico 2).

GRÁFICO 2 - Distribuição dos pacientes quanto ao sexo (\%)

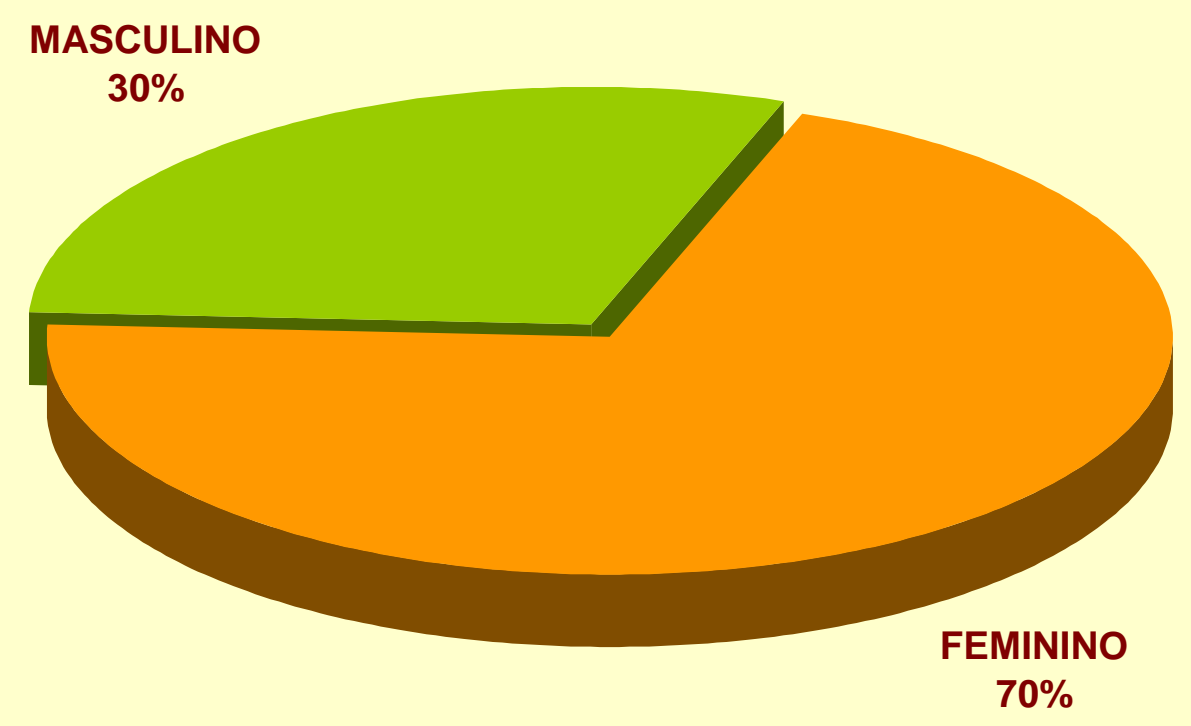


TABELA 3 - Distribuição dos resultados quanto ao sexo dos pacientes, a idade em faixas etárias, $\mathbf{N}$ e percentagem

\begin{tabular}{lcc}
\hline Faixa etária & Mulheres & Homens \\
\hline 20 a 29 anos & $4(7,1 \%)$ & $3(12,5 \%)$ \\
30 a 39 anos & $14(24,5 \%)$ & $3(12,5 \%)$ \\
40 a 49 anos & $14(24,5 \%)$ & $6(24,9 \%)$ \\
50 a 59 anos & $8(14,1 \%)$ & $4(16,7 \%)$ \\
60 a 69 anos & $10(17,5 \%)$ & $4(16,7 \%)$ \\
$>69$ anos & $7(12,3 \%)$ & $4(16,7 \%)$ \\
\hline
\end{tabular}

Houve uma incidência maior no sexo feminino nas faixas etárias de 30 e 49 anos e entre os 40 e 59 anos para o sexo masculino (Tabela 3 e Gráfico 3).

GRÁFICO 3 - Distribuição dos resultados quanto ao sexo dos pacientes, a idade em faixas etárias e percentagem

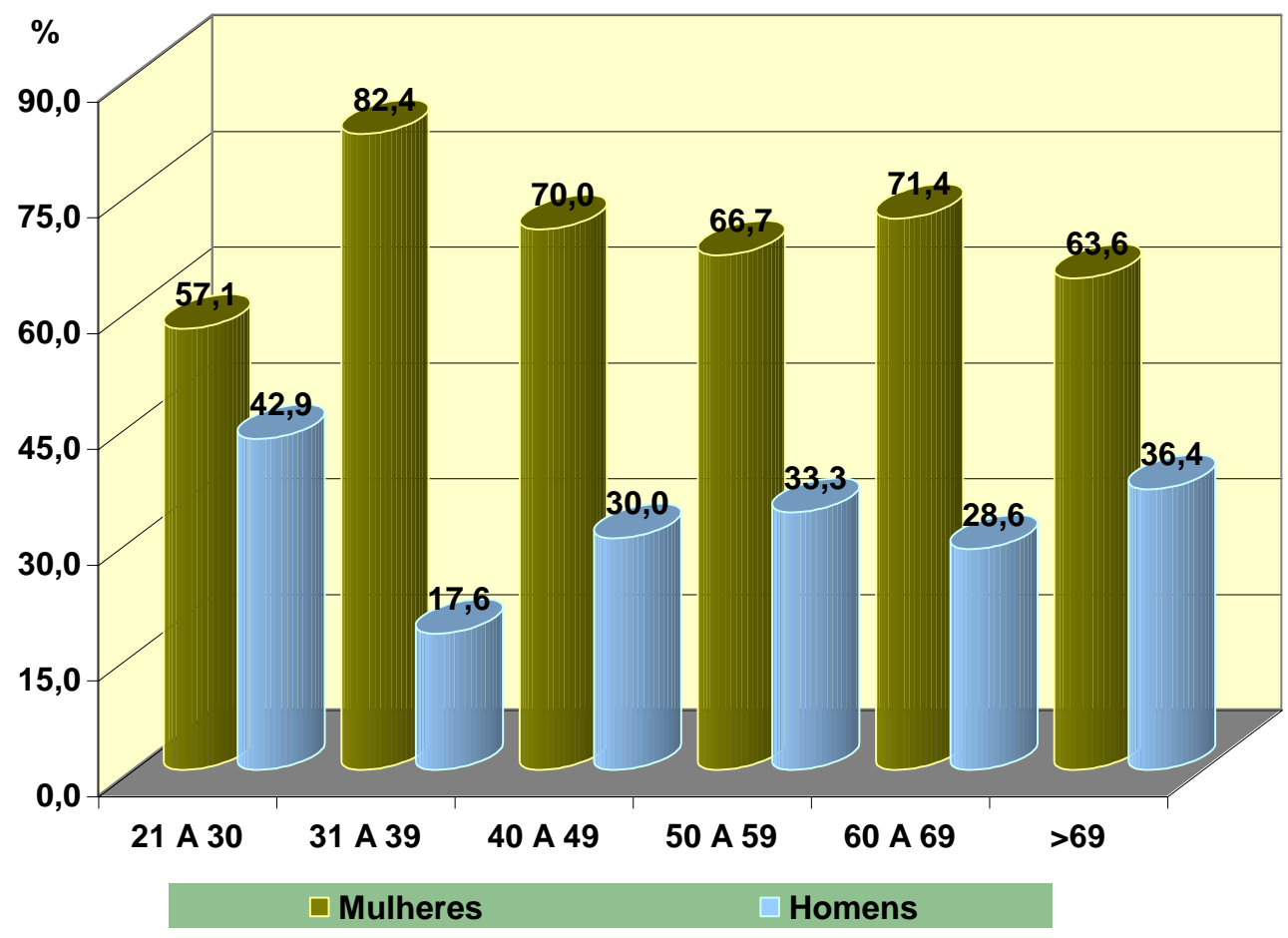


TABELA 4 - Distribuição dos pacientes quanto a região afetada pela dor e o sexo dos pacientes

\begin{tabular}{lcc}
\hline Região & Mulheres & Homens \\
\hline Ânus & $19(21,1 \%)$ & $8(19,0 \%)$ \\
Inguinal & $18(20,0 \%)$ & $10(23,8 \%)$ \\
Vagina & $14(15,6 \%)$ & 0 \\
Púbis & $20(22,2 \%)$ & $3(7,1 \%)$ \\
Períneo & $6(6,7 \%)$ & $3(7,1 \%)$ \\
Cóccix & $5(5,6 \%)$ & $3(7,1 \%)$ \\
Coxa & $5(5,5 \%)$ & $2(4,8 \%)$ \\
Inguino crural & $1(1,1 \%)$ & 0 \\
Quadril & $1(1,1 \%)$ & $1(2,4 \%)$ \\
Vulva & $1(1,1 \%)$ & 0 \\
Pênis & 0 & $5(11,9 \%)$ \\
Testículos & 0 & $1(2,4 \%)$ \\
Uréter & 0 &
\end{tabular}

A Tabela 4 e o Gráfico 4, demonstram que as regiões anal, inguinal, vaginal e pubiana são as regiões de maior prevalência na DPCOI nas mulheres, ao passo que nos homens as regiões anal, inguinal e peniana são as de maior prevalência. 
GRÁFICO 4 - Distribuição dos pacientes quanto à região afetada pela dor e o sexo em percentagem

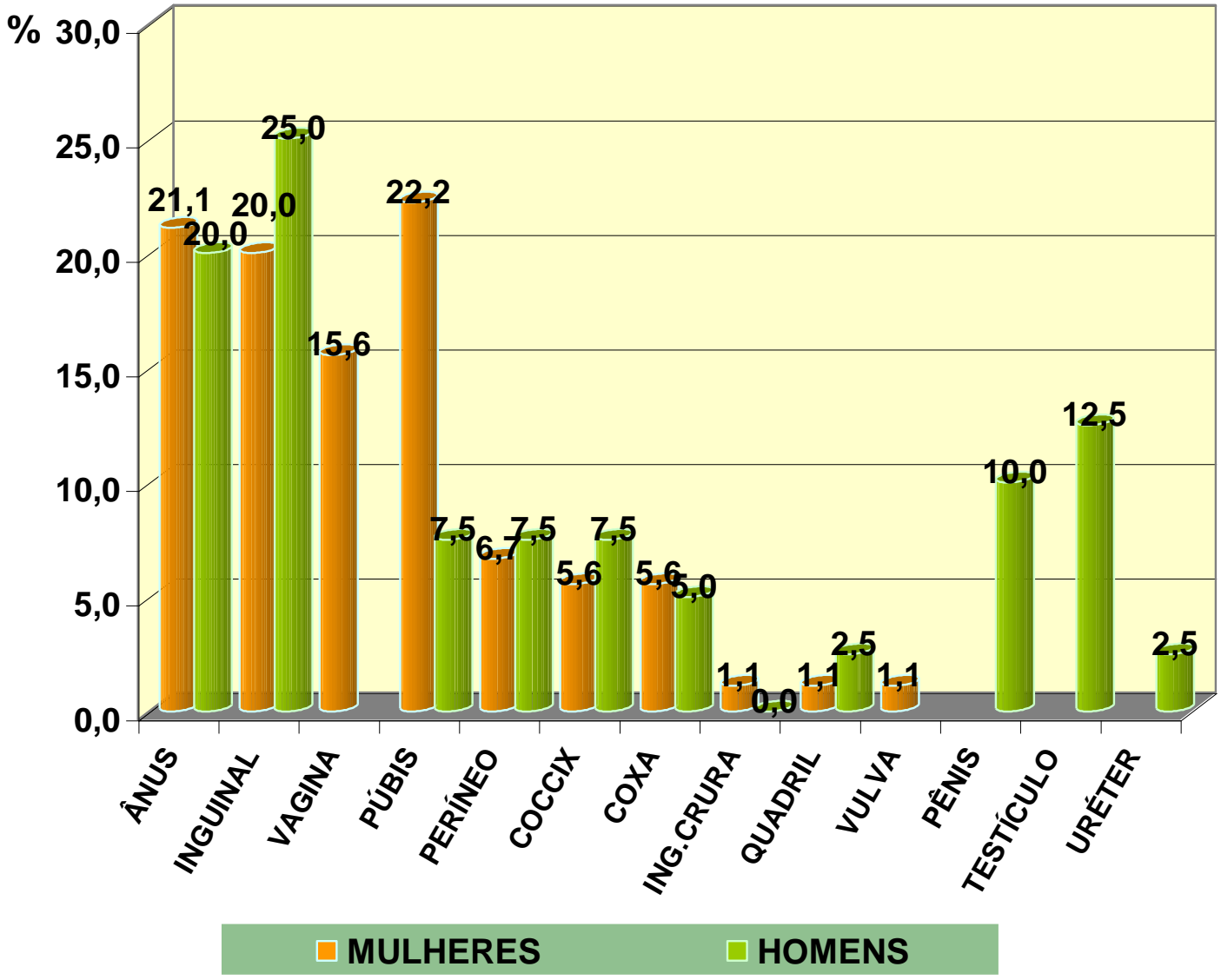


TABELA 5 - Distribuição dos pacientes quanto à característica da dor e sexo dos pacientes

\begin{tabular}{lccccc}
\hline Característica & \multicolumn{2}{c}{ Constante } & Episódica & Flutuante & Paroxística \\
\hline Mulheres & $38(66,7 \%)$ & $10(17,5 \%)$ & $5(8,8 \%)$ & $4(7,0 \%)$ \\
Homens & $20(83,3 \%)$ & $2(8,3 \%)$ & $2(8,3 \%)$ & 0 \\
\hline
\end{tabular}

Houve uma prevalência do caráter constante da DPCOI para o sexo feminino e masculino (Tabela 5 e Gráfico 5).

GRÁFICO 5 - Distribuição dos pacientes quanto à característica da dor e sexo dos pacientes

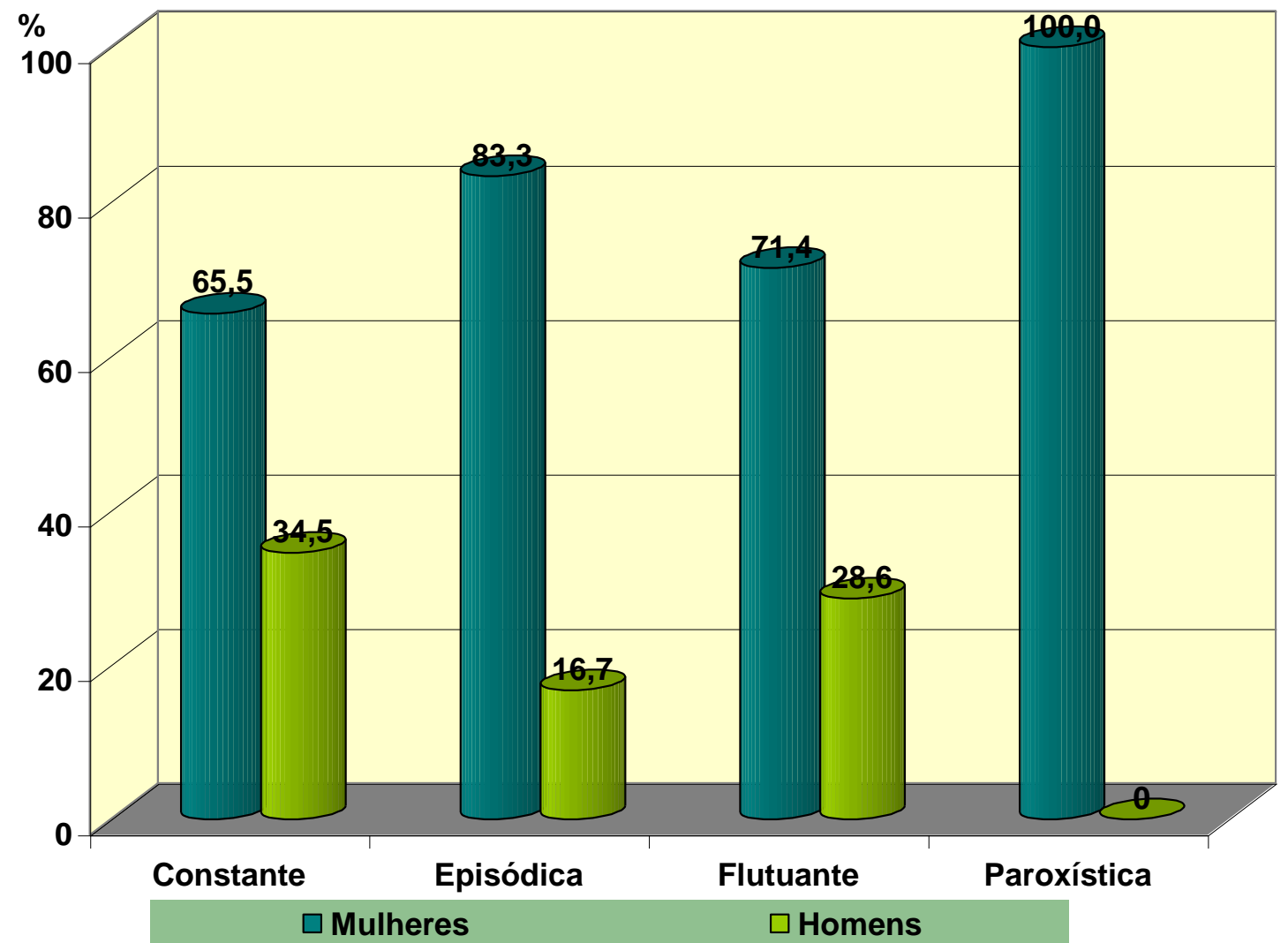


TABELA 6 - Distribuição dos pacientes quanto à expressão verbal da dor e sexo dos pacientes

\begin{tabular}{lcc}
\hline Expressão & Mulheres & Homens \\
\hline Queimor & $30(31,9 \%)$ & $11(31,4 \%)$ \\
Latejamento & $17(18,1 \%)$ & $6(17,1 \%)$ \\
Pontada & $22(23,5 \%)$ & $9(25,7 \%)$ \\
Peso & $7(7,4 \%)$ & $6(17,1 \%)$ \\
Aperto & $7(7,4 \%)$ & 0 \\
Dolorimento & $2(2,1 \%)$ & $1(2,9 \%)$ \\
Choque & $2(2,1 \%)$ & $1(2,9 \%)$ \\
Rasgada & $1(1,1 \%)$ & 0 \\
Pressão & $1(1,1 \%)$ & 0 \\
Formigamento & $1(1,1 \%)$ & 0 \\
Calor & $1(1,1 \%)$ & $1(2,9 \%)$ \\
Dormência & $1(1,1 \%)$ & 0 \\
Facada & $2(1,1 \%)$ & 0 \\
TOTAL & $57(70,4 \%$ & $24(29,6 \%)$ \\
\hline
\end{tabular}

As expressões verbais de queimor, latejamento, pontada e peso são as de maior predominância em ambos os sexos e predomina sobre o sexo feminino (Tabela 6 e Gráfico 6). 
GRÁFICO 6 - Distribuição dos pacientes quanto à expressão verbal da dor e sexo

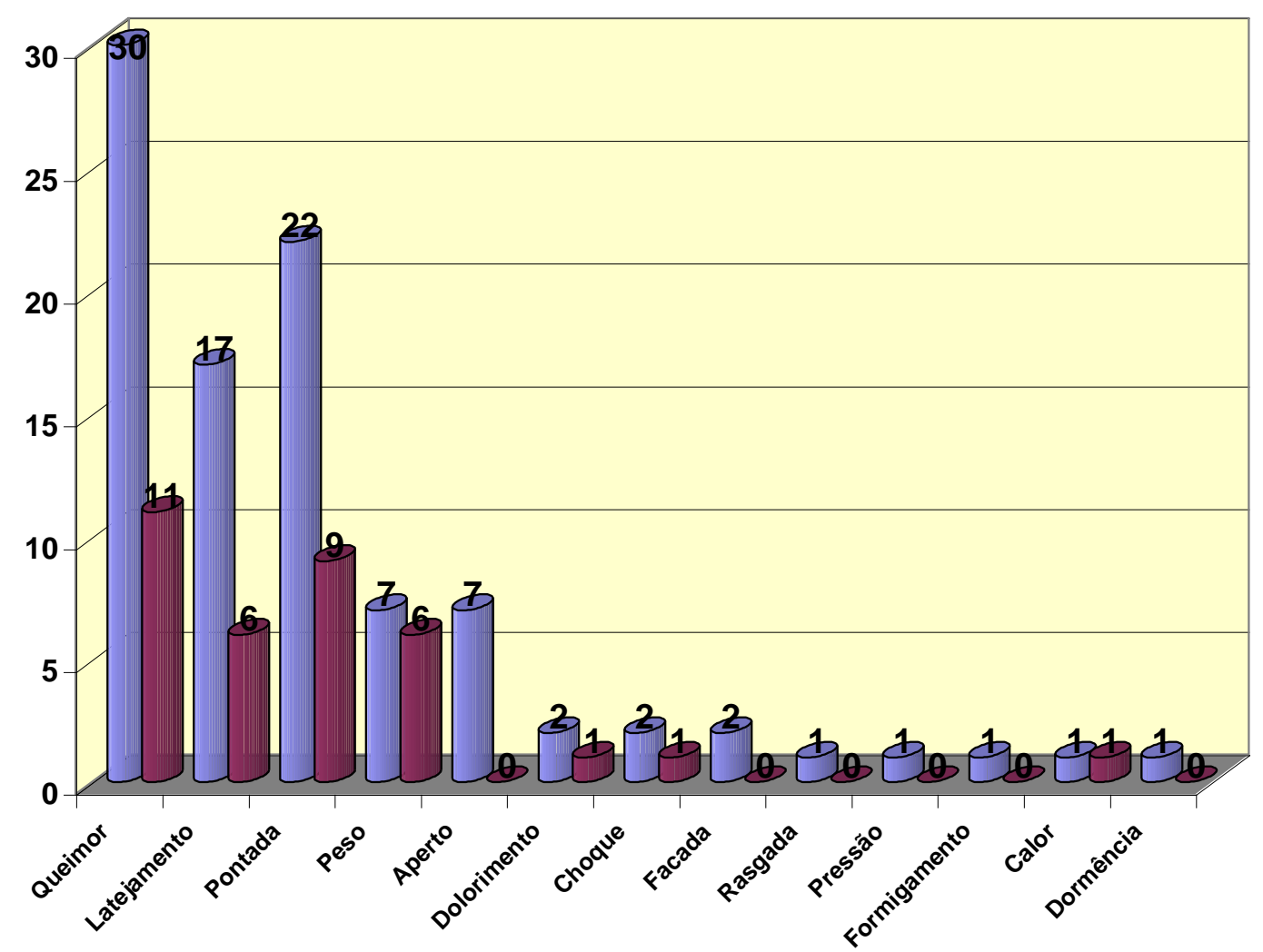

$\square$ Mulheres

$\square$ Homens 
TABELA 7 - Distribuição dos pacientes quanto aos Fatores Agravantes / Desencadeantes da dor e o sexo dos pacientes

\begin{tabular}{lcc}
\hline Fatores Agravantes e & Mulheres & Homens \\
Desencadeantes & $25(16,3 \%)$ & $11(17,7 \%)$ \\
\hline Esf. Físico & $19(12,4 \%)$ & $4(6,5 \%)$ \\
Movimentos & $13(8,5 \%)$ & $10(16,1 \%)$ \\
Marcha & $12(7,9 \%)$ & $4(6,5 \%)$ \\
Frio & $12(7,8 \%)$ & $6(9,7 \%)$ \\
Postura & $10(6,5 \%)$ & $8(12,9 \%)$ \\
Sentar & $10(6,5 \%)$ & $2(3,2 \%)$ \\
Emoções & $7(4,6 \%)$ & $2(3,2 \%)$ \\
Contato & $6(3,9 \%)$ & $1(1,6 \%)$ \\
Calor & $6(3,9 \%)$ & $3(4,8 \%)$ \\
Evacuar & $6(3,9 \%)$ & $2(3,2 \%)$ \\
Estrêsse & $6(3,9 \%)$ & $2(3,2 \%)$ \\
Sexo & $5(3,3 \%)$ & $1(1,6 \%)$ \\
Ortostatismo & $4(2,6 \%)$ & $2(3,2 \%)$ \\
Deitar & $4(2,6 \%)$ & 0 \\
Toque & $2(1,3 \%)$ & 0 \\
Disf. Visceral & $2(1,3 \%)$ & $1(1,6 \%)$ \\
Micção & $1(0,7 \%)$ & 0 \\
Compressão & $1(0,7 \%)$ & 0 \\
Espirro/Tosse & $1(0,7 \%)$ & 0 \\
Ansiedade & $1(0,7 \%)$ & 0 \\
Roupa apertada & $1(0,7 \%)$ & 0 \\
Exercícios & 0 & $1(1,6 \%)$ \\
Mudança Tempo & 0 & $1(1,6 \%)$ \\
Dirigir & 0 & \\
Depressão & 0 &
\end{tabular}

O esforço físico, movimentos, frio, calor, marcha, postura e o ato de sentar são os mais referidos como fatores agravantes da DPCOI em ambos os sexos( Tabela 7 e Gráfico 7). 
GRÁFICO 7 - Distribuição dos pacientes quanto aos Fatores Agravantes / Desencadeantes da dor e sexo dos pacientes

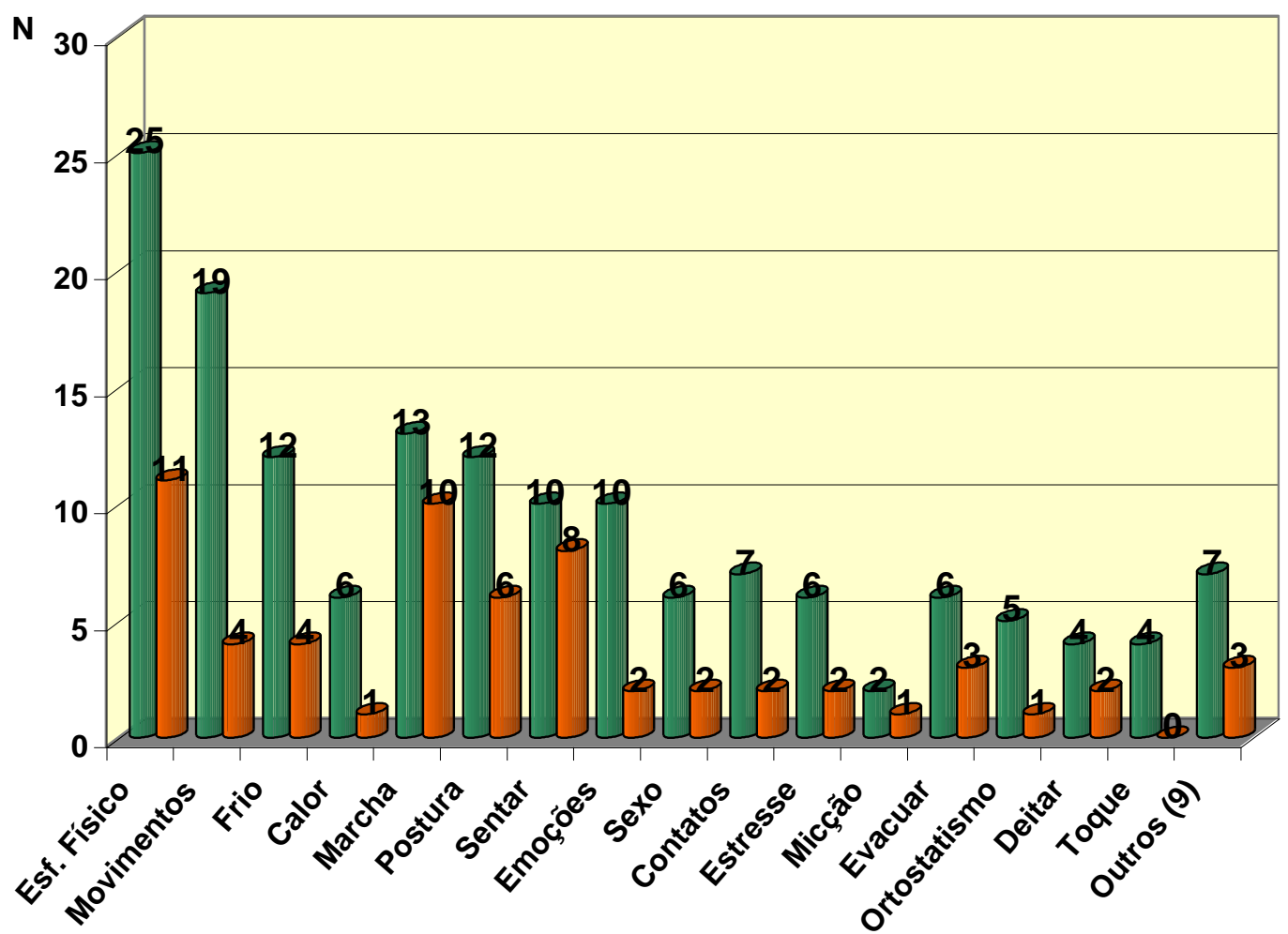


TABELA 8 - Distribuição dos pacientes quanto aos Fatores de Melhora da dor e sexo dos pacientes

\begin{tabular}{|c|c|c|}
\hline $\begin{array}{l}\text { Fatores de } \\
\text { Melhora }\end{array}$ & Mulheres & Homens \\
\hline Medicamentos & $36(27,7 \%)$ & $9(16,7 \%)$ \\
\hline Rep.Físico / Psíquico & $29(22,3 \%)$ & $10(18,5 \%)$ \\
\hline Deitar & $17(13,1 \%)$ & $9(16,7 \%)$ \\
\hline Sono & $16(12,3 \%)$ & $6(11,1 \%)$ \\
\hline Calor & $9(6,9 \%)$ & $5(9,3 \%)$ \\
\hline Frio & $3(2,3 \%)$ & 0 \\
\hline Andar & $5(3,8 \%)$ & $1(1,9 \%)$ \\
\hline Massagem & $5(3,8 \%)$ & 0 \\
\hline Ortostatismo & $5(3,8 \%)$ & $2(3,7 \%)$ \\
\hline Micção & $1(0,8 \%)$ & 0 \\
\hline Evacuar & $1(0,8 \%)$ & $1(1,9 \%)$ \\
\hline Sentar & $1(0,8 \%)$ & $5(9,3 \%)$ \\
\hline Contatos & $1(0,8 \%)$ & 0 \\
\hline Movimentos & $1(0,8 \%)$ & 0 \\
\hline Exercícios & 0 & $1(1,9 \%)$ \\
\hline Correr & 0 & $1(1,9 \%)$ \\
\hline Erecção & 0 & $1(1,9 \%)$ \\
\hline Eletroanalgesia & 0 & $1(1,9 \%)$ \\
\hline Acupuntura & 0 & $1(1,9 \%)$ \\
\hline Massoterapia & 0 & $1(1,9 \%)$ \\
\hline
\end{tabular}

A Tabela 8 e o Gráfico 8 demonstram que os medicamentos, repouso físico e psíquico, deitar, sono, calor e frio são os fatores de melhora que predominam em ambos os sexos. 
GRÁFICO 8 - Distribuição dos pacientes quanto aos Fatores de Melhora da dor e sexo dos pacientes

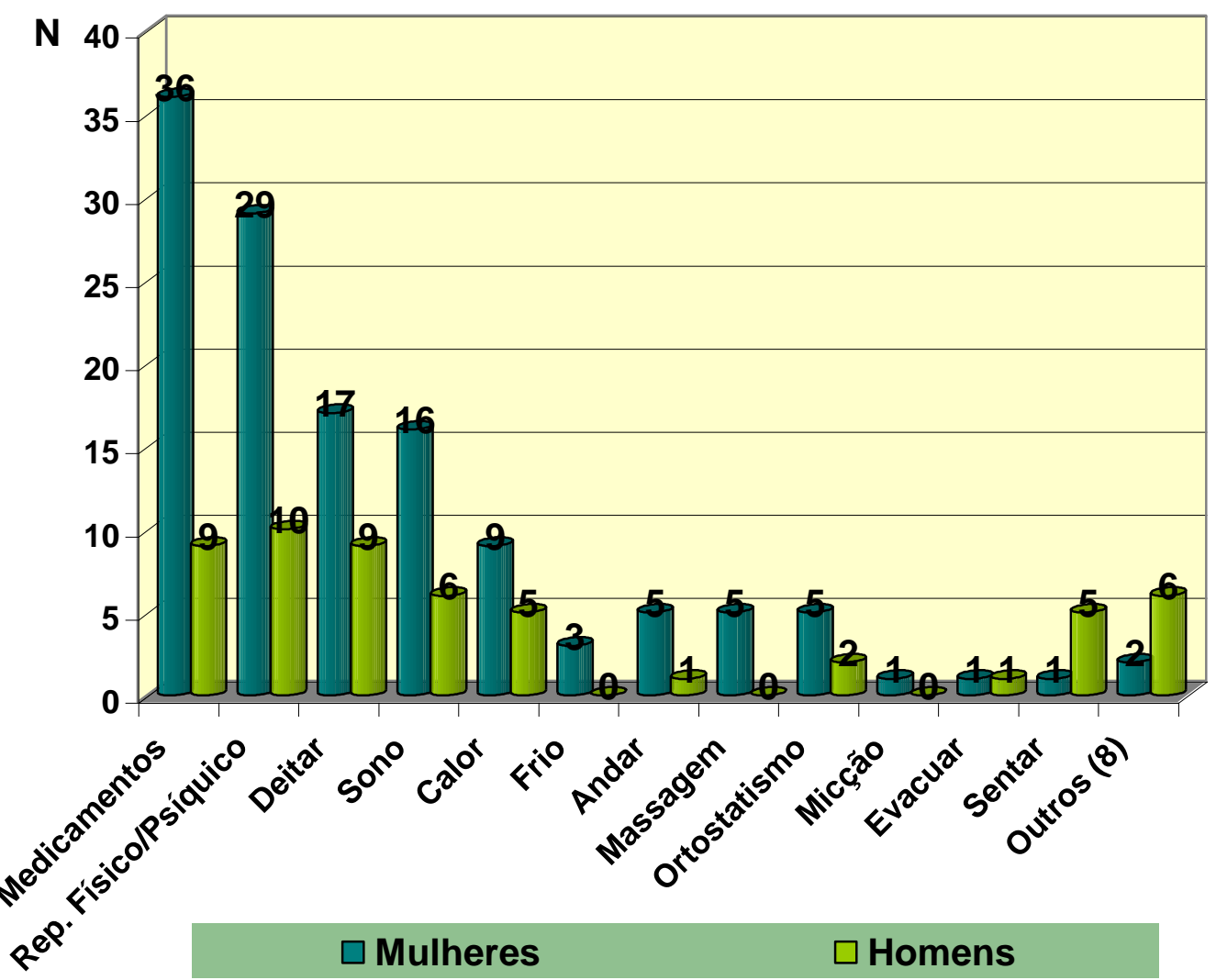


TABELA 9 - Distribuição dos pacientes quanto aos Impactos da dor sobre as Atividades da Vida Diária (AVD) e o sexo dos pacientes

\begin{tabular}{lcr}
\hline $\begin{array}{l}\text { Impactos sobre } \\
\text { as AVD }\end{array}$ & Mulheres & Homens \\
\hline Humor & $43(18,3 \%)$ & $9(14,1 \%)$ \\
Sono & $38(16,2 \%)$ & $9(14,1 \%)$ \\
Lazer & $31(13,2 \%)$ & $10(15,6 \%)$ \\
Trabalho & $30(12,8 \%)$ & $11(17,2 \%)$ \\
Sexo & $24(10,2 \%)$ & $5(7,8 \%)$ \\
Apetite & $19(8,1 \%)$ & $5(7,8 \%)$ \\
Concentração & $14(6,0 \%)$ & $2(3,1 \%)$ \\
Sentar & $11(4,7 \%)$ & $4(6,2 \%)$ \\
Psiquismo & $10(4,3 \%)$ & $1(1,6 \%)$ \\
Deambular & $6(2,6 \%)$ & $2(3,1 \%)$ \\
Deitar & $3(1,3 \%)$ & 0 \\
Relacionamento & $2(0,9 \%)$ & $1(1,6 \%)$ \\
Vestir & $1(0,4 \%)$ & $2(3,1 \%)$ \\
Micção & 0 & $1(1,6 \%)$ \\
Evacuar & $1(0,4 \%)$ & $1(1,6 \%)$ \\
Ortostatismo & $1(0,4 \%)$ & $1(1,6 \%)$ \\
Movimentos & $1(0,4 \%)$ & 0 \\
\hline
\end{tabular}

A Tabela 9 e o Gráfico 9 revelam que as atividades como sono, humor, lazer e trabalho tem a mesma incidência entre os sexos, ao passo que a atividade sexual, apetite, concentração, o ato de sentar e o psiquismo incidem mais sobre o sexo feminino. 
GRÁFICO 9 - Distribuição dos pacientes quanto aos Impactos da dor sobre as Atividades da Vida Diária (AVD) e o sexo dos pacientes

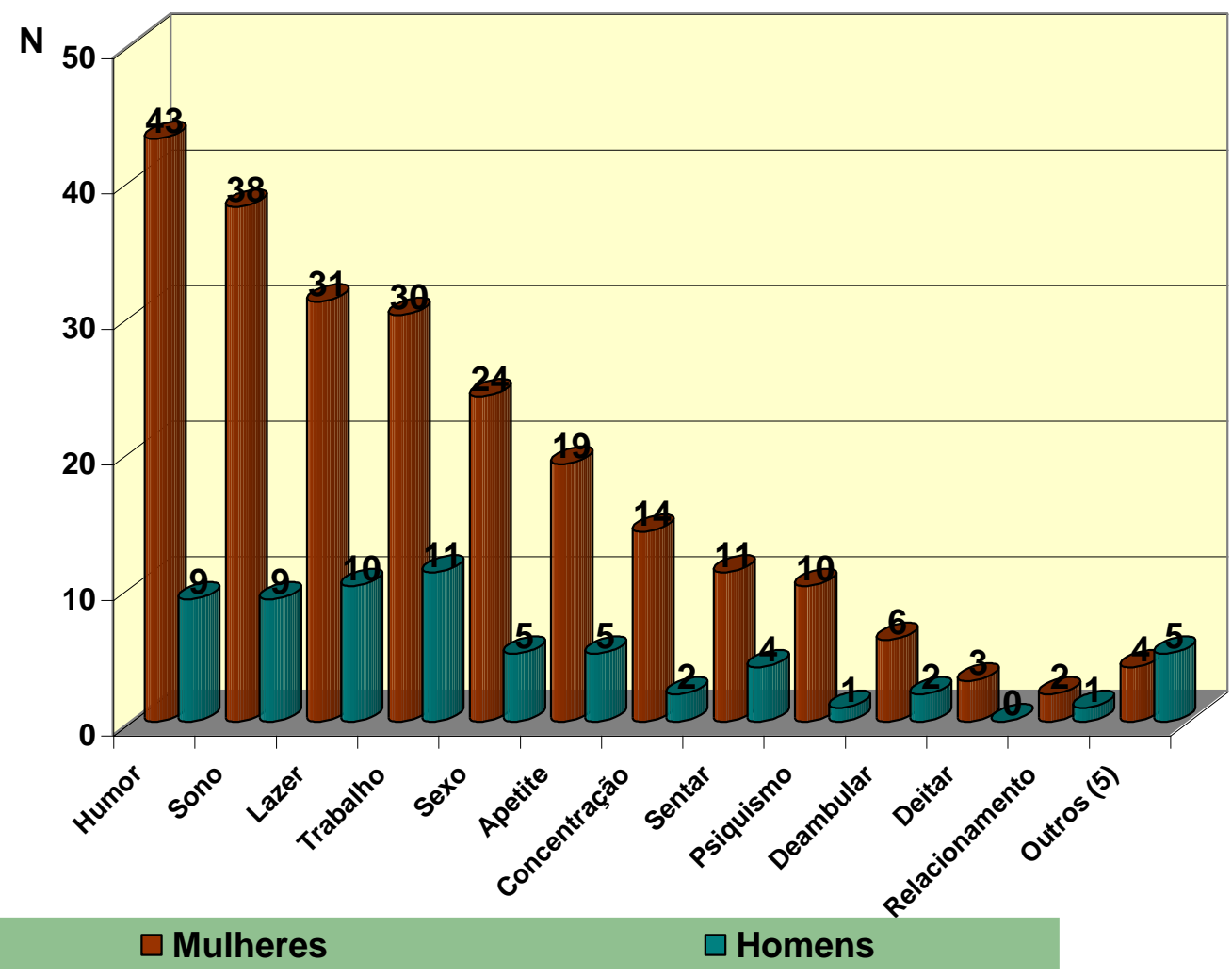


TABELA 10 - Distribuição dos pacientes quanto aos Pontos Gatilho e o sexo dos pacientes

\begin{tabular}{lcc}
\hline Pontos Gatilho & Mulheres & Homens \\
\hline Elevador do Ânus & $27(32,5 \%)$ & $9(34,6 \%)$ \\
Glúteos & $22(26,5 \%)$ & $5(19,2 \%)$ \\
Adutores & $14(16,9 \%)$ & $3(11,5 \%)$ \\
Piriforme & $10(12,0 \%)$ & $2(7,7 \%)$ \\
Quadrado Lombar & $4(4,8 \%)$ & 0 \\
Coccígeo & $3(3,6 \%)$ & $2(7,7 \%)$ \\
Multifídio & $5(6,0 \%)$ & $2(7,7 \%)$ \\
Íleo psoas & $2(2,4 \%)$ & $1(3,8 \%)$ \\
Oblíquo Int / Ext & $1(1,2 \%)$ & $1(3,8 \%)$ \\
Reto Abdominal & $1(1,2 \%)$ & $1(3,8 \%)$ \\
Vasto Medial & $1(1,2 \%)$ & 0 \\
Abdutores & $1(1,2 \%)$ & 0 \\
Bulbo Esponjoso & $1(1,2 \%)$ & 0 \\
Pectíneo & $1(1,2 \%)$ & 0 \\
\hline
\end{tabular}

Os PGs mais predominantes foram nos músculos elevador do ânus, glúteos, adutores e piriforme em ambos os sexos, com predomínio para o sexo feminino (Tabela 10 e Gráfico 10). 
GRÁFICO 10 - Distribuição dos pacientes quanto aos Pontos Gatilho e o sexo dos pacientes

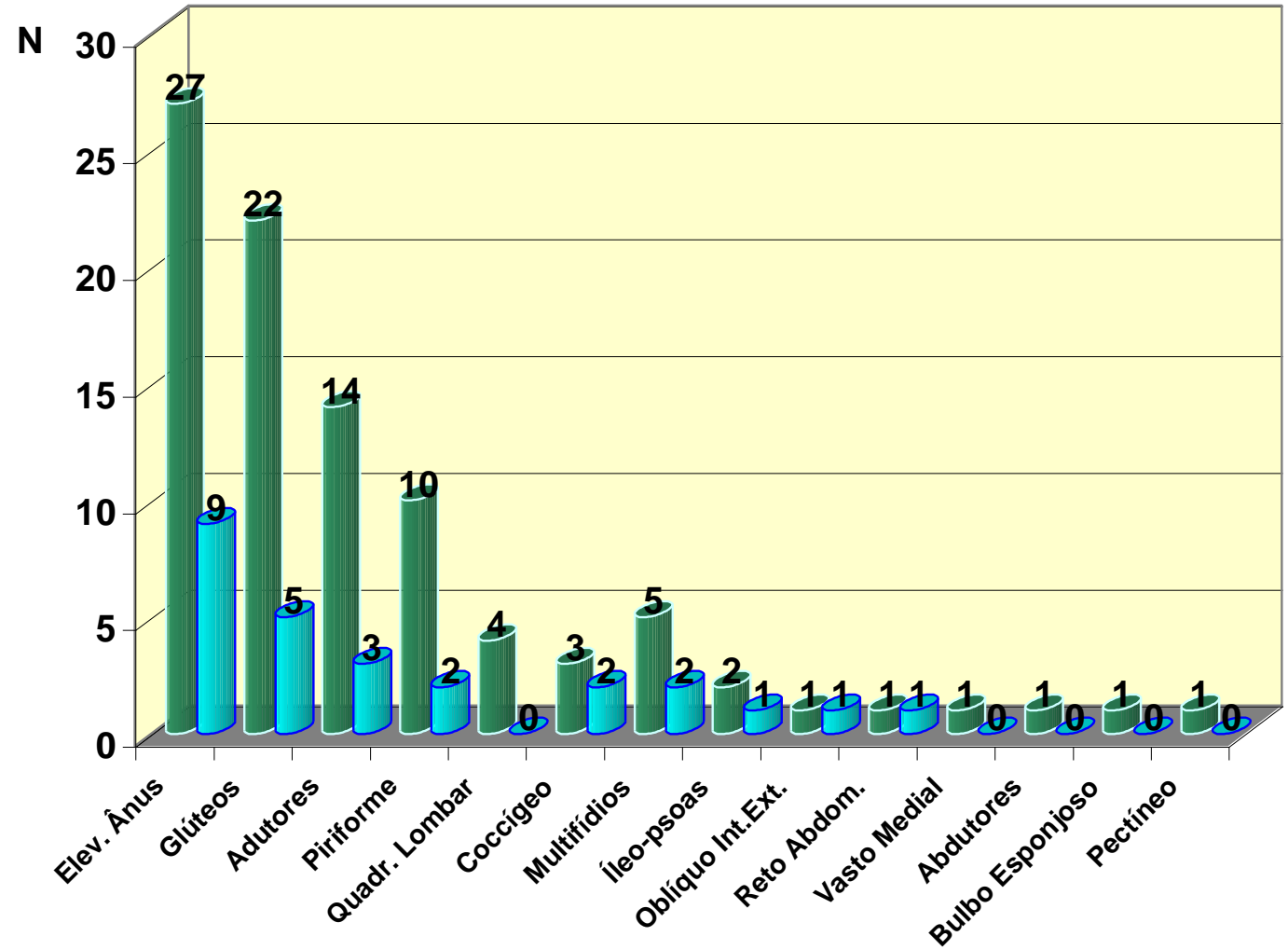


TABELA 11 - Distribuição dos pacientes quanto ao diagnóstico principal e o sexo dos pacientes

\begin{tabular}{lccc}
\hline Diagnóstico & Mulheres & Homens & TOTAL \\
\hline Miofascial & $40(70,2 \%)$ & $15(62,5 \%)$ & 55 \\
Miofascial e Neuropática & $13(22,8 \%)$ & $3(12,5 \%)$ & 16 \\
Neuropática & $4(7,0 \%)$ & $6(25,0 \%)$ & 10 \\
\hline
\end{tabular}

As dores miofascial e miofascial neuropática incidem mais sobre o sexo feminino e a dor neuropática tem ligeiro predomínio para o sexo masculino (Tabela 11 e Gráfico 11).

GRÁFICO 11 - Distribuição dos pacientes quanto ao diagnóstico principal

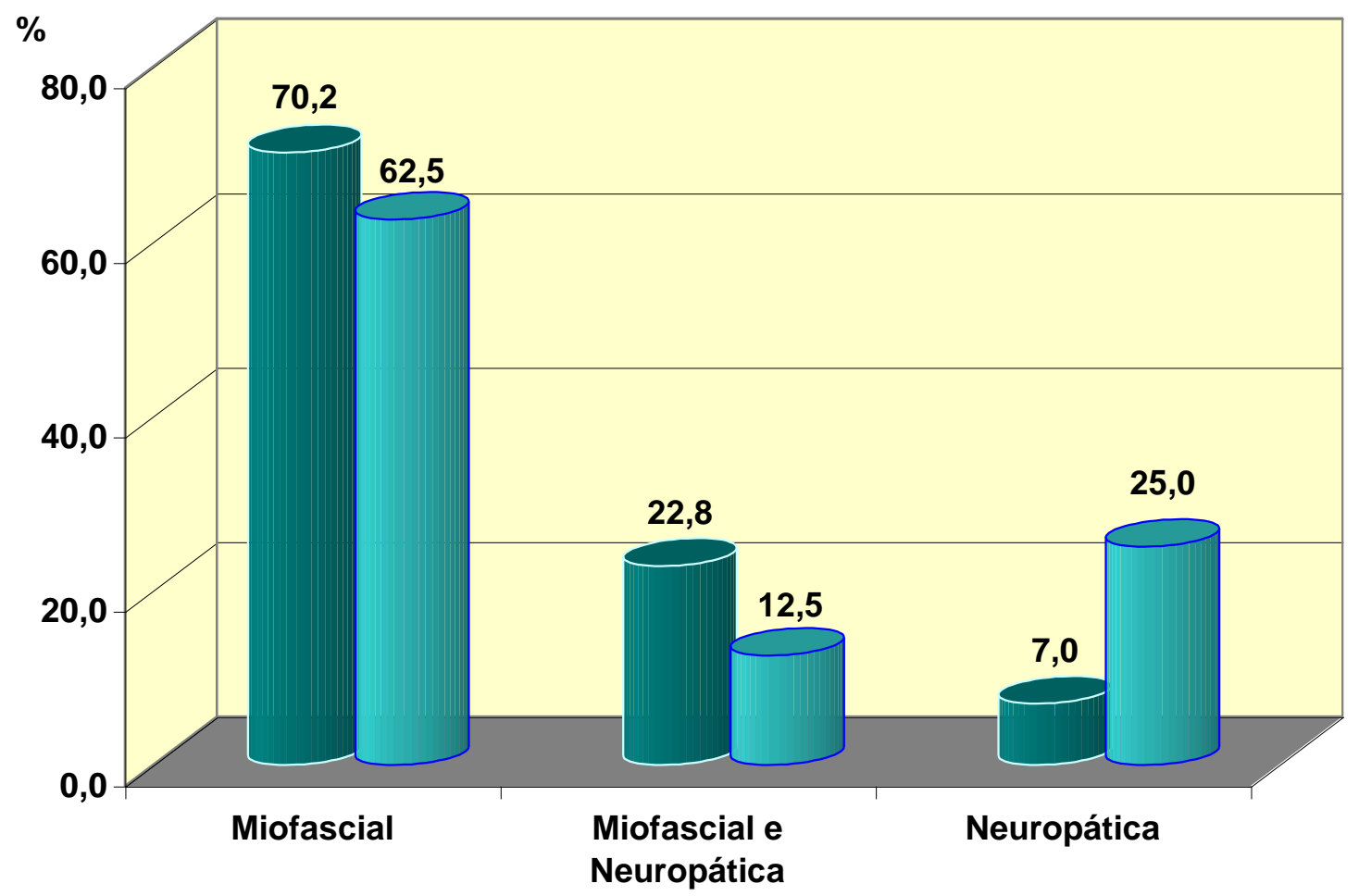

$\square$ Mulheres (\%) $\quad \square$ Homens (\%)

e o sexo dos pacientes 
TABELA 12 - Distribuição dos pacientes quanto ao diagnóstico e o sexo dos pacientes

\begin{tabular}{lcc}
\hline Diagnóstico & Mulheres & Homens \\
\hline Miofascial Pós Trauma Cirúrgico & $8(14,0 \%)$ & $3(12.5 \%)$ \\
Miosfascial Pós Trauma Não Cirúrgico & $7(12,3 \%)$ & $3(12.5 \%)$ \\
Miofascial Sem Trauma & $25(43,9 \%)$ & $9(37,5 \%)$ \\
Miofascial e Neuropática Pós Trauma & $9(15,8 \%)$ & $1(4,2 \%)$ \\
Cirúrgico & $4(7,0 \%)$ & $2(8,3 \%)$ \\
Miofascial e Neuropática Sem Trauma & $2(3,5 \%)$ & $3(12.5 \%)$ \\
Neuropática Pós Trauma Cirúrgico & $2(4,2 \%)$ \\
Neuropática Pós Trauma Não & 0 & $1(4,5 \%)$ \\
Cirúrgico & $2(8,3 \%)$ \\
Neuropática Sem Trauma & $2(3,5 \%)$ \\
\hline
\end{tabular}

As mulheres tiveram uma incidência maior nas dores miofasciais e miofasciais neuropáticas pós trauma cirúrgico, ao passo que nos homens houve uma incidência maior nas dores neuropáticas pós trauma cirúrgico (Tabela 12 e Gráfico 12). 
GRÁFICO 12 - Distribuição dos pacientes quanto ao diagnóstico e o sexo dos pacientes

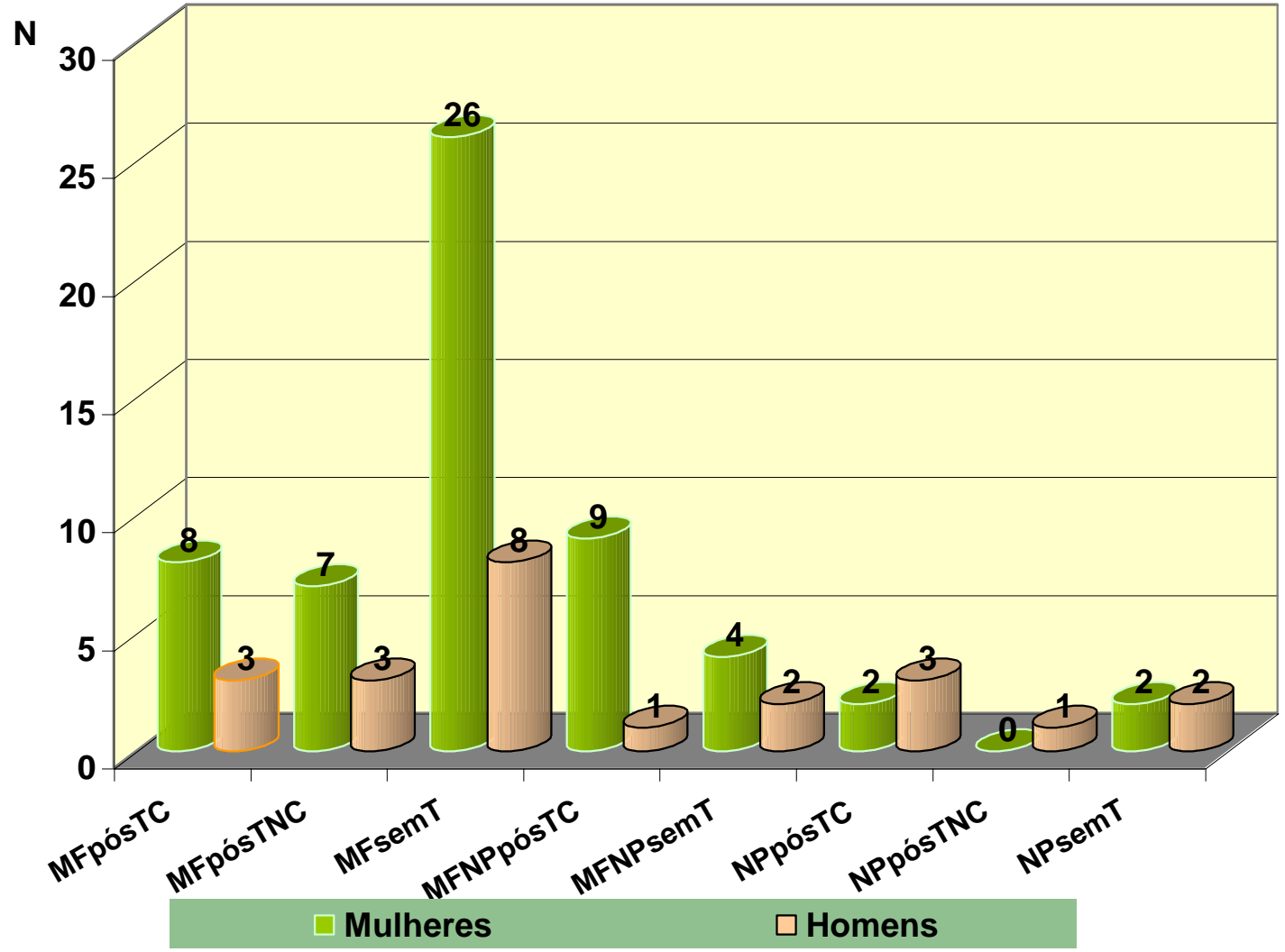


TABELA 13 - Distribuição dos pacientes quanto à região de localização da dor, a faixa etária e o sexo dos pacientes

\begin{tabular}{|c|c|c|c|c|c|c|c|c|c|c|c|c|}
\hline \multirow{2}{*}{ Região } & \multicolumn{2}{|c|}{20 a 29} & \multicolumn{2}{|c|}{30 a 39} & \multicolumn{2}{|c|}{40 a 49} & \multicolumn{2}{|c|}{50 a 59} & \multicolumn{2}{|c|}{60 a 69} & \multicolumn{2}{|c|}{$>69$} \\
\hline & M & $\mathbf{H}$ & $\mathbf{M}$ & $\mathbf{H}$ & $\mathbf{M}$ & $\mathbf{H}$ & $\mathbf{M}$ & $\mathbf{H}$ & $\mathbf{M}$ & $\mathbf{H}$ & M & H \\
\hline Inguinal & 3 & 0 & 4 & 1 & 6 & 1 & 2 & 3 & 2 & 2 & 1 & 3 \\
\hline Vagina & 1 & - & 6 & - & 2 & - & 2 & - & 1 & - & 2 & - \\
\hline Anus & 1 & 2 & 3 & 2 & 3 & 2 & 2 & 0 & 6 & 2 & 4 & 0 \\
\hline Cóccix & 1 & 0 & 2 & 1 & 1 & 2 & 1 & 0 & 0 & 0 & 0 & 0 \\
\hline Perineo & 0 & 1 & 4 & 0 & 0 & 0 & 1 & 0 & 0 & 1 & 1 & 1 \\
\hline Púbis & 0 & 0 & 3 & 0 & 6 & 1 & 4 & 0 & 6 & 1 & 1 & 3 \\
\hline Pênis & - & 1 & - & 1 & - & 1 & - & 0 & - & 1 & - & 0 \\
\hline Coxa & 0 & 0 & 1 & 0 & 3 & 0 & 1 & 2 & 0 & 0 & 0 & 0 \\
\hline Inguinocrural & 0 & 0 & 0 & 0 & 1 & 0 & 0 & 0 & 0 & 0 & 0 & 0 \\
\hline Quadril & 0 & 0 & 0 & 0 & 0 & 0 & 1 & 0 & 1 & 0 & 0 & 0 \\
\hline Ureter & - & 1 & - & 0 & - & 0 & - & 0 & - & 0 & - & 0 \\
\hline Vulva & 0 & - & 0 & - & 0 & - & 1 & - & 0 & - & 0 & - \\
\hline Testículos & - & 1 & - & 2 & - & 1 & - & 0 & - & 1 & - & 0 \\
\hline
\end{tabular}

Há prevalência das regiões inguinal, vaginal, anal e coccígea no sexo feminino (Tabela 13 e Gráficos 13A e 13B ). 
GRÁFICO 13A - Distribuição dos pacientes quanto à região de localização da dor, a faixa etária e o sexo dos pacientes (mulheres)

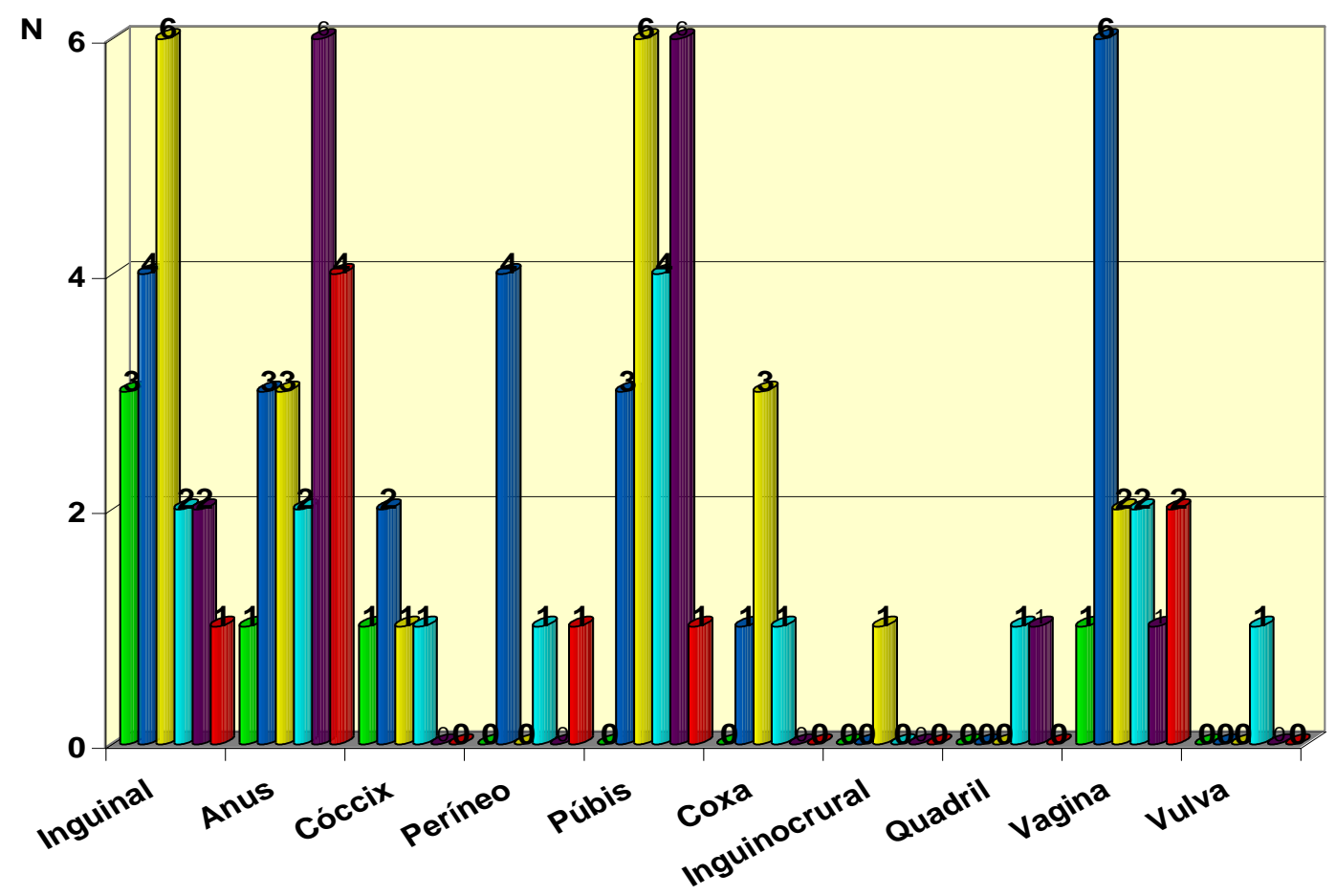

$\square 20$ a $29 \quad \square 30$ a $39 \quad \square 40$ a $49 \quad \square 50$ a $59 \quad \square 60$ a $69 \quad \square>69$

GRÁFICO 13 B- Distribuição dos pacientes quanto à região de localização da dor, a faixa etária e o sexo dos pacientes (homens)

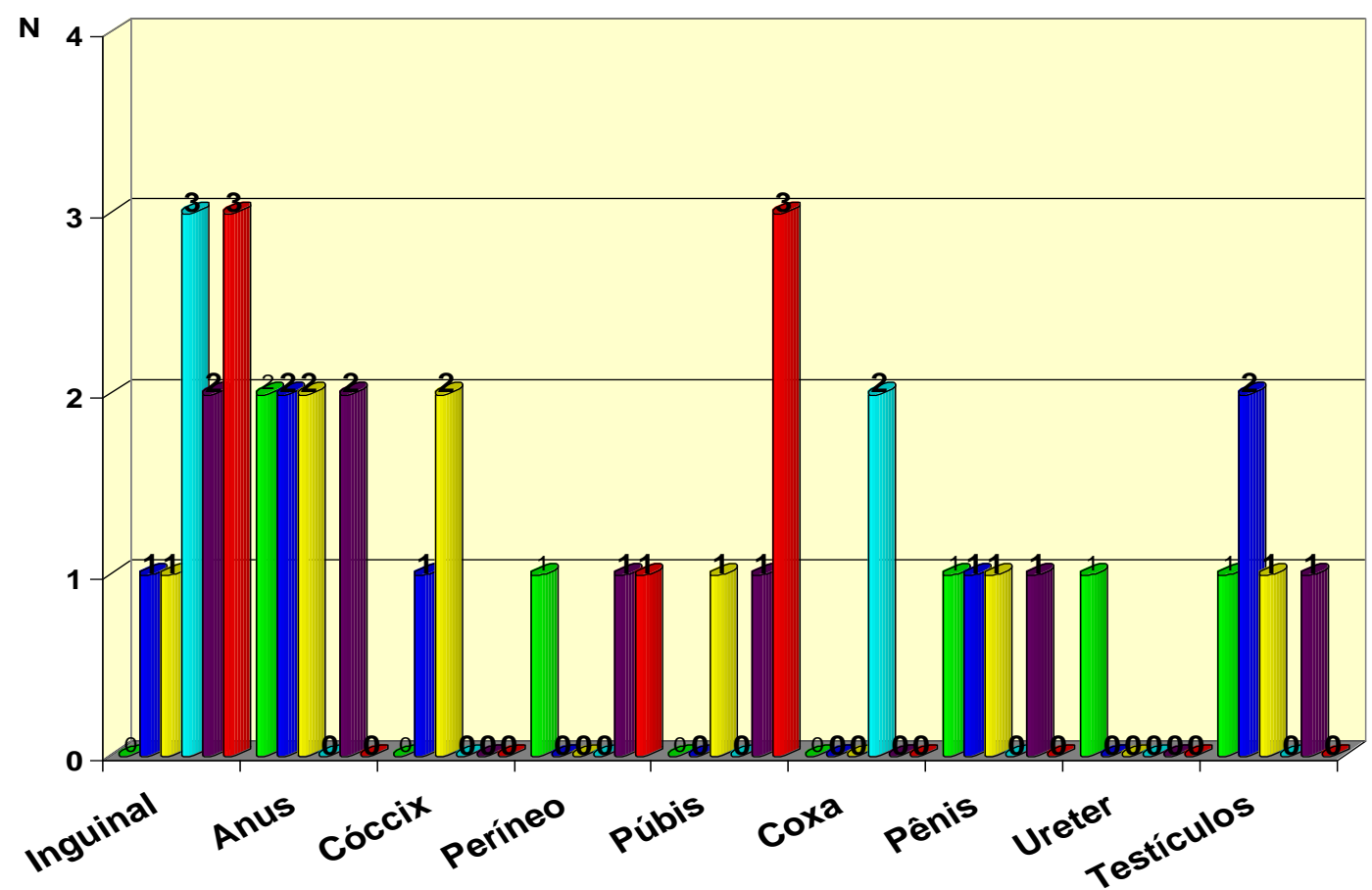


TABELA 14 - Distribuição dos pacientes quanto à expressão verbal da dor, a faixa etária e o sexo dos pacientes

\begin{tabular}{lcccccccccccc}
\hline Expressão & $\mathbf{2 0}$ a $\mathbf{2 9}$ & \multicolumn{3}{c}{$\mathbf{3 0}$ a $\mathbf{3 9}$} & $\mathbf{4 0}$ a & $\mathbf{4 9}$ & \multicolumn{3}{c}{$\mathbf{5 0}$ a 59} & $\mathbf{6 0}$ a $\mathbf{6 9}$ & \multicolumn{3}{c}{$>\mathbf{6 9}$} \\
Verbal da dor & $\mathbf{M}$ & $\mathbf{H}$ & $\mathbf{M}$ & $\mathbf{H}$ & $\mathbf{M}$ & $\mathbf{H}$ & $\mathbf{M}$ & $\mathbf{H}$ & $\mathbf{M}$ & $\mathbf{H}$ & $\mathbf{M}$ & $\mathbf{H}$ \\
\hline Queimor & 2 & 0 & 7 & 1 & 8 & 2 & 4 & 2 & 6 & 3 & 3 & 3 \\
Latejamento & 1 & 2 & 5 & 1 & 3 & 1 & 2 & 0 & 3 & 1 & 3 & 1 \\
Pontada & 1 & 2 & 6 & 2 & 5 & 2 & 3 & 2 & 4 & 0 & 3 & 1 \\
Peso & 0 & 1 & 3 & 0 & 1 & 3 & 0 & 0 & 2 & 1 & 1 & 1 \\
Dolorimento & 0 & 0 & 1 & 0 & 0 & 0 & 1 & 1 & 0 & 0 & 0 & 0 \\
Rasgada & 0 & 0 & 0 & 0 & 0 & 0 & 0 & 0 & 1 & 0 & 0 & 0 \\
Pressão & 0 & 0 & 0 & 0 & 0 & 0 & 1 & 0 & 0 & 0 & 0 & 0 \\
Choque & 0 & 0 & 0 & 0 & 1 & 0 & 0 & 0 & 1 & 1 & 0 & 0 \\
Formigamento & 0 & 0 & 0 & 0 & 0 & 0 & 1 & 0 & 0 & 0 & 0 & 0 \\
Calor & 0 & 0 & 0 & 0 & 0 & 1 & 1 & 0 & 0 & 0 & 0 & 0 \\
Dormência & 0 & 0 & 0 & 0 & 0 & 0 & 0 & 0 & 1 & 0 & 0 & 0 \\
Aperto & 1 & 0 & 0 & 0 & 4 & 0 & 1 & 0 & 1 & 0 & 0 & 0 \\
Facada & 0 & 0 & 0 & 0 & 0 & 0 & 0 & 0 & 1 & 0 & 0 & 0 \\
\hline
\end{tabular}

As expressões verbais como queimor, latejamento, pontada, ardor, peso e aperto foram as mais presentes em ambos os sexos (Tabela 14 e Gráficos $14 \mathrm{~A}$ e $14 \mathrm{~B})$. 
GRÁFICO 14A - Distribuição dos pacientes quanto à expressão verbal da dor, a faixa etária e o sexo dos pacientes - Mulheres

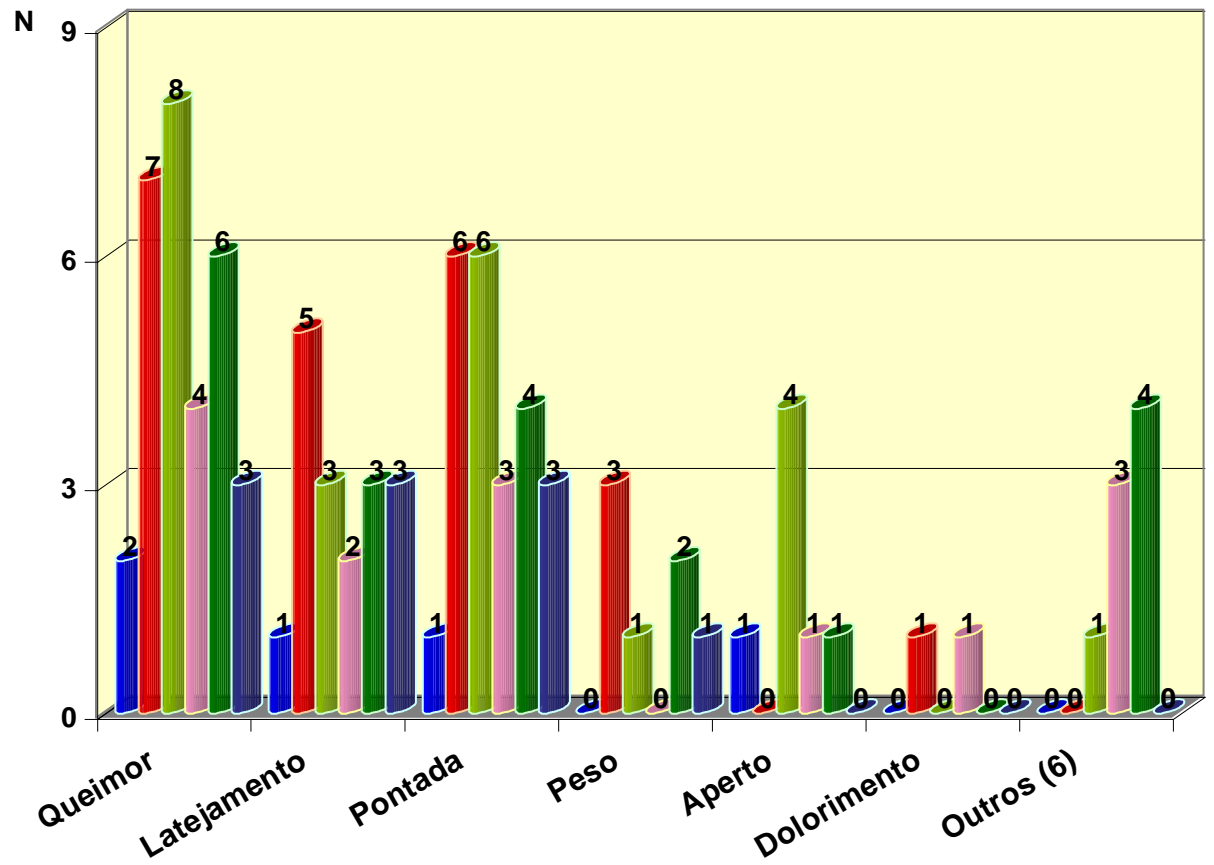

$\square 20$ a $29 \square 30$ a $39 \square 40$ a $49 \square 50$ a $59 \quad \square 60$ a $69 \quad \square>69$

GRÁFICO 14B - Distribuição dos pacientes quanto à expressão verbal da dor, a faixa etária e o sexo dos pacientes - Homens

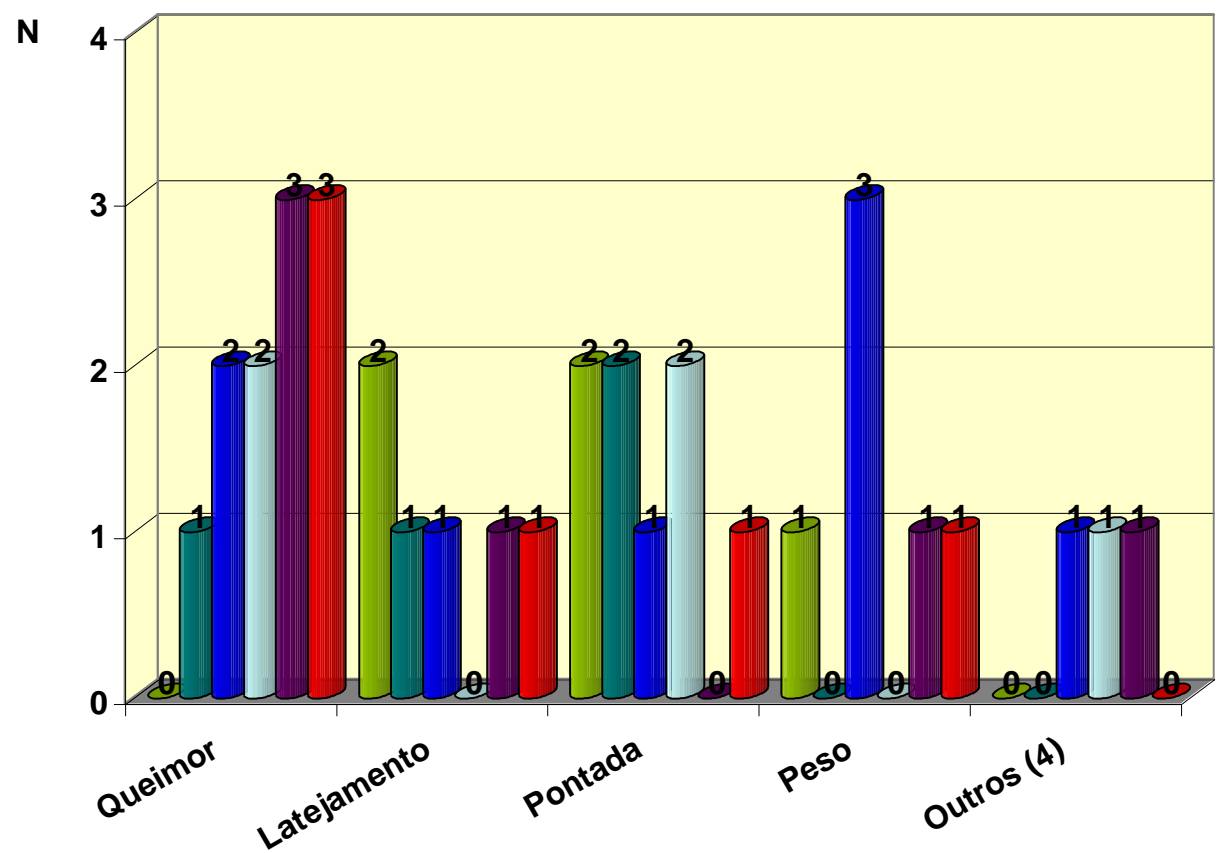


TABELA 15 - Distribuição dos pacientes quanto aos fatores agravantes e desencadeantes da dor, a faixa etária e o sexo dos pacientes

\begin{tabular}{lcccccccccccc}
\hline Agravantes e & $\mathbf{2 0}$ & $\mathbf{2}$ & $\mathbf{2 9}$ & $\mathbf{3 0}$ & $\mathbf{a} \mathbf{3 9}$ & $\mathbf{4 0}$ & $\mathbf{a} \mathbf{4 9}$ & $\mathbf{5 0}$ & $\mathbf{a} \mathbf{5 9}$ & $\mathbf{6 0}$ & $\mathbf{a} \mathbf{6 9}$ & \multicolumn{3}{c}{$\mathbf{5 9}$} \\
Desencadeantes & $\mathbf{M}$ & $\mathbf{H}$ & $\mathbf{M}$ & $\mathbf{H}$ & $\mathbf{M}$ & $\mathbf{H}$ & $\mathbf{M}$ & $\mathbf{H}$ & $\mathbf{M}$ & $\mathbf{H}$ & $\mathbf{M}$ & $\mathbf{H}$ \\
\hline Postura & 0 & 0 & 4 & 1 & 3 & 1 & 1 & 2 & 2 & 1 & 2 & 0 \\
Esforço Físico & 2 & 1 & 8 & 2 & 7 & 3 & 1 & 2 & 4 & 1 & 3 & 2 \\
Movimento & 1 & 0 & 6 & 0 & 3 & 2 & 3 & 2 & 5 & 0 & 1 & 0 \\
Compressão & 0 & 0 & 0 & 0 & 1 & 0 & 0 & 0 & 0 & 0 & 0 & 0 \\
Marcha & 0 & 0 & 4 & 0 & 4 & 3 & 2 & 3 & 1 & 2 & 2 & 2 \\
Estresse & 0 & 0 & 0 & 1 & 2 & 0 & 1 & 0 & 3 & 0 & 0 & 1 \\
Evacuar & 1 & 1 & 1 & 1 & 1 & 1 & 0 & 0 & 2 & 0 & 1 & 0 \\
Mição & 0 & 0 & 1 & 1 & 1 & 0 & 0 & 0 & 0 & 0 & 0 & 0 \\
Frio & 0 & 0 & 6 & 1 & 2 & 1 & 0 & 1 & 0 & 1 & 4 & 0 \\
Calor & 0 & 0 & 1 & 0 & 1 & 0 & 1 & 0 & 2 & 1 & 1 & 0 \\
Emoções & 1 & 0 & 3 & 0 & 0 & 0 & 0 & 0 & 4 & 1 & 2 & 1 \\
Sentar & 1 & 1 & 2 & 1 & 2 & 4 & 1 & 3 & 2 & 1 & 2 & 0 \\
Ortostatismo & 0 & 0 & 1 & 0 & 2 & 1 & 1 & 1 & 1 & 0 & 0 & 0 \\
Contato & 0 & 0 & 3 & 0 & 1 & 0 & 1 & 0 & 1 & 2 & 1 & 0 \\
Sexo & 0 & 1 & 2 & 0 & 2 & 1 & 1 & 1 & 1 & 0 & 0 & 0 \\
Espirro Tosse & 0 & 0 & 1 & 0 & 0 & 0 & 0 & 0 & 0 & 0 & 0 & 0 \\
Ansiedade & 0 & 0 & 1 & 0 & 0 & 0 & 0 & 0 & 0 & 0 & 0 & 0 \\
Disf.Visceral & 0 & 0 & 1 & 0 & 0 & 0 & 0 & 0 & 1 & 0 & 0 & 0 \\
Deitar & 0 & 0 & 0 & 0 & 1 & 1 & 1 & 1 & 1 & 1 & 1 & 0 \\
Toque & 0 & 0 & 0 & 0 & 1 & 0 & 1 & 0 & 2 & 0 & 0 & 0 \\
Roupa apertada & 0 & 0 & 1 & 0 & 0 & 0 & 0 & 0 & 0 & 0 & 0 & 0 \\
Mudança temperatura & 0 & 0 & 0 & 1 & 0 & 0 & 0 & 0 & 0 & 0 & 0 & 0 \\
Dirigir & 0 & 0 & 0 & 0 & 0 & 0 & 0 & 0 & 0 & 0 & 0 & 1 \\
Depressão & 0 & 0 & 0 & 1 & 0 & 0 & 0 & 0 & 0 & 0 & 0 & 0 \\
Exercícios & 0 & 0 & 0 & 0 & 0 & 0 & 0 & 0 & 0 & 0 & 1 & 0 \\
\hline & & & & & & & & & & &
\end{tabular}

A postura, o esforço físico e a atividade sexual predominam mais sobre o sexo feminino na faixa etária entre 31 e 50 anos. O movimento predomina no sexo feminino entre a faixa etária de 31 a 70 anos. A marcha não demonstra maior incidência sobre os sexos na faixa etária de 31 a 60 anos. O frio/calor predomina nas mulheres na faixa etária entre os 31 a 40 anos (Tabela 15). 
TABELA 16 - Distribuição dos pacientes quanto aos fatores de melhora da dor, a faixa etária e o sexo dos pacientes

\begin{tabular}{lccccccccccccc}
\hline Fatores de & $\mathbf{2 0}$ & $\mathbf{2 9}$ & $\mathbf{3 0}$ & $\mathbf{3 9}$ & $\mathbf{4 0}$ & $\mathbf{a}$ & $\mathbf{4 9}$ & $\mathbf{5 0}$ & $\mathbf{a} 9$ & $\mathbf{6 0}$ & $\mathbf{6} \mathbf{6 9}$ & \multicolumn{3}{c}{$>\mathbf{6 9}$} \\
Melhora & $\mathbf{M}$ & $\mathbf{H}$ & $\mathbf{M}$ & $\mathbf{H}$ & $\mathbf{M}$ & $\mathbf{H}$ & $\mathbf{M}$ & $\mathbf{H}$ & $\mathbf{M}$ & $\mathbf{H}$ & $\mathbf{M}$ & $\mathbf{H}$ \\
\hline Medicamentos & 3 & 1 & 9 & 1 & 9 & 2 & 4 & 2 & 6 & 3 & 5 & 0 \\
Calor & 0 & 1 & 4 & 3 & 3 & 0 & 0 & 1 & 1 & 0 & 1 & 0 \\
Frio & 0 & 0 & 0 & 0 & 1 & 0 & 1 & 0 & 1 & 0 & 0 & 0 \\
Massagem & 0 & 0 & 3 & 0 & 0 & 0 & 1 & 0 & 1 & 0 & 0 & 0 \\
Repouso Fís. Psíq. & 2 & 1 & 4 & 1 & 7 & 3 & 3 & 2 & 8 & 2 & 5 & 1 \\
Deitar & 0 & 0 & 2 & 0 & 4 & 3 & 3 & 2 & 4 & 2 & 4 & 2 \\
Sono & 0 & 0 & 2 & 0 & 2 & 3 & 2 & 2 & 6 & 2 & 4 & 0 \\
Micção & 0 & 0 & 0 & 0 & 0 & 0 & 1 & 0 & 0 & 0 & 0 & 0 \\
Evacuar & 0 & 0 & 0 & 0 & 0 & 0 & 1 & 0 & 0 & 0 & 0 & 1 \\
Sentar & 0 & 0 & 0 & 0 & 0 & 1 & 0 & 2 & 1 & 2 & 0 & 1 \\
Ortostatismo & 0 & 0 & 1 & 0 & 0 & 1 & 2 & 0 & 1 & 0 & 1 & 1 \\
Massoterapia & 0 & 0 & 0 & 0 & 0 & 1 & 0 & 0 & 0 & 0 & 0 & 0 \\
Andar & 0 & 1 & 0 & 0 & 0 & 0 & 2 & 0 & 2 & 0 & 1 & 0 \\
Eletroanalgesia & 0 & 0 & 0 & 0 & 0 & 1 & 0 & 0 & 0 & 0 & 0 & 0 \\
Acupuntura & 0 & 1 & 0 & 0 & 0 & 0 & 0 & 0 & 0 & 0 & 0 & 0 \\
Contato & 0 & 0 & 0 & 0 & 0 & 0 & 1 & 0 & 0 & 0 & 0 & 0 \\
Movimento & 0 & 0 & 0 & 0 & 1 & 0 & 0 & 0 & 0 & 0 & 0 & 0 \\
Exercícios & 0 & 0 & 0 & 0 & 0 & 0 & 0 & 0 & 0 & 0 & 0 & 1 \\
Correr & 0 & 0 & 0 & 1 & 0 & 0 & 0 & 0 & 0 & 0 & 0 & 0 \\
Ereção & 0 & 0 & 0 & 1 & 0 & 0 & 0 & 0 & 0 & 0 & 0 & 0 \\
\hline
\end{tabular}

As mulheres demonstram uso de medicamentos mais do que os homens em todas as faixas etárias. O calor/frio é fator de prevalência maior nas mulheres entre os 41 e 50 anos. O fator massagem prevalece mais nas mulheres na faixa dos 31 a 40 anos. O repouso físico e psíquico prevalecem nas mulheres entre as faixas 41 e 50 e 61 a 70 anos. Há ligeiro predomínio do ato de deitar nas mulheres após os 41 anos. O sono revela-se mais predominantemente expressivo nas mulheres entre 61 e 70 anos. (Tabela 16). 
TABELA 17 - Distribuição dos pacientes quanto aos impactos da dor sobre as Atividades da Vida Diária (AVD), a faixa etária e o sexo dos pacientes

\begin{tabular}{lcccccccccccc}
\hline Impacto sobre & $\mathbf{2 0} \mathbf{a} \mathbf{2 9}$ & $\mathbf{3 0} \mathbf{a} \mathbf{3 9}$ & $\mathbf{4 0} \mathbf{a} \mathbf{4 9}$ & $\mathbf{5 0}$ & $\mathbf{5} 9$ & $\mathbf{6 0} \mathbf{6} \mathbf{6 9}$ & \multicolumn{3}{c}{$>\mathbf{6 9}$} \\
as AVD & $\mathbf{M}$ & $\mathbf{H}$ & $\mathbf{M}$ & $\mathbf{H}$ & $\mathbf{M}$ & $\mathbf{H}$ & $\mathbf{M}$ & $\mathbf{H}$ & $\mathbf{M}$ & $\mathbf{H}$ & $\mathbf{M}$ & $\mathbf{H}$ \\
\hline Humor & 3 & 0 & 11 & 2 & 10 & 3 & 6 & 1 & 8 & 2 & 5 & 1 \\
Sexo & 0 & 0 & 10 & 2 & 5 & 0 & 4 & 1 & 4 & 1 & 1 & 1 \\
Sentar & 1 & 0 & 2 & 0 & 4 & 2 & 2 & 1 & 2 & 0 & 0 & 1 \\
Sono & 4 & 0 & 9 & 2 & 10 & 0 & 5 & 3 & 6 & 3 & 4 & 1 \\
Lazer & 0 & 1 & 10 & 1 & 8 & 3 & 6 & 2 & 7 & 2 & 0 & 1 \\
Ortostatismo & 0 & 0 & 0 & 0 & 1 & 0 & 0 & 1 & 0 & 0 & 0 & 0 \\
Vestir & 0 & 0 & 0 & 0 & 1 & 1 & 0 & 1 & 0 & 0 & 0 & 0 \\
Psiquismo & 0 & 0 & 2 & 0 & 4 & 0 & 1 & 0 & 2 & 0 & 1 & 1 \\
Relacionamento & 0 & 0 & 1 & 0 & 1 & 0 & 0 & 0 & 0 & 0 & 0 & $1\left(^{*}\right)$ \\
Micção & 0 & 0 & 0 & 0 & 0 & 0 & 0 & 0 & 0 & 0 & 0 & $1\left(^{*}\right)$ \\
Evacuar & 0 & 0 & 0 & 0 & 1 & 0 & 0 & 0 & 0 & 0 & 0 & 1 \\
Deitar & 0 & 0 & 0 & 0 & 1 & 0 & 1 & 0 & 1 & 0 & 0 & 0 \\
Trabalho & 1 & 0 & 9 & 1 & 9 & 4 & 2 & 3 & 7 & 1 & 2 & 2 \\
Concentração & 0 & 0 & 5 & 0 & 5 & 1 & 1 & 1 & 2 & 1 & 0 & 0 \\
Apetite & 1 & 1 & 4 & 1 & 6 & 1 & 4 & 0 & 4 & 1 & 0 & 1 \\
Movimentos & 1 & 0 & 0 & 0 & 0 & 0 & 1 & 0 & 0 & 0 & 0 & 0 \\
Deambular & 1 & 0 & 1 & 0 & 1 & 1 & 0 & 1 & 0 & 0 & 1 & 0 \\
\hline
\end{tabular}

$\left(^{*}\right)$ Idade não identificada

Humor, atividade sexual, sentar, sono e lazer são mais incidentes nas mulheres entre os 31 e 70 anos (Tabela 17). 
TABELA 18 - Distribuição dos pacientes quanto aos pontos gatilho, a faixa etária e o sexo dos pacientes

\begin{tabular}{|c|c|c|c|c|c|c|c|c|c|c|c|c|}
\hline \multirow{2}{*}{ Pontos Gatilho } & \multicolumn{2}{|c|}{20 a 29} & \multicolumn{2}{|c|}{30 a 39} & \multicolumn{2}{|c|}{40 a 49} & \multicolumn{2}{|c|}{50 a 59} & \multicolumn{2}{|c|}{60 a 69} & \multicolumn{2}{|c|}{$>69$} \\
\hline & $\mathbf{M}$ & $\mathbf{H}$ & $\mathbf{M}$ & $\mathbf{H}$ & $\mathbf{M}$ & $\mathbf{H}$ & $\mathbf{M}$ & $\mathbf{H}$ & $\mathbf{M}$ & $\mathbf{H}$ & $\mathbf{M}$ & $\mathbf{H}$ \\
\hline Coccígeo & 0 & 0 & 3 & 1 & 0 & 1 & 0 & 0 & 0 & 0 & 0 & 0 \\
\hline $\begin{array}{l}\text { Elevador do } \\
\text { anus }\end{array}$ & 1 & 2 & 5 & 3 & 5 & 3 & 4 & 0 & 4 & 1 & 7 & 1 \\
\hline Adutores & 0 & 0 & 3 & 1 & 7 & 0 & 3 & 0 & 1 & 1 & 0 & 1 \\
\hline Abdutores & 0 & 0 & 0 & 0 & 1 & 0 & 0 & 0 & 0 & 0 & 0 & 0 \\
\hline $\begin{array}{l}\text { Obl. Inter. } \\
\text { Exter. }\end{array}$ & 1 & 0 & 0 & 0 & 0 & 0 & 0 & 1 & 0 & 0 & 0 & 0 \\
\hline Vasto Medial & 1 & 0 & 0 & 0 & 0 & 0 & 0 & 0 & 0 & 0 & 0 & 0 \\
\hline Piriforme & 2 & 0 & 2 & 1 & 3 & 0 & 2 & 0 & 0 & 1 & 1 & 0 \\
\hline Glúteos & 3 & 0 & 7 & 1 & 5 & 2 & 2 & 1 & 4 & 0 & 1 & 1 \\
\hline Reto Abdominal & 0 & 0 & 0 & 0 & 0 & 0 & 0 & 1 & 1 & 0 & 0 & 0 \\
\hline $\begin{array}{l}\text { Bulbo } \\
\text { Esponjoso }\end{array}$ & 0 & 0 & 1 & 0 & 0 & 0 & 0 & 0 & 0 & 0 & 0 & 0 \\
\hline Íleo psoas & 0 & 0 & 2 & 0 & 0 & 0 & 0 & 1 & 1 & 0 & 1 & 0 \\
\hline $\begin{array}{l}\text { Quadrado } \\
\text { Lombar }\end{array}$ & 0 & 0 & 0 & 0 & 0 & 0 & 2 & 0 & 0 & 0 & 0 & 0 \\
\hline Multifídio & 0 & 0 & 0 & 1 & 1 & 0 & 2 & 0 & 1 & 0 & 1 & 1 \\
\hline Pectíneo & 0 & 0 & 0 & 0 & 0 & 0 & 0 & 0 & 1 & 0 & 0 & 0 \\
\hline
\end{tabular}

Os PGs no músculo coccígeo prevalece mais sobre as mulheres entre os 31 a 40 anos. O elevador do ânus prevalece mais sobre as mulheres entre as idades de 31 e 70 anos. Os adutores aparecem mais em mulheres na faixa entre 31 e 60 anos. O piriforme aparece mais nas mulheres entre os 21 e 50 anos. Os glúteos também prevalecem no sexo feminino entre as faixas etárias de 21 a 70 anos (Tabela 18). 
TABELA 19 - Distribuição dos pacientes quanto ao diagnóstico, a faixa etária e o sexo dos pacientes

\begin{tabular}{|c|c|c|c|c|c|c|c|c|c|c|c|c|}
\hline \multirow{2}{*}{ Diagnóstico } & \multicolumn{2}{|c|}{20 a 29} & \multicolumn{2}{|c|}{30 a 39} & \multicolumn{2}{|c|}{40 a 49} & \multicolumn{2}{|c|}{50 a 59} & \multicolumn{2}{|c|}{60 a 69} & \multicolumn{2}{|c|}{$>69$} \\
\hline & $\mathbf{M}$ & $\mathbf{H}$ & $\mathbf{M}$ & $\mathbf{H}$ & $\mathbf{M}$ & $\mathbf{H}$ & $\mathbf{M}$ & $\mathbf{H}$ & $\mathbf{M}$ & $\mathbf{H}$ & $\mathbf{M}$ & $\mathbf{H}$ \\
\hline \multicolumn{13}{|l|}{ Miofascial Pós } \\
\hline Trauma Cirúrgico & 0 & 0 & 3 & 1 & 4 & 0 & 0 & 1 & 0 & 0 & 1 & 1 \\
\hline \multicolumn{13}{|l|}{ Miofascial Pós } \\
\hline Trauma Não Cirúrgico & 1 & 0 & 2 & 1 & 2 & 2 & 1 & 0 & 1 & 0 & 0 & 0 \\
\hline \multicolumn{13}{|l|}{ Miofascial } \\
\hline Sem Trauma & 2 & 2 & 3 & 1 & 5 & 2 & 4 & 1 & 7 & 2 & 4 & 1 \\
\hline \multicolumn{13}{|l|}{ Miofascial e Neuropática } \\
\hline Pós Trauma Cirúrgico & 1 & 0 & 3 & 0 & 1 & 0 & 2 & 1 & 1 & 0 & 1 & 0 \\
\hline \multicolumn{13}{|l|}{ Miofascial e Neuropática } \\
\hline Sem Trauma & 0 & 0 & 1 & 0 & 2 & 1 & 0 & 0 & 0 & 0 & 1 & 1 \\
\hline \multicolumn{13}{|l|}{ Neuropática Pós Trauma } \\
\hline Cirúrgico & 0 & 1 & 1 & 0 & 0 & 1 & 0 & 0 & 1 & 1 & 0 & 0 \\
\hline \multicolumn{13}{|l|}{ Neuropática Pós Trauma } \\
\hline Trauma Não Cirúrgico & 0 & 0 & 0 & 0 & 0 & 0 & 0 & 0 & 0 & 0 & 0 & 1 \\
\hline \multicolumn{13}{|l|}{ Neuropática } \\
\hline Sem Trauma & 0 & 0 & 1 & 0 & 0 & 0 & 1 & 1 & 0 & 1 & 0 & 0 \\
\hline
\end{tabular}

A dor miofascial pós trauma cirúrgico ocorre mais nas mulheres entre os 31 e 50 anos. A dor miofascial sem trauma aparece mais no sexo feminino nas faixas etárias entre os 31 a 70 anos ou mais. A dor miofascial neuropática pós trauma cirúrgico aparece mais nas mulheres da faixa etária entre os 31 a 40 anos. A dor neuropática pós trauma cirúrgico incidiu mais sobre os homens nas faixas entre os 21 e 30 anos e nas mulheres entre os 31 a 40 anos (Tabela 19). 
TABELA 20 - Distribuição dos pacientes quanto ao diagnóstico e a região de localização da dor

\begin{tabular}{lccccccc}
\hline \multirow{2}{*}{ Região } & \multicolumn{2}{c}{ Miofascial } & \multicolumn{2}{c}{ Miofascial e } & \multicolumn{2}{c}{ Neuropática } & \multirow{2}{*}{ TOTAL } \\
& $\mathbf{N}$ & $\%$ & & $\%$ & $\mathbf{N}$ & $\%$ & \\
\hline Inguinal & 17 & 56,7 & 6 & 20,0 & 7 & 23,3 & 30 \\
Vagina & 7 & 50,0 & 6 & 42,9 & 1 & 7,1 & 14 \\
Ânus & 20 & 74,1 & 4 & 14,8 & 3 & 11,1 & 27 \\
Cóccix & 8 & 100,0 & 0 & 0,0 & 0 & 0,0 & 8 \\
Períneo & 6 & 66,7 & 1 & 11,1 & 2 & 22,2 & 9 \\
Púbis & 22 & 75,9 & 3 & 10,3 & 4 & 13,8 & 29 \\
Pênis & 3 & 75,0 & 0 & 0,0 & 1 & 25,0 & 4 \\
Perna & 4 & 57,1 & 1 & 14,3 & 2 & 28,6 & 7 \\
Inguinocrural & 0 & 0,0 & 1 & 100,0 & 0 & 0,0 & 1 \\
Quadril & 1 & 50,0 & 1 & 50,0 & 0 & 0,0 & 2 \\
Uréter & 0 & 0,0 & 0 & 0,0 & 1 & 100,0 & 1 \\
Vulva & 1 & 100,0 & 0 & 0,0 & 0 & 0,0 & 1 \\
Testículos & 5 & 100,0 & 0 & 0,0 & 0 & 0,0 & 5 \\
\hline
\end{tabular}

As regiões inguinal, vaginal, anal, coccígea, perineal, pubiana e hipogástrica apresentaram-se predominantes sobre o diagnóstico de dor miofascial (Tabela 20). 
TABELA 21 - Distribuição dos pacientes quanto à característica da dor e o diagnóstico

\begin{tabular}{lccccccc}
\hline \multirow{2}{*}{$\begin{array}{l}\text { Característica } \\
\text { da Dor }\end{array}$} & \multicolumn{9}{c}{ Miofascial } & \multicolumn{2}{c}{ Miofascial e } & Neuropática & \\
& $\mathbf{N}$ & $\%$ & $\mathbf{N}$ & $\%$ & $\mathbf{N}$ & $\%$ & TOTAL \\
\hline Flutuante & 6 & 85,7 & 0 & 0,0 & 1 & 14,3 & 7 \\
Paroxística & 1 & 25,0 & 3 & 75,0 & 0 & 0,0 & 4 \\
Constante & 38 & 65,5 & 11 & 19,0 & 9 & 15,5 & 58 \\
Episódica & 10 & 83,3 & 2 & 16,7 & 0 & 0,0 & 12 \\
TOTAL & 55 & 67,9 & 16 & 19,8 & 10 & 12,3 & 81 \\
\hline
\end{tabular}

O caráter episódico, constante e flutuante da dor prevaleceu mais na SDM, ao passo que o caráter paroxístico prevaleceu na dor miofascial e neuropática (Tabela 21). 
TABELA 22 - Distribuição dos pacientes quanto à expressão verbal da dor e o diagnóstico

\begin{tabular}{|c|c|c|c|c|c|c|}
\hline \multirow{2}{*}{$\begin{array}{l}\text { Expressão } \\
\text { Verbal } \\
\text { da Dor }\end{array}$} & \multicolumn{2}{|c|}{ Miofascial } & \multicolumn{2}{|c|}{$\begin{array}{l}\text { Miofascial e } \\
\text { Neuropática }\end{array}$} & \multicolumn{2}{|c|}{ Neuropática } \\
\hline & $\mathbf{N}$ & $\%$ & $\mathbf{N}$ & $\%$ & $\mathbf{N}$ & $\%$ \\
\hline Queimor & 26 & 68,4 & 8 & 15,8 & 7 & 15,8 \\
\hline Latejamento & 17 & 74,0 & 5 & 21,7 & 1 & 4,3 \\
\hline Pontada & 21 & 67,8 & 8 & 25,8 & 2 & 6,4 \\
\hline Peso & 10 & 76,9 & 2 & 15,4 & 1 & 7,7 \\
\hline Dolorimento & 3 & 100,0 & 0 & 0,0 & 0 & 0,0 \\
\hline Rasgada & 1 & 100,0 & 0 & 0,0 & 0 & 0,0 \\
\hline Pressão & 1 & 100,0 & 0 & 0,0 & 0 & 0,0 \\
\hline Choque & 2 & 66,7 & 0 & 0,0 & 1 & 33,3 \\
\hline Formigamento & 1 & 100,0 & 0 & 0,0 & 0 & 0,0 \\
\hline Calor & 1 & 100,0 & 0 & 0,0 & 0 & 0,0 \\
\hline Dormencia & 1 & 100,0 & 0 & 0,0 & 0 & 0,0 \\
\hline Aperto & 7 & 100,0 & 0 & 0,0 & 0 & 0,0 \\
\hline Facada & 2 & 100,0 & 0 & 0,0 & 0 & 0,0 \\
\hline
\end{tabular}

As expressões verbais de queimor, latejamento, pontada e peso dentre outras prevaleceram na dor miofascial, ao passo que ardor foi predominante na dor neuropática. Na dor miofascial-neuropática as expressões de fisgada e agulhada prevaleceram (Tabela 22). 
TABELA 23 - Distribuição dos pacientes quanto aos fatores agravantes e desencadeantes e o diagnóstico

\begin{tabular}{|c|c|c|c|c|c|c|c|}
\hline \multirow{2}{*}{$\begin{array}{l}\text { Fatores } \\
\text { Agravantes e } \\
\text { Desencadeantes }\end{array}$} & \multicolumn{2}{|c|}{ Miofascial } & \multicolumn{2}{|c|}{$\begin{array}{l}\text { Miofascial e } \\
\text { Neuropática }\end{array}$} & \multicolumn{2}{|c|}{ Neuropática } & \multirow[b]{2}{*}{ TOTAL } \\
\hline & $\mathbf{N}$ & $\%$ & $\mathbf{N}$ & $\%$ & $\mathbf{N}$ & $\%$ & \\
\hline Postura & 16 & 88,8 & 1 & 5,6 & 1 & 5,6 & 18 \\
\hline Esforço Físico & 24 & 66,7 & 8 & 22,2 & 4 & 11,1 & 36 \\
\hline Movimentos & 15 & 65,2 & 6 & 26,1 & 2 & 8,7 & 23 \\
\hline Compressão & 0 & 0,0 & 1 & 100,0 & 0 & 0,0 & 1 \\
\hline Marcha & 17 & 74,0 & 3 & 13,0 & 3 & 13,0 & 23 \\
\hline Estresse & 8 & 100,0 & 0 & 0,0 & 0 & 0,0 & 8 \\
\hline Evacuar & 6 & 66,7 & 3 & 33,3 & 0 & 0,0 & 9 \\
\hline Micção & 3 & 100,0 & 0 & 0,0 & 0 & 0,0 & 3 \\
\hline Calor & 6 & 85,7 & 0 & 0,0 & 1 & 14,3 & 7 \\
\hline Frio & 14 & 87,5 & 2 & 12,5 & 0 & 0,0 & 16 \\
\hline Emoções & 9 & 75,0 & 2 & 16,7 & 1 & 8,3 & 12 \\
\hline Sentar & 14 & 77,8 & 3 & 16,7 & 1 & 5,5 & 18 \\
\hline Ortostatismo & 6 & 100,0 & 0 & 0,0 & 0 & 0,0 & 6 \\
\hline Contato & 5 & 55,6 & 2 & 22,2 & 2 & 22,2 & 9 \\
\hline Sexo & 6 & 75,0 & 1 & 12,5 & 1 & 12,5 & 8 \\
\hline Espirro Tosse & 0 & 0,0 & 0 & 0,0 & 1 & 100,0 & 1 \\
\hline Ansiedade & 0 & 0,0 & 0 & 0,0 & 1 & 100,0 & 1 \\
\hline Disfunção Visceral & 1 & 50,0 & 1 & 50,0 & 0 & 0,0 & 2 \\
\hline Deitar & 5 & 83,3 & 0 & 0,0 & 1 & 16,7 & 6 \\
\hline Toque & 4 & 100,0 & 0 & 0,0 & 0 & 0,0 & 4 \\
\hline Roupa apertada & 1 & 100,0 & 0 & 0,0 & 0 & 0,0 & 1 \\
\hline $\begin{array}{l}\text { Mudança de } \\
\text { Temperatura }\end{array}$ & 1 & 100,0 & 0 & 0,0 & 0 & 0,0 & 1 \\
\hline Dirigir & 1 & 100,0 & 0 & 0,0 & 0 & 0,0 & 1 \\
\hline Depressão & 1 & 100,0 & 0 & 0,0 & 0 & 0,0 & 1 \\
\hline Exercícios & 1 & 100,0 & 0 & 0,0 & 0 & 0,0 & 1 \\
\hline
\end{tabular}

Os fatores compressão e micção/evacuar prevaleceram na dor miofascial-neuropática. Espirro/Tosse e ansiedade prevaleceram na dor neuropática. Os demais fatores prevaleceram na dor miofascial (Tabela 23). 
TABELA 24 - Distribuição dos pacientes quanto aos fatores de melhora e o diagnóstico

\begin{tabular}{|c|c|c|c|c|c|c|c|}
\hline \multirow{2}{*}{$\begin{array}{l}\text { Fatores } \\
\text { de } \\
\text { Melhora }\end{array}$} & \multicolumn{2}{|c|}{ Miofascial } & \multicolumn{2}{|c|}{$\begin{array}{l}\text { Miofascial e } \\
\text { Neuropática }\end{array}$} & \multicolumn{2}{|c|}{ Neuropática } & \multirow[t]{2}{*}{ TOTAL } \\
\hline & $\mathbf{N}$ & $\%$ & $\mathbf{N}$ & $\%$ & $\mathbf{N}$ & $\%$ & \\
\hline Medicamentos & 31 & 68,9 & 10 & 22,2 & 4 & 8,9 & 45 \\
\hline Calor & 13 & 92,9 & 1 & 7,1 & 0 & 0,0 & 14 \\
\hline Frio & 3 & 100,0 & 0 & 0,0 & 0 & 0,0 & 3 \\
\hline Massagem & 5 & 100,0 & 0 & 0,0 & 0 & 0,0 & 5 \\
\hline $\begin{array}{l}\text { Rep.Físico e } \\
\text { Psíquico }\end{array}$ & 26 & 63,4 & 9 & 22,0 & 6 & 14,6 & 41 \\
\hline Deitar & 20 & 76,9 & 4 & 15,4 & 2 & 7,7 & 26 \\
\hline Sono & 15 & 68,2 & 5 & 22,7 & 2 & 9,1 & 22 \\
\hline Evacuar & 1 & 50,0 & 1 & 50,0 & 0 & 0,0 & 2 \\
\hline Micção & 1 & 66,7 & 0 & 33,3 & 0 & 0,0 & 3 \\
\hline Sentar & 5 & 83,3 & 1 & 16,7 & 0 & 0,0 & 6 \\
\hline Ortostatismo & 6 & 85,7 & 1 & 14,3 & 0 & 0,0 & 7 \\
\hline Massoterapia & 1 & 100,0 & 0 & 0,0 & 0 & 0,0 & 1 \\
\hline Andar & 5 & 83,3 & 0 & 0,0 & 1 & 16,7 & 6 \\
\hline Eletroanalgesia & 1 & 100,0 & 0 & 0,0 & 0 & 0,0 & 1 \\
\hline Acupuntura & 0 & 0,0 & 0 & 0,0 & 1 & 100,0 & 1 \\
\hline Contatos & 0 & 0,0 & 0 & 0,0 & 1 & 100,0 & 1 \\
\hline Movimentos & 1 & 100,0 & 0 & 0,0 & 0 & 0,0 & 1 \\
\hline Exercícios & 1 & 100,0 & 0 & 0,0 & 0 & 0,0 & 1 \\
\hline Correr & 1 & 100,0 & 0 & 0,0 & 0 & 0,0 & 1 \\
\hline Ereção & 1 & 100,0 & 0 & 0,0 & 0 & 0,0 & 1 \\
\hline
\end{tabular}

Os fatores acupuntura e contatos prevaleceram na dor neuropática ao passo que os demais fatores tiveram prevalência na dor miofascial (Tabela 24). 
TABELA 25 - Distribuição dos pacientes quanto ao Impacto sobre as Atividades da Vida Diária (AVD) e o diagnóstico

\begin{tabular}{|c|c|c|c|c|c|c|c|}
\hline \multirow{2}{*}{$\begin{array}{l}\text { Impacto } \\
\text { sobre as } \\
\text { AVD }\end{array}$} & \multicolumn{2}{|c|}{ Miofascial } & \multicolumn{2}{|c|}{$\begin{array}{l}\text { Miofascial e } \\
\text { Neuropática }\end{array}$} & \multicolumn{2}{|c|}{ Neuropática } & \multirow[t]{2}{*}{ TOTAL } \\
\hline & $\mathbf{N}$ & $\%$ & $\mathbf{N}$ & $\%$ & $\mathbf{N}$ & $\%$ & \\
\hline Humor & 35 & 67,3 & 13 & 25,0 & 4 & 7,7 & 52 \\
\hline Sexo & 22 & 75,9 & 4 & 13,8 & 3 & 10,3 & 29 \\
\hline Sentar & 9 & 60,0 & 3 & 20,0 & 3 & 20,0 & 15 \\
\hline Sono & 28 & 59,6 & 13 & 27,7 & 6 & 12,7 & 47 \\
\hline Lazer & 31 & 75,6 & 7 & 17,1 & 3 & 7,3 & 41 \\
\hline Ortostatismo & 2 & 100,0 & 0 & 0,0 & 0 & 0,0 & 2 \\
\hline Vestir & 3 & 100,0 & 0 & 0,0 & 0 & 0,0 & 3 \\
\hline Psiquismo & 8 & 72,7 & 3 & 27,3 & 0 & 0,0 & 11 \\
\hline Relacionamento & 2 & 66,7 & 1 & 33,3 & 0 & 0,0 & 3 \\
\hline Evacuar & 1 & 100,0 & 0 & 0,0 & 0 & 0,0 & 1 \\
\hline Micção & 1 & 50,0 & 1 & 50,0 & 0 & 0,0 & 2 \\
\hline Deitar & 2 & 66,7 & 0 & 0,0 & 1 & 33,3 & 3 \\
\hline Trabalho & 27 & 65,9 & 9 & 22,0 & 5 & 12,1 & 41 \\
\hline Concentração & 10 & 62,5 & 5 & 31,3 & 1 & 6,3 & 16 \\
\hline Apetite & 17 & 70,8 & 3 & 12,5 & 4 & 16,7 & 24 \\
\hline Movimento & 1 & 100,0 & 0 & 0,0 & 0 & 0,0 & 1 \\
\hline Deambulismo & 6 & 75,0 & 1 & 12,5 & 1 & 12,5 & 8 \\
\hline
\end{tabular}

Todos os itens que exprimem o impacto sobre as AVDs tiveram prevalência na dor miofascial (Tabela 25). 
TABELA 26 - Distribuição dos pacientes quanto aos pontos gatilho e o diagnóstico

\begin{tabular}{|c|c|c|c|c|c|c|c|}
\hline \multirow[t]{2}{*}{ Pontos Gatilho } & \multicolumn{2}{|c|}{ Miofascial } & \multicolumn{2}{|c|}{$\begin{array}{l}\text { Miofascial e } \\
\text { Neuropática }\end{array}$} & \multicolumn{2}{|c|}{ Neuropática } & \multirow[t]{2}{*}{ TOTAL } \\
\hline & $\mathbf{N}$ & $\%$ & $\mathbf{N}$ & $\%$ & $\mathbf{N}$ & $\%$ & \\
\hline Coccígeo & 4 & 80,0 & 1 & 20,0 & 0 & 0,0 & 5 \\
\hline Elevador do Ânus & 33 & 91,7 & 3 & 8,3 & 0 & 0,0 & 36 \\
\hline Adutores & 13 & 76,5 & 4 & 23,5 & 0 & 0,0 & 17 \\
\hline Abdutores & 1 & 100,0 & 0 & 0,0 & 0 & 0,0 & 1 \\
\hline $\begin{array}{l}\text { Oblíquo Interno e } \\
\text { Externo }\end{array}$ & 1 & 50,0 & 1 & 50,0 & 0 & 0,0 & 2 \\
\hline Vasto Medial & 0 & 0,0 & 1 & 100,0 & 0 & 0,0 & 1 \\
\hline Piriforme & 10 & 83,3 & 2 & 16,7 & 0 & 0,0 & 12 \\
\hline Glúteos & 20 & 74,1 & 7 & 25,9 & 0 & 0,0 & 27 \\
\hline Reto Abdominal & 2 & 100,0 & 0 & 0,0 & 0 & 0,0 & 2 \\
\hline Bulbo Esponjoso & 0 & 0,0 & 1 & 100,0 & 0 & 0,0 & 1 \\
\hline Ileo Psoas & 3 & 100,0 & 0 & 0,0 & 0 & 0,0 & 3 \\
\hline Quadrado Lombar & 2 & 50,0 & 2 & 50,0 & 0 & 0,0 & 4 \\
\hline Multifídio & 5 & 50,0 & 2 & 50,0 & 0 & 0,0 & 7 \\
\hline Pectíneo & 1 & 100,0 & 0 & 0,0 & 0 & 0,0 & 1 \\
\hline
\end{tabular}

Os Pontos Gatilho vasto medial, bulbo esponjoso e sacrococcígeo prevaleceram na dor miofascial e neuropática. Os Pontos Gatilho coccígeo, elevador do ânus, adutores, abdutores, piriforme, glúteos, reto abdominal, íliopsoas, pectíneo e lombar prevaleceram na SDM. Os Pontos Gatilho oblíquos interno / externo, quadrado lombar, multifídios e PV lombar não tiveram predomínio entre essas duas condições de dor citadas. Não houve presença de Pontos Gatilho na dor neuropática (Tabela 26). 
TABELA 27A - Distribuição dos pacientes quanto ao diagnóstico e a região de localização da dor

\begin{tabular}{|c|c|c|c|c|c|c|c|}
\hline Diagnóstico & Inguinal & Vagina & Ânus & Cóccix & Períneo & Púbis & Pênis \\
\hline \multicolumn{8}{|l|}{ Miofascial e Neuropática } \\
\hline Pós Trauma Cirúrgico & 5 & 5 & 2 & 0 & 1 & 1 & 0 \\
\hline \multicolumn{8}{|l|}{ Miofascial e Neuropática } \\
\hline Sem Trauma & 1 & 2 & 3 & 0 & 0 & 2 & 1 \\
\hline \multicolumn{8}{|l|}{ Miofascial Pós } \\
\hline Trauma Cirúrgico & 5 & 1 & 1 & 2 & 2 & 3 & 0 \\
\hline \multicolumn{8}{|l|}{ Miofascial Pós Trauma } \\
\hline Não Cirúrgico & 4 & 1 & 2 & 4 & 0 & 3 & 0 \\
\hline \multicolumn{8}{|l|}{ Miofascial Sem } \\
\hline Trauma & 8 & 4 & 16 & 2 & 4 & 16 & 2 \\
\hline \multicolumn{8}{|l|}{ Neuropática Pós } \\
\hline Trauma Cirúrgico & 3 & 0 & 1 & 0 & 0 & 0 & 1 \\
\hline \multicolumn{8}{|l|}{ Neuropática Sem } \\
\hline Trauma & 1 & 1 & 2 & 0 & 2 & 0 & 0 \\
\hline \multicolumn{8}{|l|}{ Neuropática Pós Trauma } \\
\hline Não Cirúrgico & 1 & 0 & 0 & 0 & 0 & 0 & 0 \\
\hline
\end{tabular}

TABELA 27B - Distribuição dos pacientes quanto ao diagnóstico e a região de localização da dor (continução)

\begin{tabular}{lcccccc}
\hline Diagnóstico & Coxa & $\begin{array}{c}\text { Inguino- } \\
\text { crural }\end{array}$ & Quadril & Uréter & Vulva & $\begin{array}{c}\text { Testí- } \\
\text { culos }\end{array}$ \\
\hline $\begin{array}{l}\text { Miofascial e Neuropática } \\
\quad \text { Pós Trauma Cirúrgico }\end{array}$ & 0 & 0 & 1 & 0 & 0 & 0 \\
$\begin{array}{l}\text { Miofascial e Neuropática } \\
\quad \text { Sem Trauma }\end{array}$ & 1 & 1 & 0 & 0 & 0 & 1 \\
$\begin{array}{l}\text { Miofascial Pós Trauma } \\
\quad \text { Cirúrgico }\end{array}$ & 0 & 0 & 0 & 0 & 0 & 0 \\
$\begin{array}{l}\text { Miofascial Pós Trauma } \\
\quad \text { Não Cirúrgico }\end{array}$ & 2 & 0 & 0 & 0 & 1 & 1 \\
$\begin{array}{l}\text { Miofascial Sem } \\
\quad \text { Trauma }\end{array}$ & 2 & 0 & 1 & 0 & 0 & 3 \\
$\begin{array}{l}\text { Neuropática Pós Trauma } \\
\quad \text { Cirúrgico }\end{array}$ & 0 & 0 & 1 & 1 & 0 & 0 \\
$\begin{array}{l}\text { Neuropática Sem } \\
\quad \text { Trauma }\end{array}$ & 2 & 0 & 0 & 0 & 0 & 0 \\
$\begin{array}{l}\text { Neuropática Pós } \\
\quad \text { Trauma Não Cirúrgico }\end{array}$ & 0 & 0 & 0 & 0 & 0 & 0 \\
\hline
\end{tabular}

As regiões anal e pubiana foram as mais significativamente acometidas na SDM sem trauma. (Tabelas 27A e 27B e Gráfico 15). 
GRÁFICO 15 - Distribuição dos pacientes quanto ao diagnóstico e a região de localização da dor

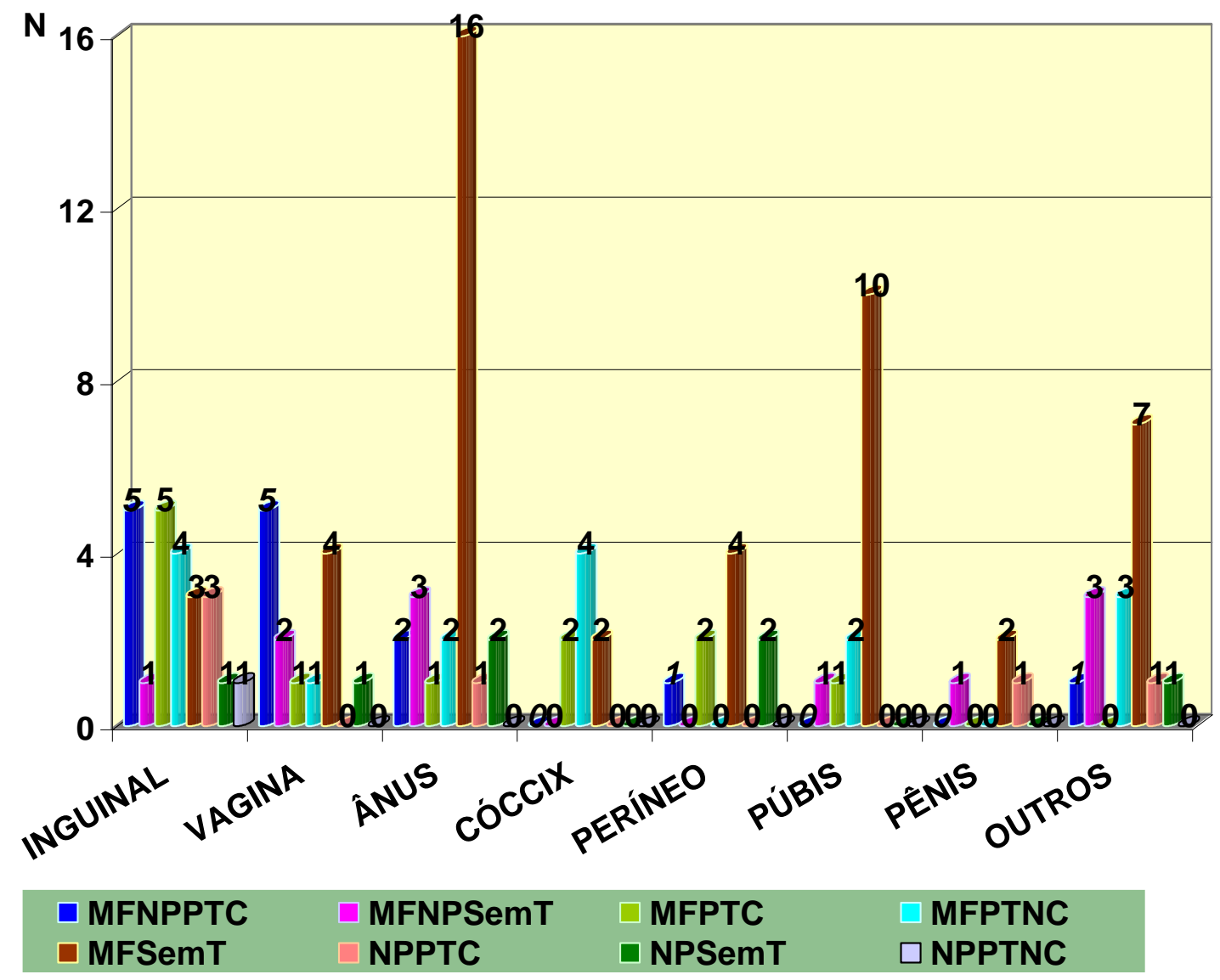


TABELA 28A - Distribuição dos pacientes quanto à região de localização da dor e os pontos gatilho

\begin{tabular}{lccccc}
\hline Região & Coccígeo & $\begin{array}{c}\text { Elevador } \\
\text { Ânus }\end{array}$ & Adutores & $\begin{array}{c}\text { Abdutores } \\
\text { Obl. Int. } \\
\text { Ext. }\end{array}$ \\
\hline Inguinal & 0 & 6 & 7 & 0 & 2 \\
Vagina & 1 & 8 & 4 & 0 & 1 \\
Ânus & 2 & 20 & 5 & 0 & 0 \\
Cóccix & 3 & 6 & 0 & 0 & 0 \\
Períneo & 1 & 6 & 1 & 0 & 0 \\
Púbis & 0 & 8 & 10 & 1 & 0 \\
Pênis & 1 & 2 & 0 & 0 & 0 \\
Coxa & 0 & 1 & 1 & 0 & 0 \\
Ing. Crural & 0 & 0 & 1 & 0 & 0 \\
Quadril & 0 & 0 & 0 & 0 & 0 \\
Uréter & 0 & 0 & 0 & 0 & 0 \\
Vulva & 0 & 1 & 0 & 0 & 0 \\
Testículos & 1 & 4 & 1 & 0 & 0 \\
\hline
\end{tabular}

TABELA 28B - Distribuição dos pacientes quanto à região de localização da dor e os pontos gatilho (continuação)

\begin{tabular}{lccccc}
\hline Região & $\begin{array}{c}\text { Vasto } \\
\text { Medial }\end{array}$ & Pirirforme & Glúteos & $\begin{array}{c}\text { Reto } \\
\text { Abdominal }\end{array}$ & $\begin{array}{c}\text { Bulbo } \\
\text { Esponjoso }\end{array}$ \\
\hline Inguinal & 1 & 5 & 10 & 1 & 0 \\
Vagina & 1 & 0 & 6 & 0 & 1 \\
Ânus & 0 & 1 & 9 & 0 & 0 \\
Cóccix & 0 & 2 & 3 & 0 & 0 \\
Períneo & 0 & 2 & 3 & 0 & 0 \\
Púbis & 0 & 4 & 13 & 1 & 0 \\
Pênis & 0 & 0 & 2 & 0 & 0 \\
Coxa & 0 & 2 & 2 & 0 & 0 \\
Ing. Crural & 0 & 0 & 0 & 0 & 0 \\
Quadril & 0 & 0 & 1 & 1 & 0 \\
Uréter & 0 & 0 & 0 & 0 & 0 \\
Vulva & 1 & 0 & 0 & 0 & 0 \\
Testículos & 1 & 0 & 2 & 0 & 0 \\
\hline
\end{tabular}


TABELA 28C - Distribuição dos pacientes quanto à região de localização da dor e os Pontos Gatilho (continuação)

\begin{tabular}{lcccc}
\hline Região & ĺleo psoas & Quadrado Lombar & Multifídio & Pectíneo \\
\hline Inguinal & 1 & 0 & 3 & 1 \\
Vagina & 0 & 0 & 0 & 0 \\
Ânus & 1 & 0 & 1 & 0 \\
Cóccix & 0 & 1 & 1 & 0 \\
Períneo & 0 & 1 & 2 & 0 \\
Púbis & 2 & 1 & 4 & 0 \\
Pênis & 0 & 0 & 1 & 0 \\
Coxas & 0 & 1 & 0 & 0 \\
Ing. Crural & 0 & 0 & 0 & 0 \\
Quadril & 0 & 0 & 0 & 0 \\
Uréter & 0 & 0 & 0 & 0 \\
Vulva & 0 & 0 & 0 & 0 \\
Testículos & 0 & 0 & 1 & 0 \\
\hline
\end{tabular}

Na região anal, os PGs ocorreram mais freqüentemente no músculo elevador do ânus. Na região inguinal, os PGs ocorreram mais em musculatura glútea. Na região pubiana, os músculos glúteos foram os responsáveis pelo maior número de PGs. Os $\mathrm{mm}$. glúteos também apareceram em grande número na região pubiana (Tabelas 28A, 28B e 28C). 
TABELA 29A - Distribuição dos pacientes homens, quanto ao diagnóstico, sexo e cirurgias a que foram submetidos (HOMENS)

\begin{tabular}{|c|c|c|}
\hline Diagnóstico & Cirurgias & Núm. \\
\hline \multicolumn{3}{|l|}{ Miofascial e Neuropática } \\
\hline Pós Trauma Cirúrgico & Hérnia Inguinal & 1 \\
\hline \multicolumn{3}{|l|}{ Miofascial e Neuropática } \\
\hline Sem Trauma & Nenhuma & 0 \\
\hline \multicolumn{3}{|l|}{ Miofascial Pós } \\
\hline \multirow[t]{2}{*}{ Trauma Cirúrgico } & Hérnia Inguinal & 2 \\
\hline & Exérese Cóccix & 1 \\
\hline \multicolumn{3}{|l|}{ Miofascial Pós Trauma } \\
\hline Não Cirúrgico & Apendicectomia & 1 \\
\hline \multicolumn{3}{|l|}{ Miofascial Sem } \\
\hline \multirow[t]{2}{*}{ Trauma } & Hérnia Inguinal & 1 \\
\hline & Fissura Anal & 1 \\
\hline \multicolumn{3}{|l|}{ Neuropática Sem } \\
\hline Trauma & Abscesso Perianal & 1 \\
\hline \multicolumn{3}{|l|}{ Neuropática Pós } \\
\hline \multirow[t]{2}{*}{ Trauma Cirúrgico } & Hérnia Inguinal & 2 \\
\hline & Cálculo Ureteral & 1 \\
\hline \multicolumn{3}{|l|}{ Neuropática Pós } \\
\hline Trauma Não Cirúrgico & Hérnia Inguinal & 1 \\
\hline
\end{tabular}

A herniorrafia inguinal foi o procedimento cirúrgico mais freqüente em todos os grupos de dor (Tabela 29A). 


\section{TABELA 29B - Distribuição dos pacientes mulheres, quanto ao diagnóstico, sexo e cirurgias a que foram submetidos (MULHERES)}

\begin{tabular}{|c|c|c|}
\hline Diagnóstico & Cirurgias & Núm. \\
\hline \multicolumn{3}{|l|}{ Miofascial e Neuropática } \\
\hline \multirow[t]{6}{*}{ Pós Trauma Cirúrgico } & Ooforectomia & 1 \\
\hline & Histerectomia & 3 \\
\hline & Apendicectomia & 1 \\
\hline & Hérnia Inguinal & 1 \\
\hline & Hérnia Umbilical & 1 \\
\hline & Varizes & 1 \\
\hline \multicolumn{3}{|l|}{ Miofascial e Neuropática } \\
\hline Sem Trauma & Apendicectomia & 1 \\
\hline \multicolumn{3}{|l|}{ Miofascial Pós } \\
\hline \multirow[t]{7}{*}{ Trauma Cirúrgico } & Bartolinectomia & 1 \\
\hline & Histerectomia & 5 \\
\hline & Ooforectomia & 1 \\
\hline & Laqueadura & 2 \\
\hline & Exérese Cisto Supra-renal & 1 \\
\hline & Hérnia Inguinal & 1 \\
\hline & Dermoplastia & 1 \\
\hline \multicolumn{3}{|l|}{ Miofascial Pós Trauma } \\
\hline \multirow[t]{4}{*}{ Não Cirúrgico } & Parto Normal & 1 \\
\hline & Histerectomia & 2 \\
\hline & Perineoplastia & 1 \\
\hline & Exérese Cóccix & 1 \\
\hline \multicolumn{3}{|l|}{ Miofascial Sem } \\
\hline \multirow[t]{8}{*}{ Trauma } & Laparotomia & 2 \\
\hline & Gastroplastia & 1 \\
\hline & Drenagem abscesso & 1 \\
\hline & Histerectomia & 2 \\
\hline & Apendicectomia & 1 \\
\hline & Exérese Cóccix & 1 \\
\hline & Cesariana & 1 \\
\hline & Exérese Nódulo Tiróides & 1 \\
\hline \multicolumn{3}{|l|}{ Neuropática Pós } \\
\hline Trauma Cirúrgico & $\begin{array}{l}\text { Hemorróidas } \\
\text { Hérnia Inguinal }\end{array}$ & 1 \\
\hline \multicolumn{3}{|l|}{ Neuropática Sem } \\
\hline Trauma Cirúrgico & Nenhuma & 0 \\
\hline \multicolumn{3}{|l|}{ Neuropática Pós Trauma } \\
\hline Não Cirúrgico & Nenhuma & 0 \\
\hline
\end{tabular}

Nas mulheres a histerectomia foi o procedimento cirúrgico que mais apareceu nesta casuística, só não aparecendo na dor neuropática (Tabela 29B). 
TABELA 30 - Distribuição dos pacientes quanto à Escala Visual Analógica (EVA) e o sexo dos pacientes

\begin{tabular}{lccccc}
\hline \multirow{2}{*}{ Sexo } & \multicolumn{5}{c}{ Escala Visual Analógica } \\
& N / \% & Mínima & Máxima & Soma Total & Média \\
\hline Mulheres & $57(70,3 \%)$ & 0 & 10 & 465 & 8,2 \\
Homens & $24(29,7 \%)$ & 0 & 10 & 151 & 6,3 \\
TOTAL & $81(100,0 \%)$ & 0 & & 616 & 7,6 \\
\hline
\end{tabular}

A média dos valores da EVA nas mulheres foi de 8,2 e 6,3 nos homens (Tabela 30 e Gráfico 16).

GRÁFICO 16 - Distribuição dos pacientes quanto à Escala Visual Analógica (EVA) e o sexo dos pacientes

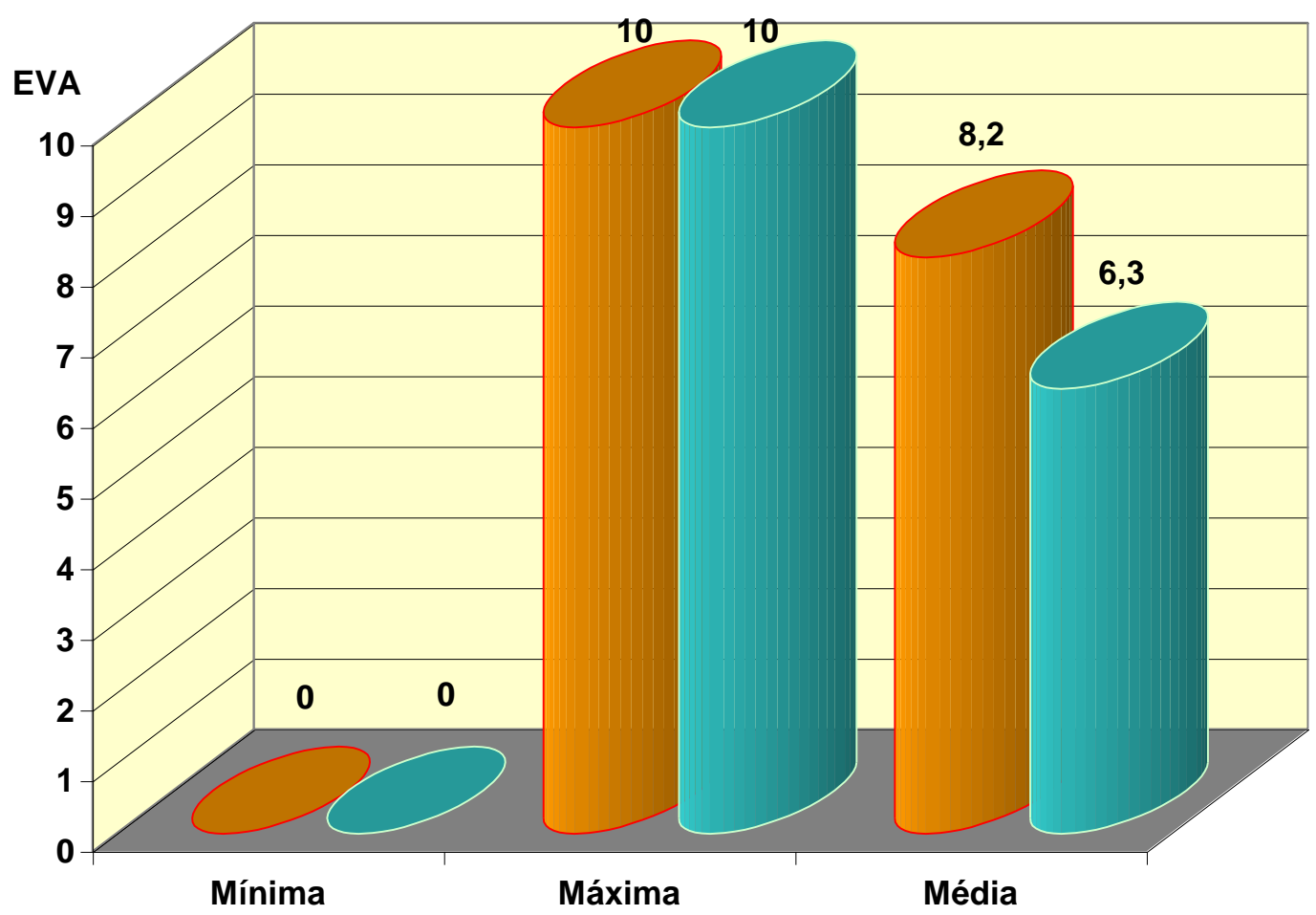


TABELA 31 - Distribuição dos pacientes quanto à Escala Visual Analógica (EVA) e o diagnóstico

\begin{tabular}{lccccc}
\hline Diagnóstico & N & Mínima & Máxima & Soma Total & Média \\
\hline Miofascial & 16 & 0 & 10 & 121 & 7,6 \\
Miofascial e & 55 & 0 & 10 & 426 & 7,7 \\
Neuropática & 10 & 0 & 10 & 69 & 6,9 \\
\hline Neuropática & 10
\end{tabular}

A média dos valores da EVA na dor miofascial e na dor miofascial e neuropática foi semelhante (Tabela 31 e Gráfico 17).

GRÁFICO 17 - Distribuição dos pacientes quanto à Escala Visual Analógica (EVA) e o diagnóstico

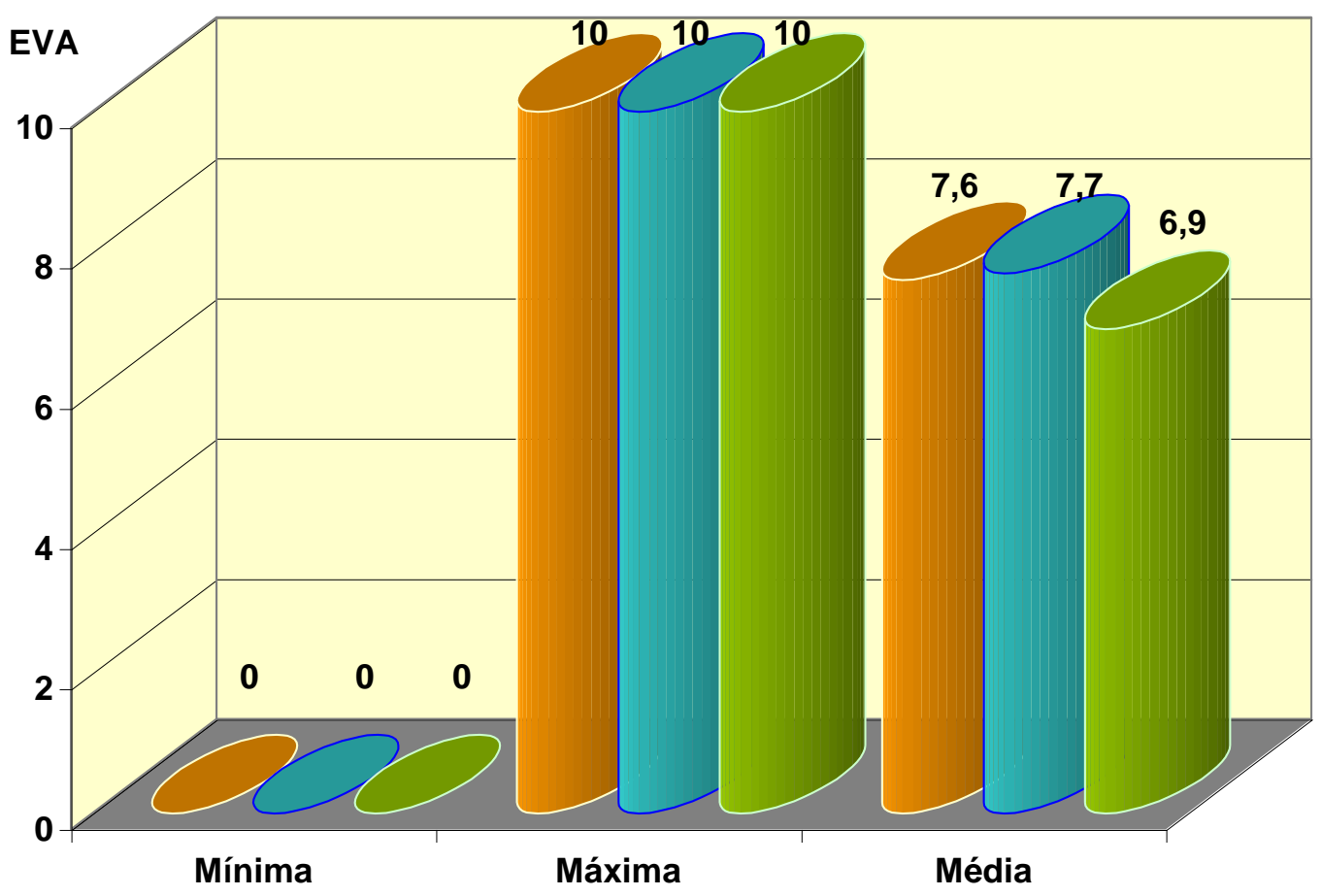

Miofascial ( $\mathrm{N}=16) \quad \square$ Miofascial e Neuropática ( $\mathrm{N}=55) \quad \square$ Neuropática ( $\mathrm{N}=10)$ 
TABELA 32 - Distribuição dos pacientes quanto à Escala Visual Analógica (EVA) e as faixas etárias dos pacientes

\begin{tabular}{lccccc}
\hline $\begin{array}{l}\text { Faixa etária } \\
\text { (anos) }\end{array}$ & N & Mínima & Máxima & Soma Total & Média \\
\hline 20 a 29 & 7 & 5 & 10 & 58 & 8,3 \\
30 a 39 & 17 & 0 & 10 & 128 & 7,5 \\
40 a 49 & 20 & 0 & 10 & 143 & 7,2 \\
50 a 59 & 12 & 5 & 10 & 104 & 8,7 \\
60 a 69 & 14 & 3 & 10 & 108 & 7,7 \\
$>69$ & 10 & 0 & 10 & 67 & 6,7 \\
\hline
\end{tabular}

A média dos valores da EVA foi mais significativamente alta na faixa etária compreendida entre 20 a 29 anos e 50 a 59 anos (Tabela 32 e Gráfico 18).

GRÁFICO 18 - Distribuição dos pacientes quanto à Escala Visual Analógica (EVA) e as faixas etárias dos pacientes

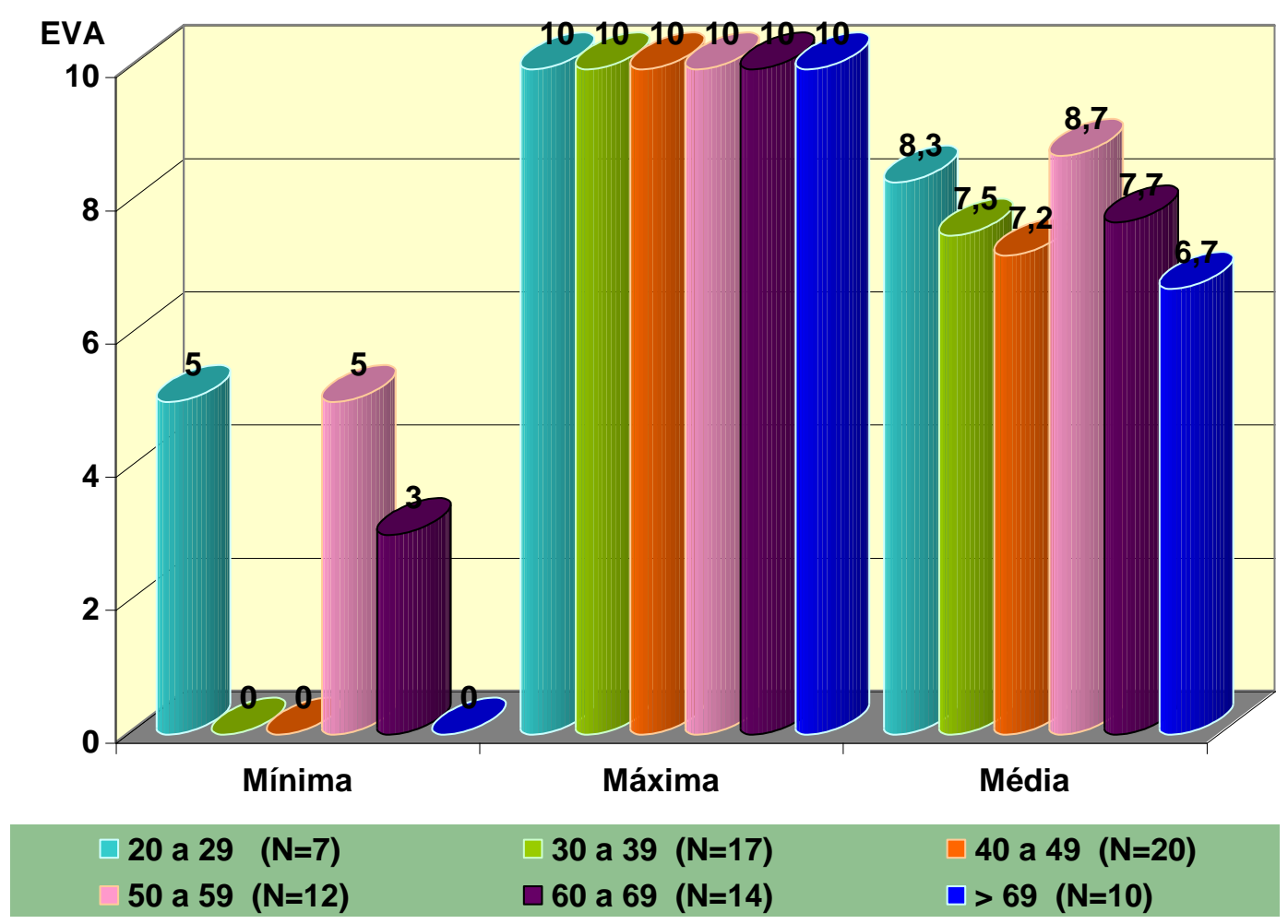


TABELA 33 - Distribuição dos pacientes quanto à Escala Visual Analógica (EVA), as faixas etárias dos pacientes e o sexo

\begin{tabular}{lcccccc}
\hline $\begin{array}{l}\text { Faixa etária } \\
\text { (anos) }\end{array}$ & Sexo & $\mathbf{N}$ & Mínima & Máxima & Soma Total & Média \\
\hline 20 a 29 & $\mathrm{F}$ & 4 & 5 & 10 & 35 & 8,8 \\
& $\mathrm{M}$ & 3 & 5 & 10 & 23 & 7,7 \\
30 a 39 & $\mathrm{~F}$ & 14 & 1 & 10 & 117 & 8,4 \\
& $\mathrm{M}$ & 3 & 0 & 8 & 11 & 3,7 \\
40 a 49 & $\mathrm{~F}$ & 14 & 5 & 10 & 110 & 7,9 \\
& $\mathrm{M}$ & 6 & 3 & 10 & 33 & 5,5 \\
50 a 59 & $\mathrm{~F}$ & 8 & 6 & 10 & 71 & 8,9 \\
& $\mathrm{M}$ & 4 & 5 & 10 & 33 & 8,3 \\
60 a 69 & $\mathrm{~F}$ & 10 & 5 & 10 & 81 & 8,1 \\
& $\mathrm{M}$ & 4 & 3 & 9 & 27 & 6,8 \\
$>69$ & $\mathrm{~F}$ & 7 & 0 & 10 & 51 & 7,3 \\
& $\mathrm{M}$ & 3 & 5 & 6 & 16 & 5,3 \\
TOTAL & & $\mathbf{8 0}$ & & & 608 & $\mathbf{7 , 6}$ \\
\hline
\end{tabular}

A média dos valores da EVA foi sempre maior no sexo feminino em todas as faixas etárias (Tabela 33 e Gráfico 19).

GRÁFICO 19 - Distribuição dos pacientes quanto à Escala Visual Analógica (EVA), as faixas etárias dos pacientes e o sexo

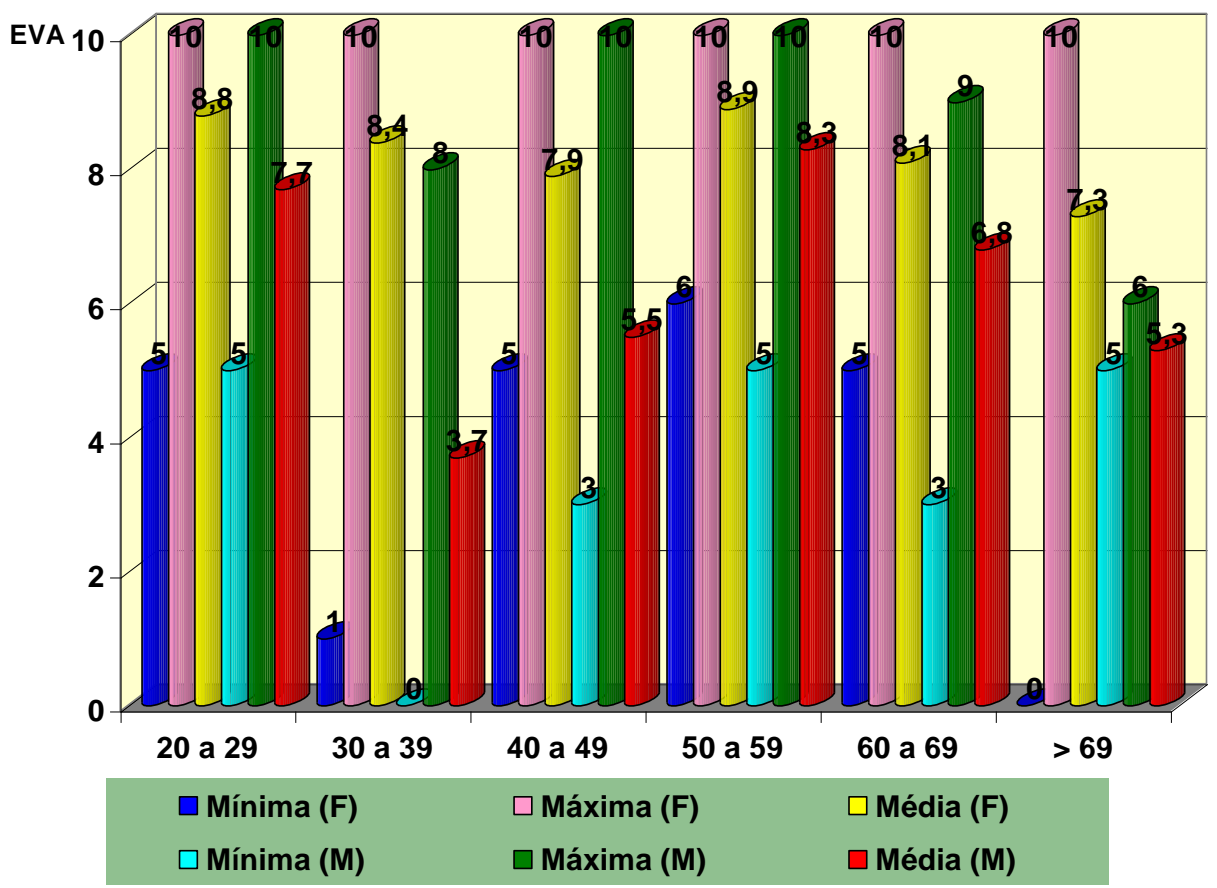


TABELA 34 - Distribuição dos pacientes quanto ao tempo de dor e o sexo

\begin{tabular}{lccccc}
\hline & \multicolumn{5}{c}{ Tempo de dor (meses) } \\
Sexo & N & Mínimo & Máximo & Total & Média \\
\hline Mulheres & 57 & 0 & 360 & 3676 & 64,5 \\
Homens & 24 & 6 & 336 & 1376 & 57,3 \\
TOTAL & 81 & & & 5052 & 62,4 \\
\hline
\end{tabular}

A média do tempo de dor no sexo feminino foi ligeiramente superior ao tempo de dor do sexo masculino (Tabela 34 e Gráfico 20).

GRÁFICO 20 - Distribuição dos pacientes quanto ao tempo de dor e o sexo

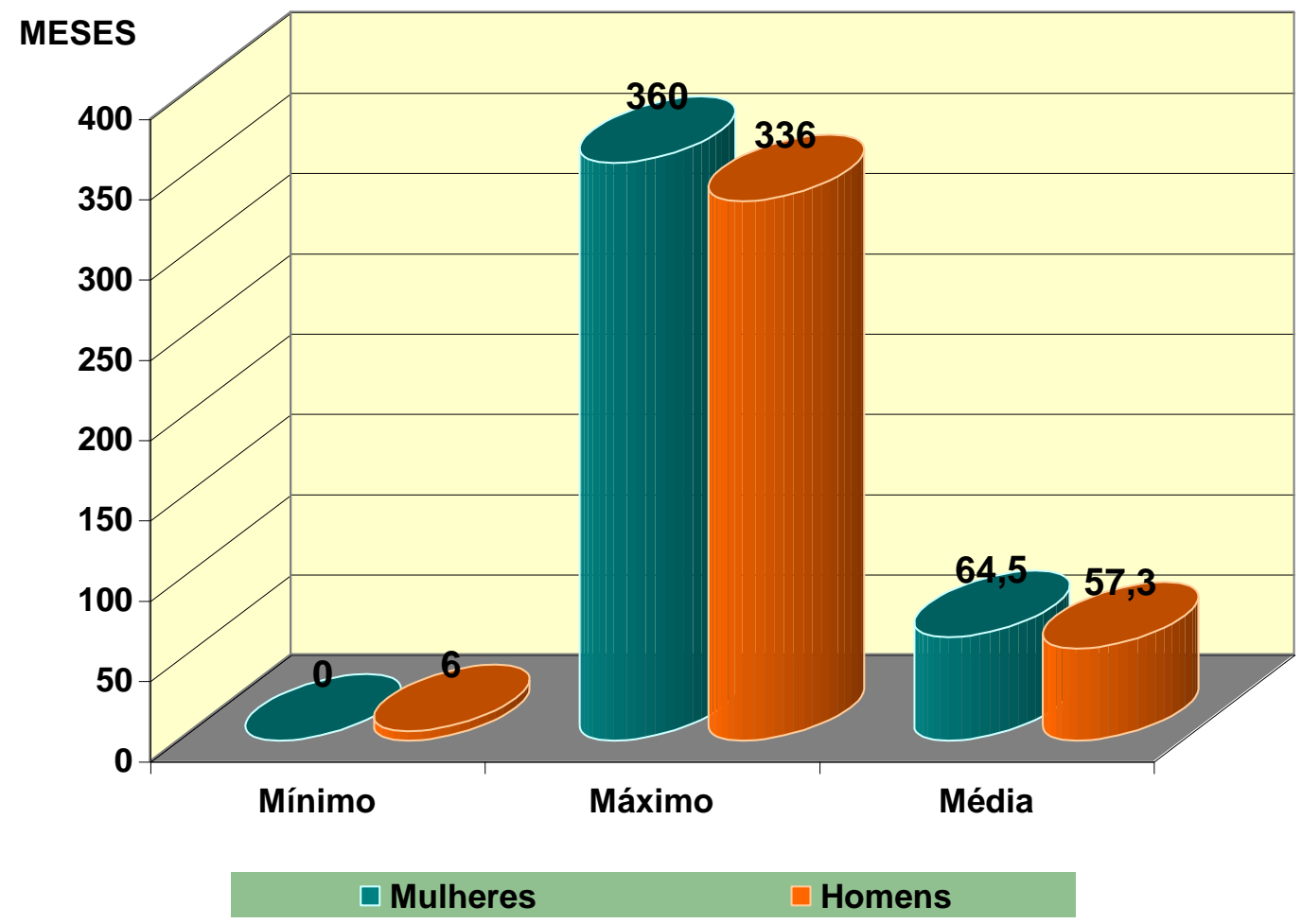


TABELA 35 - Distribuição dos pacientes quanto ao tempo de dor e o diagnóstico

\begin{tabular}{lccccc}
\hline \multirow{2}{*}{ Diagnóstico } & \multicolumn{5}{c}{ Tempo de dor (meses) } \\
& N & Mínimo & Máximo & Total & Média \\
\hline Miofascial e & 16 & 0 & 348 & 1038 & 64,9 \\
Neuropática & 55 & 1 & 360 & 3504 & 63,7 \\
Miofascial & 10 & 6 & 336 & 510 & 51,0 \\
Neuropática & 81 & & & 5052 & 62,4 \\
TOTAL & & & & & \\
\hline
\end{tabular}

A média dos tempos de início da dor foi muito semelhante entre os doentes com daignóstico de dor miofascial e dor miofascial e neuropática. Os doentes com diagnóstico de dor neuropática tiveram um tempo menor, em média, de aparecimento do quadro doloroso (Tabela 35 e Gráfico 21).

GRÁFICO 21 - Distribuição dos pacientes quanto ao tempo de dor e o diagnóstico

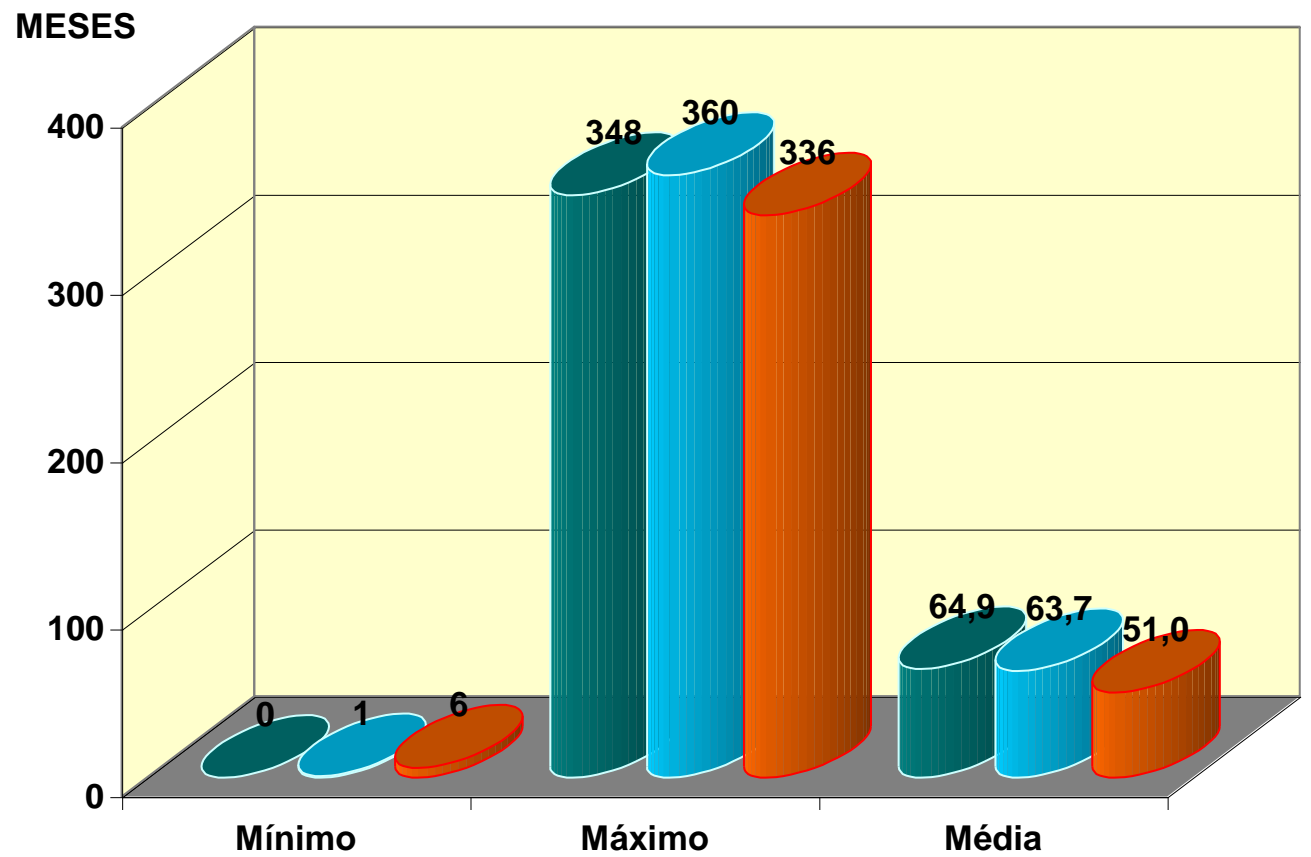

$\square$ Miofascial e Neuropática $\quad \square$ Miofascial $\quad \square$ Neuropática 
TABELA 36 - Distribuição dos pacientes quanto ao tempo de dor e as faixas etárias

\begin{tabular}{lccccc}
\hline Faixa etária & \multicolumn{5}{c}{ Tempo de dor (meses) } \\
(anos) & N & Mínimo & Máximo & Total & Média \\
\hline 20 a 29 & 7 & 6 & 72 & 259 & 37,0 \\
30 a 39 & 17 & 6 & 240 & 958 & 56,4 \\
40 a 49 & 20 & 11 & 156 & 937 & 46,9 \\
50 a 59 & 12 & 11 & 360 & 1244 & 103,7 \\
60 a 69 & 14 & 1 & 240 & 957 & 68,4 \\
> 69 & 10 & 0 & 336 & 673 & 67,3 \\
TOTAL & 80 & & & 5028 & 62,9 \\
\hline
\end{tabular}

A média do tempo de aparecimento da dor na faixa etária entre 50 a 59 anos foi absolutamente maior do que nas demais apresentadas (Tabela $36 \mathrm{e}$ Gráfico 22).

GRÁFICO 22 - Distribuição dos pacientes quanto ao tempo de dor e as faixas etárias

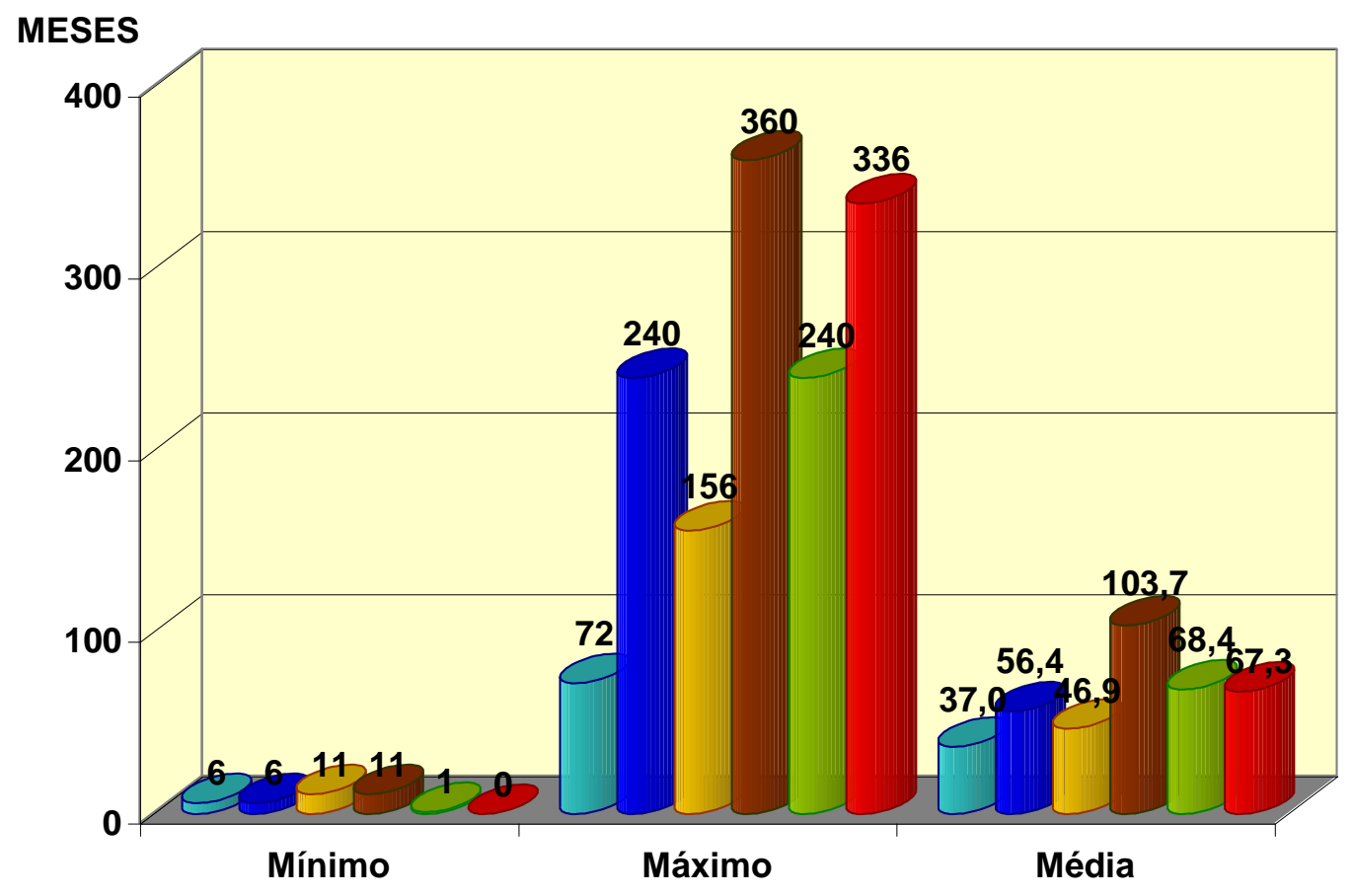

$\square 20$ a $29 \square 30$ a $39 \square 40$ a $49 \quad \square 50$ a $59 \quad \square 60$ a $69 \quad \square>69$ 
TABELA 37 - Distribuição dos pacientes quanto ao tempo de dor, as faixas etárias e o sexo

\begin{tabular}{|c|c|c|c|c|c|c|}
\hline \multirow{2}{*}{$\begin{array}{l}\text { Faixa etária } \\
\text { (anos) }\end{array}$} & \multirow{2}{*}{ Sexo } & \multirow[b]{2}{*}{$\mathbf{N}$} & \multicolumn{4}{|c|}{ Tempo de dor (meses) } \\
\hline & & & Mínimo & Máximo & Total & Média \\
\hline \multirow[t]{2}{*}{20 a 29} & $\mathrm{~F}$ & 4 & 36 & 72 & 217 & 54,3 \\
\hline & $M$ & 3 & 6 & 24 & 42 & 14,0 \\
\hline \multirow[t]{2}{*}{30 a 39} & $\mathrm{~F}$ & 14 & 6 & 240 & 726 & 51,9 \\
\hline & M & 3 & 52 & 120 & 232 & 77,3 \\
\hline \multirow[t]{2}{*}{40 a 49} & $\mathrm{~F}$ & 14 & 11 & 156 & 665 & 47,5 \\
\hline & $M$ & 6 & 20 & 20 & 272 & 45,3 \\
\hline \multirow[t]{2}{*}{50 a 59} & $\mathrm{~F}$ & 8 & 11 & 360 & 936 & 117,0 \\
\hline & M & 4 & 12 & 240 & 308 & 77,0 \\
\hline \multirow[t]{2}{*}{60 a 69} & $\mathrm{~F}$ & 10 & 1 & 240 & 836 & 83,6 \\
\hline & M & 4 & 6 & 84 & 121 & 30,3 \\
\hline \multirow[t]{2}{*}{$>69$} & $\mathrm{~F}$ & 7 & 0 & 120 & 296 & 42,3 \\
\hline & $M$ & 3 & 6 & 336 & 377 & 125,7 \\
\hline TOTAL & & 80 & & & 5028 & 62,9 \\
\hline
\end{tabular}

A faixa etária compreendida entre 50 a 59 anos foi a que apresentou maior tempo médio de aparecimento da dor no sexo feminino e nesta faixa foram observados 08 casos. Observou-se que na faixa etária $>69$ anos a média do tempo de dor foi maior no sexo masculino, com 3 casos. O menor tempo no sexo feminino foi observado na faixa etária > 69 anos com 7 casos e no sexo masculino na de 20 a 29 anos com 3 casos (Tabela 37 e Gráfico 23). 
GRÁFICO 23 - Distribuição dos pacientes quanto ao tempo de dor, as faixas etárias e o sexo

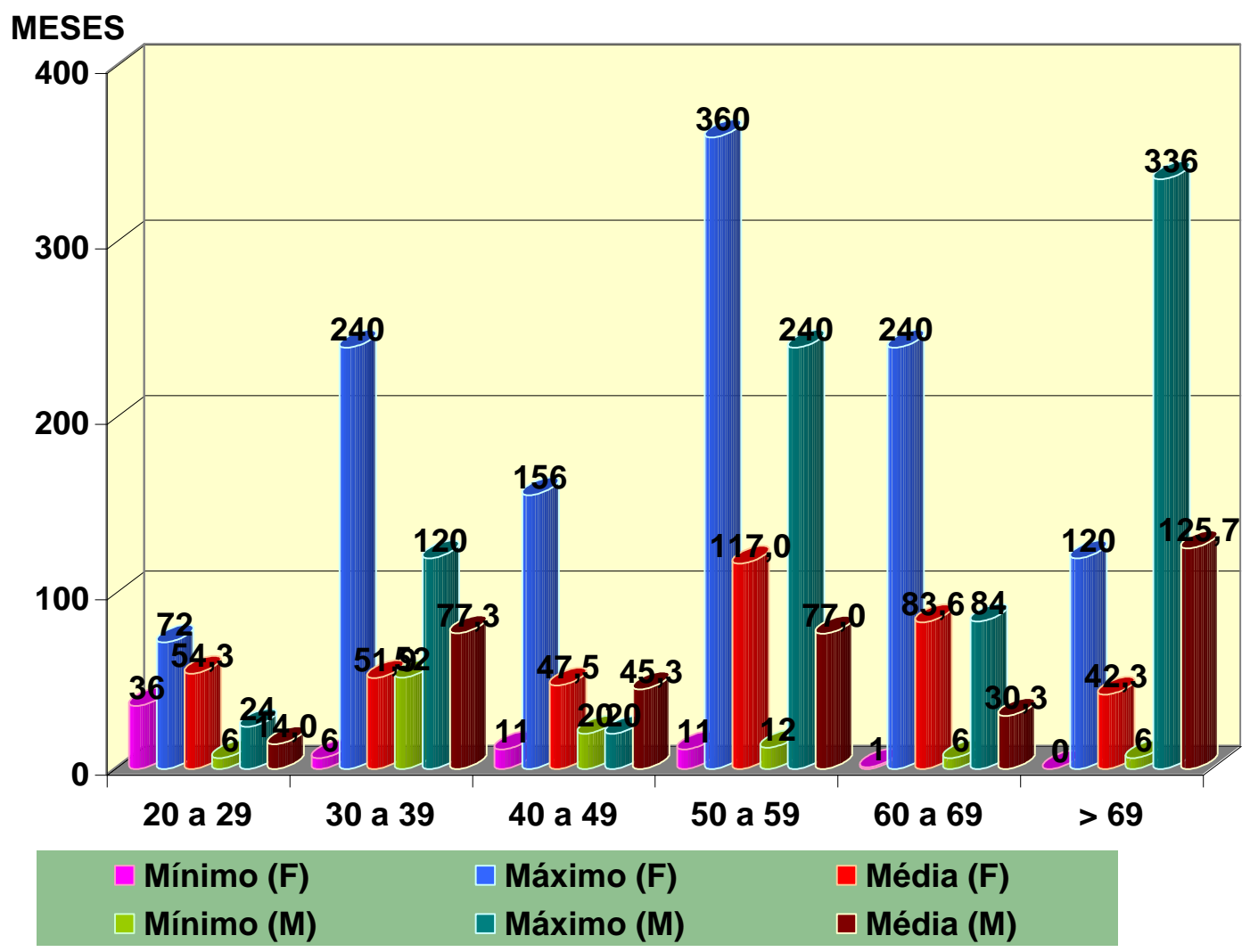


TABELA 38 - Distribuição dos pacientes quanto ao diagnóstico e nervos comprometidos

\begin{tabular}{|c|c|c|c|}
\hline Diagnóstico & $\mathbf{N}$ & $\begin{array}{l}\text { Nervos } \\
\text { comprometidos }\end{array}$ & Freqüência \\
\hline \multicolumn{4}{|l|}{ Miofascial e Neuropática } \\
\hline \multirow[t]{4}{*}{ Pós Trauma Cirúrgico } & $7 / 10$ & Pudendos & 2 \\
\hline & & Gênito femural & 2 \\
\hline & & Íleo inguinal & 2 \\
\hline & & Íleo hipogástricos & 1 \\
\hline \multicolumn{4}{|l|}{ Miofascial e Neuropática } \\
\hline \multirow[t]{3}{*}{ Sem Trauma } & $3 / 6$ & Pudendos & 1 \\
\hline & & Gênito femural & 1 \\
\hline & & Plexo sacral & 1 \\
\hline \multicolumn{4}{|l|}{ Miofascial Pós } \\
\hline Trauma Cirúrgico & $0 / 11$ & & \\
\hline \multicolumn{4}{|l|}{ Miofascial Pós } \\
\hline Trauma Não Cirúrgico & $0 / 10$ & & \\
\hline \multicolumn{4}{|l|}{ Miofascial Sem } \\
\hline Trauma Cirúrgico & $1 / 34$ & Íleo psoas & 1 \\
\hline \multicolumn{4}{|l|}{ Neuropática Pós } \\
\hline \multirow[t]{5}{*}{ Trauma Cirúrgico } & $5 / 5$ & Pudendos & 1 \\
\hline & & Gênito femural & 2 \\
\hline & & Íleo inguinal & 1 \\
\hline & & Gênito femural & 1 \\
\hline & & Dorsal do pênis & 1 \\
\hline \multicolumn{4}{|l|}{ Neuropática Pós } \\
\hline Trauma Não Cirúrgico & $1 / 1$ & Íleo inguinal & 1 \\
\hline \multicolumn{4}{|l|}{ Neuropática Sem } \\
\hline \multirow[t]{3}{*}{ Trauma Cirúrgico } & $4 / 4$ & Pudendos & 2 \\
\hline & & Gênito femural & 1 \\
\hline & & Plexo sacral & 1 \\
\hline TOTAL & $21 / 81$ & & \\
\hline
\end{tabular}


6. DISCUSSÃO 
$\mathrm{Na}$ grande maioria dos estudos publicados sobre a DPC observa-se uma preocupação constante em apresentar e correlacionar dados que são mais expressivamente direcionados para a população feminina, talvez porque a mulher tenha muito mais chance de ter uma DPC do que o homem em vista de suas condições anatômicas na pelve, suas constantes transformações hormonais e pela presença muitas vezes da gravidez, condição em que várias alterações não só anatômicas, mas também por modificações da biomecânica entre a coluna e a pelve, alterando suas relações e modificando até os pontos de contato e apoio de toda a região glútea e até mesmo dos membros inferiores. No homem existe uma farta associação de DPC com patologias viscerais e pouco se demonstrou até o momento detalhes sobre condições não viscerais responsáveis pelo aparecimento de dor crônica na pelve.

Apesar de a dor pélvica crônica (DPC) ser bastante comum, sua real incidência e prevalência não foram estabelecidas (TEIXEIRA et al, 2003).

$\mathrm{Na}$ idade reprodutiva é que as mulheres apresentam os maiores picos de DPC, numa média de idade que gira em torno de trinta anos. No estudo recente de HOWARD (2000) em consultórios não ginecológicos, foi demonstrado que $12 \%$ das mulheres relataram DPC e $33 \%$ relataram um passado de DPC. Em um estudo Gallup, 36\% reportaram problemas pélvicos. Em um outro estudo realizado em consultório de medicina clínica geral, $11,7 \%$ das mulheres reportou DPC por mais de cinco dias por mês ou ao menos um dia inteiro ou mais a cada mês (STEEGE, 1997), o que demonstra que a prevalência da DPC é maior no sexo feminino do que no masculino e parece prevalecer na população do sexo feminino em idade reprodutiva, porém estes dados estatísticos são mais genéricos sobre a DPC e não são claros na DPCOI. A presente casuística demonstrou que a média 
de idade dos doentes com DPCOI foi de 48,6 anos. 48,4 anos para o sexo feminino e 51,5 anos para o sexo masculino, onde a incidência foi maior no sexo feminino (57casos, 70,4\%) do que no masculino (24 casos, 29,6\%) e prevaleceu mais significativamente na faixa etária que está entre os 30 e 49 anos para o sexo feminino (49\%), faixa etária que inclui o pico da idade reprodutiva da mulher, e entre os 40 e 59 anos para o sexo masculino (41,6\%), corroborando os achados de HOWARD (2000) e STEEGE(1997) para a DPC.

A quantificação e a qualificação da dor são fundamentais para que se possam obter subsídios para a elaboração de sugestões de tratamento. Desta forma, a coleta de informações sobre a qualidade da dor utilizado neste presente estudo foi baseada na expressão verbal livre, adaptada à linguagem médica correta. A dor foi caracterizada como constante na grande maioria dos casos tanto no sexo masculino (83,3\%), quanto no sexo feminino (66,7\%), ao passo que dores episódicas tiveram uma presença menor no sexo masculino $(8,3 \%)$ do que no sexo feminino $(17,5 \%)$, seguido de dores flutuantes em 8,8\% nas mulheres e 8,3\% nos homens e dores paroxísticas em $7,0 \%$ nas mulheres. As expressões verbais livres mais comuns foram o queimor em $31,9 \%$ nas mulheres e em $31,48 \%$ nos homens, pontadas em $23,5 \%$ das mulheres e $25,7 \%$ dos homens, latejamento em $18,1 \%$ nas mulheres e em $17,1 \%$ dos homens, peso em $7,4 \%$ para as mulheres e em $17,1 \%$ para os homens, aperto em $7,4 \%$ das mulheres, fisgadas em 3,2 \% das mulheres, choques e dolorimento em 2,1 $\%$ das mulheres e 2,9\% dos homens. Todas as expressões verbais descritas predominam no sexo feminino. Segundo LIN e cols (2003), o diagnóstico da síndrome dolorosa miofascial depende exclusivamente da história e do exame físico. É uma condição dolorosa muscular regional caracterizada pela ocorrência de bandas musculares tensas palpáveis, na qual identificamse pontos intensamente dolorosos (PGs), que quando estimulados por palpação digital ou durante a punção localizada com agulha ocasionam dor local ou referida à distância. Suas características são de dor difusa em um músculo ou em grupos musculares. Geralmente são expressas em peso, 
queimor ou latejamento, surtos de dor e referência de dor à distância e às vezes com queixas de parestesias (sem padrão neuropático). OKADA e TEIXEIRA (2003) denotaram a importância da expressão verbal na presença de uma dor neuropática. Não há uniformidade quanto à apresentação dos sintomas nos doentes que apresentam esta condição. Geralmente a dor é descrita como choques, tremor, pontadas e agulhadas. Pode ser paroxística, episódica ou contínua, referida ou irradiada em locais distantes e ser superficial ou profunda, ser acompanhada ou não de déficits sensitivos, alodínea, hiperpatia, hiperalgesia, disestesias e parestesias, espontânea ou evocada por estímulos físicos, químicos ou emocionais. Quando superficial, usualmente é descrita como queimor, agulhada e ardor e quando profunda, como doída, em pressão ou em aperto. Quando paroxística, tem caráter lancinante, em choque, pontada, agulhada ou facada, com duração de alguns segundos. Quando constante, é descrita como queimor, formigamento ou peso. Podem ocorrer períodos de remissão prolongados em algumas condições. Nesta casuística as expressões verbais de queimor, latejamento, pontadas e peso dentre outras, apareceram com maior freqüência talvez porque na sua grande maioria a DPCOI apresenta como causa uma SDM, como veremos a seguir, e as expressões de choques em menor número devido ao fato da síndrome dolorosa neuropática ter ocorrido com menor freqüência que a primeira condição. Do mesmo modo, observamos a presença de um caráter mais constante da dor em 58 casos, na DPCOI, dores episódicas (12 casos) e flutuantes ( 7 casos) com predomínio da SDM. As dores paroxísticas (04 casos) tiveram predomínio na dor miofascial e neuropática. Todas estas condições estão mais bem expressas na tabela 22.

A média dos valores da EVA no sexo feminino foi de 8,2, ao passo que no sexo masculino, o valor foi de 6,3. Na SDM e dor miofascial e neuropática apresentaram valores de média da EVA maiores (7,6 e 7,7 respectivamente), ao passo que a dor neuropática apresentou como média 0 valor de 6,9. Observou-se que em todas as faixas etárias as médias dos valores da EVA foi maior no sexo feminino do que no sexo masculino. 
Conforme descreveram BAKER (1998) e LIN e cols. (1997), a SDM é uma das causas mais comuns de dor pelviperineal crônica de origem não visceral. As causas miofasciais são mais freqüentes no sexo feminino onde as modificações anatômicas das estruturas ósteo-articulares e musculares por vários fatores, representados principalmente pela degeneração estrutural própria do progredir da idade, as posturas viciosas, as sobrecargas mecânicas, redução da potência funcional e da elasticidade tecidual o aumento do tônus muscular, os múltiplos partos e as possíveis seqüelas de fraturas desencadeiam sobrecarga dos sistemas de sustentação. Na mulher a SDM é mais comum porque as dimensões da pelve são maiores e a musculatura regional mais desenvolvida. Os músculos mais freqüentemente comprometidos são os m.elevador do ânus, o coccígeo, o glúteo médio, o glúteo mínimo, o piriforme, os adutores da coxa, o íliopsoas e o pectíneo. Embora estas descrições tenham sido feitas com bastante veemência não há detalhes sobre as porcentagens de acometimento dos músculos com relação às respectivas síndromes dolorosas. São apenas citações. $O$ mesmo ocorreu nos estudos feitos por PARADIS e MARGANOFF (1968), LILIUS e VALTONEN (1973), GRANET (1946), THIELE (1937) e SCHAPIRO (1950). Nesta casuística identificou-se 55 casos (67,9\%) de SDM, 16 ocorrências (19,8\%) de dor miofascial e neuropática e 10 doentes (12,3\%) com dor neuropática onde a SDM ocorreu mais freqüentemente no sexo feminino $(70,8 \%)$ do que no sexo masculino $(60,9 \%)$. Nos doentes com manifestações de dores miofasciais e neuropáticas a incidência maior também foi sobre o sexo feminino $(22,4 \%)$ do que no masculino (13\%). Nas dores de origem neuropática encontrou-se $26,1 \%$ de indivíduos do sexo masculino e 6,8\% do sexo feminino. Estes dados corroboram os achados de LIN (1997) e BAKER (1998) acima citados e ainda detalham a incidência das demais formas de apresentação da síndrome dolorosa crônica não visceral.

As regiões coccígea, vulvar e testicular (100,0\%) foram as regiões mais acometidas na síndrome dolorosa miofascial, seguida pelas regiões pubiana $(75,9 \%)$, peniana $(75,0 \%)$, anal $(74,1 \%)$, perineal $(66,7 \%)$, inguinal $(56,7 \%)$ e vaginal $(50,0 \%)$ dentre outras. Na síndrome dolorosa miofascial e 
neuropática as regiões de maior acometimento foram as regiões inguino crural $(100,0 \%)$, glútea $(50,0 \%)$, vaginal $(42,9 \%)$ e inguinal $(20 \%)$, anal $(14,8 \%)$ e outras. Na dor neuropática, as regiões de maior expressividade foram a região ureteral $(100,0 \%)$, coxa $(28,6 \%)$, peniana $(25 \%)$, inguinal $(23,3 \%)$, região pubiana $(13,8 \%)$, região perineal $(22,2 \%)$, anal $(11,1 \%)$ e vaginal (7,1\%). As regiões anal, inguinal, vaginal e pubiana são as regiões de maior predominância na DPCOI nas mulheres, ao passo que nos homens as regiões anal, inguinal, testicular e peniana são as que mais apareceram (Tabela 4). Os músculos mais freqüentemente apresentados por presença de PGs na SDM foram o complexo elevador do ânus em 91,7\% dos casos, glúteos em 74,1\%, adutores da coxa em 76,5\%, piriforme em 83,3\%, coccígeo em $80 \%$, íliopsoas e pectíneo e abdutores em $100 \%$ cada, reto abdominal em $100,0 \%$ e quadrados lombares em $50 \%$, dentre outros em menor número. Na síndrome dolorosa miofascial e neuropática os músculos mais acometidos pela presença dos PGs foram os vasto medial e bulbo esponjoso (100\%), glúteos (25,9\%), os adutores da coxa $(23,5 \%)$, os $\mathrm{mm}$. elevadores do ânus $(8,3 \%)$ e os $\mathrm{mm}$. piriforme $(16,7 \%)$ e quadrados lombares, oblíquos int/ext e multifídios (50\% respectivamente) dentre outros. Não foram encontrados PGs nos casos de dor neuropática. Os PGs mais predominantes no sexo feminino foram nos mm. elevador do ânus (32,5\%), glúteos (26,5\%), adutores (16,9\%) e piriforme (12\%) como demonstrado na Tabela 10. Tais achados enriquecem e detalham as regiões de acometimento das variadas síndromes dolorosas pélvicas não viscerais e evidenciam a importância da determinação dos grupos musculares para uma melhor compreensão do comportamento clínico para um melhor diagnóstico desta síndrome dolorosa.

O impacto funcional que a DPC exerce sobre os indivíduos é observação de extrema relevância para o entendimento do comportamento desta síndrome dolorosa. Porém mais uma vez estes dados não são muito bem detalhados quando se estuda a DPCOI. Sabendo-se que na sua grande maioria a síndrome dolorosa tem predomínio miofascial, entende-se que a limitação para movimentos e esforços físicos sejam fatores de impacto 
e limitação importantes, dentre outros, mas existem vários outros fatores limitantes e de impacto que foram estudados e determinados. Segundo TEIXEIRA e cols (2003), dor pélvica é causa de absenteísmo no trabalho em $15 \%$ dos casos, reduz a produtividade em 45\%, impõe limitação para as atividades do lar em $11 \%$ e para atividades sexuais em $11,9 \%$. Implica no uso de analgésicos em 15,8\% dos casos e resulta em perda de pelo menos um dia de trabalho em 3,9\%. Em outro estudo com 581 mulheres na idade fértil atendidas em serviços de assistência primária, a dor (não dismenorreica, dispareunia ou intestinal) foi referida por $39,1 \%$ das doentes em algum período de suas vidas, durou mais que 5 dias ao mês ou mais de um dia em 11,7\% dos casos. Em uma população em idade reprodutiva, 2 a $5 \%$ reportaram significante impedimento no trabalho ou nas atividades do lar causadas pela DPC. Freqüentemente cirurgias ginecológicas são realizadas por esta condição, incluindo 15 a $40 \%$ de laparoscopias e $12 \%$ de histerectomias (STEEGE, 1997). No estudo publicado por MATHIAS e cols em 1996, 773 mulheres responderam a uma entrevista sobre o impacto da DPC em suas vidas. Em 310 (56\%), DPC foi reportada interferindo moderadamente, bastante ou extremamente, no humor dessas mulheres. $82 \%$ disseram que tinham energia suficiente ou pouca energia ou nenhuma energia para fazer as coisas que elas tinham vontade. $47 \%$ relataram desânimo por algumas vezes, na maioria do tempo ou todo o tempo. 432 responderam vida sexualmente ativa e $88 \%$ responderam ter dor às relações sexuais por alguma vez, na maioria do tempo ou o tempo todo no último mês. 557 mulheres que tiveram dor durante o mês anterior $26 \%$ reportaram ter ficado na cama por mais da metade de um dia ou um ou mais dias no mês passado por causa da dor. 58\% ainda responderam ter reduzido as suas atividades corriqueiras em um ou mais dias do mês anterior pelo mesmo motivo. Neste estudo sobre DPCOI, determinamos mais detalhadamente o impacto funcional sobre diversas atividades, onde os doentes referiram importante redução das mesmas. $59,6 \%$ dos doentes estavam trabalhando no momento da entrevista inicial e 40,4\% não estavam trabalhando. $76,5 \%$ dos entrevistados foram considerados em bom estado 
geral e $17,3 \%$ em regular estado geral. Nenhum doente foi considerado em mau estado geral, na impressão do exame propedêutico. O humor foi afetado em $18,3 \%$ das mulheres e $14,1 \%$ dos homens. A atividade sexual em $10,2 \%$ das mulheres e em $7,8 \%$ dos homens. O sono foi reduzido em $16,2 \%$ das mulheres e $14,1 \%$ dos homens. O lazer mostrou-se diminuido em $13,2 \%$ das mulheres e $15,6 \%$ dos homens. O impacto sobre o trabalho ocorreu em $12,8 \%$ para as mulheres e $17,2 \%$ para os homens. A concentração estava reduzida em $6 \%$ das mulheres e em 3,1\% dos homens. $\mathrm{O}$ apetite em $8,1 \%$ das mulheres e $7,8 \%$ dos homens. A deambulação demonstrou-se prejudicada em $2,6 \%$ das mulheres e $3,1 \%$ dos homens. $O$ psiquismo alterado em $4,3 \%$ nas mulheres e $1,6 \%$ dos homens. $O$ ato de sentar em $4,7 \%$ das mulheres e $6,3 \%$ dos homens. A Tabela 9 revela que as atividades como sono, humor, lazer e trabalho tem a mesma predominância entre os sexos, ao passo que a atividade sexual, apetite, concentração, o ato de sentar e o psiquismo predominam mais sobre o sexo feminino. Humor, atividade sexual, sentar, sono e lazer são mais predominantes nas mulheres entre os 31 e 70 anos (Tabela 17). Todos os itens utilizados para exprimir o impacto sobre as AVDs tiveram predomínio na dor miofascial (Tabela 25). Estes dados de impacto sobre o trabalho, humor, atividades do lar e atividades sexuais são contrastantes com relação aos achados de TEIXEIRA e cols. (2003) e MATHIAS e cols (1996) para DPC. As atividades que exigem movimentação acabam por ter um importante impacto funcional na vida destes indivíduos, dentre outras da esfera psicossocial demonstradas nesta casuística.

Fatores agravantes e de melhora da DPCOI foram também determinados para uma melhor compreensão da condição clínica. Dentre os fatores agravantes e desencadeantes da dor, ganharam destaque o esforço físico (16,3\% nas mulheres e $17,7 \%$ nos homens), a postura $(7,8 \%$ nas mulheres e $9,7 \%$ nos homens), os movimentos (12,4\% nas mulheres e $6,5 \%$ nos homens), a marcha (8,5\% nas mulheres e $16,1 \%$ nos homens), o estresse (3,9\% nas mulheres e $3,2 \%$ nos homens), as emoções $(6,5 \%$ nas mulheres e $3,2 \%$ nos homens), o ato de sentar (6,5\% nas mulheres e $12,9 \%$ 
nos homens), o contato físico ( $4,6 \%$ nas mulheres e $3,2 \%$ nos homens) e a atividade sexual (3,9\% nas mulheres e 3,2\% nos homens). A postura, o esforço físico e a atividade sexual predominam mais sobre o sexo feminino na faixa etária entre 31 e 50 anos. O movimento predomina no sexo feminino entre a faixa etária de 41 a 70 anos. A marcha não demonstra maior relevância sobre os sexos na faixa etária de 31 a 60 anos. O frio/calor predomina nas mulheres na faixa etária entre os 31 a 40 anos (Tabela 15). Os fatores compressão e micção/evacuar prevaleceram na dor miofascialneuropática. Espirro/Tosse e ansiedade prevaleceram na dor neuropática. Os demais fatores prevaleceram na dor miofascial (Tabela 23).

Dentre os fatores de melhora, o uso de medicamentos esteve presente em $27,7 \%$ dos casos femininos e $16,7 \%$ dos masculinos, calor e frio em $9,2 \%$ no sexo feminino e $9,3 \%$ no sexo masculino, massagem em $3,8 \%$ no sexo feminino e $0 \%$ no sexo masculino, repouso físico e psíquico em $22,3 \%$ no sexo feminino e $18,5 \%$ no sexo masculino, o ato de deitar em $13,1 \%$ no sexo feminino e $16,7 \%$ no sexo masculino, o sono em $12,3 \%$ no sexo feminino e $11,1 \%$ no sexo masculino, o ato de sentar em $0,8 \%$ nas mulheres e 9,3\% nos homens, andar em 3,8\% nas mulheres e 1,9\% dos homens, o ortostatismo em 3,1\% das mulheres e 3,7\% dos homens, dentre outros. As mulheres demonstram uso de medicamentos mais do que os homens em todas as faixas etárias. O calor/frio é fator de predominância maior nas mulheres entre os 41 e 50 anos. O fator massagem ocorre mais nas mulheres na faixa dos 31 a 40 anos. O repouso físico e psíquico ocorrem mais nas mulheres entre as faixas 41 e 50 e 61 a 70 anos. Há ligeiro predomínio do ato de deitar nas mulheres após os 41 anos. O sono revela-se mais predominantemente expressivo nas mulheres entre 61 e 70 anos (Tabela 16). Os fatores de melhora descritos como "acupuntura" e "contatos" prevaleceram na dor neuropática ao passo que os demais fatores tiveram maior relevância na dor miofascial (Tabela 24). Estes dados reforçam, detalham e enriquecem o entendimento do comportamento da DPCOI uma vez que não se tenha encontrado nenhum dado avaliativo desta natureza nos estudos até mais recentes. 
Pouco se conhece sobre o comportamento da DPCOI nos doentes que já tenham sido submetidos a procedimentos cirúrgicos na tentativa de melhorarem as suas dores, ou mesmo quando o quadro clínico doloroso tenha se iniciado após o ato cirúrgico desencadeador da síndrome. HOWARD em 1993 achou que 40\% das laparoscopias foram feitas para a DPC. 12 a 16\% das histerectomias são realizadas nos Estados Unidos da América por DPC, o que daria cerca de oitenta mil procedimentos por ano aproximadamente. $25 \%$ das mulheres em avaliação de DPC referiram ter sido submetidas a uma histerectomia prévia sem uma resolução dos seus sintomas (MILBURN, 1993). Um estudo feito nos EUA aponta que aproximadamente $20 \%$ das laparoscopias realizadas foram por DPC (REITER, 1991). No estudo feito por REITER e GAMBONE (1991), 122 mulheres com DPC já tinham sido submetidas a uma laparoscopia negativa e patologia somática oculta foi encontrada em $47 \%$ dos doentes incluindo 19 doentes com coexistente diagnóstico psicopatológico. Dor miofascial foi o mais comum diagnóstico somático. Nenhuma etiologia somática plausível fora diagnosticada nas 65 mulheres remanescentes (53\%). 29\% não apontaram patologia somática não ginecológica, contra 19\% de patologias ginecológicas e somente $6 \%$ já tinham sido submetidas a uma histerectomia prévia. Na presente casuística, identificamos e estratificamos em grupos os doentes com desenvolvimento da síndrome dolorosa após um trauma cirúrgico. Encontrou-se 15 doentes (18,5\%) com diagnóstico de SDM após trauma cirúrgico sendo 9 mulheres $(11,1 \%)$ e 6 homens $(7,4 \%), 06$ doentes $(7,4 \%)$ com diagnóstico de dor neuropática após trauma cirúrgico sendo 02 mulheres $(2,4 \%)$ e 04 homens $(4,9 \%)$ e 15 doentes (18,5\%) com síndrome miofascial e neuropática também após trauma cirúrgico em 10 mulheres $(12,3 \%)$ e 05 homens $(6,2 \%)$. A dor miofascial pós trauma cirúrgico ocorreu mais nas mulheres entre os 31 e 50 anos. A dor miofascial sem trauma apareceu mais no sexo feminino nas faixas etárias entre os 31 e 70 anos ou mais. A dor miofascial neuropática pós trauma cirúrgico apareceu mais nas mulheres da faixa etária entre os 31 e 40 anos. A dor neuropática pós trauma cirúrgico ocorreu mais sobre os homens nas faixas entre os 21 e 30 
anos e nas mulheres entre os 31 e 40 anos (Tabela 19). Dos doentes com dor miofascial desenvolvidas após um trauma cirúrgico, 5 casos $(6,1 \%)$ foram de histerectomia e 01 caso $(1,2 \%)$ de bartolinectomia, 01 (1,2\%) de dermoplastia, $01(1,2 \%)$ de exérese de cisto de supra renal e $01(1,2 \%)$ de herniorrafia inguinal e 02 casos $(2,4 \%)$ de laqueadura para o sexo feminino e, no sexo masculino, ocorreram 02 casos $(2,4 \%)$ de herniorrafia inguinal e 01 caso $(1,2 \%)$ de exérese do coccix. Com relação aos doentes com dor miofascial e neuropática após trauma cirúrgico, 02 casos $(2,4 \%)$ eram do sexo feminino e cirurgias realizadas foram 01 caso $(1,2 \%)$ de herniorrafia umbelical e 01 caso $(1,2 \%)$ de cirurgia para varizes. Somente 01 caso $(1,2 \%)$ do sexo masculino foi submetido a uma herniorrafia inguinal. Dos doentes com dor neuropática após o trauma cirúrgico, 02 casos $(2,4 \%)$ eram do sexo feminino, sendo 01 caso $(1,2 \%)$ por ter sido submetido à hemorroidectomia e 01 caso $(1,2 \%)$ de herniorrafia inguinal. 03 casos do sexo masculino ocorreram. Herniorrafia inguinal em 02 doentes $(2,4 \%)$ e 01 doente foi submetido à retirada de cálculo ureteral a céu aberto $(1,2 \%)$.

Nos casos de dor miofascial desenvolvidos após um trauma cirúrgico, encontramos 06 ocorrências $(7,4 \%)$ de PGs para os mm. elevadores do ânus nas cirurgias de histerectomias $(4,9 \%)$, bartolinectomia e exérese do coccix $(1,2 \%$ dos casos respectivamente). PGs nos $\mathrm{mm}$. adutores ocorreram nos dois casos de herniorrafia inguinal (2,5\%) e nos casos de bartolinectomia e histerectomia combinada à laqueadura e dermoplastia (1,2\% para cada caso). Duas ocorrências $(1,2 \%)$ de PGs nos mm. piriforme foram observados na exérese do coccix e na histerectomia combinada à dermoplastia e laqueadura (1,2\%). O m. coccígeo apresentou-se com PGs no doente submetido à cirurgia de exérese do coccix $(1,2 \%)$. Os PGs coccígeo, elevador do ânus, adutores, abdutores, piriforme, glúteos, reto abdominal, íliopsoas, pectíneo e lombar ocorreram mais na SDM (Tabela 26).

Com relação aos casos de dor miofascial e neuropática após trauma cirúrgico, o caso de apendicectomia do sexo masculino revelou-se com PGs no $\mathrm{m}$. vasto medial(1,2\%) e oblíquo externo (1,2\%). Na bartolinectomia os 
mm. glúteos $(1,2 \%)$ e bulbo esponjoso (1,2\%) apresentaram PGs. $\mathrm{Na}$ neurectomia gênito femural (sexo feminino), os PGs apareceram nos mm. adutores da coxa $(1,2 \%)$ e glúteos $(1,2 \%)$. Nos três casos de histerectomia, os mm. glúteos apresentaram PGs em somente um dos casos $(1,2 \%)$ e o m. elevador do ânus em outro caso (1,2\%). Na herniorrafia inguinal, tivemos PGs nos mm. adutores da coxa $(1,2 \%)$. Na episiotomia encontramos PGs nos $\mathrm{mm}$. piriforme, quadrado lombar e multifídios (1,2\% respectivamente). $\mathrm{Na}$ herniorrafia umbelical observamos PGs em $\mathrm{mm}$. paravertebrais lombares $(1,2 \%)$ e glúteos $(1,2 \%)$. Todos estes últimos casos descritos ocorreram no sexo feminino. Não encontramos dados desta natureza na literatura pesquisada. Os PGs vasto medial, bulbo esponjoso e sacrococcígeo prevaleceram na dor miofascial-neuropática (Tabela 26).

Nos três casos de dor neuropática após trauma cirúrgico que foram submetidos à herniorrafia inguinal, encontramos sinais de lesões neuropáticas nos $\mathrm{nn}$. gênito femural em dois casos $(2,5 \%)$ e no n. ílioinguinal em um caso $(1,2 \%)$. Na hemorroidectomia encontramos lesões dos receptores nociceptivos na pele peri-anal $(1,2 \%)$ e na exérese de cálculo ureteral a céu aberto encontramos lesões nos nn. pudendos e $n$. dorsal do pênis $(1,2 \%$ respectivamente).

Nas ocorrências de dor miofascial e neuropática, encontramos lesões neuropáticas nos nn. gênito femural $(1,2 \%)$ na apendicectomia e na neurectomia gênito femural respectivamente, lesão de nn. pudendos $(1,2 \%)$ na bartolinectomia e episiotomia, n. Ílioinguinal (2,5\%) nas cirurgias de herniorrafia inguinal e lesão do $\mathrm{n}$. íliohipogástrico $(1,2 \%)$ na herniorrafia umbelical. Não encontramos lesões neuropáticas nas histerectomias realizadas neste grupo.

O tempo médio de aparecimento da dor no sexo feminino foi de 64,5 meses e 57,3 meses para o sexo masculino. Nos doentes portadores de dor miofascial e miofascial e neuropática, o tempo médio de dor fora semelhante (63,7 e 64,9 respectivamente), ligeiramente maior do que nos portadores de dor neuropática $(51,0)$ o que demonstra que lesões neuropáticas produzem dores que são de aparecimento mais precoce do que em lesões miofasciais 
ou miofasciais e neuropáticas. Na faixa etária compreendida entre os 50 a 59 anos observou-se uma média do tempo de dor absolutamente superior $(103,7)$ às demais e todas relatadas pelo sexo feminino. No sexo masculino, o maior tempo médio de aparecimento da dor $(125,7)$ foi na faixa etária compreendida entre os maiores de 69 anos. Não há razões plausíveis para entendermos estas condições.

Neste grupo de doentes submetidos a intervenções cirúrgicas, o tempo de aparecimento da dor variou desde o pós-operatório imediato até 720 dias (24 meses), com uma média de 50 dias (1,6 mês).

Com relação à ocorrência de doenças associadas à DPCOI, esta amostra revelou a presença de hipertensão arterial sistêmica em 05 doentes. Diabetes ocorreu em 05 doentes dos quais 03 foram submetidos à uma herniorrafia inguinal. Destes 03 casos, 01 teve diagnóstico de dor miofascial neuropática com lesão neuropática do n. ílioinguinal pós trauma cirúrgico e 02 tiveram diagnóstico de dor miofascial pós trauma cirúrgico, sem sinais de lesões neuropáticas. Os 02 restantes dos 05 casos foram diagnosticados como dor miofascial sem trauma cirúrgico. 01 caso de gota foi considerado como dor miofascial pós trauma cirúrgico por herniorrafia inguinal. Isto demonstra que nesta casuística as doenças associadas não exerceram qualquer influência no diagnóstico das DPCOI.

BASU em 1981 relatou que a prevalência de depressão em mulheres com DPC é de $28 \%$, comparado com $3 \%$ de mulheres com afecções ginecológicas em geral. Em um estudo com 52 mulheres, RAPKIN et al acharam $66 \%$ dos casos com somatização, frequencia que se elevou para $80 \%$ quando a história de dor foi superior a 5 anos. As doentes geralmente eram deprimidas e procuravam um maior número de vezes assistência médica e apresentavam queixas vagas e numerosas mais frequentemente que aquelas com lesões demonstráveis. Neste estudo encontramos 23 casos $(28,3 \%)$ de depressão, sendo $18(32,7 \%)$ do sexo feminino e $5(9,1 \%)$ casos do sexo masculino. Tivemos 48 casos $(59,2 \%)$ de ansiedade detectados na avaliação, sendo 28 casos (51\%) do sexo feminino e 27 casos (49\%) do sexo masculino, num total de 55 casos. Esses dados são um 
pouco discrepantes com relação aos achados de RAPKIN e BASU. Isto reforça a idéia de que quando estes doentes forem submetidos a um tratamento, uma abordagem psicológica e psiquiátrica deva ser considerada como imprescindível. 
7. CONCLUSÕES 
1. A DPCOI ocorre mais no sexo feminino do que no sexo masculino.

2. As SDM, neuropática e a miofascial e neuropática são as causas mais comuns da DPCOI.

3. Com relação ao comportamento clínico da DPCOI:

a. O caráter da dor mais freqüente é o caráter constante e ocorre mais no sexo feminino.

b. As regiões anal, inguinal, vaginal e pubiana aparecem mais predominantemente no sexo feminino.

c. As regiões anal, inguinal e peniana são as regiões mais acometidas no sexo masculino.

d. A história clínica e o exame físico detalhado são fundamentais para o diagnóstico.

e. A SDM predomina na DPCOI.

f. As síndromes miofascial e neuropática e SDM predominam no sexo feminino.

g. A síndrome dolorosa neuropática predomina no sexo masculino. 
8. FIGURAS 


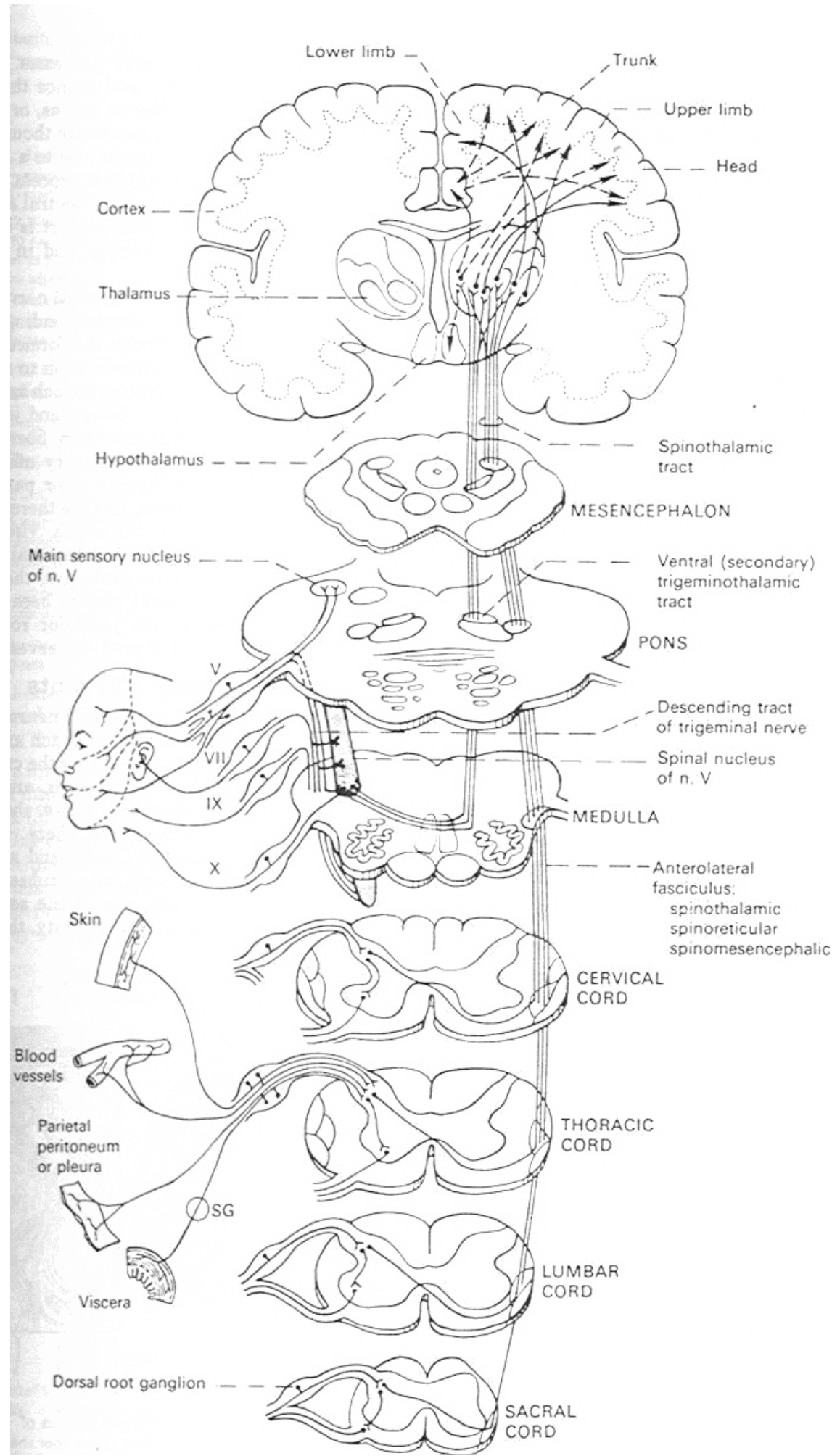

FIGURA 1. Vias ascendentes da interpretação da dor.

Extraída de BONICA J.J. The management of pain. 2 ed. Philadelphia, Lea Feibiger, p. 29,1990 


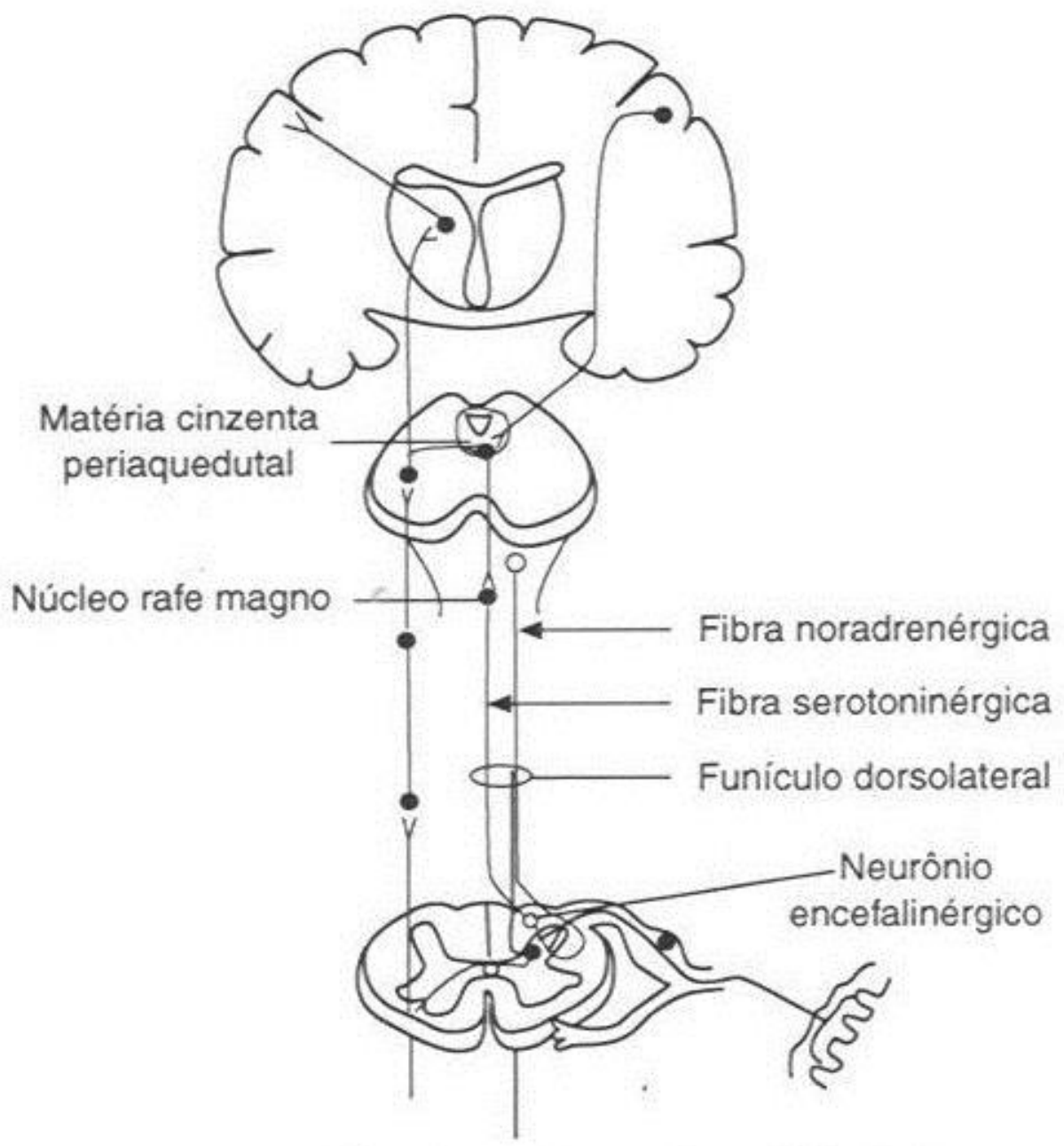

Figura 1.3 - Vias descendentes de controle da dor.

FIGURA 2. Vias descendentes de controle da dor.

Extraída de ANDRADE FILHO A.C.C. Dor diagnóstico e tratamento. São Paulo, Roca, p. 3, 2001. 


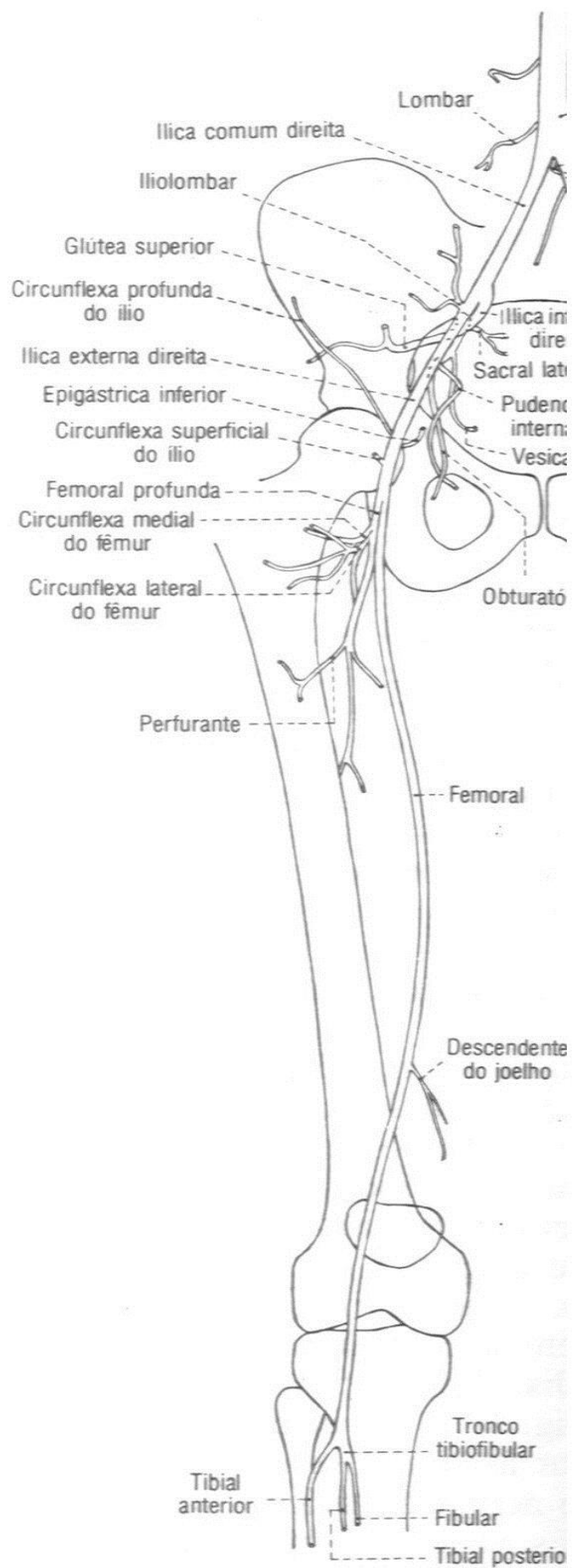

FIGURA 3. Sistema arterial de irrigação.

Extraída de GARDNER E.; GRAY D.J.;O'RAHILLY R.; ed.04. Anatomia estudo regional do corpo humano. Rio de Janeiro, Guanabara Koogan, p.440, 1978. 


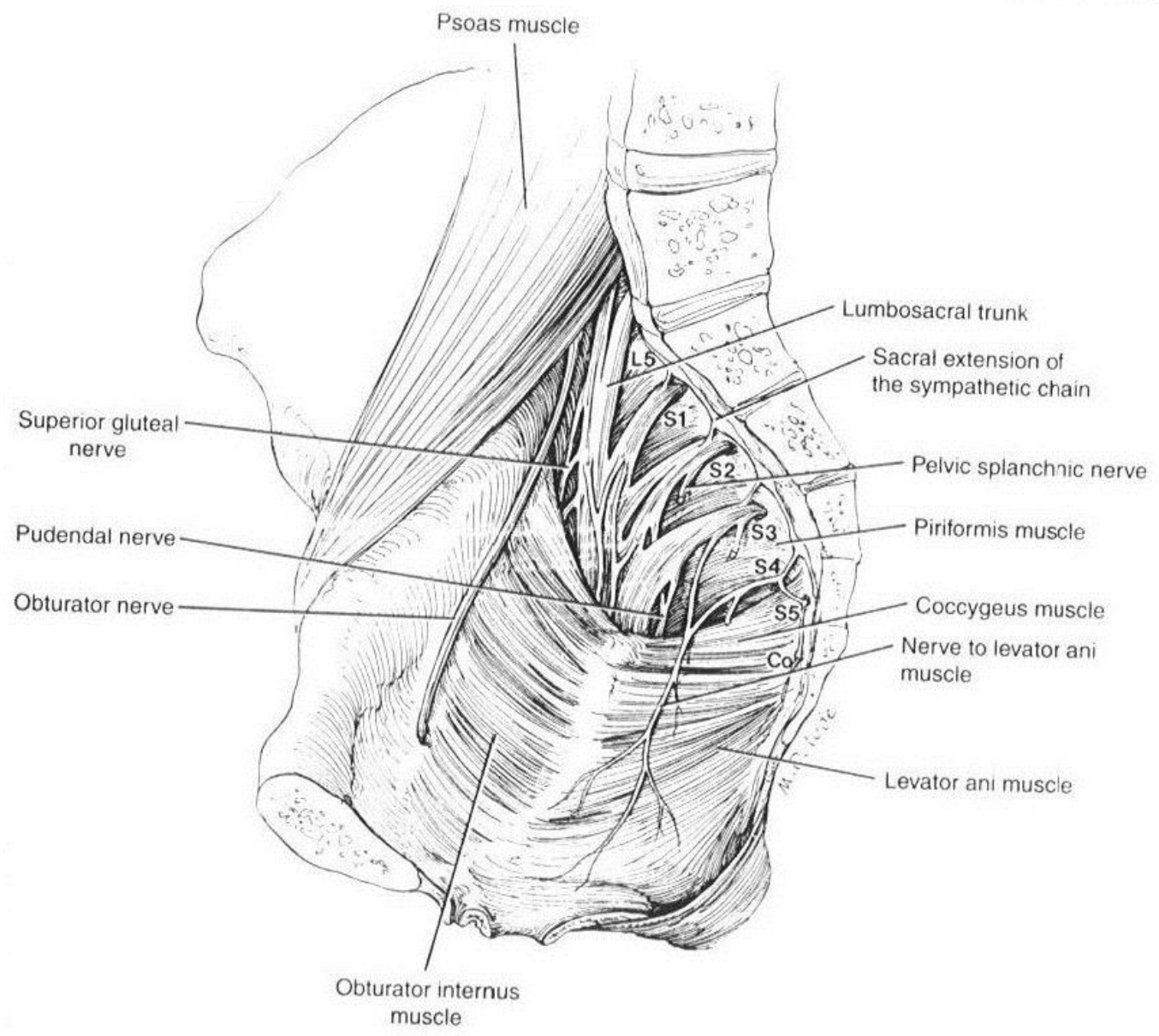

FIGURA 4. Plexo sacral de nervos.

Extraída de STEEGE JF.; MELTZGER, D.A; LEVY, B.B.(Eds) Chronic pelvic pain. An integrated approach. Philadelphia. W.B.Saunders, p.43, 1998. 


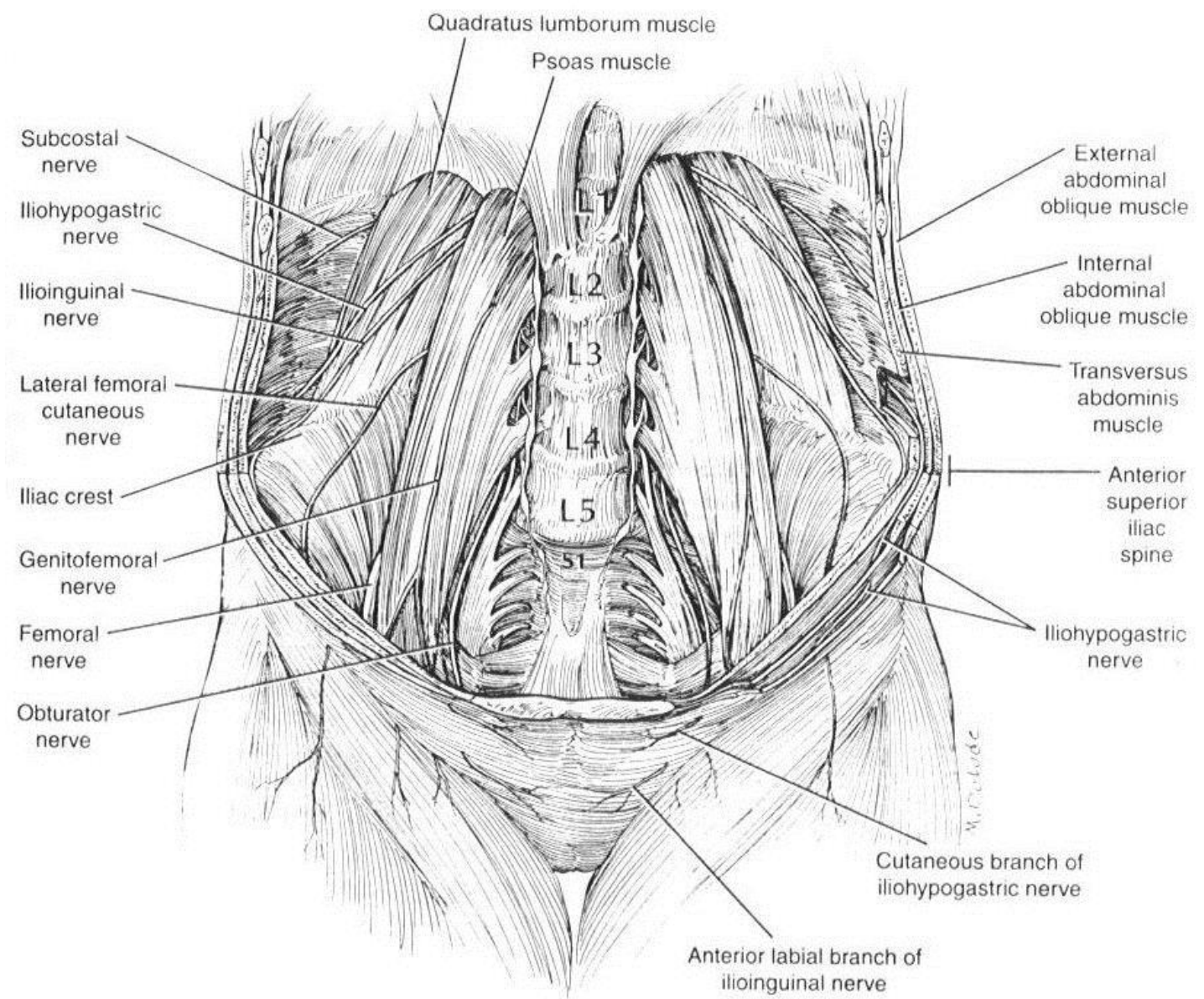

FIGURA 5. Plexo lombar de nervos.

Extraída de STEEGE JF.; MELTZGER, D.A; LEVY, B.B.(Eds) Chronic pelvic pain. An integrated approach. Philadelphia. W.B.Saunders, p.39, 1998. 


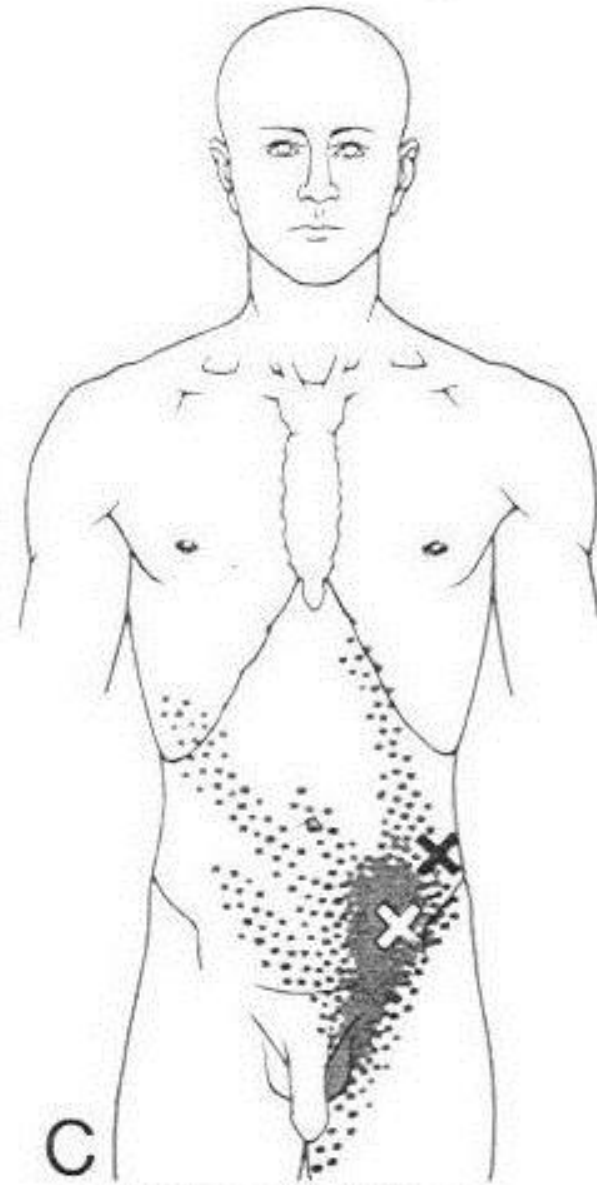

External oblique

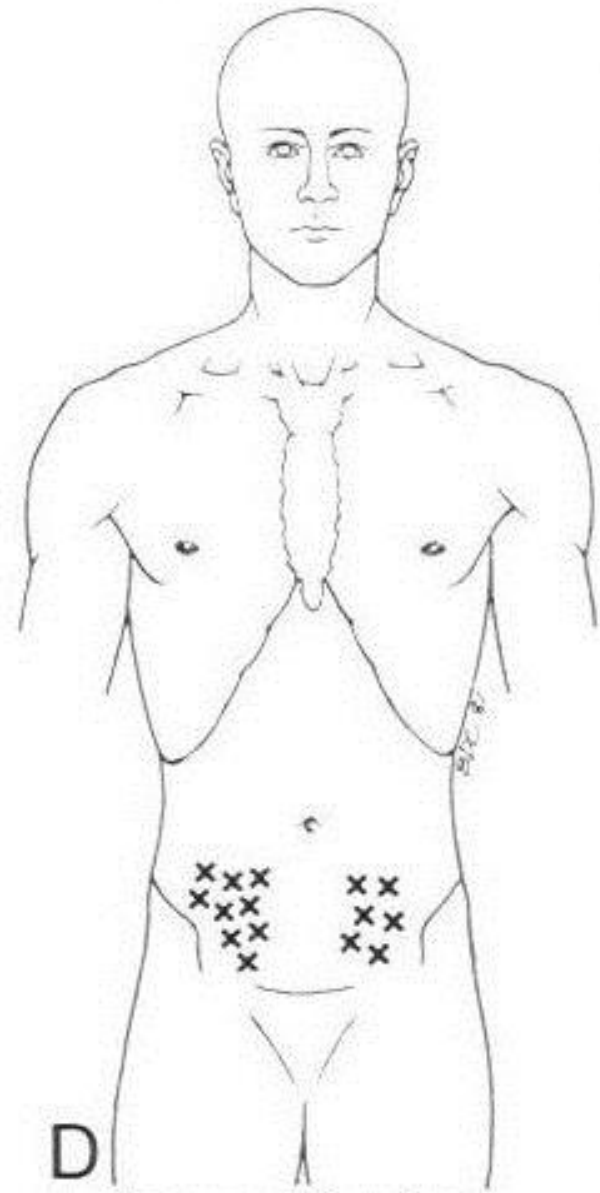

Causes diarrhea

FIGURA 6. PGs no $\mathrm{m}$. obliquo externo.

Extraída de TRAVEL J.G.; SIMONS D.G., Miofascial pain and dysfunction: The trigger point manual. Baltimore, Williams and Wilkins, vol. 01, p.638, 1992. 

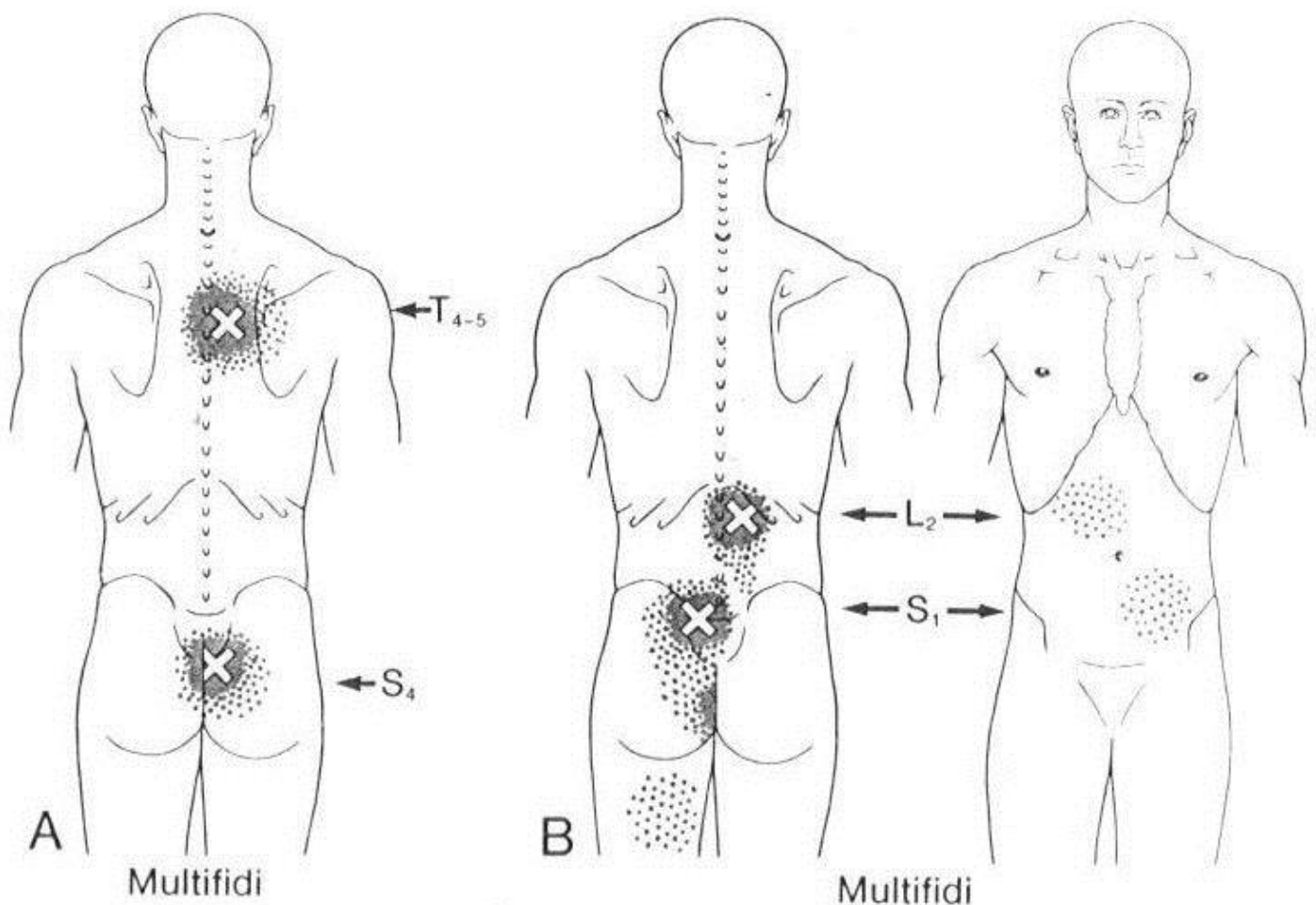

FIGURA 7. PGs no m. multifídio.

Extraída de TRAVEL J.G.; SIMONS D.G., Miofascial pain and dysfunction: The trigger point manual. Baltimore, Williams and Wilkins, vol. 01, p.639, 1992. 

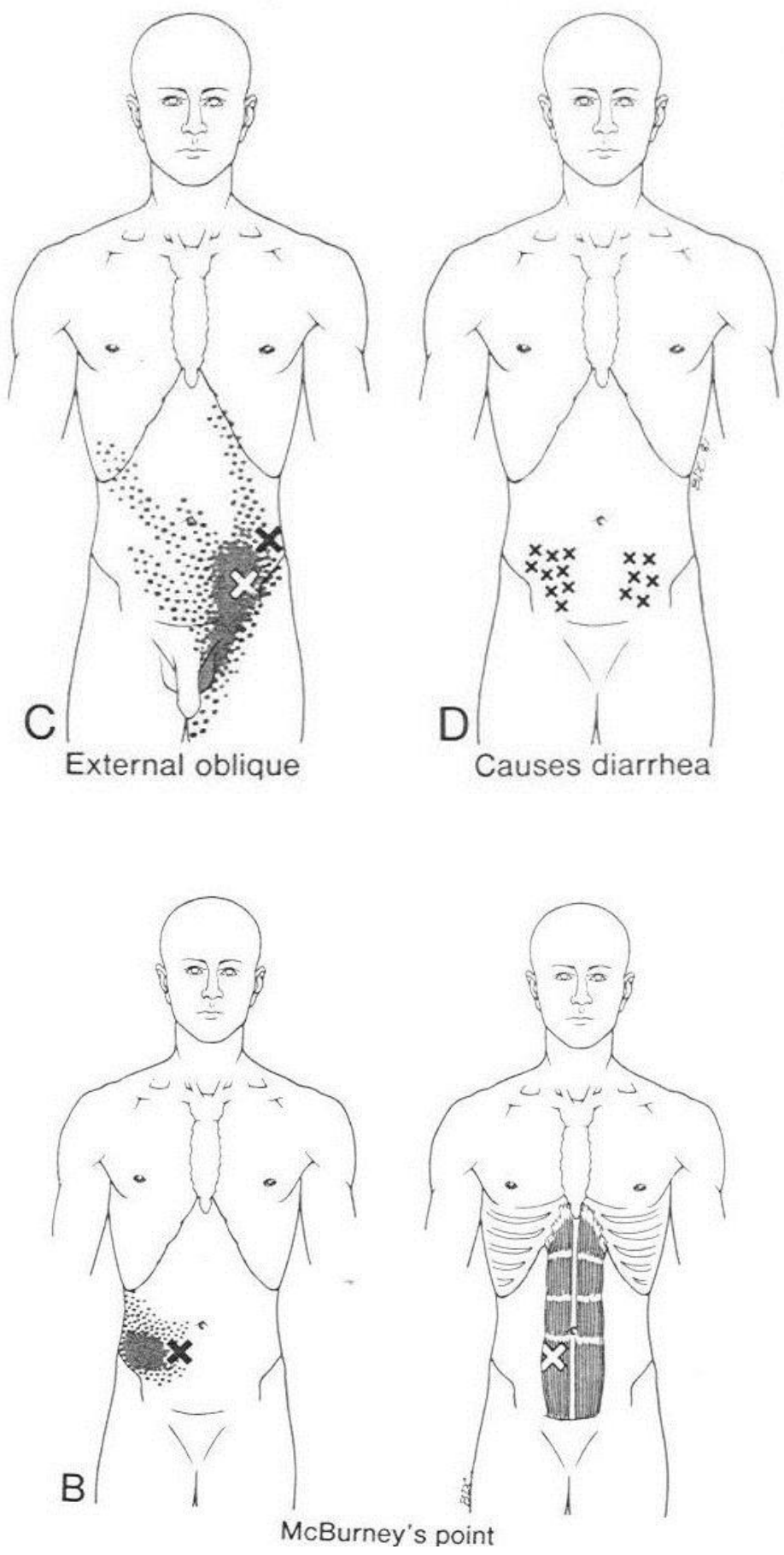

FIGURA 8. PGs no $\mathrm{m}$. reto abdominal.

Extraída de TRAVEL J.G.; SIMONS D.G., Miofascial pain and dysfunction: The trigger point manual. Baltimore, Williams and Wilkins, vol. 01, p.662, 1992. 


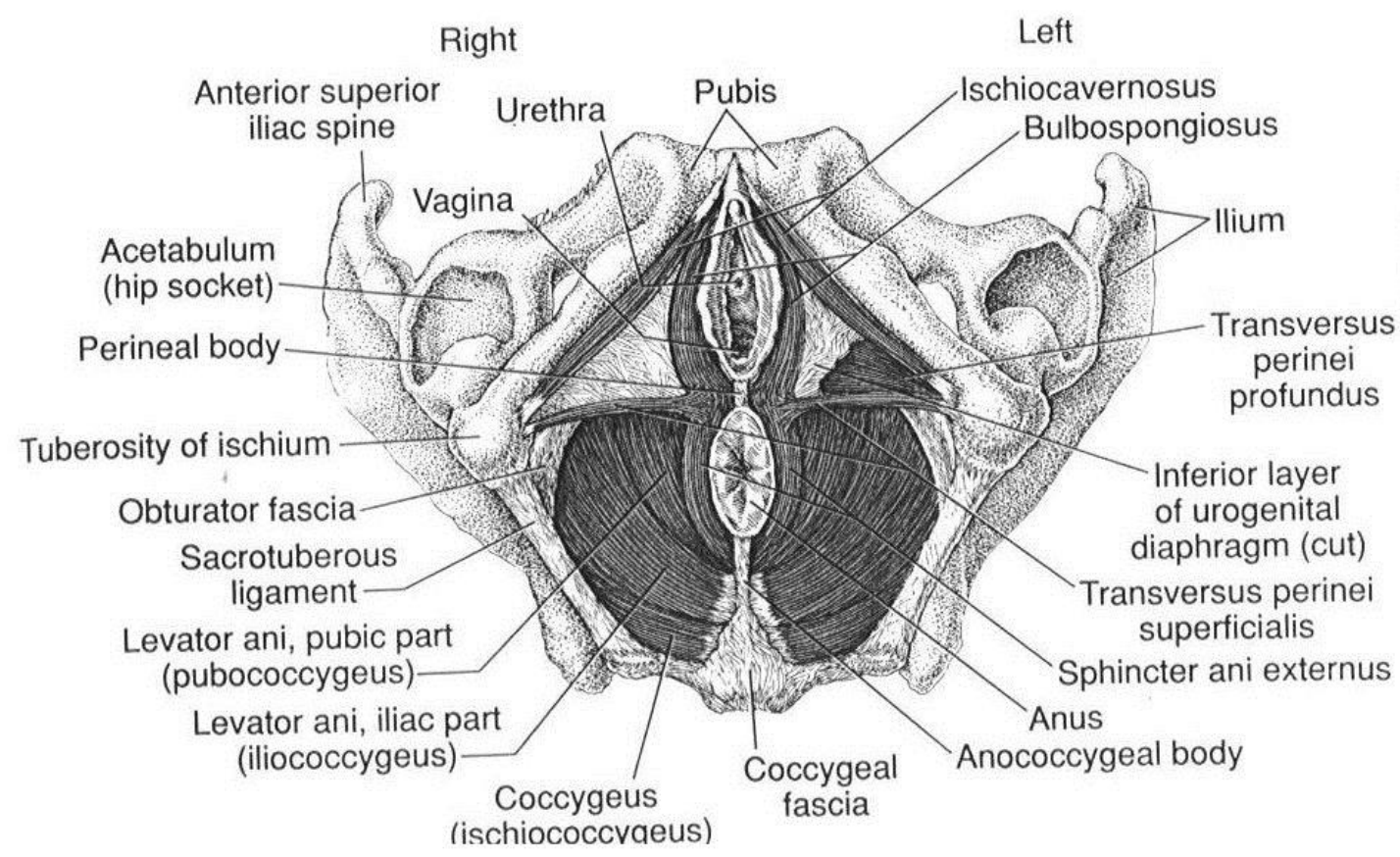

FIGURA 9. Músculos na pelve feminina (visão inferior).

Extraída de TRAVEL J.G.; SIMONS D.G., Miofascial pain and dysfunction: The trigger point manual. Baltimore, Williams and Wilkins, vol. 01, p.664, 1992. 


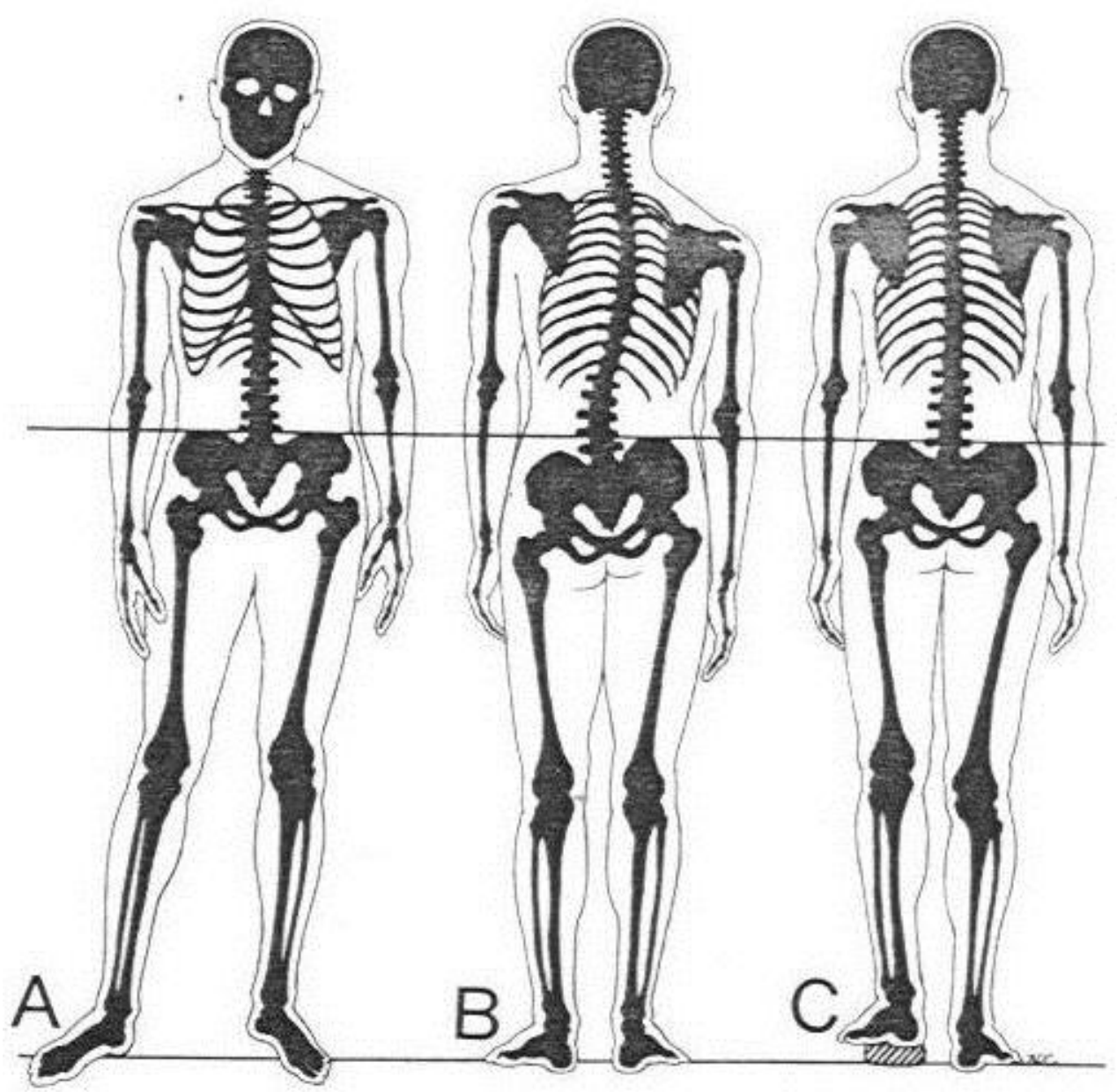

FIGURA 10. Alterações posturais da coluna vertebral.

Extraída de TRAVEL J.G.; SIMONS D.G., Miofascial pain and dysfunction: The trigger point manual. Baltimore, Williams and Wilkins, vol. 02, p.113, 1992. 
9. ANEXOS 


\section{ANEXO 1}

\section{CENTRO INTERDISCIPLINAR DE DOR DA CLÍNICA NEUROLÓGICA DO HC-FMUSP FICHA DE AVALIAÇÃO MÉDICA}

1.1 IDENTIFICAÇÃO

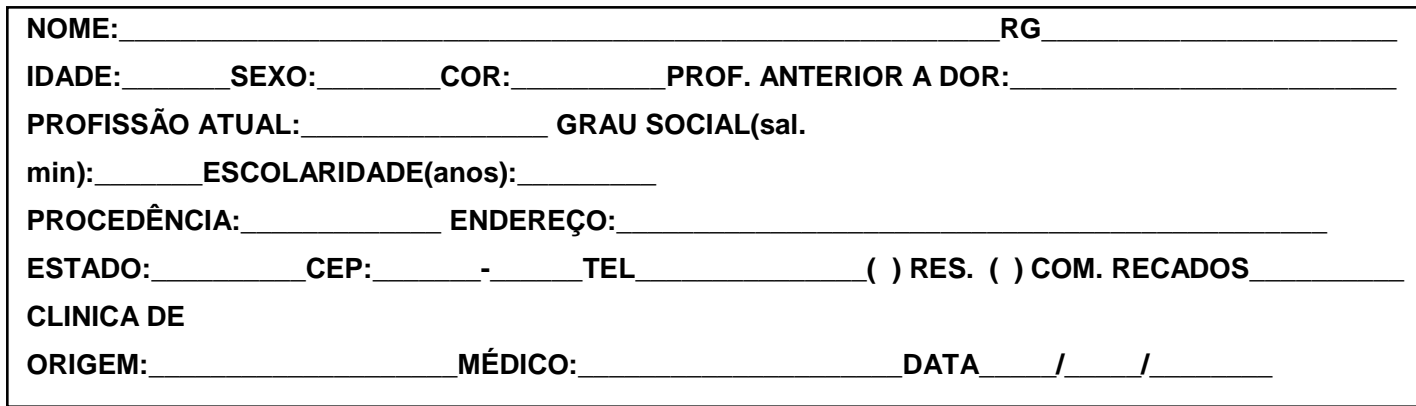

1.2 DIAGNÓSTICOS (Descrever o diagnóstico):

\begin{tabular}{||l|l||l||}
\hline 1.2.1. PRINCIPAL & $\mathbf{1 . 2 . 2 .}$ SECUNDÁRIO & $\mathbf{1 . 2 . 3}$ OUTROS DIAGNÓSTICOS \\
1.2 .1 .1 ( ) Artropatia degenerativa & 1.2 .2 .1 ( ) Actínica & 1.2 .3 .1 \\
1.2 .1 .2 ( ) Artropatia inflamatória & 1.2 .2 .2 ( ) Degenerativa & 1.2 .3 .2 \\
1.2 .1 .3 ( ) Encefálica & 1.2 .2 .3 ( ) Funcional & 1.2 .3 .3 \\
1.2 .1 .4 ( ) Mielopática & 1.2 .2 .4 ( ) Infecciosa & 1.2 .3 .4 \\
1.2 .1 .5 ( ) Neuropatica periférica & 1.2 .2 .5 ( ) Inflamatória & 1.2 .3 .5 \\
1.2 .1 .6 ( ) Oncológica & 1.2 .2 .6 ( ) Metabólica & \\
1.2 .1 .7 ( ) Sindrome dolorosa miofascial & 1.2 .2 .7 ( ) Neoplásica & \\
1.2 .1 .8 ( ) sindrome fibromiálgica & 1.2 .2 .8 ( ) Tóxica & \\
1.2 .1 .9 ( ) Traumática & 1.2 .2 .9 ( ) Traumática & \\
1.2 .1 .10 ( ) Visceral & 1.2 .2 .10 ( ) Vascular & \\
1.2 .1 .11 ( ) Outras & 1.2 .2 .11 ( ) Outras & \\
\hline
\end{tabular}

1.3 HISTÓRICO

QD:

HMA: 
1.4 ANTECEDENTES Para aferir os dados utilize, quando aplicável, a seguinte codificação: x - Aplicável 0 - Não aplicável

\begin{tabular}{|c|c|c|c|}
\hline 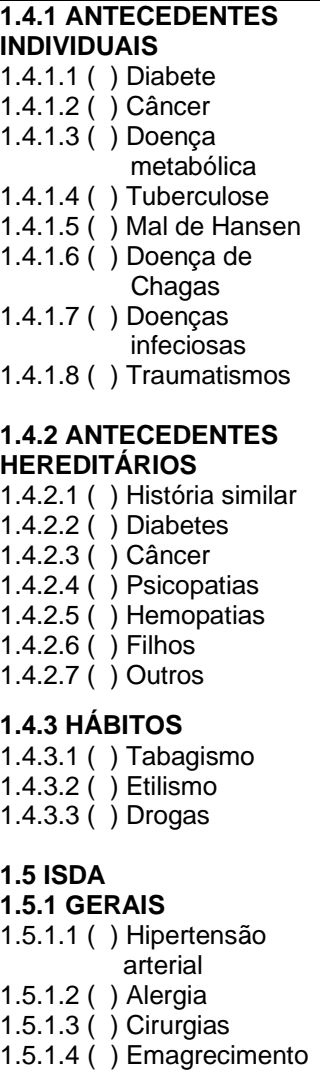 & 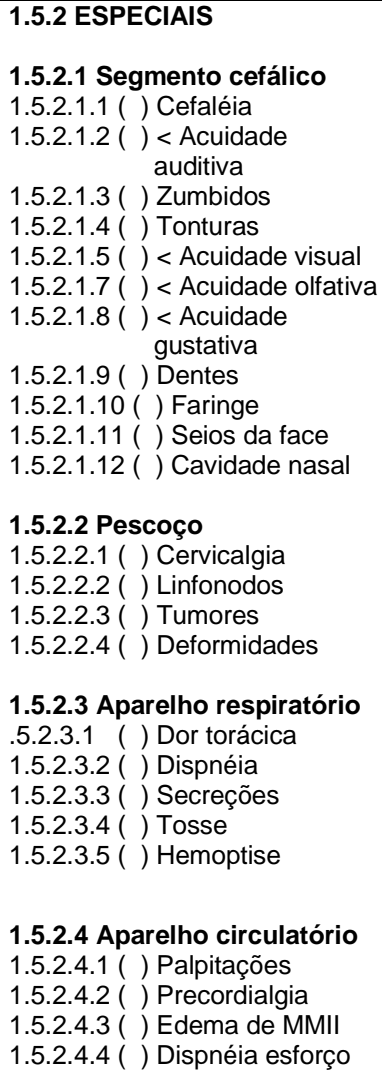 & 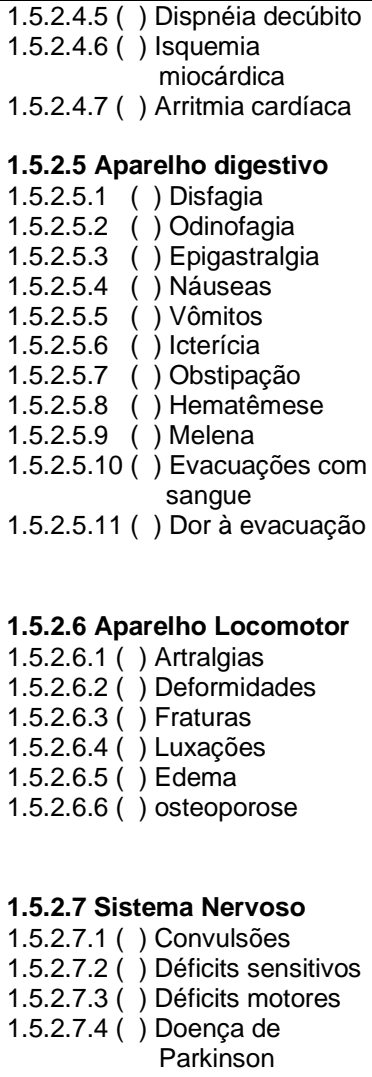 & 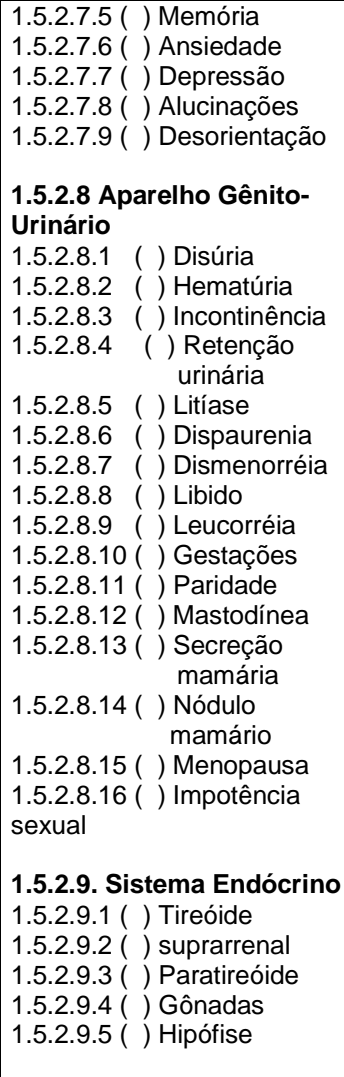 \\
\hline
\end{tabular}

\section{QUADRO DOLOROSO}

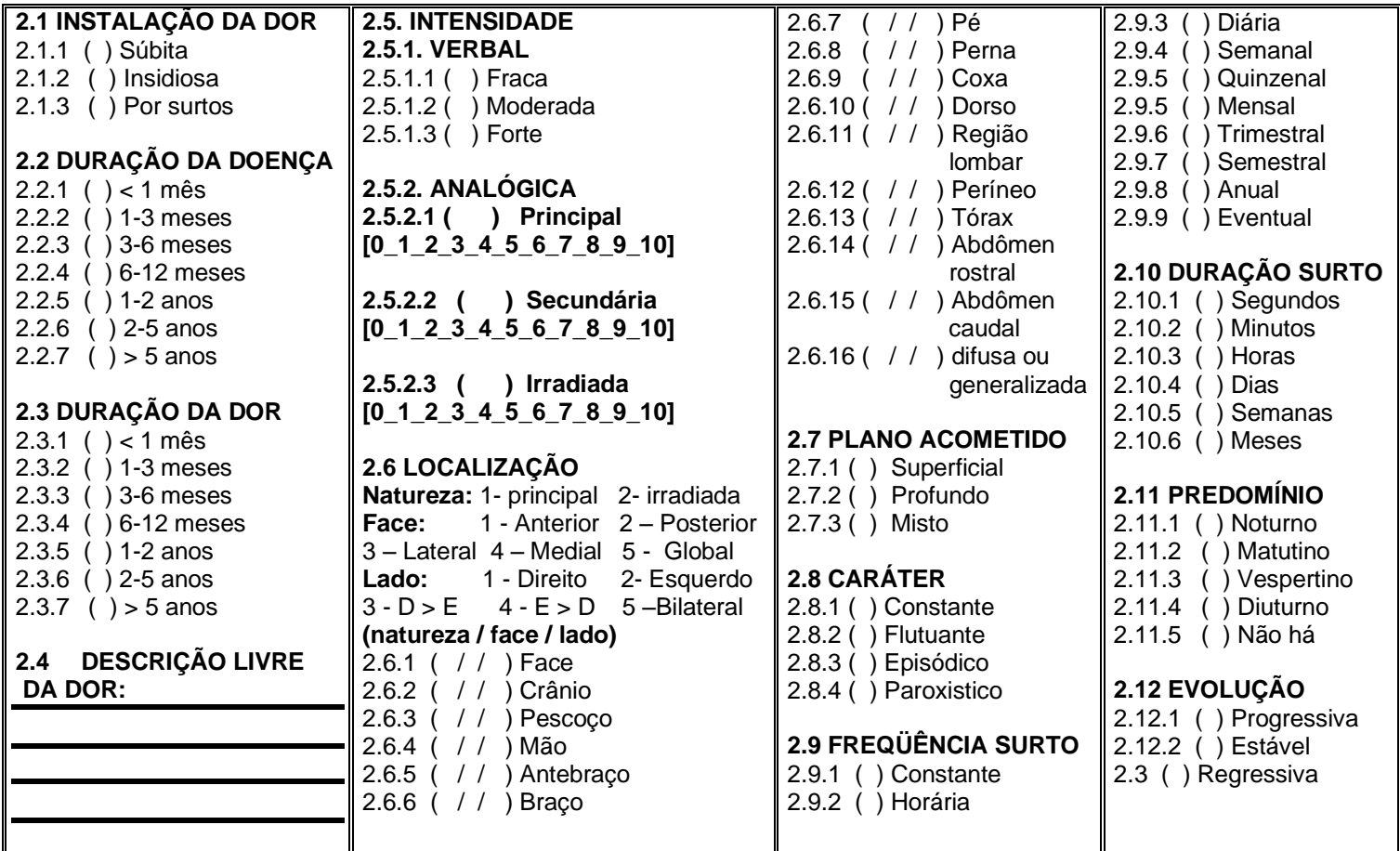


2.12.3 PADRÃO DA DOR. Questionário de Dor McGill. Escolha dentre estas, as expressões que melhor descrevam sua dor atual. Assinale, no máximo, uma expressão de cada grupo. Não assinale palavras que não se aplicam.

SENSITIVOS (1-10); AFETIVOS (11-15); AVALIATIVOS (16); MISCELÂNEA (17-20).

\begin{tabular}{|c|c|c|c|c|c|}
\hline 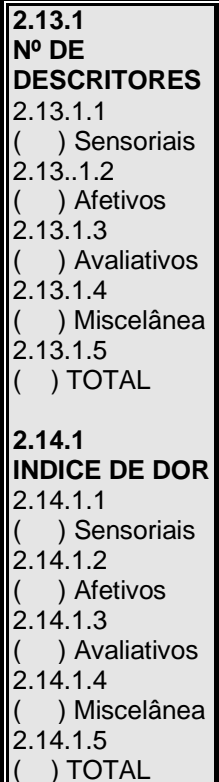 & 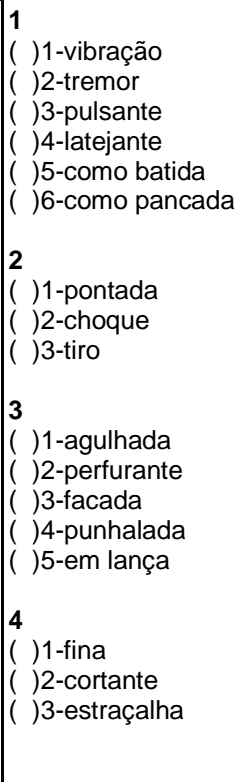 & $\begin{array}{l}5 \\
\text { ( )1-beliscão } \\
\text { ( )2-aperto } \\
\text { ( )3-mordida } \\
\text { ( )4-cólica } \\
\text { ( )5-esmagamento } \\
6 \\
\text { ( )1-fisgada } \\
\text { ( )2-puxão } \\
\text { ( )3-em torção } \\
7 \\
\text { ( )1-calor } \\
\text { ( )2-queimação } \\
\text { ( )3-fervente } \\
\text { ( )4-em brasa } \\
8 \\
\text { ( )1-formigamento } \\
\text { ( )2-coceira } \\
\text { ( )3-ardor } \\
\text { ( )4-ferroada }\end{array}$ & $\begin{array}{l}9 \\
\text { ( )1-mal localizada } \\
\text { ( )2-dolorida } \\
\text { ( )3-machucada } \\
\text { ( )4-doída } \\
\text { ( )5-pesada } \\
10 \\
\text { ( )1-sensível } \\
\text { ( )2-esticada } \\
\text { ( )3-esfolante } \\
\text { ( )4-rachando } \\
11 \\
\text { ( )1-cansativa } \\
\text { ( )2-exaustiva } \\
12 \\
\text { ( )1-enjoada } \\
\text { ( )2-sufocante }\end{array}$ & $\begin{array}{l}13 \\
\text { ( )1-castigante } \\
\text { ( )2-atormenta } \\
\text { ( )3-cruel } \\
14 \\
\text { ( )1-amedrontadora } \\
\text { ( )2-apavorante } \\
\text { ( )3-aterrorizante } \\
\text { ( )4-maldita } \\
\text { ( )5-mortal } \\
15 \\
\text { ( )1-miserável } \\
\text { ( )2-enloquecedora } \\
\text { 16 } \\
\text { ( )1-chata } \\
\text { ( )2-que incomoda } \\
\text { ( )3-desgastante } \\
\text { ( )4-forte } \\
\text { ( )5-insuportável }\end{array}$ & $\begin{array}{l}17 \\
\text { ( )1-espalha } \\
\text { ( )2-irradia } \\
\text { ( )3-penetra } \\
\text { ( )4-atravessa } \\
18 \\
\text { ( )1-aperta } \\
\text { ( )2-adormece } \\
\text { ( )3-repuxa } \\
\text { ( )4-espreme } \\
\text { ( )5-rasga } \\
\text { 19 } \\
\text { ( )1-fria } \\
\text { ( )2-gelada } \\
\text { ( )3-congelante } \\
\text { 20 } \\
\text { ( )1-aborrecida } \\
\text { ( )2-dá náusea } \\
\text { ( )3-agonizante } \\
\text { ( )4-pavorosa } \\
\text { ( )5-torturante }\end{array}$ \\
\hline
\end{tabular}

\begin{tabular}{|c|c|c|}
\hline 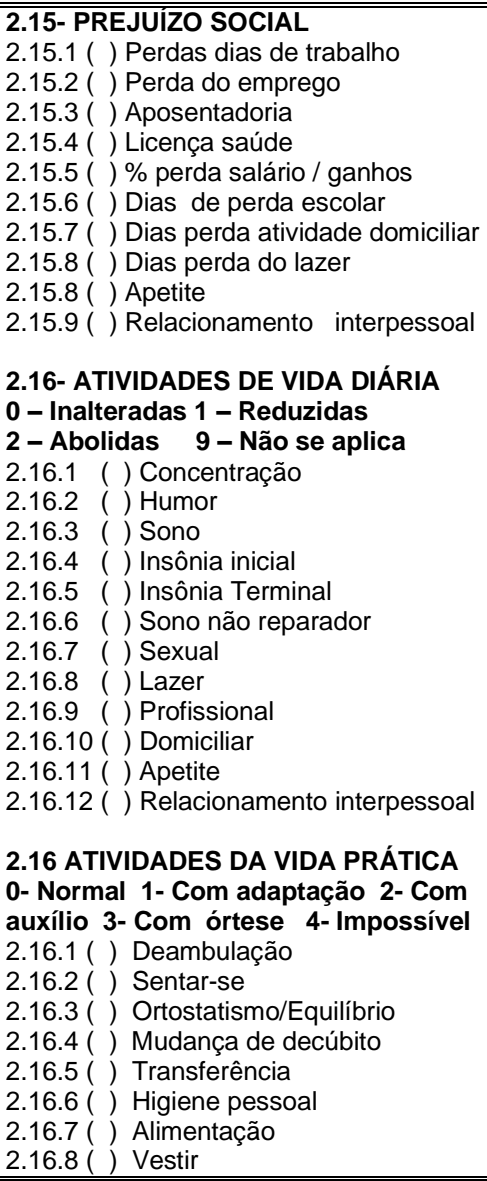 & 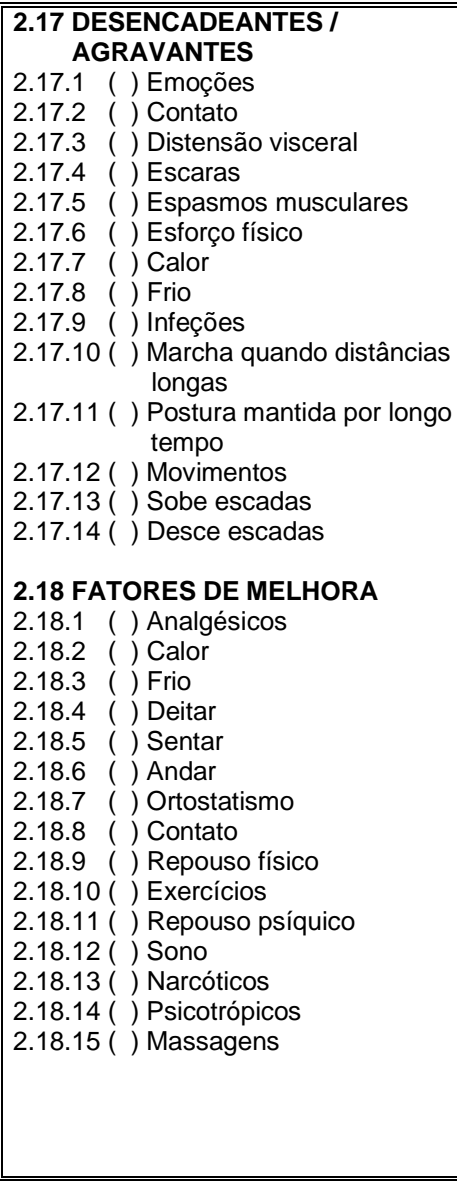 & $\begin{array}{l}\text { 2.19 TRATAMENTOS PRÉVIOS DA DOR } \\
\text { 1- Ineficaz 2- Regular 3- Bom } \\
\text { 4-Excelente } \\
\text { 5- Eficaz sem efeitos adversos } \\
\text { 6- Ineficaz c / efeitos adversos } \\
2.19 .1 \text { ( ) AINH } \\
2.19 .2 \text { ( ) Corticosteróides } \\
2.19 .3 \text { ( ) Narcóticos } \\
2.19 .4 \text { ( ) Antidepressivos } \\
2.19 .5 \text { ( ) Fenotiazinas } \\
2.19 .6 \text { ( ) Diazepínicos } \\
2.19 .7 \text { ( ) Anticonvulsivantes } \\
2.19 .8 \text { ( ) Baclofeno } \\
2.19 .9 \text { ( ) Miorrelaxantes } \\
2.19 .10 \text { ( ) Fisiatria } \\
2.19 .11 \text { ( ) Infiltrações } \\
2.19 .12 \text { ( ) Acupuntura } \\
2.19 .13 \text { ( ) Estimulação transcutânea } \\
2.19 .14 \text { ( ) Estimulação medular } \\
2.19 .14 \text { ( ) Estimulação encefálica } \\
2.19 .16 \text { ( ) Narcóticos intratecais } \\
2.19 .17 \text { ( ) Neurotomias } \\
2.19 .18 \text { ( ) Rizotomias } \\
2.19 .19 \text { ( ) DREZ } \\
2.19 .21 \text { ( ) Cordotomia } \\
2.19 .22 \text { ( ) Mielotomia } \\
2.19 .23 \text { ( ) Mesencefalotomia } \\
2.19 .24 \text { ( ) Talamotomia } \\
2.19 .25 \text { ( ) Cingulotomia } \\
2.19 .26 \text { ( ) Hipotalamotomia } \\
2.19 .27 \text { ( ) Outros agentes intrarraque } \\
2.19 .28 \text { ( ) Infiltração ponto-gatilho } \\
2.19 .29 \text { ( ) Psicoterapia } \\
2.19 .30 \text { ( ) Cirúrgico } \\
2.19 .31 \text { ( ) Radioterápico } \\
2.19 .32 \text { ( ) Quimioterápico } \\
2.19 .33 \text { ( ) Hormonioterápico } \\
2.19 .34 \text { ( ) Imunoterápico } \\
2.19 .35 \text { ( ) Outros } \\
\end{array}$ \\
\hline
\end{tabular}




\begin{tabular}{|c|c|c|}
\hline $\begin{array}{l}\text { 2.20 GRAU FUNCIONAL } \\
\text { 2.21.1 ( ) Sem dor } \\
\text { 2.21.2 ( ) Sem dor com AINH ou } \\
\text { esteróides } \\
\text { 2.21.3 ( ) Sem com } 2+\text { psicotrópicos } \\
\text { 2.21.4 ( ) Sem dor com 2 + 3 + } \\
\text { psicotrópicos } \\
\text { 2.21.5 ( ) Com dor com } 2+3+4 \\
\text { OBS: } \\
\text { 2.21 TRATAMENTO DA DOENÇA } \\
\text { PRIMÁRIA } \\
\text { 1. Sem intercorrências } \\
\text { 2. Com intercorrências } \\
\text { 2.21.1 ( ) Fisioterapia } \\
\text { 2.21.2 ( ) Psicoterapia } \\
\text { 2.21.3 ( ) Acupuntura } \\
\text { 2.21.4 ( ) Medicina alternativa } \\
\text { 2.22 AUTO-INTERPRETAÇÃo } \\
\text { 2.22.1- Devido a sua saúde, você tem } \\
\text { dificuldade para fazer atualmente } \\
\text { essas atividades durante um dia } \\
\text { comum nas últimas } 4 \text { semanas? } \\
\text { 1- Dificulta muito } \\
\text { 2- Dificulta Um pouco } \\
\text { 3- Não dificulta de modo algum } \\
\text { 4- Não aplicável } \\
\text { ( ) Atividades vigorosas (correr, } \\
\text { levantar objetos pesados, esportes } \\
\text { árduos) } \\
\text { ( ) Atividades moderadas (mover uma } \\
\text { mesa, jogar bola, varrer a casa) } \\
\text { ( ) Levantar ou carregar mantimentos } \\
\text { ( ) Subir vários lances de escada } \\
\text { ( ) Subir um lance de escada } \\
\text { ( ) Curvar-se, ajoelhar-se ou dobrar-se } \\
\text { ( ) andar mais que } 1 \text { quilômetro } \\
\text { ( ) Andar vários quarteirões } \\
\text { ( ) Andar um quarteirão } \\
\text { alguma atividade diária nas últimas } \\
\text { ( ) Tomar banho ou vestir-se } \\
\text { 1- Sim semanas? } \\
\text { 2.22.2- Devido a sua saúde física, } \\
\text { você teve algum dos Seguintes } \\
\text { ( ) Você diminuiu a quantidade de } \\
\text { tempo que dedicava a seu } \\
\text { trabalho ou a outras atividades? } \\
\text { ( ) Realizou menos tarefas do que } \\
\text { você gostaria? } \\
\text { ( ) Esteve limitado no seu tipo de } \\
\text { trabalho ou outras atividades? } \\
\text { ( ) Teve dificuldade ou oute de fazer seu } \\
\text { (pessitou atividadesforço extra)? }\end{array}$ & $\begin{array}{l}\text { 2.22.3- Devido a alguma anormalidade } \\
\text { emocional (como sentir-se deprimido } \\
\text { ou ansioso), você teve algum dos } \\
\text { seguintes problemas com o seu } \\
\text { trabalho ou outra atividade regular } \\
\text { diária nas últimas quatro semanas? } \\
\text { 1 - Sim - Não } \\
\text { ( ) Você diminuiu a Quantidade de tempo } \\
\text { que se dedicava ao seu trabalho como } \\
\text { geralmente faz? } \\
\text { ( ) Realizou menos tarefa do que você } \\
\text { gostaria? } \\
\text { ( ) Não trabalhou ou não fez qualquer } \\
\text { das atividades com tanto cuidado } \\
\text { como geralmente faz? } \\
\text { 2.22.4- Dê uma resposta que mais se } \\
\text { aproxime da maneira como você se } \\
\text { sente nas últimas } 4 \text { semanas. } \\
\text { 1- Todo tempo } \\
\text { 2- Maior parte do tempo } \\
\text { 3- Alguma parte do tempo } \\
\text { 4- Pequena parte do tempo } \\
\text { 5- Nunca } \\
\text { ( ) Quanto tempo você se sente cheio de } \\
\text { vigor, cheio de vontade, cheio de } \\
\text { força? } \\
\text { ( ) Quanto tempo você tem se sentido } \\
\text { uma pessoa muito nervosa? } \\
\text { ( ) Quanto tempo você tem se sentido } \\
\text { tranqüilo? } \\
\text { ( ) Quanto tempo você tem se sentido } \\
\text { desanimado? } \\
\text { 2.22.5- O Quanto é verdadeiro ou falso } \\
\text { cada uma das afirmações para você? } \\
\text { 1- Verdadeiro } \\
\text { 2- Não sei } \\
\text { 3- Falsa } \\
\text { ( ) Eu costumo adoecer um pouco mais } \\
\text { facilmente que as outras pessoas } \\
\text { ( ) Eu sou tão saudável quanto qualquer } \\
\text { pessoa que eu conheço } \\
\text { ( ) Eu acho que a minha saúde vai piorar } \\
\text { ( ) Minha saúde é excelente } \\
\text { 2.22.6- Em geral, você diria que sua } \\
\text { saúde é } \\
\text { ( ) Excelente } \\
\text { ( ) Muito boa } \\
\text { ( ) Boa } \\
\text { ( ) Ruim } \\
\text { ( ) Muito Ruim }\end{array}$ & $\begin{array}{l}\text { 2.22.7- Comparada há um ano } \\
\text { atrás, como você classifica sua } \\
\text { saúde em geral, agora? } \\
\text { ( ) Muito melhor agoira do que há } \\
\text { um ano atrás } \\
\text { ( ) Um pouco melhor agoira do que } \\
\text { há um ano atrás } \\
\text { ( ) Quase a mesma de um ano } \\
\text { atrás } \\
\text { ( ) Um pouco pior agora do que há } \\
\text { um ano atrás } \\
\text { ( ) Muito pior agora do que há um } \\
\text { ano atrás } \\
\text { 2.22.8- Quanta dor no corpo você } \\
\text { teve durante as últimas quatro } \\
\text { semanas } \\
\text { ( ) Nenhuma } \\
\text { ( ) Muito leve } \\
\text { ( ) Leve } \\
\text { ( ) Moderada } \\
\text { ( ) Grave } \\
\text { ( ) Muito grave } \\
\text { 2.22.9- De que maneira sua saúde } \\
\text { física ou problemas emocionais } \\
\text { interfeririam nas suas atividades } \\
\text { sociais normais, em relação a } \\
\text { família, vizinhos, amigos ou em } \\
\text { grupo nas últimas quatro semanas? } \\
\text { ( ) De forma nenhuma } \\
\text { ( ) Ligeiramente } \\
\text { ( ) Moderadamente } \\
\text { ( ) Bastante } \\
\text { ( ) Extremamente } \\
\text { 2.22.10- Quanto a dor interferiu } \\
\text { com o seu trabalho normal } \\
\text { (incluindo trabalho fora e dentro de } \\
\text { casa) nas últimas quatro semanas? } \\
\text { ( ) De maneira alguma } \\
\text { ( ) Um pouco } \\
\text { ( ) Moderadamente } \\
\text { ( ) Bastante } \\
\text { ( ) Extremamente }\end{array}$ \\
\hline
\end{tabular}




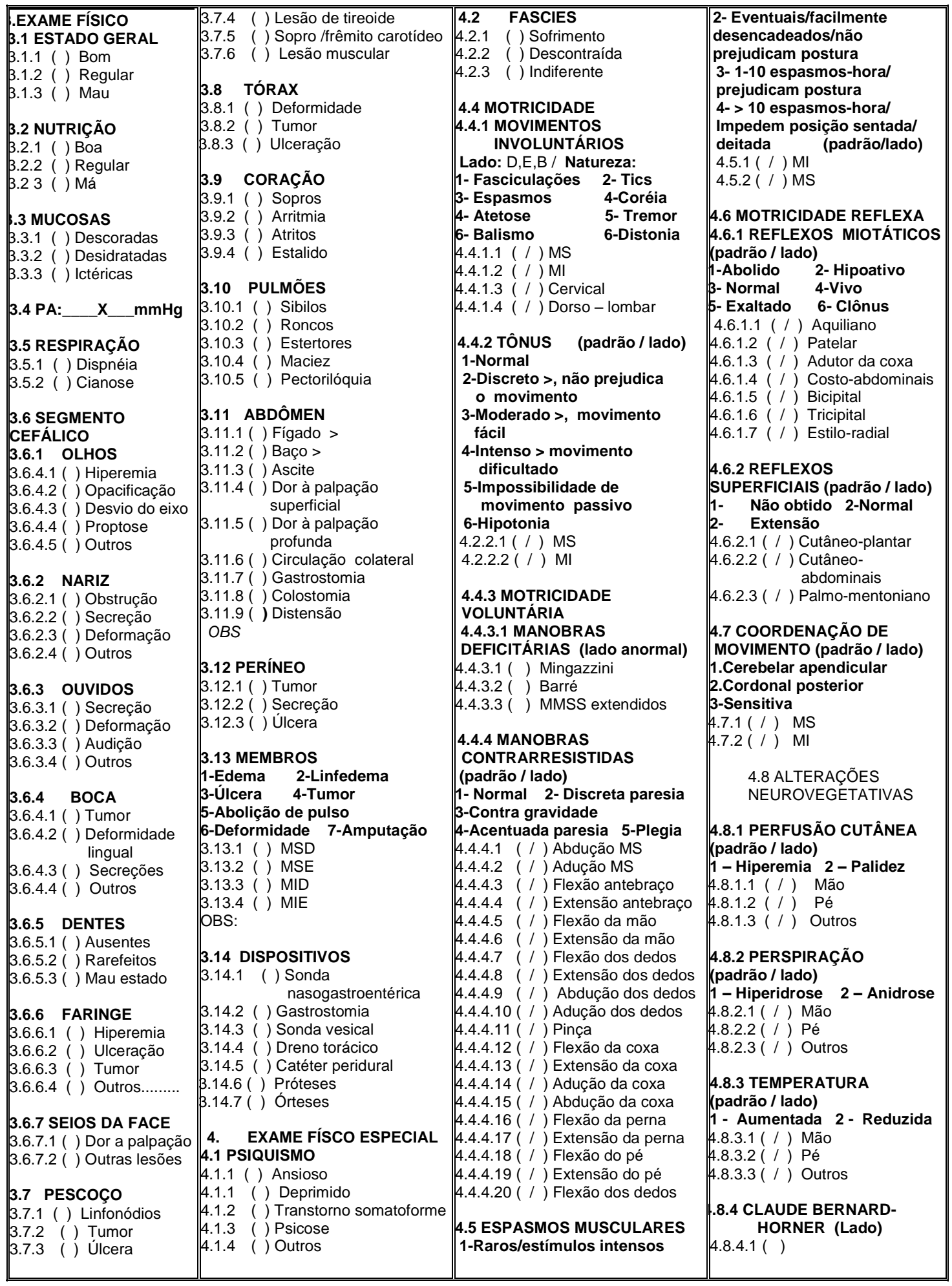




\begin{tabular}{|c|c|c|c|}
\hline 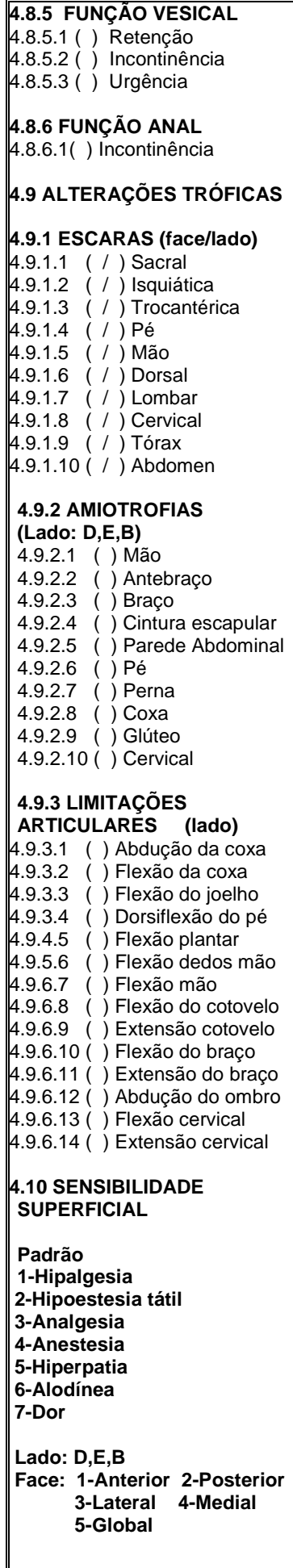 & 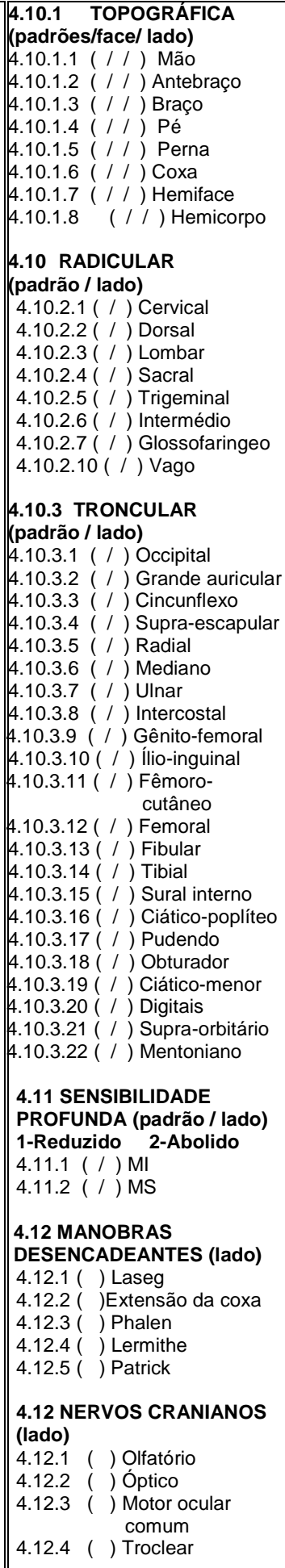 & 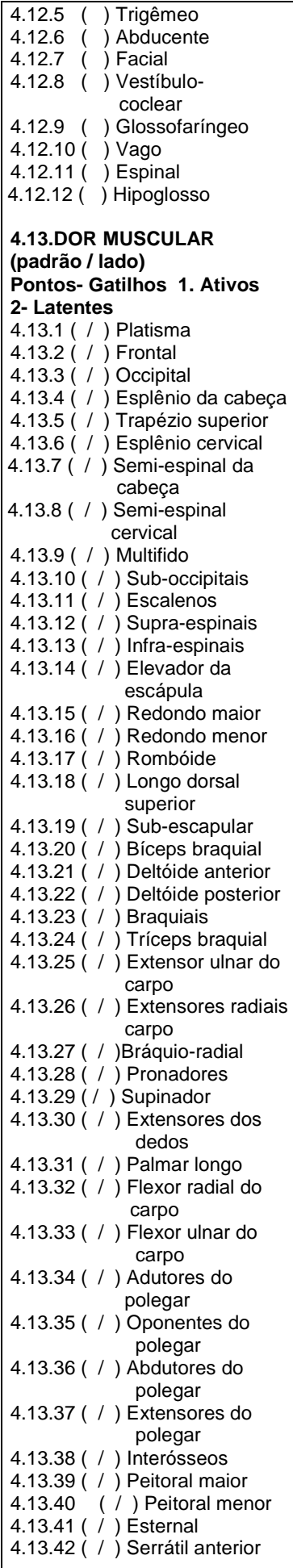 & 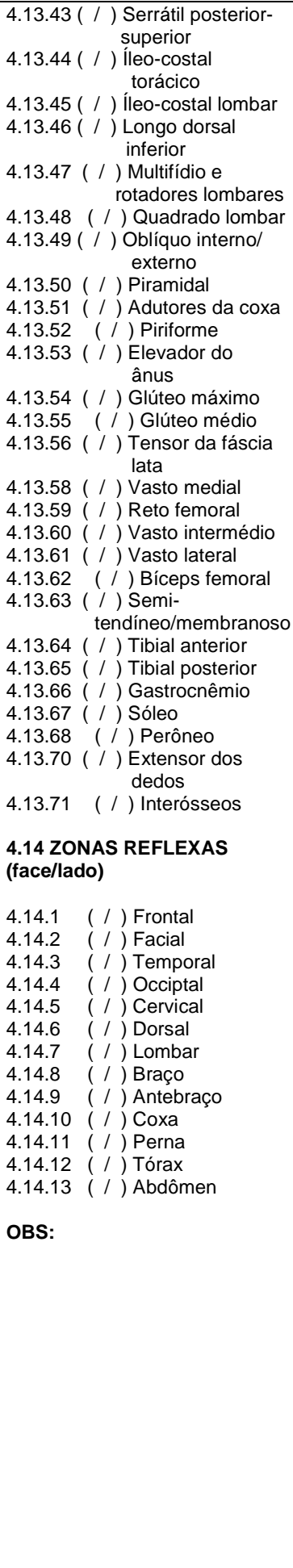 \\
\hline
\end{tabular}



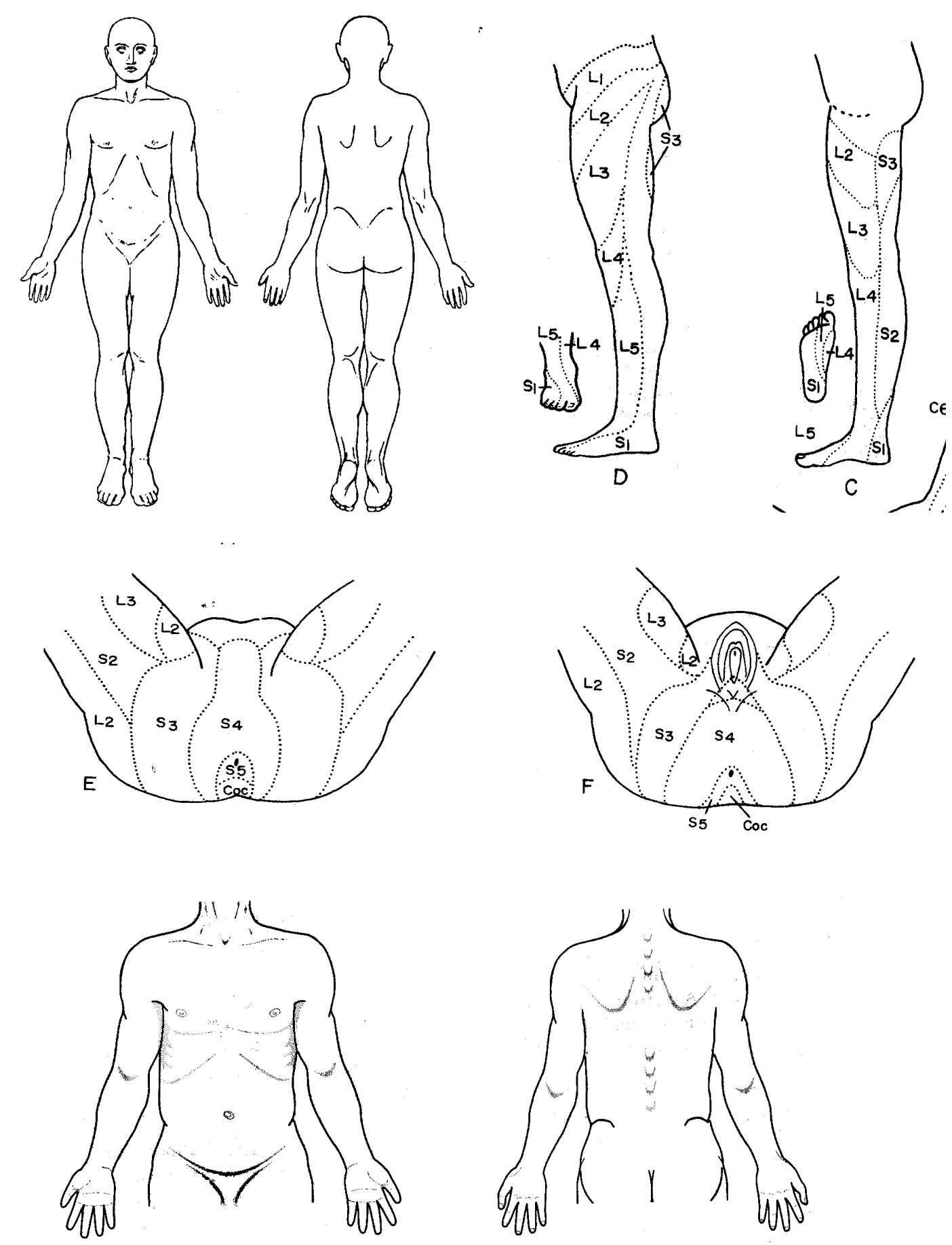

Hipalgesia:

Hipostesia:

Analgesia: $=======$ Anestesia: 000000 


\begin{tabular}{|c|c|c|c|}
\hline 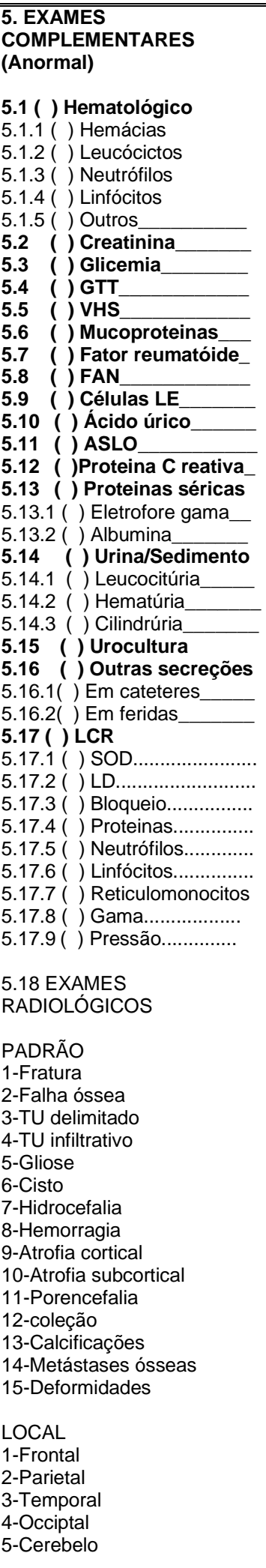 & 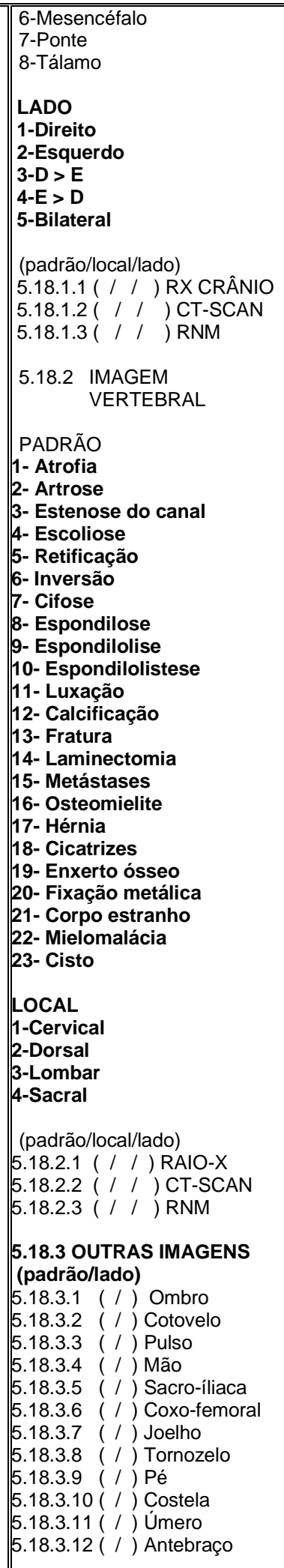 & 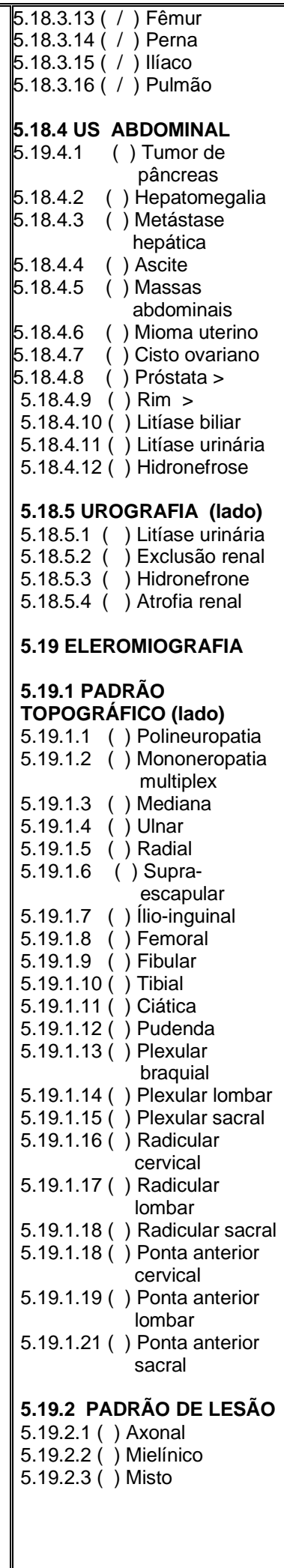 & 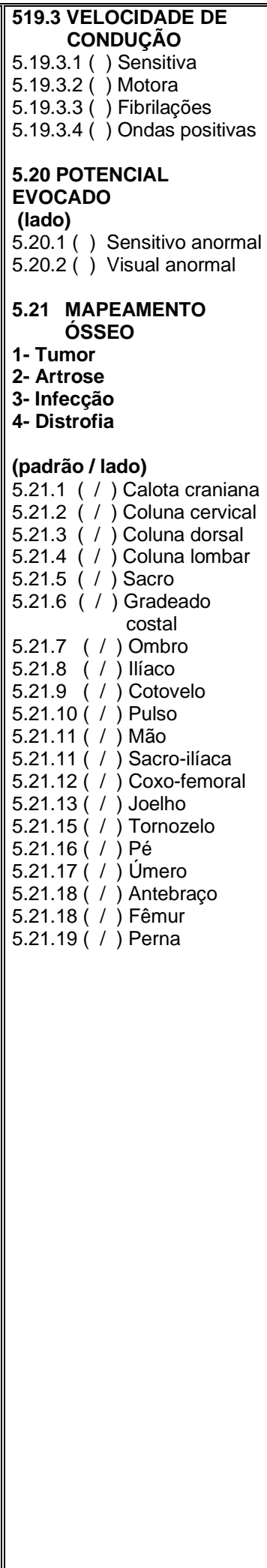 \\
\hline
\end{tabular}


Diagnóstico

\begin{tabular}{|c|c|c|c|c|c|c|}
\hline DATA: & & & & & & \\
\hline 6.0.1SIUAÇĀO GERAL & $\begin{array}{l}\text { 6.0.1.1( ) Melhor } \\
6 \cdot 0.1 .2(\text { ) lgual } \\
\end{array}$ & 6.0.1.3 ( ) Pior & $\begin{array}{l}\text { 6.0.1.1( ) Melhor } \\
6.0 .1 .2(\text { ) Igual } \\
\end{array}$ & S.0.1.3 ( ) Pior & $\begin{array}{l}6.0 .1 .1(\text { ) Melhor } \\
6.0 .1 .2() \text { Igual } \\
\end{array}$ & 0.1.3 ( ) Pior \\
\hline 6.0.1.2 INTENSIDADE & (0-- & 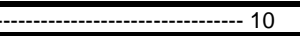 & 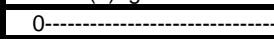 & 10 & (1) & ---10 \\
\hline $\begin{array}{l}\text { 6.1 McGill resumido } \\
\text { Assinale apenas as } \\
\text { expressões que melhor } \\
\text { caracterize a sua dor } \\
\text { 6.1.1 E.A Verbal: } \\
\text { 1-Fraca 2- Moderada } \\
\text { 3- Forte 4-Insuportável }\end{array}$ & $\begin{array}{ll}6.1 .1 & \text { ( ) Latejante } \\
6.1 .2 & (\text { ) Pontada } \\
6.1 .3 & \text { () Choque } \\
6.1 .4 & (\text { ) Agulhada } \\
6.1 .5 & \text { ( ) Fina } \\
6.1 .6 & \text { ( ) Fisgada } \\
6.1 .7 & \text { ( ) Queimação }\end{array}$ & 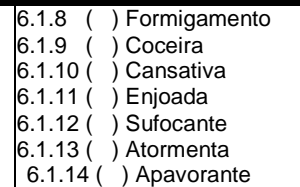 & $\begin{array}{ll}6.1 .1 & \text { ( ) Latejante } \\
6.1 .2 & (\text { ) Pontada } \\
6.1 .3 & \text { () Choque } \\
6.1 .4 & \text { () Agulhada } \\
6.1 .5 & \text { ( ) Fina } \\
6.1 .6 & \text { () Fisgada } \\
6.1 .7 & \text { (r) Queimação }\end{array}$ & $\begin{array}{ll}6.1 .8 & \text { ( ) formigamento } \\
6.1 .9 & \text { ( ) Coceira } \\
6.1 .10 & \text { ( ) Cansativa } \\
6.1 .11 & \text { ( ) Enjoada } \\
6.1 .12 & \text { ( ) Sufocante } \\
6.1 .13 & \text { ( ) Atormenta } \\
6.1 .14 & \text { ( ) Apavorante }\end{array}$ & $\begin{array}{ll}6.1 .1 & \text { ( ) Latejante } \\
6.1 .2 & \text { ( ) Pontada } \\
6.1 .3 & \text { ( ) Choque } \\
6.1 .4 & \text { ( ) Agulhada } \\
6.1 .5 & \text { ( ) Fina } \\
6.1 .6 & \text { ( ) Fisgada } \\
6.1 .7 & \text { ( ) Queimação } \\
\end{array}$ & $\begin{array}{ll}6.1 .8 & \text { ( ) Formigamento } \\
6.1 .9 & \text { ( ) Coceira } \\
6.1 .10 & \text { ( ) Cansativa } \\
6.1 .11 & \text { ( ) Enjoada } \\
6.1 .12 & \text { ( ) Sufocante } \\
6.1 .13 & \text { ( ) Atormenta } \\
6.1 .14 & \text { ( ) Apavorante }\end{array}$ \\
\hline 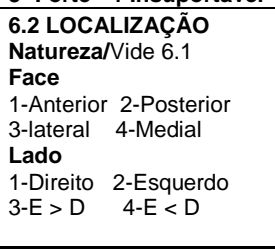 & 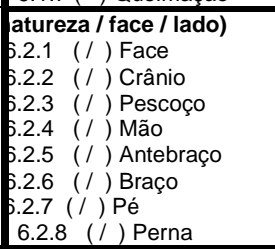 & 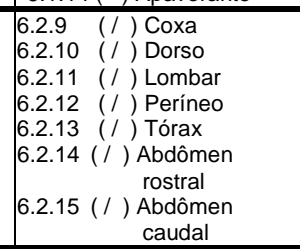 & $\begin{array}{ll}\text { (Natureza / face / lado) } \\
\$ .2 .1 & \text { ( / ) Face } \\
\$ .2 .2 & \text { ( / ) Crânio } \\
\$ .2 .3 & \text { ( / ) Pescoço } \\
\$ .2 .4 & \text { ( / ) Mão } \\
\$ .2 .5 & \text { ( / ) Antebraço } \\
\$ .2 .6 & \text { ( / ) Braço } \\
\$ .2 .7 & \text { ( / ) Pé } \\
6.2 .8 & \text { ( / ) Perna }\end{array}$ & 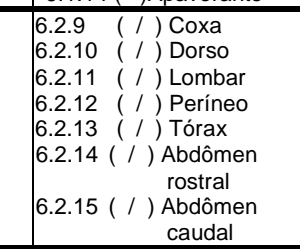 & 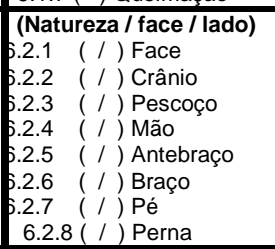 & 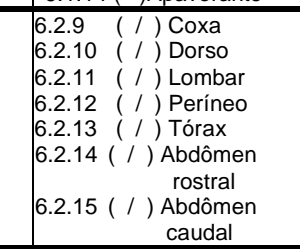 \\
\hline 6.4 CARÁTER & $\begin{array}{l}6.4 .1 \text { ( ) Constante } \\
6.42 \text { () Flutuante }\end{array}$ & $\begin{array}{l}\text { 6.4.3 ( ) Episódico } \\
\text { 6.4.4 () Paroxístico }\end{array}$ & $\begin{array}{l}6.4 .1 \text { ( ) Constante } \\
6.42 \text { ( ) Flutuante }\end{array}$ & $\begin{array}{l}6.4 .3 \text { () Episódico } \\
6.4 .4 \text { ( ) Paroxístico }\end{array}$ & $\begin{array}{l}6.4 .1 \text { ( ) Constante } \\
6.42 \text { ( ) Flutuante }\end{array}$ & $\begin{array}{l}6.4 .3 \text { () Episódico } \\
6.4 .4 \text { ( ) Paroxistico }\end{array}$ \\
\hline 6.5 FREQÜËNCIA & $\begin{array}{ll}6.5 .1 & \text { ( ) Constante } \\
6.5 .2 & \text { () Horária } \\
6.5 .3 & \text { () Diária } \\
6.5 .4 & \text { () Quinzenal } \\
6.5 .5 & \text { () Mensal } \\
\end{array}$ & $\begin{array}{ll}6.5 .6 & \text { () Trimestral } \\
6.5 .7 & \text { () Semestral } \\
6.5 .8 & \text { () Anual } \\
6.5 .9 & \text { () Trianual } \\
6.5 .11 & \text { ( ) Eventual } \\
\end{array}$ & $\begin{array}{ll}6.5 .1 & \text { ( ) Constante } \\
6.5 .2 & \text { () Horária } \\
6.5 .3 & \text { () Diária } \\
6.5 .4 & \text { () Quinzenal } \\
6.5 .5 & \text { () Mensal } \\
\end{array}$ & $\begin{array}{ll}6.5 .6 & \text { () Trimestral } \\
6.5 .7 & (\text { ) Semestral } \\
6.5 .8 & (\text { ) Anual } \\
6.5 .9 & \text { () Trianual } \\
6.5 .11 & \text { () }) \text { Eventual } \\
\end{array}$ & $\begin{array}{ll}6.5 .1 & \text { ( ) Constante } \\
6.5 .2 & \text { () Horária } \\
6.5 .3 & \text { () Diária } \\
6.5 .4 & \text { () Quinzenal } \\
6.5 .5 & \text { () Mensal } \\
\end{array}$ & $\begin{array}{ll}6.5 .6 & \text { () Trimestral } \\
6.5 .7 & \text { () Semestral } \\
6.5 .8 & \text { () Anual } \\
6.5 .9 & \text { () Trianual } \\
6.5 .11 & \text { ( ) Eventual } \\
\end{array}$ \\
\hline 6.6 DURAÇÁOO & $\begin{array}{ll}6.6 .1 & \text { ( ) Segundos } \\
6.6 .2 & \text { ( ) Minutos } \\
6.6 .3 & \text { () Horas }\end{array}$ & $\begin{array}{ll}6.6 .4 & \text { () Dias } \\
6.6 .5 & \text { () Semanas } \\
6.6 .6 & \text { () Meses } \\
\end{array}$ & $\begin{array}{ll}6.6 .1 & \text { ( ) Segundos } \\
6.6 .2 & \text { () Minutos } \\
6.6 .3 & \text { () Horas }\end{array}$ & $\begin{array}{ll}6.6 .4 & \text { () Dias } \\
6.6 .5 & \text { () Semanas } \\
6.6 .6 & \text { () Meses }\end{array}$ & $\begin{array}{ll}6.6 .1 & \text { ( ) Segundos } \\
6.6 .2 & \text { ( ) Minutos } \\
6.6 .3 & \text { () Horas } \\
6\end{array}$ & $\begin{array}{ll}6.6 .4 & \text { () Dias } \\
6.6 .5 & \text { () Semanas } \\
6.6 .6 & \text { () Meses } \\
\end{array}$ \\
\hline 6.7 PREDOMINIO & $\begin{array}{lll}6.7 .1 & \text { () Noturno } \\
6.7 .2 & \text { () Matutino } \\
6.7 .3 & \text { () Vespertino }\end{array}$ & $\begin{array}{l}6.7 .4 \text { ( ) Diuturno } \\
6.7 .5 \text { ( ) Não há }\end{array}$ & 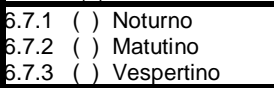 & $\begin{array}{l}6.7 .4 \text { () Diuturno } \\
6.7 .5 \text { () ) Não há }\end{array}$ & \begin{tabular}{|l|l|l|}
6.7 .1 & () Noturno \\
6.7 .2 & () Matutino \\
6.7 .3 & () Vespertino \\
6
\end{tabular} & $\begin{array}{l}6.7 .4 \text { () Diuturno } \\
6.7 .5 \text { () Não há }\end{array}$ \\
\hline 6.8 EVOLUÇAO & \begin{tabular}{|l}
6.8 .1 () Progressiva \\
6.8 .2 () Estável \\
\end{tabular} & 6.8.3 () Regressiva & $\begin{array}{l}6.8 .1 \text { () Progressiva } \\
6.8 .2 \text { () Estável } \\
\end{array}$ & 6.8.3 () Regressiva & \begin{tabular}{|l|l}
.8 .1 ( ) Progressiva \\
6.8 .2 () Estável \\
\end{tabular} & 6.8 .3 ( ) Regressiva \\
\hline 6.9 PREJUÍZO SOCIAL & $\begin{array}{l}6.9 .1 \text { ( ) Dias de trabalho } \\
6.9 .2 \text { () Perda emprego } \\
6.9 .3 \text { () Aposentadoria } \\
6.9 .4 \text { () Licença saúde }\end{array}$ & $\begin{array}{l}\text { 6.9.5 ( ) Perda Salário } \\
6.9 .6 \text { ( ) Perda escolar } \\
6.9 .7 \text { ( ) Ativ. domiciliar } \\
6.9 .8 \text { ( ) Perda do lazer } \\
\end{array}$ & $\begin{array}{l}6.9 .1 \text { ( ) Dias de trabalho } \\
6.9 .2 \text { () Perda emprego } \\
6.9 .3 \text { ( ) Aposentadoria } \\
6.9 .4 \text { ( ) Licença saúde }\end{array}$ & \begin{tabular}{|l|}
6.9 .5 ( ) Perda Salário \\
6.9 .6 ( ) Perda escolar \\
6.9 .7 ( ) Ativ. domiciliar \\
6.9 .8 ( ) Perda do lazer
\end{tabular} & $\begin{array}{l}6.9 .1 \text { ( ) Dias de trabalho } \\
6.9 .2 \text { () Perda emprego } \\
6.9 .3 \text { () Aposentadoria } \\
6.9 .4 \text { () Licença saúde } \\
\end{array}$ & $\begin{array}{l}\text { 6.9.5 ( ) Perda Salário } \\
6.9 .6 \text { () Perda escolar } \\
6.9 .7 \text { () Ativ. domiciliar } \\
6.9 .8 \text { () Perda do lazer } \\
\end{array}$ \\
\hline $\begin{array}{l}6.10 \text { AT. HABITUAIS } \\
\text { 0-Inalteradas } \\
\text { 1-Reduzidas } \\
\text { 2-Abolidas 3-Melhoradas } \\
\text { 4-Não aplicável }\end{array}$ & $\begin{array}{l}6.10 .1 \text { ( ) Concentração } \\
6.10 .2 \text { ( ) Humor } \\
6.10 .3 \text { ( )Sono } \\
6.10 .4 \text { ()Sexual } \\
6.10 .5 \text { ( ) Lazer }\end{array}$ & \begin{tabular}{|c|}
6.10 .6 ( ) Profissional \\
6.10 .7 ( ) Domiciliar \\
6.10 .8 ( ) Apetite \\
6.10 .9 ( ) Relaciona- \\
mento interpessoal
\end{tabular} & $\begin{array}{l}6.10 .1 \text { ( )Concentração } \\
6.10 .2 \text { () Humor } \\
6.10 .3 \text { ()Sono } \\
6.10 .4 \text { ()Sexual } \\
6.10 .5 \text { ( ) Lazer }\end{array}$ & \begin{tabular}{|c|}
6.10 .6 ( ) Profissional \\
6.10 .7 ( ) Domiciliar \\
6.10 .8 ( ) Apetite \\
6.10 .9 ( ) Relaciona- \\
mento interpessoal
\end{tabular} & $\begin{array}{l}\text { 6.10.1 ( )Concentração } \\
6.10 .2 \text { ( ) Humor } \\
6.10 .3 \text { ( )Sono } \\
6.10 .4 \text { ( )Sexual } \\
6.10 .5 \text { ( )Lazer }\end{array}$ & $\begin{array}{l}6.10 .6 \text { ( ) Profissional } \\
6.10 .7 \text { ( ) Domiciliar } \\
6.10 .8 \text { ( ) Apetite } \\
6.10 .9 \text { ( ) Relaciona- } \\
\text { mentp interpessoal }\end{array}$ \\
\hline $\begin{array}{l}\text { 6.11 AT. DIARIAS } \\
\text { 1-Com adaptação } \\
\text { 2-Com auxílio } \\
\text { 3-Com órtese } \\
\text { 4-Impossível }\end{array}$ & $\begin{array}{l}\text { 6.11.1 () Deambulação } \\
6.11 .2 \text { ( ) Sentar-se } \\
6.11 .3 \text { ( ) Ortostatismo } \\
6.11 .4 \text { ( ) Mudança de } \\
\text { decúbito }\end{array}$ & $\begin{array}{l}6.11 .5 \\
6.11 .6 \\
6.11 .7 \text { () Transferência } \\
6.11 .8 \text { () Mlimene } \\
6.11 \text { () Vestir }\end{array}$ & $\begin{array}{c}6.11 .1 \text { ( ) Deambulação } \\
6.11 .2 \text { ( ) Sentar-se } \\
6.11 .3 \text { ( ) Ortostatismo } \\
6.11 .4 \text { ( )Mudança de } \\
\text { decúbito }\end{array}$ & $\begin{array}{ll}6.11 .5 & \text { () Transferência } \\
6.11 .6 & \text { () Higiene } \\
6.11 .7 & \text { () Alimentação } \\
6.11 .8 \text { () ) Vestir }\end{array}$ & \begin{tabular}{|c|}
6.11 .1 ( ) Deambulação \\
6.11.2 ( ) Sentar-se \\
6.11 .3 ( ) Ortostatismo \\
6.11 .4 ( )Mudança de \\
decúbito
\end{tabular} & $\begin{array}{ll}6.11 .5 & \text { () Transferência } \\
6.11 .6 & \text { () Higiene } \\
6.11 .7 & \text { () Alimentação } \\
6.11 .8 & \text { () ) Vestir }\end{array}$ \\
\hline
\end{tabular}


EVOLUÇÃo AMBULATORIAL

Nome

RG

Diagnóstico

continuação

DATA:

6.12.1 MEDICACÁO

Dose (mg/dia)

Adesão (sim/parcial/não)

1 -falta de receita

2-Inexistência do produto

4-Opiniòes de terceiros

Result. (inalt/melhor/sem

Result. (inal

12.2 EFEITOS
COLATERAIS

6.12.2.1 ( )Náuseas

2.2.3 ()Eigastralgia

0.12.2.4 () Obstipacãa

RESULTADO
RESTIATIA

6.14CIRURGIA/BLOQUEIO

Cateter 1-alívio total 2-alívi

15 PA / P

6.16 PESO / NUTRIÇÁO

6.17 EXAME FISICO

5.18 PSIQUISMO

(

$\begin{array}{lll}4.1 .1 & \text { () Ansioso } \\ 4.1 .2 \text { () ) Deprimido } & 4.13\end{array}$ () Transiono

4.1.3 () Transtorno

somatoforme

6.19 EXAMES

COMPLEMENTARES

\begin{tabular}{|l|l|}
\hline \\
\hline 6.12 .2 .5 ( ) Sonolência \\
6.12 .2 .6 ( ) Insônia \\
6.12 .27 ( ) Confusão \\
6.12 .2 .8 ( ) Alergia
\end{tabular}
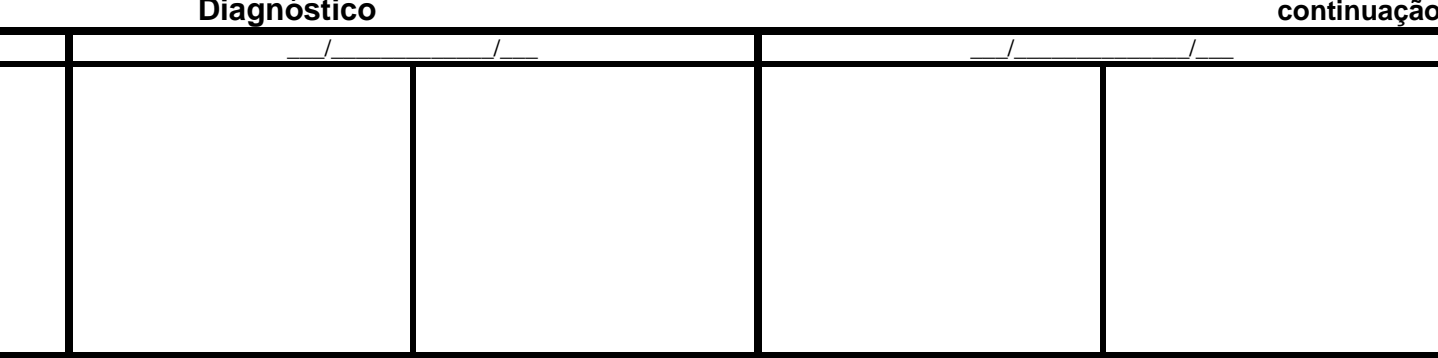

6.12.2.1 () Náuseas

6.12.2.5 ( ) Sonolência

0.12.2.1 ( )Náuseas

6.12.2.5 ( ) Sonolência

\begin{tabular}{l|l}
6.12 .2 .6() & Insônia \\
\hline & 6.122 .7() Confusaso
\end{tabular}

.12.2.2 ()Vômitos

6.12.2.6 ( ) Insônia

\begin{tabular}{l|lll} 
6.12.2.4 () Obstipação & $6.12 .2 .8($ ) $)$ Alergia & 6.12 .2 .4 ( ) Obstipação & 6.12 .2 .7 () Confusãa \\
\hline
\end{tabular}

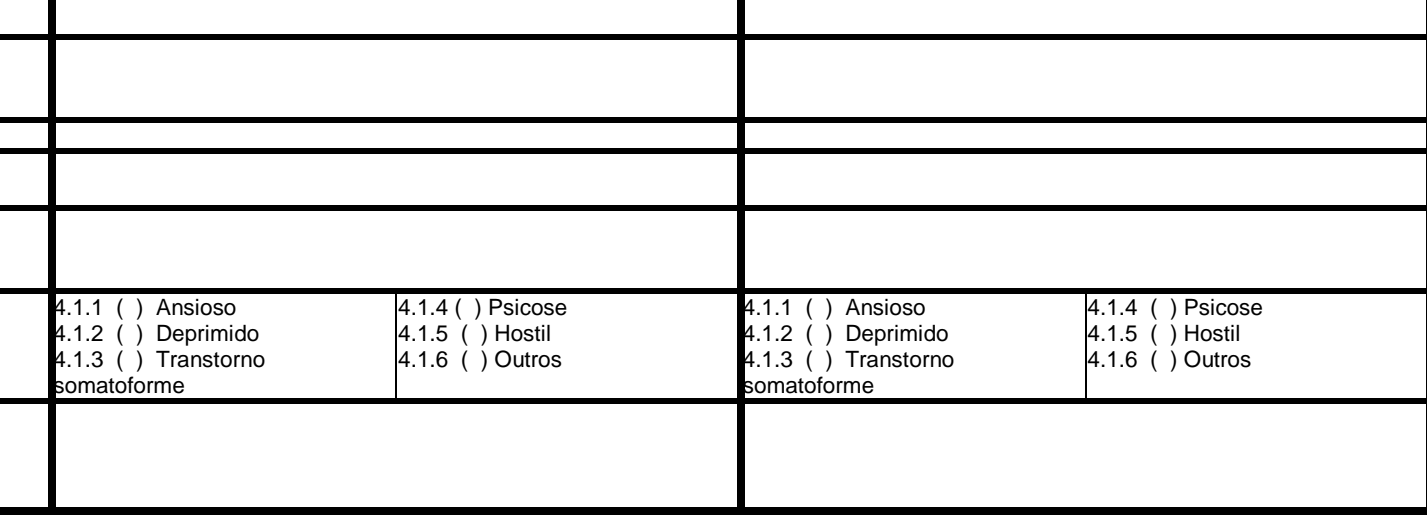


ANEXO 2

ESCALA VISUAL ANALÓGICA

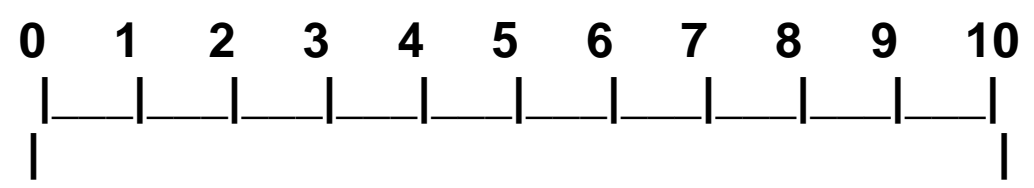

SEM DOR DOR MÁXIMA POSSÍVEL 


\section{ANEXO 3}

\section{PROTOCOLO DE DOR PÉLVICA E ABDOMINAL}

Nome: sexo. ...cor: Estado

Idade (nexo...... $R G$

civil. Profissão

Bairro:

End:.

Cidade:. CEP: TEL:

Data da 1a consulta:..........................Tempo de dor pré-HC:

Duração da dor:

1-Intensidade: VAS inicial: VAS atual: VAS final:

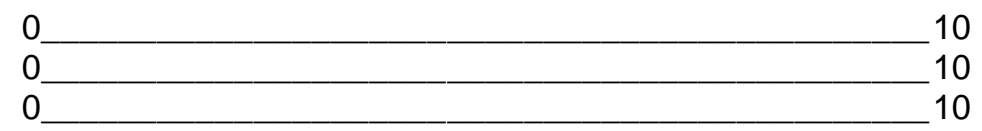

2- Local: ( ) abdomen superior ( ) abdomen inferior ( ) inguinal ( ) peri umbilical ( ) púbis ( ) vulva ( ) vagina ( ) anus ( ) glúteo ( ) lombar ( ) coxa ( ) perna ( ) outros 1.D $>$ E 2.E $>$ D 3.D=E
( ) superficial
( ) profunda
( ) ambas

3- Padrão: ( ) queimor ( ) latejante ( ) peso ( ) aperto ( ) caimbra ( ) pontada ( ) choque ( ) formigamento ( ) outros:

4- Fatores de alívio: ( ) calor local ( ) frio local ( ) dia quente ( ) dia frio ( ) movimentação ( ) micção ( ) evacuação ( ) sono ( ) repouso físico ( ) repouso mental ( ) ato sexual ( ) massagem posição: ( ) sentada ( ) deitada ( ) ortastismo( ) marcha ( ) transporte () analgésicos ( ) fisioterapia ( ) acupuntura ( ) Bloqueios quais? ( ) outros

5- Fatores de piora: ( ) calor local ( ) frio local ( ) dia quente ( ) dia frio/chuvoso

( ) mudança de tempo ( ) estresse emocional ( ) fisioterapia ( ) sono ( ) repouso ( ) toque ( ) ato sexual ( ) movimentação ( ) micção ( ) evacuação ( ) esforço físico posição: ( ) sentada ( ) deitada ( ) ortostatismo ( ) marcha ( ) transporte

6-Instalação: ( ) aguda ( ) insidiosa. Tempo de instalação

7-Etiologia
a) ( )Traumatismo
b) ( )Visceropatia
( ) ginecológico
( ) proctológico
( ) urológico
c) ( )Algia vertebral
( ) ginecológico
( ) proctológico
( ) urológico
e) ( ) Idiopática
f) ( )Estresse físico
g) ( )Estresse emocional
Outros

8- Período de dor:

( ) matutino ( ) vespertino ( ) noturno ( ) diurno

9-Sintomas associados: ( ) fadiga ( ) cefaléia ( ) dismenorréia ( ) disúria ( ) diarréia

( ) obstipação ( ) alternante: diarréia e obstipada

() menopausa: com anos de idade 
10-Impactos funções vitais:

sono: ( ) sem alteração ( ) acorda cansado ( ) insônia ( )melhor após medicação

humor: ( ) ansiedade ( ) depressão ( ) estresse ( ) fobia

vícios: () fumo () etilismo () drogas () café

qualidade de vida: ..................pontos

psiquismo: ( ) normal ( ) alterado

apetite: ( ) normal ( ) aumentado ( ) aumentado com medicam ( ) diminuído

lazer: () normal () diminuído

atividades esportivas: ( ) normal ( ) diminuído

atividades sexuais: () normal () diminuído

11-Tratamento prévios:

AINH.

Psicotrópicos

Cirurgia.

Acupuntura

Bloqueio

Outros.

12-Tratamento atual:

AINH.

Psicotrópicos

Acupuntura.

Bloqueio

Morfina.

Cirurgia.

13-Resultado dos tratamentos:

Medicamentoso: ( ) mau ( ) regular ( ) bom ( ) ótimo

Fisioterapia: ( ) mau ( ) regular ( ) bom ( ) ótimo

Tipo.

Acupuntura: ( ) mau () regular ( ) bom ( ) ótimo

Cateter peri-dural: ( ) mau ( ) regular ( ) bom ( ) ótimo

14- Número de atos operatórios:

() tratamento de dor ( ) causa de dor

15- Alterações sensitivas ( ) alodínea ( ) hiperpatia ( ) hiperalgesia ( ) hipostesia ( ) analgesia

16- Alterações motoras:.

17- Toque retal:

18- Toque vaginal: 
10. REFERÊNCIAS BIBLIOGRÁFICAS 
1. ANDRADE FILHO, A.C.C. Dor diagnóstico e tratamento. São Paulo, Roca, 2001. p.1-2.

2. BAKER, P.K. Musculoskeletal problems. In: STEEGE, J.F.; MELTZGER, D.A.; LEVY, B.B., ed. Chronic pelvic pain: an integrated approach. Philadelphia, W B Saunders, 1998. BASU, H.K. Chronic pelvic pain. Br. J. Hosp. Med., v.26, p.150, 1981.

3. BENSON, J.T. Neuropathic pain. In: STEEGE, J.F.; MELTZGER, D.A.; LEVY, B.B., ed. Chronic pelvic pain: an integrated approach. Philadelphia, W B Saunders, 1998BENSON, R.C.; HANSON, K.H.; MATARAZZO, J.D. Atypical pelvic pain in women: gynecologicpsychiatric considerations. Am. J. Obstet. Gynecol., v.77, p.806-25, 1959.

4. BOISSONNAULT, J.S.; BLASCHAK, M.J. Incidence of diastasis recti abdominis during the childbearing year. Phys. Ther., v.68, p.1082-6, 1988.

5. BONICA, J.J. The management of pain. 2 ed. Philadelphia, Lea Feibiger, 1990. p.1388.

6. BONICA J.J.; YAKSHT.; LIEBESKIND, J.C.; PECHNICK, R.N.; DEPAULIS A. Biochemistry and modulation of nociception and pain. In: BONICA, J.J., ed. The management of pain. Philadelphia, Lea Feibiger, 1990. p.95-121. 
7. BOWSHER, D. Termination of the central pain pathway in man: the conscious appreciation of pain. Brain, v.80, p.606-22, 1957.

8. CAMPBELL, J.N.; SOLOMON, C.T.; JAMES, C.S. The Hopkins experience with lesions of the dorsal horn for pain from avulsion of the brachial plexus. Appl. Neurophysiol., v.51, p.170-4, 1988.

9. CORREA, C.F. Estimulação elétrica da medula espinhal para o tratamento da dor por desaferentação. São Paulo, Lemos Editorial, 1997. p.25-33.

10. COSTELLO, K. Myofascial syndromes. In: STEEGE, J.F.; MELTZGER, D.A.; LEVY, B.B., ed. Chronic pelvic pain. An integrated approach. Philadelphia, W B Saunders, 1998.

11. DAVIES, L.; GANGAR, K.F.; DRUMMOND, M.; SAUNDERS, D.; BEARD R.W. The economic burden of intractable gynaecological pain. J. Obstet. Gynecol., v.12, p.S54-S6, 1992.

12. DELLENBACH, P.; REMPP, C.; HAERINGER, M.T.; SIMON T.; MAGNIER, F.; MEYER, C. Douleur pelvienne chronique. Une autre approche diagnostique et thérapeutique. Gynecol. Obstét. Fertil., v.29, p.234, 2001.

13. FIGUEIRÓ, J.A.B.; TEIXEIRA, M.J. Reações comportamentais desencadeadas pela dor. Rev. Méd., v.73, p.67-8, 1995.

14. GAL, P.L.; KAZIYAMA, H.H.S.; LIN, T.Y.; TEIXEIRA, M.J. CORRÊA, C. Síndrome miofascial: abordagem fisiátrica. Arq. Bras. Neurocir., v.10, p.4, 1991. 
15. GALLEGOS, N.C.; HOBSLEY, M. Abdominal wall pain: an alternative diagnosis. Br. J. Surg., v.77, p.1167-70, 1990.

16. GARDNER, E.; GRAY, D.J.; O'RAHILLY, R. Anatomia estudo regional do corpo humano. Rio de Janeiro, Guanabara Koogan, 1978. p.439-43.

17. GARDNER, E.; GRAY, D.J.; O’RAHILLY, R. Anatomia estudo regional do corpo humano. Rio de Janeiro, Guanabara Koogan, 1978. p.443-4.

18. GARDNER, E.; GRAY, D.J.; O'RAHILLY, R. Anatomia estudo regional do corpo humano. Rio de Janeiro, Guanabara Koogan, 1978. p.445-6.

19. GARDNER, E.; GRAY, D.J.;O’RAHILLY, R. Anatomia estudo regional do corpo humano. 4. ed. Rio de Janeiro, Guanabara Koogan, 1978. p.343-7.

20. GARDNER, E.; GRAY, D.J.; O’RAHILLY, R. Anatomia estudo regional do corpo humano. 4. ed. Rio de Janeiro, Guanabara Koogan, 1978. p.482-3.

21. GRANET, E. Proctalgias and allied non-inflammatory perineal dyscrasias: coccygodynia, proctalgia fugax, neurogenic pruritus ani. Am. J. Dig. Dis., v.13, p.330-3, 1946.

22. GRAY, D.J. Ossos junturas e paredes da pelve. In: GARDNER, E.; GRAY, D.J.; O'RAHILLY, R. Anatomia estudo regional do corpo humano. 4. ed. Rio de Janeiro, Guanabara Koogan, 1978. p.429-38. 23. HANID, M.A.; LEVI, A.J. Medical causes of pain in the lower abdomen. Clin. Obstet. Gynecol., v.8, p.15-26, 1981. 
24. HARMS, B.A.; DEHAAS, D.R.; STARLING, J.R. Diagnosis and management of genitofemoral neuralgia. Arch. Surg., v.119, p.339-41, 1984.

25. HOWARD, F.M.; PERRY, C.P.; CARTER, J.E.; EL-MINAWI, A.M. Pelvic pain diagnosis and treatment. Philadelphia, Lippincott Williams \& Wilkins, 2000. p.3-4.

26. HOWARD, F.M.; EL-MINAWI, A.M. Mononeuropathy and nerve entrapment. In: HOWARD, F.M.; PERRY, C.P.; CARTER, J.E.; ELMINAWI, A.M., ed. Pelvic pain diagnosis and treatment. Philadelphia, Lippincott Williams \& Wilkins, 2000. IGNELZI, R.J.; ATIKINSON, J.H. Pain and its modulation. Neurosurgery, v.6, p.577-83, 1980.

27. KESSLER, R.M.; HERTLING, D. Management of commom musculoskeletal disorder: physical therapy principles and methods. 2. ed. Philadelphia, JB Lippincott, 1990.

28. KOPELL, H.P.;THOMPSON, W.A.; POSTEL, A.H. Entrapment neuropathy of the ilioinguinal nerve. N. Engl. J. Med., v.266, p.16-9, 1962.

29. KOTARINOS, R.K. Diastasis recti and review of abdominal wall. J. Obstet. Gynaecol. Phys. Ther., v.14, p.8, 1990.

30. LILIUS, H.G.; VALTONEN, E.J. The levator ani spasm syndrome. Ann. Chir. Gynaecol. Fenn., v.62, p-93-7.

31. LIN, T.Y.; TEIXEIRA, M.J.; LIN, E.; KAZIYAMA, H.; IMAMURA, S. Non visceral chronic abdominal pain: the role of myofascial and neuropathic pain syndromes. In: SATOSHI, U.;RYUICHU, N.; SHIGENOBU, I., ed. The Proceedings of $8^{\text {th }}$ World Congress Of The International 
Rehabilitation Medicine Association. Bologna:Monduzzi Editore, 1997. p.1355-9.

32. LIN, T.Y.; KAZIYAMA, H.H.S.; TEIXEIRA, M.J. Síndrome dolorosa miofascial. In: TEIXEIRA, M.J.; BRAUM, J.L.; MARQUEZ, J.O.; YENG, L.T., ed. Dor contexto interdisciplinar. Curitiba, Editora Maio, 2003. Cap.18, p.271-87.

33. LYON E.K. Genitofemural causalgia. Can. Med. Assoc. J., v.53, p.213$6,1945$.

34. MATHIAS, S.D.; KUPPERMANN, M.; LIBERMAN, R.F.; LIPSCHUTZ, R.C.; STEEGE, J.F. Chronic pelvic pain: prevalence, health-related quality of life, and economic correlates. Obstet. Gynecol., v. 87, p.321-7, 1996.

35. MILBURN, A. et al. Multidisciplinary approach to chronic pelvic pain. Obstet. Gynecol. Clin. North Am., v.20, p.643-61, 1993.

36. NENNESMO, I.; REINHOLT, F. Mast cells in nerve an neuromas of mice. Neurosci. Lett., v.69, p.296-301, 1986.

37. OKADA, M.; TEIXEIRA, M.J. Dor neuropática. In: TEIXEIRA, M.J.; BRAUM, J.L.; MARQUEZ, J.O.; YENG, L.T., ed. Dor contexto interdisciplinar. Curitiba, Editora Maio, 2003. Cap.22, p.343-61.

38. PARADIS, H.; MARGANOFF, H. Rectal pain of extrarectal origin, Read at the Meeting of the American Proctologic Society. Denver, 1968.

39. RANGER, I.; MEHTA, M. Persistent abdominal pain. Anaesthesia, v.26, p.330-3, 1971.

40. RAPKIN, A.J. Neuroanatomy, neurophysiology and neuropharmacology of pelvic pain. Clin. Obstet. Gynecol., v.33, p.119-29, 1990. 
41. RAPKIN, A.J.; KAMES, L.D.; DARKE, L.L.; STAMPLER, F.M.; NALIBOFF, B.D. History of physical and sexual abuse in women with chronic pelvic pain. Obstet. Gynecol., v.76, p.92-6, 1990.

42. RASKIN, D.E. Diagnosis in patients with chronic pelvic pain. Am. J. Psychiatry, v.141, p.6, 1984.

43. REITER, R.C.; GAMBONE, J.C. Non gynecologic somatic pathology in women with chronic pelvic pain and negative laparoscopy. J. Reprod. Med., v.36, p.253-9, 1991.

44. ROGERS, R.M. Basic pelvic neuroanatomy. In: STEEGE J.F.; METZGER D.A.; LEVY B.S., ed. Chronic pelvic pain. An integrated approach. Philadelphia, W B Saunders, 1998. p.42-3.

45. ROGERS, R.M. Basic pelvic neuroanatomy, In: STEEGE, J.F.; METZGER, D.A.; LEVY, B.S., ed. Chronic pelvic pain. An integrated approach. Philadelphia, W B Saunders, 1998. p.41.

46. SCHAPIRO S. Low back and rectal pain from an orthopedic and proctologic viewpoint: with a review of 180 cases.. Am. J. Surg., v.79, p.117-128, 1950.

47. SHOOK, M.F. Ilioinguinal nerve entrapment during needle suspension for stress incontinence. Obstet. Gynecol., v.80, p.246, 1992.

48. SINDOU, M. Étude de la junction raduculo-medullaire posterieure. La radiculotomie posterieure selective dnas la chirurgie de la douleur. Tese. Travail de L'Hospital Neurologique e de l'únite de recherchers de physiopathologie du systeme nerveux, 1972. 
49. SMITH S.E.; DELEE J.C.; RAMAMURTHY S. Ilioinguinal neuralgia following iliac bone-grafting. J. Bone Joint Surg., v.66, p.1306-8, 1984.

50. SOHN, N.; WEINSTEIN, M.A.; ROBBINS, R.D. The levator syndrome and its treatment with high-voltage electrogalvanic stimulation. Am. J. Surg., v.144, p.580-2, 1982.

51. STEEGE, J.F. Office assessment of chronic pelvic pain. Clin. Obstet. Gynecol., v.40, p.555, 1997.

52. STEEGE, J.F..; MELTZGER, D.A.; LEVY, B.B. Chronic pelvic pain. An integrated approach. Philadelphia, W B Saunders, 1998. p.220.

53. STARLING, J.R.; HARMS, B.A.H.; SCHROEDER, M.E.; EICHMAN, P.L., Diagnosis and treatment of genitofemural and ilioinguinal entrapment neuralgia. Surgery, v.102, p.581-6, 1987.

54. TEIXEIRA, M.J.; BRAUM FILHO, J.L.; MARQUEZ, J.O.; YENG, L.T. Dor: contexto Interdisciplinar. Curitiba, Editora Maio, 2003. v.5, p.89.

55. TEIXEIRA MJ, BRAUM FILHO JL, MARQUEZ JO, YENG LT. Dor:Contexto Interdisciplinar, Curitiba, Editora Maio, vol.05, p.120, 2003. 56. TEIXEIRA MJ, BRAUM FILHO JL, MARQUEZ JO, YENG LT. Dor:Contexto Interdisciplinar, Curitiba, Editora Maio, vol.37, p.509, 2003.

57. TEIXEIRA, M.J.; FIGUEIRÓ, J.A.B. Dor: epidemiologia, fisiopatologia, avaliação, síndromes dolorosas e tratamento. São Paulo, Grupo Editorial Moreira Jr, 2001. v.2, p.8.

58. TEIXEIRA, M.J. Mecanismos de ocorrência de dor. Rev. Med. (São Paulo), v.80, p.33-5, 2001. 
59. TEIXEIRA, M.J. Mecanismos de ocorrência de dor. Rev. Med. (São Paulo), v.80, p.37-9, 2001.

60. TEIXEIRA, M.J.; LIN, T.Y.; NEVES, A.T.A. Dor e endometriose: modalidades de tratamento sintomático. In: ABRÃO, M.S. ed. Endometriose uma visão contemporânea. p.25-33, p.25-33. Rio de Janeiro, Revinter, 2000. p.177-238.

61. THIELE, G.H. Coccygodynia and pain in the superior gluteal region. JAMA, v.109, p.1271-5,1937.

62. TRAVEL, J.G.; SIMONS, D.G. Miofascial pain and dysfunction: the trigger point manual. Baltimore, Williams and Wilkins, 1992. v.1, p.636-59.

63. TRAVEL, J.G.; SIMONS, D.G. Miofascial pain and dysfunction: the trigger point manual. Baltimore, Williams and Wilkins, 1992. v.1, p.660-5.

64. TRAVEL, J.G.; SIMONS, D.G. Miofascial pain and dysfunction: the trigger point manual. Baltimore, Williams and Wilkins, 1992. v. 2, p.110-9.

65. WALL, P.; MELZACK, R. Textbook of pain. 3. ed. Edinburgh, Churchill Livingstone, 1994. v.1, p.28-30.

66. WALL, P.; MELZACK, R. Textbook of pain. 2. ed. Edinburgh, Churchill Livingstone, 1989. p.63-81.

67. WALL, P.; MELZACK, R. Textbook of pain. 3. ed. Edinburgh, Churchill Livingstone, 1994. p.79-100.

68. WESSELMAN, U. Management of chronic pelvic pain. In: ARONOFF, G.M. Evaluation and treatment of chronic pain. 3. ed. Baltimore, Williams \& Wilkins, 1999. 